OAK RIDGE

NATIONAL LABORATORY

MANAGED BY UT-BATTELLE

FOR THE DEPARTMENT OF ENERGY
ORNLTM-2001/56

\section{National Energy Audit \\ (NEAT) \\ Users Manual \\ (Version 7)}

Mike Gettings John Krigger Mark Fishbaugher

5

L 
This report has been reproduced from the best available copy.

Available to DOE and DOE contractors from the Office of Scientific and Technical information, P.O. Box 62, Oak Bidge, TN 37831; prices available from (615) 576-8401, FTS 6268401.

Available to the public from the National Technical Information Service, U.S. Department of Commerce, 5285 Port Royal Rd., Springfield, VA 22161.

This report was prepared as an account of work sponsored by an agency of the United States Government. Neither the United States Government nor any agency thereof, nor any of their emplovees. 


\title{
National Energy Audit (NEAT) Users Manual
}

\author{
Mike Gettings \\ Energy Division \\ Oak Ridge National Laboratory \\ Oak Ridge, Tennessee \\ John Krigger \\ Nate Adams \\ Saturn Resource Management \\ Helena, Montana \\ Mark Fishbaugher \\ Fishbaugher and Associates, LLC \\ Ferndale, Washington
}

ORNL/TM-2001/56

April 2001

\begin{abstract}
"The submitted manuscript has been authored by a contractor of the U.S. Government under contract No. DE-AC05-00OR22725. Accordingly, the U.S. Government retains a nonexclusive, royalty-free license to publish or reproduce the published form of this contribution, or allow others to do so, for U.S. Government purposes."
\end{abstract}

Research sponsored by the Office of State and Local Assistance Programs, Weatherization Assistance Program, U.S. Department of Energy, under Contract DE-AC05-00OR22725 with UT-Battelle, LLC. 
Welcome to the U.S. Department of Energy's (DOE's) energy auditing tool, called "NEAT." NEAT, an acronym for National Energy Audit Tool, a program for personal computers that was designed for use by local agencies in the Weatherization Assistance Program. It is an approved alternative audit that meets all auditing requirements set forth by the Program.

NEAT is easy to use. It applies engineering and economic calculations to evaluate energy conservation measures for single-family, detached houses or small multifamily buildings. You can use it to rank measures for each individual house, or to establish a priority list of conservation measures for nearly identical housing types.

NEAT was written for the Weatherization Assistance Program by Oak Ridge National Laboratory. Many building energy consumption algorithms are taken from Lawrence Berkeley Laboratory's Computerized Instrumented Residential Audit (CIRA), published in 1982 for the Department of Energy. Equipment retrofit conservation measures are based on published reports on various heating retrofits. Heating and cooling system replacement conservation measures are based on the energy ratings of new heating and cooling equipment.

The Weatherization Program anticipates that this computer-based energy audit will offer substantial performance improvements to many states who choose to incorporate it into their programs.

When conservation measures are evaluated locally according to climate, fuel cost, measure cost, and existing house conditions, the Program will be closer to its goal of assuring the maximum return for every federal dollar spent. 
Foreword

How To Use This Manual

Chapter 1 - An Overvicw of NEAT .

1.1 Hardware Requirements

1.2 NEAT-Assisted Energy Audit .................................................. 2

1.3 What NEAT Does ................................................................ 3

Chapter 2 - Installing and Starting NEAT ........................................ 7

2.1 Program Installation......................................................... 7

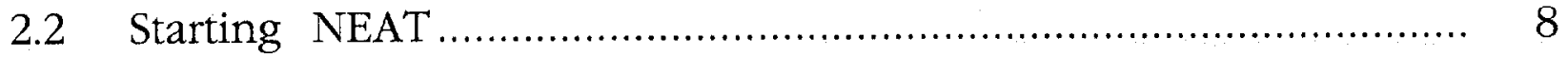

2.3. Special Cases ........................................................................ 9

2.4 The Data Link Feature ..................................................... 10

Chapter 3 - Basic NEAT Tasks .......................................................... 13

3.1 The Building Characterization and Analysis Window ................... 14

3.2 Selecting an Existing Building Description ................................... 15

3.3. Creating a New Building Description ....................................... 16

3.4 Running NEAT and Viewing the Reports ................................. 17

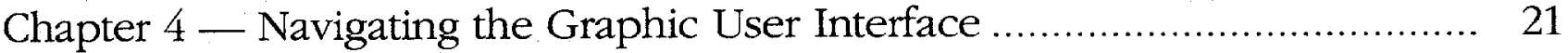

$4.1 \quad$ Forms and Records .......................................................... 21

4.2 Entering Data into NEAT ............................................................. 23

4.3 Navigating Between Controls ............................................... 25

4.4 The Escape Key ............................................................................ 26

4.5 Required Versus Optional Fields ........................................... 26

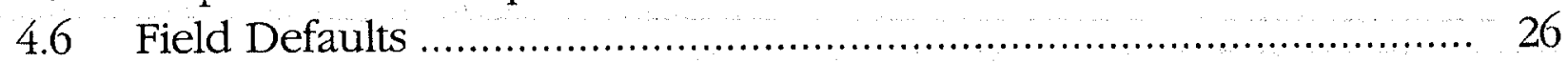

4.7 Field Range Checking ........................................................ 27

4.8 Data Sheet and Form Views of Records ..................................... 27

4.9 Copying and Pasting a Record or Field ..................................... 29

4.10 Deleting a Record ................................................................. 29

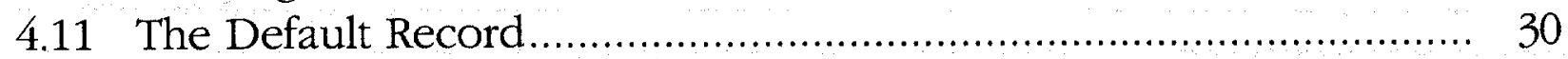

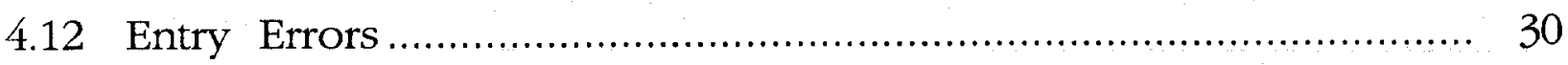

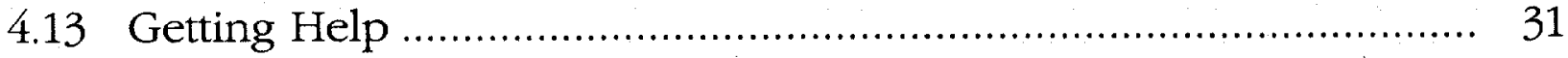

Chapter 5 - NEAT Definitions ...................................................... 33

$5.1 \quad$ Building Descriptions ....................................................... 33

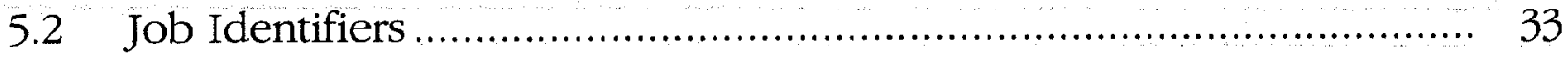

5.3 Component Codes ............................................................... 34

5.4 Measure Numbers ............................................................ 36

Chapter 6 - The NEAT Building Description ........................................ 39

6.1 General House Data .......................................................... 39

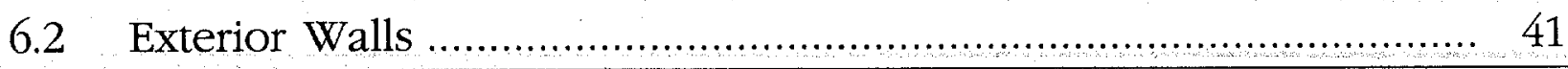


6.3 Windows ............................................................................. 42

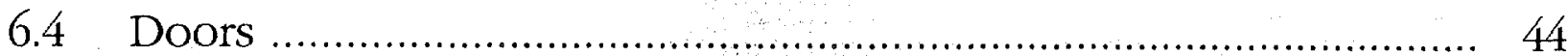

6.5 Unfinished Attics .................................................................... 45

6.6 Finished Attics ....................................................................... 17

6.7 Foundations ..................................................................... 48

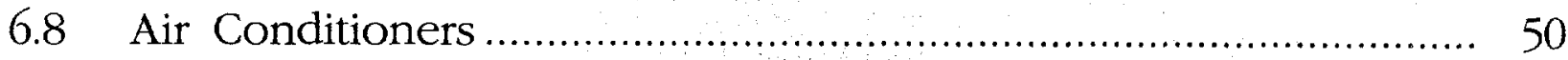

6.9 Heating Systems-General Data .............................................. 51

6.10 Heating Systems -Details Sub-Form ......................................... 52

6.11 Secondary Heating Systems .................................................... 55

6.12 Ducts and Infiltration ......................................................... 55

6.13 Base Loads-Refrigerators ....................................................... 63

6.14 Base Loads_-Water Heating ....................................................... 66

6.15 Base Loads-Lighting ...................................................... 68

6.16 Itemized Additional Costs and User-Defined Measures .................. 69

6.17 Utility Bills ............................................................................... $\quad 70$

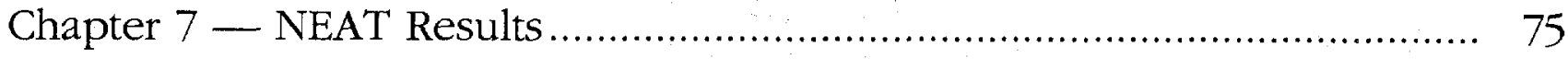

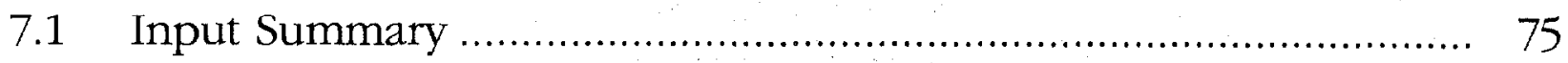

7.2 Annual Energy and Cost Savings ............................................... 75

7.3 Energy Saving Measure Economics ............................................ 76

7.4 Material List ................................................................... 77

7.5 Pre- and Post-Retrofit Energy and Loads (Annual Loads) ................ 77

7.6 Billing Data Adjusted Results ....................................................... 78

7.7 Heating and Cooling Energy Comparisons ............................... 78

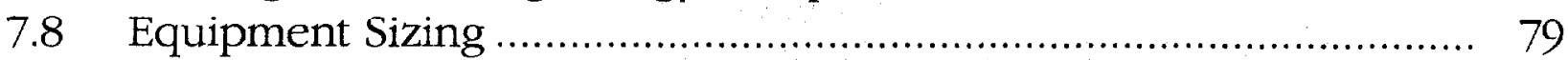

7.9 Special Notes and Comments ................................................. 80

Chapter 8 - Customizing a NEAT Audit................................................. 83

8.1 Creating Your Own Parameter Sets ............................................ 83

8.2 Changing Parameters .................................................................. 84

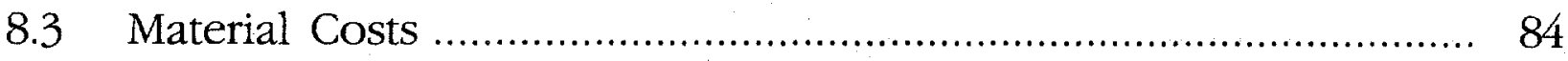

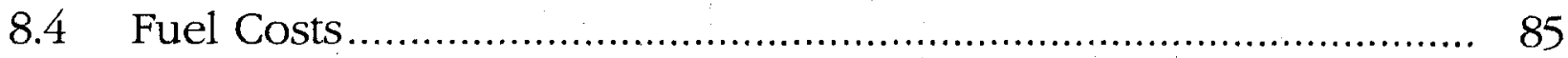

8.5 Fuel Escalation Rates........................................................... 86

8.6 Selecting Candidate Conservation Measures .............................. 86

8.7 Altering Key Parameters ......................................................... 86

8.8 User Defined Insulation Types ............................................ 88

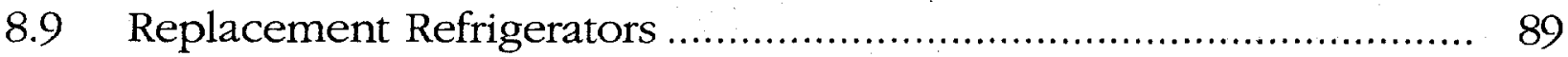

8.10 Replacement Water Heaters ................................................. 90

Chapter 9 - Preferences .......................................................................... 91

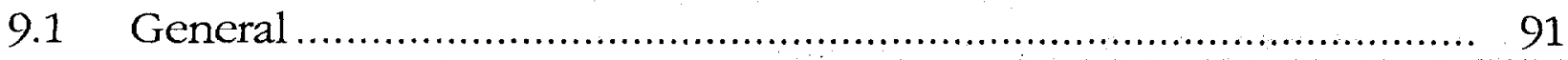


9.2 Range Check and Default Values ……............................................. 92

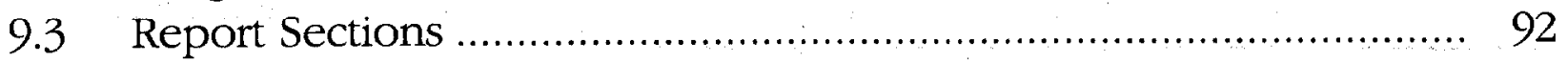

Chapter 10 - NEAT Energy Conservation Measures …….......................... 95

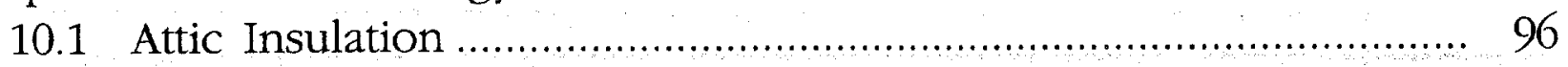

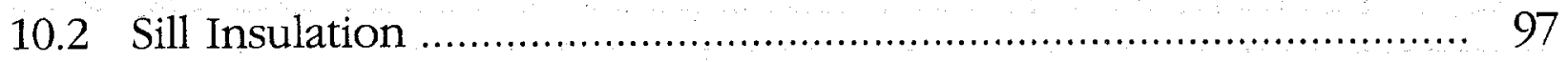

10.3 Foundation Wall Insulation ……………................................... 97

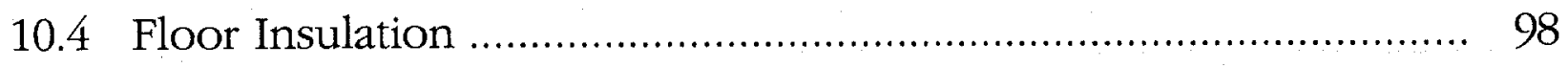

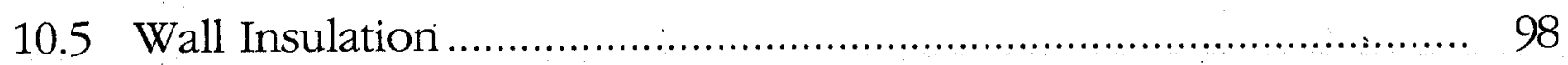

10.6 Duct Installation …………...................................................... 99

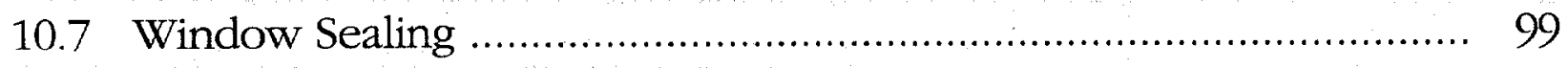

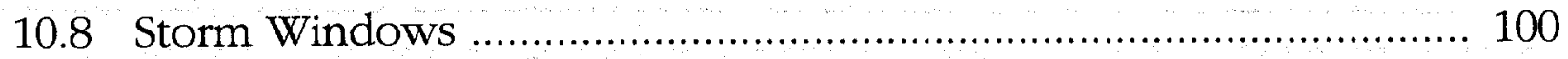

10.9 Window Replacement ................................................................. 100

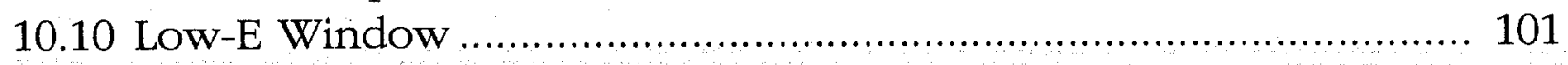

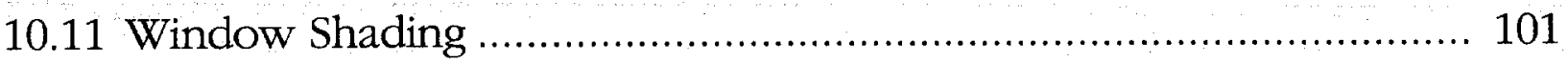

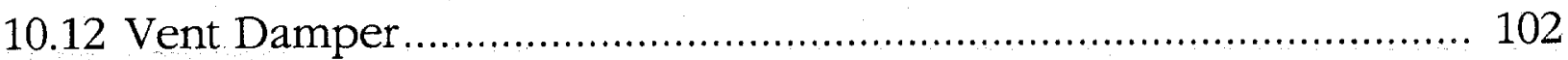

10.13 Intermittent Ignition Device .......................................................... 103

10.14 Flame Retention Head Oil Burner ..................................................... 103

10.15 Furnace Tune-up ....................................................................... 104

10.16 Furnace/Boiler Replacement …................................................. 104

10.17 Space Heater Replacement .......................................................... 105

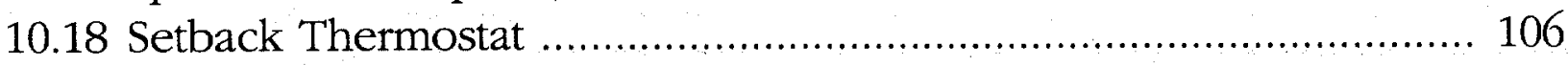

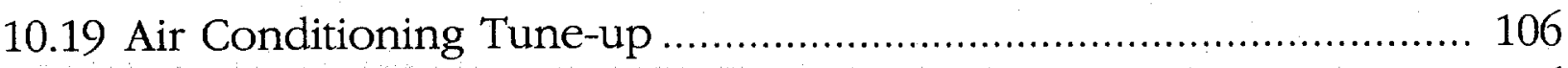

10.20 Air Conditioner Replacement ....................................................... 106

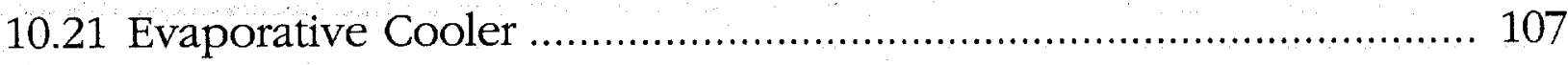

10.22 Heat Pump Replacement ………................................................. 108

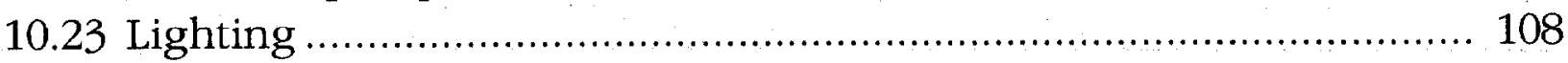

10.24 Refrigerator Replacement ……….............................................. 109

10.25 Water Heater Tank Insulation ..................................................... 110

10.26 Water Heater Pipe Insulation ........................................................ 110

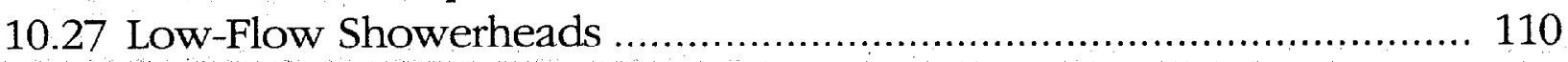

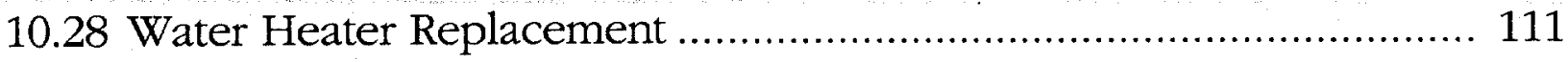

Appendix A - Audit Example …………………………………………... 113

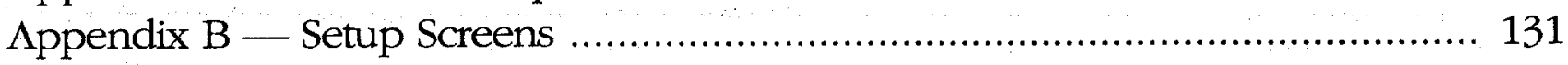

Appendix C - Sample NEAT Forms …………………............................. 145

Appendix D - Data Input Forms ………………………........................... 157

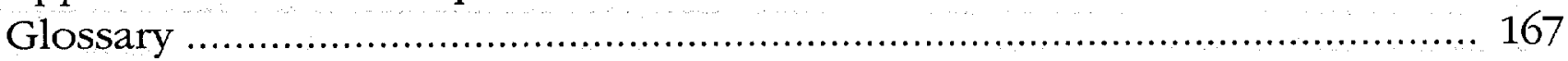

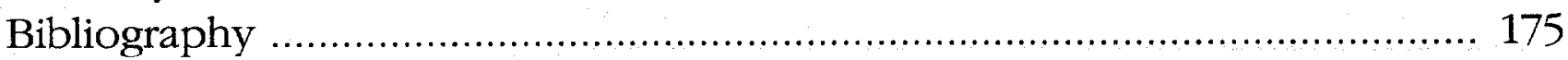


How you use this manual will depend on your experience with computers and energy auditing. NEAT is a user-friendly program. Energy auditors who are experienced computer users may only occasionally refer to this manual. Lessexperienced auditors and new computer users should read at least the first four chapters to avoid frustration when entering their first audits.

- Chapter One, An Overview of NEAT, tells what NEAT is and how it works.

- Chapter Two, Installing and Starting NEAT, shows how to install and start NEAT and have the program install an icon on your desktop.

- Chapter Three, Basic NEAT Tasks, describes the functions accessible from the toolbar on the Building Characterization and Analysis Window. This toolbar directs most of the basic functions of NEAT related to entire jobs: creating, selecting, executing, and viewing results.

- Chapter Four, Navigating the Graphic User Interface, provides explicit instructions on moving around and entering data into NEAT.

- Chapter Five, NEAT Definitions, gives detailed definitions of four basic terms used in NEAT: building descriptions, building identifiers, component codes, and measure numbers.

- Chapter Six, The NEAT Building Description, explains NEAT's different building description screens and the data entries required of each.

- Chapter Seven, NEAT Results, talks about the report that NEAT produces from the data you enter.

- Chapter Eight, NEAT Auxiliary Functions, describes optional features of NEAT, including computation of a home's energy use ratio and an estimate of the minimum cost-effective infiltration reduction rate for your location, entry of both pre- and post-weatherization billing data, and a means for recording the actual work and materials used on a job.

- Chapter Nine, Customizing a NEAT Audit, tells how to adjust NEAT to local conditions (price of fuel, weather conditions, material and labor costs, and other parameters).

- Chapter Ten, NEAT Energy Conservation Measures, talks about technical considerations of conservation measures considered by NEAT.

- Appendix A, Audit Example, shows floor plans, completed NEAT input screens, and energy conservation recommendations for the hypothetical Morris residence of St. Louis, Mo. For many of the input screens, an alternative format, the Data Sheet View, is used for conciseness. 
- Appendix B, Setup Screens, shows the screens and options presented to you when using Setup to customize NEAT to reflect local conditions.

- Appendix C, Sample NEAT Forms, contains all energy audit input forms as seen in the standard format, Form View.

- Appendix D, Data Input Forms, contains NEAT data input forms to be used in the field to record data as an audit is performed, for later entry into the program.

- The Glossary defines all technical terms used in this manual.

- The Bibliography lists the references used to develop NEA'T. 



\section{Chapter 1}

NEAT, an acronym for National Energy Audit Tool, is a program for personal computers that was designed for use by local agencies in the Weatherization Assistance Program. It can assist these agencies select energy conservation measures for primarily single-family site-built homes that meet government criteria for costeffectiveness.

This manual has been written to describe the operation of NEAT Version 7. This version of NEAT is being distributed with the Manufactured Home Energy Audit (MHEA) in a package of programs referred to as the "Weatherization Assistant." MHEA performs a similar task to that of NEAT except for manufactured housing.

Installation of the Weatherization Assistant, described in Chapter 2 of this manual, Installing and Starting NEAT, will provide you with both of these programs, NEAT and MHEA, having graphical user interfaces (GUI) consistent with current Windows conventions. The remainder of this manual describes the operation of NEAT only. A separate companion manual, describes the MHEA program.

The GUI interface helps speed up data entry by use of a mouse and provides alternate formats to enter and view the data: a traditional Windows ${ }^{\mathrm{TM}}$ form approach and the tabular datasheet format, which displays more information on each screen.

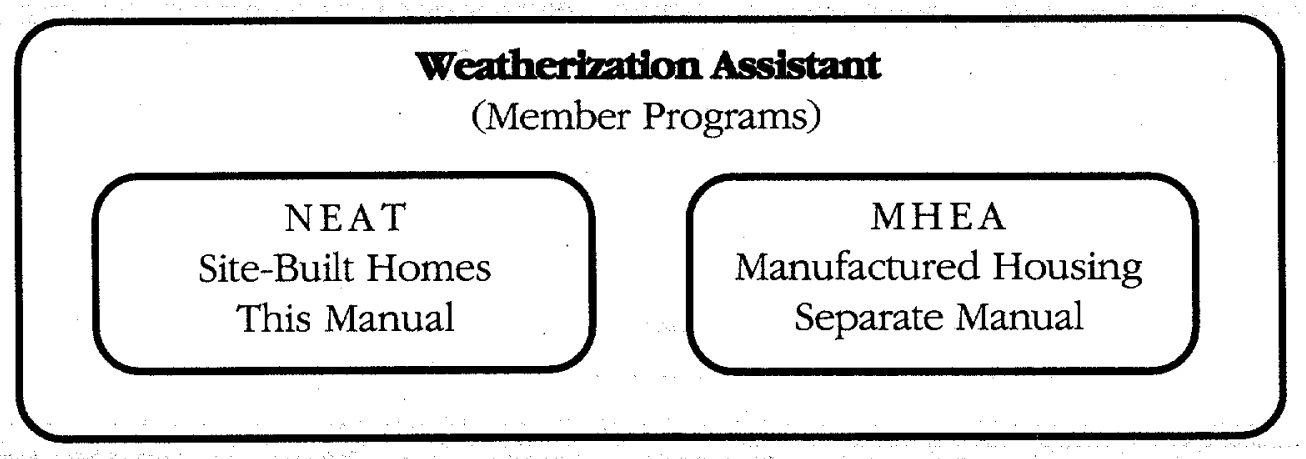

\subsection{Hardware Requirements}

The analysis module in NEAT is written in the programming language " $\mathrm{C}$ " with an interface and data storage format using Microsoft's Access. However, NEAT requires no software associated with either $\mathrm{C}$ or Access in order to run. The program needs only a Windows operating system (Win95, 98, NT4.0, or Win2000), which normally comes with the purchase of a computer. 
NEAT runs on any IBM-compatible computer having at least 32 mega-bytes (MB) of free random-access memory (RAM). Installation of both NEAT and MHEA requires approximately 15 Mega-bytes (MB) of available hard disk space. Your graphics card and monitor should be able to produce a display with a minimum resolution of $800 \times 600$ pixels in order to allow windows to be seen without scrolling. All files necessary to run both NEAT and MHEA are stored on a single $\mathrm{CD}$, including weather files for 216 cities in the continental United States. (These files can be accessed from the General Information screen to select the city nearest the audited residence.)

NEAT uses your existing Windows printer setup to print results. No reconfiguring of your printer is necessary. Output produced by the program is stored in the audit database and displayed in rich-text format from within the program. In addition, the program provides a standard ASCII formatted file of the output for the most recent run, which is readable by any word processor or text editor and can be viewed in DOS.

Version 7 of NEAT utilizes a commercially produced database software, Microsoft Access, to store the information you provide and the results of running the program. Previous versions of NEAT and MHEA used separate files to store audit inputs and resulting reports. Now, instead of files, this information is stored in "records" of relational database tables. When you enter a new job (or audit), you are really just creating a new record in the "Job" table in the database. All of the jobs you have entered are available simply by requesting to view different records of this database. Users of other software products based on Microsoft Access may be familiar with the concept of tables, records, and forms.

\subsection{NEAT-Assisted Energy Audit}

NEAT is a method for selecting energy conservation measures for houses. A complete weatherization program includes many steps in addition to selecting these measures. These steps, and some of their relationships to NEAT, may include:

1. Selecting eligible houses and determining the expenditure limit for each.

2. Visiting each house to collect information. Inspecting and measuring various components. Interviewing clients. Noting health and safety problems. Making sketches. And, possibly, performing general repairs to the house. (NEAT has certain data requirements, but local agencies' programs may collect additional information.) 
3. Conducting air leakage repairs. NEAT can use blower door measurements, but these measurements are not required. NEAT will calculate the weatherization energy savings and Savings-to-Investment Ratio (SIR) for infiltration reduction work that has been performed, if data from blower door tests and cost of the work are provided.

4. Installing cost-effective low-cost and no-cost conservation measures (such as replacing furnace filters, servicing evaporative coolers, or installing energysaving showerheads). These measures, which must be approved by the DOE, often can be installed as quickly as they can be analyzed and are not evaluated within NEAT.

5. Inspecting and diagnosing heating and cooling equipment. Combustion tests measure the steady-state efficiency of heating systems. If such tests are available, NEAT will use them to more accurately estimate savings from equipment replacement or tune-up. If testing is not available, NEAT's default values will estimate efficiency.

6. Choosing measures based on the building description data. NEAT will generate a report of cost- effective energy conservation measures for both the building envelope and heating/cooling equipment.

7. Obtaining energy consumption data from the customers' utilities. NEAT can use these data to adjust savings estimates for various energy conservation measures.

8. Installing measures following state-of-the-art procedures.

9. Performing an on-site quality assurance inspection of installed energy conservation measures.

10. Educating customers about what they can do to minimize energy consumption.

\subsection{What NEAT Does}

NEAT uses engineering calculations to compute the savings of individual energy conservation measures. NEA' requires a description of each building and its energyrelated information. You may take data input forms to the building site and record information by hand, or you may enter information directly into a portable computer.

You enter data onto computer screens that store information about the characteristics of the house and its mechanical systems. You enter data onto computer screens that store information about the characteristics of the house and its mechanical systems. Screens contain fields in which you enter values or characters, 
drop-down boxes from which you select one of several prescribed responses, or buttons you turn on or off using your computer's mouse.

NEAT uses this data to rank individual energy conservation measures and also evaluates the interaction between conservation measures. For example, since insulation reduces the amount of energy used for heating, it also reduces the energy savings from a furnace replacement.

NEAT follows eight steps to select the most cost-effective energy conservation measures for a particular single-family house:

1. NEAT guides the auditor through the process of entering data from the house.

2. NEAT computes heat loss, heat gain, and energy required to keep the house at a specific thermostatic set point.

3. NEAT reviews possible conservation measures and checks their applicability to the house described by the auditor.

4. NEAT calculates savings for each applicable conservation measure and computes the discounted savings-to-investment-ratio (SIR). The SIR tells you how many times a conservation measure will repay the initial investment during its lifetime.

5. NEAT ranks the energy conservation measures in order of their SIR.

6. Beginning with the highest SIR, NFAT applies each conservation measure to the house and then recomputes a new SIR for the remaining measures, taking into account savings gained by preceding measures.

7. NEAT again ranks the conservation measures and prepares an essential materials list.

8. NEAT adjusts measure savings based on actual consumption data from the utility company, if the user desires.

NEAT calculates heat loss and gain on a monthly basis, using ten-year average weather data for the selected city. NEAT then evaluates all conservation measures by how much they reduce the flow of heat through the envelope and by how much they reduce the house's "balance point" (the outdoor temperature above which no heating is needed or below which no cooling is needed).

NE $\Lambda T$ estimates heating and cooling efficiency based on information you cnter. NEAT also accepts values determined from combustion efficiency measurements.

The amount of solar energy absorbed by a house varies according to area and orientation of its walls, windows, and doors. To help NEAT consider this effect, 
you need to enter the nearest cardinal direction that exterior walls face, as well as in which wall windows and doors are located.

NEAT also accounts for the typical amount of heat generated inside a house by people and their refrigerator, water heater, other appliances and lights.

Since conservation measures typically remain after occupants move, NEAT assumes a house is maintained at average conditions, regardless of specific occupants. This follows the intent of government and utility programs that finance energy conservation savings to be realized for up to 20 years.

NEAT reports the cost-effectiveness of conservation measures-both individually and cumulatively-to fit varying budgets and guidelines of different weatherization programs.

If you follow NEAT, money spent on residential energy conservation will be an economical investment according to the Program rules. 



\section{Chapter 2}

NE $\Lambda \mathrm{T}$ is being distributed as part of a package of energy auditing tools collectively known as the "Weatherization Assistant." The following instructions will install all of these tools onto your computer. They assume you have an IBMcompatible computer with at least $15 \mathrm{MB}$ of available hard disk space. Installation only adds a new directory tree to your hard drive at a location you specify.

Programs in the Weatherization Assistant will execute on a variety of platforms, including Windows 95, 98, 2000, and NT4.0. The following instructions will cover all platforms with only minor modifications. See Section 2.3 , special Cases, or the "install.txt" file on the distribution disk for further guidance under the specific conditions indicated.

Remember:

- Keyboard characters this manual wants you to type are printed in bold. Example: INSTAIL.

- Command keys you are to press, such as Enter, have brackets [ ] around them. Example: [Enter].

\subsection{Program Installation}

The procedure used to install the Weatherization Assistant onto a computer uses the standard Windows process for the platform you are using and an installation program common to most software. A summary is given below. More details can be found in your Windows manual.

Turning on your computer places you in the Windows desktop. If you have not just turned on your computer, you should close any applications currently open. From the desktop, double click on the following icons: My Computer, Control Panel, then Add/Remove Programs. Place the Weatherization Assistant program disk into your computer's CD ROM drive. For Windows 2000, click on Add New Programs then on CD or Floppy. Otherwise, click on the Install button, then Next. Windows should find the "X: \setup.exe" file and place this text in the input window. The "X" stands for the drive letter assigned to your CD ROM. Press [Enter] or click on the Finish button to begin installation. The installation procedure will warn you to close any open applications before proceeding. Click 
on the Continue button if you have already done this. Otherwise choose Exit Setup and close your open applications prior to re-initiating the installation.

The next screen in the installation process allows you to change the location on your computer to which the program files will be copied. The default location is c: \Program Files $\backslash$ Weatherization Assistant. If this is satisfactory, choose OK. Otherwise click on Change Folder and select the preferred location from the Drives then Folders windows. If you choose Network, the installation process permits you to designate a location on your network and map, or assign, it to an available drive designation letter. Click on $\mathrm{OK}$ if you wish to accept your location selection or Cancel if you wish to return to using the default location. Once you are satisfied with your selection, displayed in the Folder window, click on OK to proceed.

The next screen would permit you to choose the mode of installation, Typical, Custom, or Compact. The installation of Weatherization Assistant has only the Typical mode. Click on this button to continue. You will see a window with a bar which meters the progress of installing the necessary files. When complete, you will be presented with the readme.txt file. You may browse the contents of this file at this time. It may be helpful to select the File, Print menu item and print the file to allow future reference. The file contains important notes on installation and operation of the Weatherization Assistant under other than ordinary conditions. It may also contain notes available at the time of release but not in this manual.

When you are finished, close the readme.txt file. After installation, the file will be located in the Weatherization Assistant execution directory (e.g., c: $\backslash$ Program Files \Weatherization Assistant) and can always be accessed through any text editor, such as Notepad.

If the installation was executed successfully, you will be so informed. Close any other windows associated with the install procedure to return to your normal desktop.

\subsection{Starting NEAT}

Installing the Weatherization Assistant as described above will not automatically load a desktop icon for you. This process will be performed if you wish the first time you open the program. To do so, use the Start, Programs menu item and locate the Weatherization Assistant folder, then click on the Weatherization Assistant selection. The program will tell you that it must connect to the back-end database. This operation need be performed only once, just after installation. Click 
on the OK to continue. You will then be asked to confirm that the linking was successful. You are next given the option of installing an icon on your desktop. If you do not choose to do this, you can always open the program in the same manner as just used in this initial execution. If you choose Yes, an icon will be installed on your desktop, which you can move to any folder you wish in the customary manner.

Also during this first session of program execution, you will be asked to enter your agency information. This information will be associated with each execution of the program, identifying your agency's ownership of the job. See Chapter 7 , The NEAT Building Description, for additional information on the individual items needed for this screen. Once completed successfully, you will not be asked for this information again, unless you request to change it.

Subsequent initiations of the Weatherization Assistant will either be accomplished using the desktop icon (if you choose to load one) or using the Start, Programs, Weatherization Assistant menu item. Either approach will now briefly display an introductory banner indicating that the Weatherization Assistant has been developed for the Department of Energy and giving a version number and release date. This will be followed by the main menu screen for the Weatherization Assistant from which you may select which program, NEAT or MHEA, you wish to execute. Click on which ever box lies next to your selection. From this screen, you may also edit your Agency Information or exit the program. Note, single clicks are all that is required to make selections from this main menu form. Inadvertent double clicks may take you down two levels in the menu hierarchy.

\subsection{Special Cases}

In most all instances, the above installation procedure will provide you with a working version of NEAT. However, in two cases, some additional steps will need to be performed in order to allow the program to execute successfully.

If NEAT is installed onto a computer which has Microsoft's Access 2000 software also loaded, NEAT may not executc properly. This is because NEAT was developed using a different version of Access, Access 97. To remedy this situation, an alternative executable has been provided to permit consistency with your computer's existing software.

To implement this alternative, right click your mouse on the Weatherization Assistant icon on your desktop. Choose "Properties" from the menu displayed then select the "Shortcut" tab. In the field labeled "Target" on the Weatherization 
Assistant Properties form, modify the entry by replacing the text "wa97.mde" with "wa2k.mde" (making sure to leave the terminating quotation mark). Lastly, click on OK to save the change.

If you haven't added a Weatherization Assistant icon to your desktop, you can access the same Weatherization Assistant Properties form from your Windows 95 or 98 operating system by choosing Start/Settings/Taskbar/Start Menu Programs/ Advanced. In the directory tree displayed, locate the Weatherization Assistant symbol under the Programs/Weatherization folder and right click on the file symbol then choose Properties.

For Windows 98 or 2000 operating systems, this same form is accessible by right clicking on the Weatherization Assistant file symbol located under Start/ Programs/Weatherization Assistant and choosing Properties.

The second case which may present difficulties results from the older versions of Windows 95 (95A) not having the appropriate system files to run NEAT. This is normally the case if you get a system error referring to "VBJET32.TLB." when you try to execute (run) a NEAT job. To remedy this situation, insert the Weatherization Assistant $C D$ into your computers $C D$ drive. Use Windows Explorer to open the "support" folder on the CD. Run the following programs in this folder: vbrun60.exe, DCom98.exe, and mdac_typ.exe, in that order. Note that after executing the last two, your computer will reboot. You do not need to reinstall the Weatherization Assistant. It should now execute successfully without any additional changes.

\subsection{The Data Link Feature}

As discussed in Chapter 1, An Overview of NEAT, Version 7 of the program stores information you provide and the results of running the program for each job in a record of a database. Thus, if you have performed NEAT audits on twenty homes, your database would have twenty job records.

These records are stored in a database file on your computer named "WAB1.mdb." Each user of the program will have a similar file on their computer. If you wish to view someone else's database of jobs, you may do this using the Data Link feature. Have the agency whose jobs you wish to view send you a copy of their WAB1.mdb file. After receiving it, rename it to have a different name than your file, retaining the "mdb" extension (e.g., WAB2.mdb). Copy the renamed file into your Weatherization Assistant subdirectory (under c: \Program Files, if you chose to load NEAT into the default location on your computer). 
The next time you start the Weatherization Assistant program, you may then select this database by selecting the Data Link option from the Weatherization Assistant main menu. Choose the Browse button then locate the database file (WAB2.mdb in the above example) you wish to view from the files displayed in the look-up table and click the mouse on it. Choose Link to have NEAT make these jobs available to you, as were your jobs previously. A window should appear indicating that the link was successful.

The next time you select an existing job (see Section 3.2, Selecting an Existing Building Description), the jobs you may choose from will be those from the database to which you just linked. Also, if you create a new job, its information will be stored in this same database.

To access your own jobs again, repeat the process above using the Data Link feature, but choose your original database, WAB1.mdb.

If you regularly access a substantial number of databases, you may create a listing of them to ease selection. Use the Edit button on the Data Link screen to access an input screen which allows you to record a database name and location for each database you regularly access. Type in a name of your choosing under "Name." Any characters in this name you enclose in parentheses will be displayed over the logo on the Weatherization Assistant main menu screen to remind you of the database you are currently accessing. Next enter the full path and filename of the database file (e.g., c: \Program Files \Weatherization Assistant $\backslash W A B 2 . m d b)$ associated with your name. A quick way to obtain this path and filename is to use the Browse button, as described above, to locate the database of interest and transfer its name and path into the "New Location" field. Then you can highlight this path and location, use [Cntl-C] to copy it, position yourself at the "Location" field under the "Edit" button, and finally use [Cntl-V] to paste the path and filename into this field (see Section 4.9, Copying and Pasting a Record or Field.)

Having done this for all databases you wish to access, the "Select Database" window in the main Data Link form will display the names of the available databases. Selecting any one of them from this window will automatically transfer its location to the "New Location" field and allow you to link to it by selecting the "Link" button. 


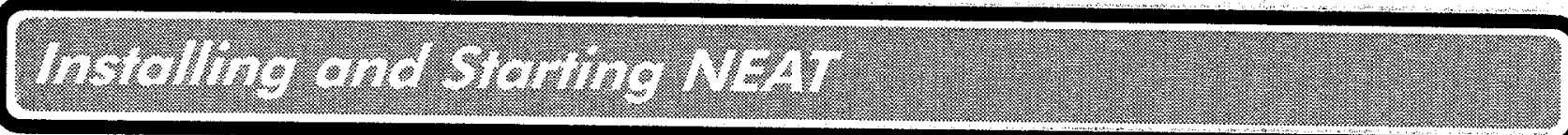

\section{NOTES:}




\section{Chapter 3}

Choosing the "National Energy Audit Tool" from the Weatherization Assistant main menu displays the NEAT introductory screen. From here, you have the option to choose one of three primary activities, which, combined, encompass all the tasks available in NEAT. Through the "Building Characterization and Analysis" selection, homes are described, recommended energy efficiency measures are determined, and reports are requested and printed. The "Setup" selection permits you to customize NEAT to reflect your specific local climate, fuel cost, material and labor costs, and other parameters (see Chapter 8, Customizing a NEAT Audit). The "Preferences" allow you to further choose features in the program to meet your personal needs (see Chapter 9, Preferences).

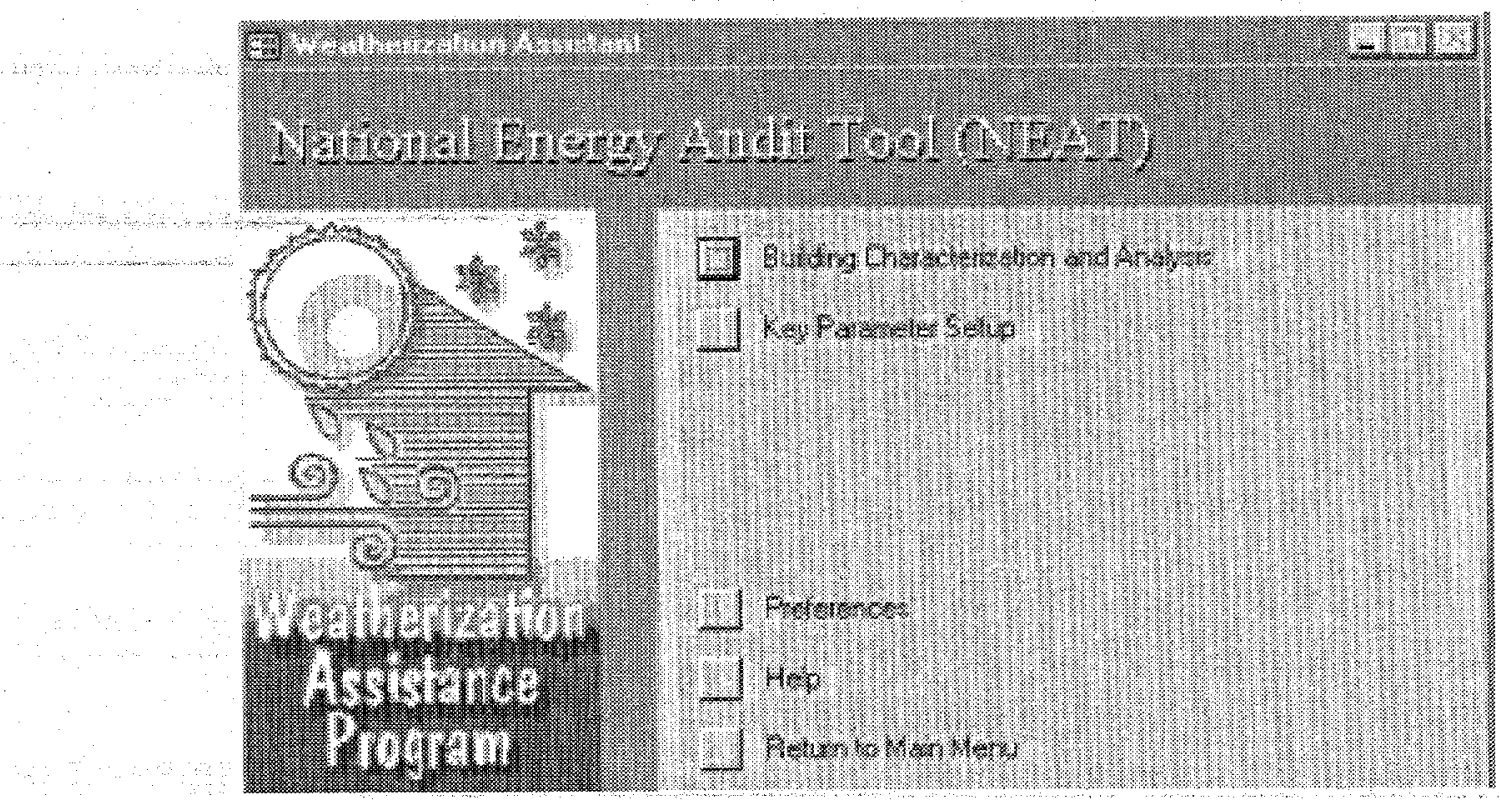

NEAT introductory screen

This chapter will discuss the main tasks available under the "Building Characterization and Analysis" selection that affect entire building descriptions, including (1) finding and retrieving previous building descriptions to modify or reexecute, (2) initiating a new building description, (3) copying building descriptions, (4) executing the program to produce recommendations, and (5) viewing and printing reports. Detailed discussion of the information required to describe a house to NEAT, also supplied under the "Building Characterization and Analysis" selection, is contained in Chapter 6, The NEAT Building Description. 
Note, the words "Job" and "Building Description" are used interchangeably in the discussions of this chapter. The former often for the sake of brevity. Strictly speaking, however, the term "Job" would apply not only to the building description but also to all the setup parameters and reports associated with having run the analysis of the building.

\subsection{The Building Characterization and Analysis Window}

Selecting "Building Characterization and Analysis" from the NEAT menu window automatically initiates the data input segment of the program. A new window, the "Building Characterization and Analysis Window," will open. Note, when opening this window, the database is opening numerous tables to allow rapid access of individual items within a Job. Therefore, depending on the speed of your computer, this process may take some time. The disappearance of the hourglass icon will indicate the program's readiness to proceed. Changing to a new audit job or running an analysis are two other activities that may take a noticeable amount of time.

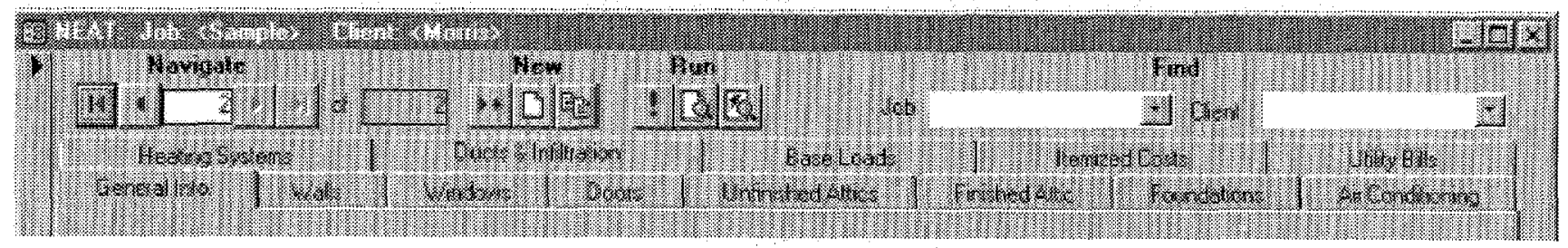

Top portion of the Building Characterization and Analysis Window

In the Title Bar at the top of the Building Characterization and Analysis Window, you will see "NEAT," identifying the program currently accessed, and the words "Job" and "Client." To the right of each of these words will be entries surrounded by carrot symbols, "<" and ">." Within the carrots will be the Job Identifier and Client Name of the building description to which NEAT currently has access. You will supply these names for jobs as you enter them into the program. Each time NEAT is started, it will automatically open the "last job created."

Just below the Title Bar in this window, you will see a Tool Bar containing buttons and fields which will allow you to perform operations on entire building descriptions. These operations will be discussed in this chapter. The remainder of the window is dedicated to entering the details of individual building descriptions, as described in Chapter 6. 


\subsection{Selecting an Existing Building Description}

In the Building Characterization and Analysis Window below the word "Find" in the tool bar are two controls which allow you to search for an existing job, either by Job Identifier or Client. These are data that would have been entered earlier as you described a specific job. Examples are "Manual Example" and "Morris," respectively, as can be viewed on the Title Bar of this screen when first opened. These controls can be used in two different ways to locate an existing job. First, you can begin typing the Job Identifier or Client Name of the job you are looking for into the appropriate field. As soon as the characters you type match those of one of your existing jobs, the remainder of the name will automatically appear in the field. You can then press [Enter] to accept and move to that job.

Alternately, you may click the mouse on the downward pointing arrow to the right of either Job or Client fields to display an entire list of existing jobs in alphabetical order by Job Identifier or Client Name, respectively. Position the mouse over one of these selections and double click the mouse to select that job (or single click then press the [Enter] key). You will be positioned to that job.

Note, whenever you select a job, the program loads all of the building description data for that job into the fields of all forms. On slower computers, this may take some time. So be patient. On more modern computers, it will take only two to three seconds.

A second set of controls on the screen's tool bar, below the word "Navigate," allows you to step through the existing jobs which currently lie in your database. The control has an entry field between two sets of arrow controls arranged horizontally. The number in the field is the number of job currently accessed as determined by an alphabetical ordering of jobs according to what ever parameter on the General Information form you have selected (see last paragraph in Section 4.8, Data Sheet and Form Vieus of Records). Note that this number assignment changes as jobs are added to your data base and will not be in any anticipated order until you re-order them as indicated in Section 4.8. Thus, the number may be of use only in giving you a relative indication of the position of the currently accessed job in your entire list of jobs.

Clicking on the button to the left of this field containing an arrow pointing to a line will position you to the first job in your database. Using the adjacent button, with a left pointing arrow, will access the next lower numbered job. The buttons to the right of the job number field perform similar operations but taking you to the next higher numbered job or to the last job in your database. 
You may also enter a number in the field, then press the [Enter] key to be positioned at the job that has that number. As already mentioned, the use of these "Navigate" controls to locate a job is not as convenient as the "Find" controls since the Job Number with which they work is not uniquely associated with a job.

\subsection{Creating a New Building Description}

There are three different ways you can begin a new building description (or job):

1. Open an entirely blank job record. The data entry forms will have no entries made in them and you will have to supply all required entries individually.

To begin a new job in this manner, click your mouse on the arrow pointing to an asterisk $\left({ }^{*}\right)$ positioned under the word "New" in the tool bar. You will be presented with a blank General Information form except for the "Date" field, which will contain the current date. You will have to fill out the required data on this form before progressing to other forms. This same blank job record would also be created by entering a Job Number in the Navigate field which was larger than the number of jobs you currently have.

2. Open a job containing previously defined default entries.

NEAT provides you with, and allows you to alter, a "Default" building description or job record (see Section 4.11, The Default Record). By selecting the blank page button under the word "New" on the tool bar, NEAT opens a new building description with the same entries as the Default job. The only difference will be that the Job Identifier will be New $[<$ current date and time>]. This entire entry will be selected (highlighted) immediately after choosing to create a new job from the default. It is expected that you will next type in the Job Identifier you wish to assign this new job. From there, you modify the default job to reflect the characteristics of the actual house.

3. The third way to initiate a new job is to copy any other existing job and make modifications to it, saving both the original job and its modified copy. 
To do this, use one of the methods described in Section 3.2, Selecting an Existing Building Description, to select an existing job, the job you want copied to create a new job. Then, select the tool bar button showing two cascading pages with writing on them, located under the word "New." You will be positioned at a new job which is a copy of the existing job except that its Job Identifier will be that of the original job followed by "(copy)." This Job Identifier will be highlighted, indicating the expectation that you will enter a new Job Identifier for this job. You are then free to make any modifications necessary to describe this new house.

\subsection{Running NEAT and Viewing the Reports}

After entering new building description data or revising the data from a previously described building, select the exclamation mark (!) button on the tool bar under the title "Run/Report." NEAT will perform the calculations necessary to provide recommendations for the home's weatherization. Note, having assigned a Job Identifier to the job at the time it was initiated, there is no need to perform this task after entering the building description data. Data you enter is saved each time you leave a specific building component record (or screen form). Thus, activating the Run button will immediately execute the job.

Having requested execution, NEAT examines your input to see that all necessary information is available. Though NEAT performs a check on each form's content every time you exit a form, it doesn't know until you request execution whether an entire form with required information has not been visited. If such is the case, a warning box will indicate the form which contains the required data and its need of being visited. NEAT requires that at least the information on the General Information, Heating Systems, and Ducts and Infiltration forms be provided as well as the description of at least onwall before it can run the job.

Provided all necessary data is available, activating the Run button will change your mouse pointer to an hourglass while the calculations are being performed. You will also see the word "Calculating" in the status bar at the bottom of the window. Wait for the operations to be completed before attempting further interaction with NEAT.

Depcnding on your settings in Preferences (see Section 9.1, General, Preferences), NEAT will either present you with the Output Report for the job you just ran, or return you to the Building Characterization and Analysis Window. If the latter occurs, you will be able to tell that the execution is complete by the mouse 
pointer changing back into its standard form and the word "Calculating" disappearing from the status bar. The "Last Run On" field will also be updated with the current time stamp.

If you are not presented with the Output Report after execution and wish to view it, select the right- most magnifying glass button under the word "Run/ Report" on the Building Characterization and Analysis Window toolbar. The Output Report will be displayed in a separate window_ It is wise to immediately maximize this window by using the standard Windows maximize button in the upper right corner of the window. You can then use the scroll bars to position the page on your screen.

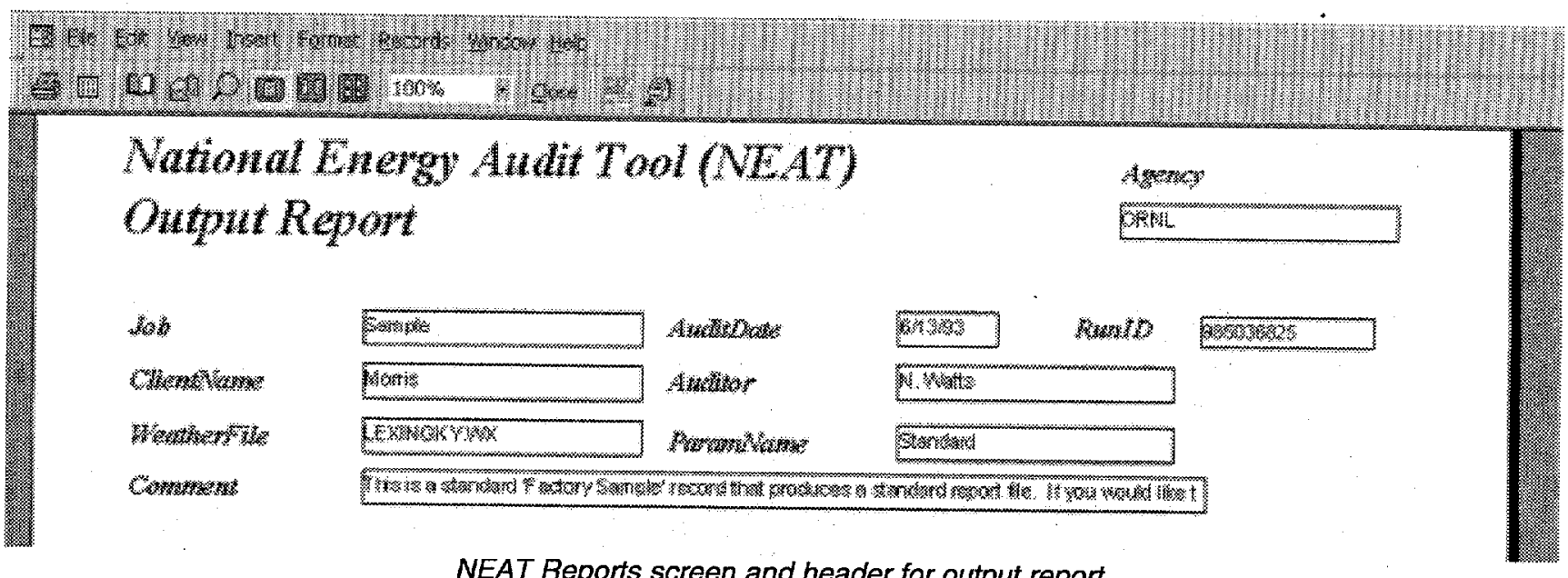

NEAT Reports screen and header for output report

There is no NEAT generated tool bar associated with the Output Report window. However, standard Access toolbars still exist at the top of the program window. Among these are buttons allowing you to display varying numbers of output pages in the report. They appear below the menu bar and each look like a single dark screen with light colored pages in it. A single page in the button's screen indicates viewing one page at a time, two pages side by side allows you to view two pages at one time (though scrolling will likely be necessary), and the button containing a picture of four small pages allows you to choose the display from six predefined layouts. Depending on the resolution you have chosen for your graphics, many of these displays will not have large enough text to read. In this same Access toolbar is a magnifying glass which zooms in on whatever display you have chosen. You may be better able to read the output if you magnify it, but scrolling will most likely be necessary to see all of the display. 
Also on this same Access toolbar for the Output Report is a printer button, normally at the extreme left of the toolbar. If you have a printer assigned to your computer through your Windows setup, clicking the mouse on this button will send a copy of the report to your printer. You may also press the [Ctrl-P] key combination to display the Windows Print screen and print your output from there. If you have not defined any printers to the Windows operating system, pressing the print button will result in an error message.

One other Access toolbar button on the Output Report window may be of interest. On the extreme right of the toolbar is the "Output to Notepad" button. Selecting this will export the Output Report to a pure ASCII text file and display it in Notepad. From there, it may be saved to any location on your computer with any file name you wish.

The report may be closed by clicking on the "Close" button on the Access menu bar or by using the standard Windows Close button at the upper right of the Output Report window. Note, all or parts of other windows may be displayed at the same time as the Output Report window. Be sure the close button you select is associated with the window you actually wish to close. After closing the Output Report window, the program will return you to the Building Characterization and Analysis Window.

For a description of contents of the Output Report, see Chapter 7, NEAT Results.

From the Building Characterization and Analysis Window, you may also choose to display a Job Input Summary Report. Select the button on the window's tool bar located under the word "Run/Report" and between the Run exclamation button and the Output Report button. You will be shown a report of all the building description data in a tabular format. This may or may not be of use, depending on your needs. The intent is to provide a summary report of all of the inputs that define the audit job. The same Access toolbar options described for the Output Report are also available for this Input Summary Report. 


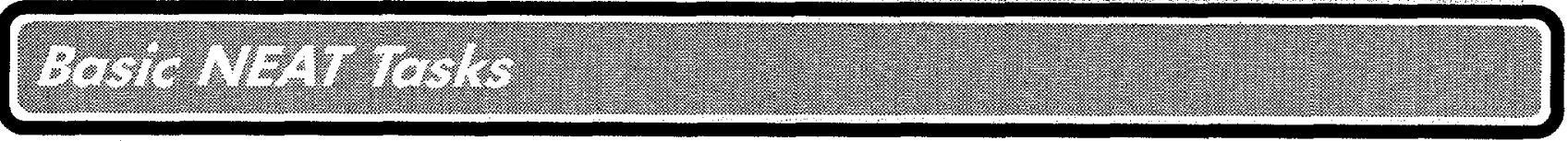

\section{NOTES:}




\section{Chapter 4}

Version 7 of NEAT uses the graphic user interface (GUI) provided by Microsoft's Access 97. NEAT uses all the standard Access forms, controls, and the concept of records contained in this software. Thus, if you are familiar with Access, you are probably already proficient with the mechanics of entering data into NEAT. Otherwise, the following chapter will supply you with the basics needed for this task.

\subsection{Forms and Records}

Data entry in NEAT uses screen forms, each form containing information to describe a specific component or topic, such as general information, a wall, or a ceiling, etc. While on the Building Characterization and Analysis window, left click your mouse on the tab corresponding to the type of component you wish to describe. (See Section 3.1, The Building Characterization and Analysis Window.) Some component types allow entry of more than one component of that type. For instance, you may describe as many as 24 different window types under the Window tab. Each description of a particular component forms a "record" of that component type.

Below is a list of the maximum record counts for each component type in NEAT Version 7.

Maximum Number of Records by Component Type

\begin{tabular}{lrl}
\hline Walls & 18 \\
Windows & 24 & \\
Door & 10 & \\
Unfinished Attic & 7 \\
Finished Attic & 4 & \\
Foundation & 5 & \\
Lighting Systems & 9 & \\
Itemized Costs & 10 & \\
Air Conditioners & 5 & \\
Heating Systems & 2 & (one primary and one secondary system) \\
\hline
\end{tabular}


Multiple copies of a component type's form are provided to enter these records. One to as many as three may be visible at a given time, depending on the component type selected. (See Appendix C, Sample NEAT Forms, for examples of component input forms.) Several means are provided to move from one record to another within the same component type:

- Pressing the $[\mathrm{PgUp}]$ and $[\mathrm{PgDn}]$ keys will move you to the next or previous record.

- When more than one record for a particular component type are visible at the same time, left clicking any data entry item, or "control," will automatically move your cursor to that record and control. Since not all records of a given type may be visible at one time, you may use the vertical scroll bar to the right of the forms to locate additional records.

- Left click your mouse in the vertical record selection bar to the left of the record of the particular component you wish to describe. You may again use the vertical scroll bar to view additional records. Note that an asterisk (*) appears in the bar to the left of the first record available for describing a new component. If you had started from a completely blank building description and were just beginning to describe components of a particular component type, this asterisk would appear beside the first record.

- You may use the record positioning control bar at the bottom of the screen form. The number in the window indicates the number of the record you are presently addressing. Click on the right or left arrows in the control bar to move to the next or previous record. Click on the arrows pointing to vertical lines to go to either the first or last record of the component type. If you wish to move to a blank record to enter a new component description, click on the right arrow pointing to an asterisk.

The Walls form is unique in that it is capable of displaying descriptions of more than just the wall component type. It will simultaneously display a wall description and a window and door which have been designated as lying on that wall. All three of these component types displayed on the Walls form have the record positioning tools described above. However, in the case of the window and door records accessed from a wall form, these tools will allow you to move only to 
records of windows or doors that have been designated as lying on the wall being described or to a blank record.

Forms for other component types, such as Heating Systems and Ducts and Infiltration, can request different data, depending on responses already provided on the form. (See Chapter 6, The NEAT Building Description for more details.) Thus, it is good policy to provide data from the top down to avoid being asked information that is not needed. It is also a good idea to review the list of candidate energy conservation measures in the parameter set because a number of controls on forms are dependent on the list of candidate measures considered (see Section 8.6, Selecting Candidate Conservation Measures).

Data for a record are loaded into your computer's temporary memory (not on disk) whenever you start filling in data on a blank form or modify data on an existing form. You will notice that the icon in the record selection bar on the left of the form changes from a solid triangle (indicating selection) to a pencil (indicating editing). When you exit that form or try to navigate to a new record, the record you were working on gets saved to the database file in your computer's permanent memory, the "disk." There are a number of range and completeness checks as well as relational integrity checks performed by Access when the record is being saved to disk. This is why you can get warning and error messages when you try to leave a form or navigate to a new record.

\subsection{Entering Data into NEAT}

The forms contain three types of controls which accept input from the user: the field, the combo box, and the check box.

Fields allow you to type in entries from the keyboard and are not restricted to any pre-selected set of responses. However, they often must satisfy certain conditions to be acceptable. For example, a field expecting a number cannot contain an alphabetic character.

Combo-boxes look like fields except that they have a square with a downward pointing arrow to the right of the field. Entries into these controls may be restricted to one of several prescribed responses. The selection may be made in several ways:

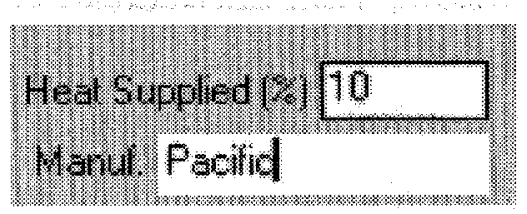

Two fields, the second accessed in insert mode

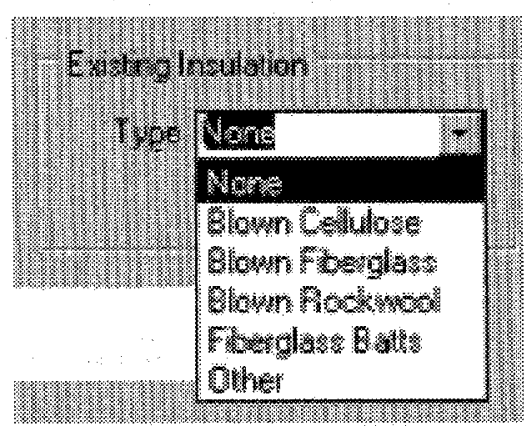

A combo-box control in overwrite mode 
- Left click the mouse on the box with the arrow, then click on the desired response from the drop- down list which will appear.

- Having navigated to the control, press the [Ctrl-Down Arrow] key combination to display the drop- down list, then use the [Up Arrow ] and [Down Arrow] keys to highlight the desired response and press [Enter] or [Tab] to make the selection.

- Or, whenever the entire field is selected (in reverse video), you may begin to type in one of the acceptable responses. As soon as the characters you type uniquely match one of the acceptable responses, the remainder of the field will be automatically filled in and the selection is complete. Then press [Enter] or [Tab] to make the selection.

Most combo boxes are restricted to the list of predefined entries and you must make a selection from that list. The exceptions are the combo boxes for the Existing and Replacement Refrigerator Manufacturer and Model, which do not restrict the entry to an item in the list. In these cases, the combo box can behave as a regular text entry field. However, you will obtain the data from the data base only if your entry matches one that is in the data base. (See also Sections 6.13, Base Loads-Refrigerators, and 8.9, Replacement Refrigerators.)

In all of the cases above, navigating to a new control saves the selection. You will not be allowed to exit a combo-box control unless an acceptable response has been provided, or you press the [Esc] key to back out of your changes.

When the characters in a field or combo-box are highlighted (displayed in reverse video), the control is said to be in "overwrite" mode. Any characters that are highlighted in a control will be replaced by keystrokes you enter. Any number of characters can be highlighted by left clicking the mouse while dragging it across those you wish highlighted. To switch to "insert" mode, position the mouse pointer to a location within the field and left click. This will allow you to insert characters between existing ones.

While in insert mode within a field, the [Left Arrow], [Right Arrow], [Home], [End], [Backspace], and [Delete] keys retain their traditional functions positioning the cursor within the field. Single character highlighting (replacing only individual characters) can be obtained by pressing the [Insert] key on your keyboard. 


\section{Novigatiog he Grobhic Userthenfoce}

The check box is a small white box in which a check mark may or may not be visible. If a check is visible, it implies a yes response to the question associated with the box. You may change the response in a check box either by left clicking the mouse on the box or pressing the [Space] key whenever the box has been selected

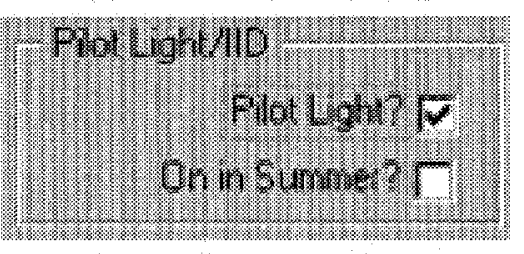

Two check boxes, the first selected (indicated by a dotted rectangle around the control name).

\subsection{Navigating Between Controls}

You can use either the mouse or keyboard to navigate around the controls on forms. Typically you will use a mixture of the methods. The mouse is most intuitive for navigating between forms, menus, and tabs, but you may find the keyboard [Tab] or other keys to be quite handy as well, especially during lots of data entry where constantly moving between the mouse and keyboard can be tedious. Experiment and see which methods are most comfortable for you.

1. You can point and click the left mouse button on the field you want to edit or the check box you want to select. Accessing a field or combo box in this manner will automatically put you into "insert" mode within the field, a vertical line indicating where the next keyboard character will be inserted.

2. You can use the [Tab] and [Shift-Tab] keys to cycle through the controls in forward or reverse order, respectively. These keys will place you in overwrite mode within the control, highlighting the entire contents of the field or combo-box. In most cases, the [Enter] key will act in the same manner as the [Tab] key. One exception is when positioned in a comment field. Here, the [Enter] key is reserved for moving the cursor to a new line within the comment.

3. The [Up Arrow], and [Down Arrow] keys will work the same as the [ShiftTab] and [Tab] keys unless you are (1) in the insert mode within a field, during which the keys will be inoperative, or (2) positioned on one of the tabs at the top of a multi-tab form (indicated by a dotted rectangle around the form name) in which case the keys will cycle between the tabs, changing the form displayed. 


\subsection{The Escape Key}

The [Esc] key is a useful way to back out of your changes. It is similar to an "Undo" command. If you have made changes to a field but have not yet left the field, pressing the [Esc] key restores the value that was in the field prior to your change. Two consecutive [Esc] keys will back out of all changes you have made to all the controls on a form since entering it. Note, once leaving a record and navigating to another, the changes in the former are saved and cannot be reversed. Thus, if you have doubts whether many changes you will make to a building description are desired, you might make a copy of the entire building description prior to initiating the changes (see Section 3.3, Creating a New Building Description). Recall that a "record" refers to information provided to fill in a particular form, such as the description of a given window or the air conditioning system.

\subsection{Required Versus Optional Fields}

Required fields have a single solid border. If you try to exit a form with a required field blank, you will be reminded to complete all fields and the cursor will be positioned to the first missing field. If you decide NOT to save the record, you can use the [Esc] key to cancel your changes.

Fields without the solid line border are not necessary for NEAT to execute, although, if entered,

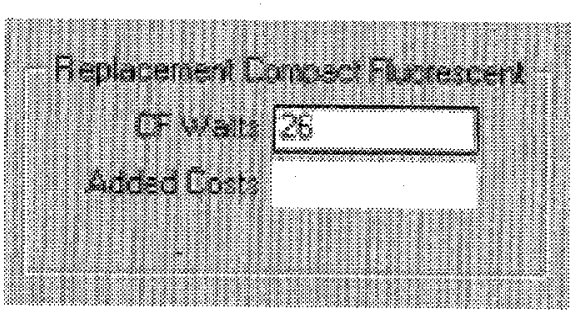

Two fields, the first required, the second optional may contain data which will affect NEAT's recommendations. Other such entries are for informational purposes only and not used by NEAT in its computations and need not be entered. You may use them as you see fit.

\subsection{Field Defaults}

All numerical fields have a user adjustable default value. This ficld default value is displayed in the lower left portion of the screen in the status bar when you enter a field. If you leave the field blank, the default value is applied. This allows you to quickly press the [Tab] or [Enter] key to cycle around the field controls on a form to apply the field defaults. This is different than the Default Record which is a way to apply defaults to an entire audit job (see Section 4.11, The Default Record). 
You can edit the field default values on the Range Check and Default Value tab on the Preferences main menu form. See Section 9.2, Range Check and Default Values.

\subsection{Field Range Checking}

Numerical fields have range checks applied as soon as you exit the field. There are two ranges that are checked. The Acceptable range determines which kinds of numbers will be acceptable to the analysis engine. All numeric entries must fall within the acceptable range. When you enter a number outside the field's acceptable range, you get an error message and are forced to change the data in that field. Remember that you can use the [Esc] key to back out of field and record changes.

The second range is called the Reasonable range which can be overridden or changed by the user. The values of the minimum and maximum are displayed in the status bar in the lower left corner of the screen when you enter the field. When you enter a value outside the reasonable range, you get a warning message that you can override. Use the Range Check and Default Values tab on the Preferences main menu form to alter reasonable ranges for individual fields. See. Section 9.2, Range Check and Default Values.

\subsection{Data Sheet and Form Views of Records}

One of the useful features of the MSAccess User Interface is the ability to display different views of your records. You can select the view that best suits your needs. You can edit the data from any view displayed. There are two basic views supported.

- Standard Form View: The Form View is the most common view, allowing you to see and edit all of the information for a particular record. The controls on the form may be arranged or grouped in ways which will contribute to your understanding of the information requested. The screens in Appendix C are all in this Standard Form View.

- Datasheet View: In the Datasheet View, ALL of the records of a given component type are displayed in a spreadsheet format. All fields for a given item of requested information from all records of a given component type are in the same column in the spreadsheet. In the datasheet view, you can see all records, but typically, the number of fields is too wide to fit on one 
screen, so you must scroll horizontally to view all of the fields. The Datasheet View is not available for the Heating Systems, Ducts and Infiltration, and Base Loads Screens.

Some additional features of the datasheet view may prove to be helpful. For example, if you wished to change Exterior Types from Wood to Brick for all the walls in a house, you would simply travel down the Exterior Type column in the Datasheet View, changing each type as you go. (Note, the automatic fill- in feature will help you make such a change quickly. For this example, you need only enter a "b" in each field, pressing the down arrow after each entry to make the changes. Or, instead of entering the "b," you could use the [Ctrl-'] (control-apostrophe) key combination that copies the contents of the same field from the previous record, which, in the datasheet view, is the field immediately above.)

Datasheet views are also handy for sorting and filtering the list of records shown. You can temporarily change the column ordering, width of columns, freeze position on certain columns, sort in ascending and descending order, and filter for certain entries. Selecting multiple columns in the data sheet (clicking and dragging in the column header) allows the sorting to operate on multiple key fields. The width of columns can be adjusted by dragging the column header borders. The ordering of columns can be changed by highlighting column(s) then clicking and dragging the column to a new position. All column width and position settings only effect the current datasheet view. When you close the form, the original column widths and order will be restored

It is often helpful to temporarily switch from form view to datasheet view to see all of your records for a given component type. To switch from form view to datasheet view, right click in the form away from any control. Depending on where on the form you right click, either a rectangular "Subform Datasheet" popup window or a "View/Filter" menu will appear. Left click on rectangular window or on the Datasheet View selection on the menu. The view will change to the datasheet view.

To change back to form view, right click again in the form. The same window or menu will appear. Either left click on the rectangular window or, if displayed, choose the Form View in the menu.

If you change to datasheet view from the General Information form, you will see a datasheet displaying this form's data for all of your audit jobs. This can be very useful in locating a particular building description. By left clicking on any one of the column headers in the table, then clicking on sort buttons in the tool 
bar ["AZ" or "ZA"], you can display your jobs in the order prescribed by the contents of the column. Thus, you can arrange the listing of your jobs in alphabetic or chronological order by Client Name, Job Identifier, Audit Date, etc. Left clicking on any data field for a particular job, then switching back to form view will present you with all of the input forms for that job.

\subsection{Copying and Pasting a Record or Field}

MSAccess provides a means for copying records and fields. Before you can copy a field or record, however, you must first understand how records and fields are selected. To select a record, press the record selection bar on the left side of the form. When the bar is highlighted, the record is selected. To select a field, click and drag the mouse over the contents of the field or Tab to the field. Either way, the contents of the field will become highlighted and selected. If the field has only one word in it, you can simply double click on the field to highlight and select it.

To copy the contents of the record or field, press the [Ctrl-C] key combination after having selected it. To paste the copied record or field into another location, select the new record or field and press [Ctrl-V]. Instead of using the [Ctrl-C] and $[\mathrm{Ctrl}-\mathrm{V}]$ key combinations, you may instead use either the copy and paste icons on Access's toolbar or the Copy and Paste menu items under Edit on Access's menu, positioned at the top of your Weatherization Assistant window. If you are pasting an entire record, make sure you have selected an entire new record using the record selection bar before pressing the [Ctrl-V]. Also, it makes little sense to copy a field to a field of a different data item.

You can also use the [Ctrl-'] (control-apostrophe) key combination when you are in a field to copy the contents of the same field from the previous record. This is particularly useful in the datasheet view when you just want to make a copy of the field "directly above" the current field in the same datasheet column.

\subsection{Deleting a Record}

To delete a record, first highlight the record using the record selection bar, then either press the [Del] key or select the Edit, Delete Record menu item on Access's menu. Caution: if you delete a Job, you automatically are deleting all of the records (walls; windows...etc.) that are associated with that Job. Similarly, if you delete a wall, you erase all window and door descriptions previously associated with the wall. So be careful. Access will prompt you to make sure you really intend to delete the records. 
NEAT will not allow you to delete a Parameter Set record that is referenced by existing Jobs. If you try, you will get the error, "The record cannot be deleted or changed because table 'tblNJob' included related records." You must first change all the Parameter Set references, making sure the Parameter Set you want to delete is NOT referenced by any audit Job records before you attempt to delete the parameter set.

To delete multiple records, first switch to datasheet view. Use the sorting features of the datasheet view to make those records you wish to delete appear together. Select multiple records by moving the cursor to the rccord selectors on the left side of the datasheet. The cursor will change to a right arrow. Then click and drag the mouse across the record selectors until the records you want to delete are highlighted. Now press the Delete key. Access will ask you if "you are sure you want to delete these records."

\subsection{The Default Record}

When you use the New Default NEAT Job button, you create a new job by creating a copy of the Job with the Job Identifier "DEFAULT" (see Section 3.3, Creating a New Building Description). This Default Job is already in your database when the software is first installed. You can navigate to this default record using the Find controls and make whatever changes are appropriate to your area, such as the weather file selection. You can use this Default Job to specify the most common insulation types, construction details or other common inputs that you find yourself making in your audit inputs. NEAT will not allow you to change the Job Identifier for the default job, or the New Default Job button would no longer work. The program will also not allow you to delete this job.

\subsection{Entry Errors}

Following an entry or when you have selected the run button, the database may detect an error in the input. Although the entire error message may not be completely understood, it will normally contain a reference to a "table" followed by the program's name for the cntry in question. This name will lie in single quotes and begin with "tbl" followed by a name which can be recognized as a specific entry. For example, "tblAgency" refers to the Agency input field on the General Information form. In such instances, locate the entry and examine its contents for conformity with the requirements given in this manual. 


\subsection{Getting Help}

You can get help by pressing the [F1] key anywhere in NEAT. If you press [F1] having selected a specific data item (field, combo-box, or, check box), you will see help material specific to that item. If tabs or buttons are selected when you press the [F1] key, you will see the "NEAT Main Form" help topic.

The title of the help material is always shown at the top left of the help screen. Tabs are also available which allow you to "Print" the material in the displayed help topic and, if you have searched multiple topics, go "Back" to previous topics.

Every help screen also contains a "Contents" tab at the upper left corner. To view a listing of all topics available in Help, click on the Contents tab. From here, you can choose topics by browsing through the expandable Contents tree (double clicking on a topic in the tree will reveal any sub-topics associated with it) or use the Find feature to search for a particular topic. Type a word in the field supplied and the program will search for all occurrences of that word in the help material.

Hypertext items are the highlighted help text you see in a different color. If you move the mouse cursor to the highlighted word(s) and press the left mouse key, you will see more information on that topic or word.

You can leave the help form and return to NEAT at any time by pressing the [Esc] key, clicking on the close button [X] in the upper right corner of the help window, or choosing File, Exit on the help menu bar. 


\section{Chapter 5}

\subsection{Building Descriptions}

The term "building description" will be used within this manual to designate all the data supplied to NEAT in describing a particular building. The building description is tailored to single-family, site-built, detached houses, although NEAT may also be used with small, multi-family buildings. The term "job" can often be used interchangeably with "building description," although the former would apply not only to the building description but also to all the setup parameters and reports associated with having run the analysis of the building.

A building is described to NEAT by entering building characteristics into the computer on separate screens (see Appendix C, Sample NEAT Forms). These screens are accessed from tabs on the Building Characterization and Analysis Window of the program. Each titled tab, when selected, displays a screen permitting entry of information about one of the following building components:

General Information; Walls; Windows; Doors; Unfinished Attics; Finished Attics; Foundation Spaces; Air Conditioning; Heating Systems; Ducts and Infiltration; Base Loads; Itemized Additional Costs and User-Defined Measures; and Utility Bills.

For NEAT to process a job, you must enter all essential data on the General Information, Heating Systems, and Ducts and Infiltration screens, and define at least one wall on the Walls screen (see Sections 6.1, 6.9, 6.12, and 6.2, respectively).

\subsection{Job Identifiers}

The Job Identifier is an important data item. It is supplied by the user on the General Information form. It uniquely identifies the building description to NEAT and the user. Future reference to a particular building description will use this identifier, as when using the Find feature to locate a previously entered job.

A commonly used Job Identifier is the job number assigned by an agency to a particular audit. Other examples are combinations of the audit date, occupant or landlord's name, etc., even though there are other fields in the input for these data items individually. Common building descriptions could be saved using Job Identifiers such as "RANCH," "Two Story," "SPLIT LEVEL," etc. Any characters, 
including spaces, may be used to construct the Job Identifier, but it must be unique from any other Job Identifier in your database and be less than or equal to 50 characters.

\subsection{Component Codes}

Component codes are abbreviated names, which identify specific house components (for example, a north facing wall segment or a window on the east wall). They must be unique for each component of the same type for the same Job. They can contain up to four letters or numbers which are not case-sensitive in determining their uniqueness. In most cases, default entries are available. If this is so, they will appear in the status bar at the bottom of the Weatherization Assistant window. However, you are encouraged to enter codes of your own choosing which may help remind you of the particular building components they refer to.

Whenever an input form is exited, the component code you supplied will be checked to insure its uniqueness. If it is not, a warning box will be displayed stating, "The changes you requested to the table were not successful because they would create duplicate values in the index, primary key, or relationship," then asking you to correct the situation. For example, if the copy and paste functions had been used to copy an Unfinished Attic segment, you would need to change the Code on the duplicated segment so that it no longer was the same as the Code of the original segment from which it had been copied.

Codes can link a floor plan (drawn as an aid to auditing and data entry) to the entry of different data fields (walls, attics, foundation spaces, and air conditioners). Wall Codes can separate walls into sections that face different directions, have different construction characteristics, and/or contain different insulation levels.

Entries for Exterior Walls, Windows, and Doors are related by the wall code. Wall codes are used in the window and door input screens, for example, to allow NEAT to subtract window and door areas from the area of the wall that encloses them.

From the accompanying floor plan sketch, it is apparent that the north wall has a segment exposed to the outside, and a segment buffered by an enclosed porch. These segments are distinguished by wall codes "N1" and "N2," respectively. Thus, the 28 in. $\times 48$ in. window receives the $\mathrm{N} 1$ wall code and the $32 \mathrm{in.} \times 77 \mathrm{in.} \mathrm{door}$ receives the $\mathrm{N} 2$ wall code. The codes are also used in the report to designate to which component a particular measure is to be applied. 


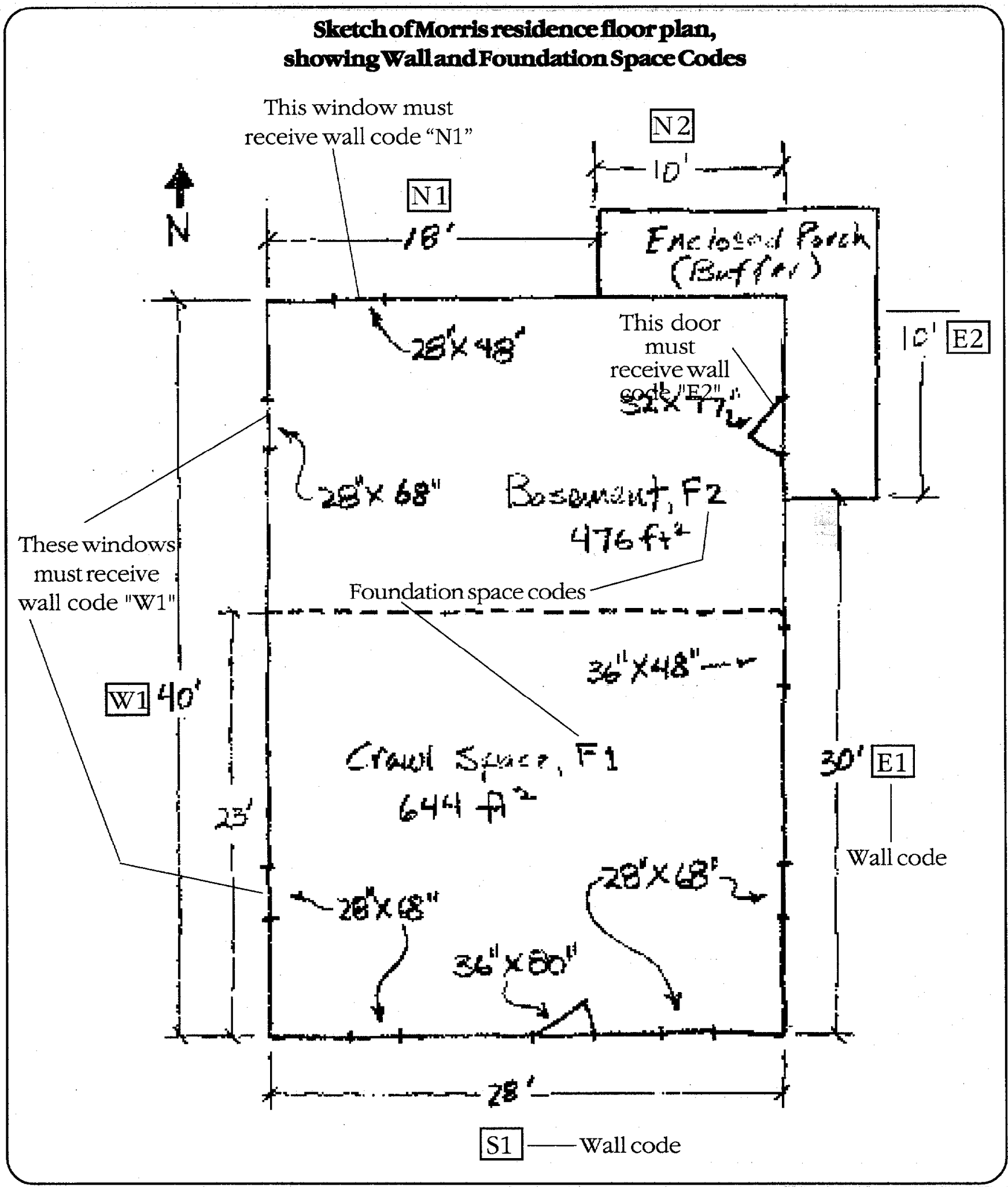


The codes for the finished attic components are fixed and indicate the type of finished attic component being described. In the output reports, these codes are abbreviated: "ocj"-outer ceiling joist, "cbm"-collar beam, "knw"-kneewall, and "rrt"roof rafter. See Section 6.6, Finished Attics, for a description of these types.

\subsection{Measure Numbers}

Measure numbers group together building components which are to receive the same energy conservation measure, that is, for which a single SIR will be determined. For component types that require measure numbers, assign numbers beginning with 1 , followed by 2 , etc. Don't try to assign a measure number of 3 unless energy conservation measures 1 and 2 already exist for a particular component type. NEAT will not permit it.

Measure Numbers for component types where specific records have been deleted or existing Measure Numbers changed will be automatically adjusted to prevent any disruption of consecutive values. Thus, for example, if only one wall with Measure Number 2 exists and it is either deleted or changed to a value of 1 , all Measure Numbers of walls greater than 2 will be lowered by one.

Measure numbers on the Exterior Walls screen group walls to be considered together in receiving wall insulation. Those on the Unfinished Attic and Finished Attic screens group components for the attic insulation measures. Those on the Foundation Spaces screcn group components for floor or foundation space wall insulation.

Consider building components of the same type, for example, attics. Those attic components having the same measure number will receive a savings-toinvestment ratio (SIR) and separate ranking from other attic components having a different measure number. For example, there may be an attic section which has room for four inches of fiberglass insulation, and another section which has room for twelve inches of insulation. If you desire separate SIRs for each, assign measure number "1" to the first attic section, and measure number " 2 " to the second.

The accompanying illustration further demonstrates application of measure numbers. A screen from the Data Sheet view of NEAT is used to show more directly the relationship between the Measure Numbers and the description of the wall segments. The north wall has two sections (wall codes N1 and N2). They are both uninsulated. However, the heat loss through them will be significantly different because N1 is exposed, while N2 is buffered by an enclosed patio. Thus, N1 is assigned "Meas. No. 1," and N2 is assigned "Meas. No. 2." 


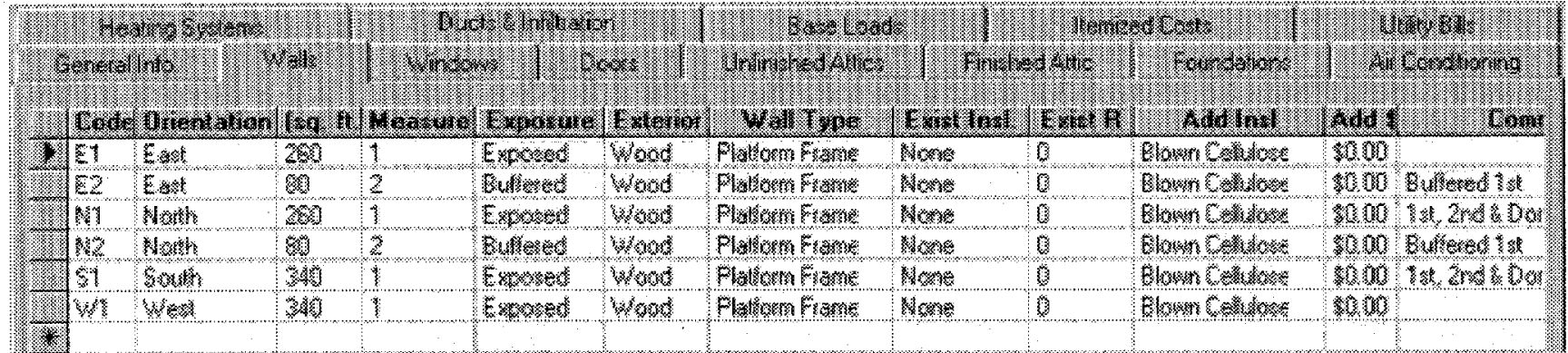

Walls Form (note the selection of measure numbers)

You are not required to assign different measure numbers to each component. If a single measure number is assigned to all components of the same type, a single SIR will be assigned to insulating those components and the same insulation level will be recommended for them. However, any member of the group for which the measure is not applicable (such as a wall which is already insulated) will automatically be dropped from the group.

Typically, walls with different exposures (buffered versus exposed) or significantly different construction should be given separate measure numbers as should attics with differing current or possible insulation levels. 


\section{Chapter 6}

The building description contains all of the information needed to describe a particular building to NEAT. Entry of this data is divided into component types, such as walls, windows, attics, etc. Similarly, this chapter is divided into subsections, one for each component type, each describing the data required to characterize a member of that component type.

Copies of the screens which you will see when entering data into NEAT are included in the Appendices. Appendix $\mathrm{C}$ contains the form views as seen during input of the building description. Appendix D contains screens similar to the data sheet view for each component type. Copies of these pages could be used by the auditor in collecting data while in the field.

Throughout this chapter, references will be made to specific choices you are asked to make regarding the building description. For example, you are asked to indicate whether an attic is "1-Unfloored," "2-Floored," or "3-Cathedral/Flat." The numbers preceding the brief description are used internally to the program and can be ignored here.

Entries are mandatory unless followed by the word "optional" in the descriptions which follow. The "Range of values" listed for numerical entries indicate the range of responses within which the program will not question the value. Outside this range, the program will ask you to confirm the value by pressing the selecting the OK key in the warning box. You may adjust these ranges under Preferences (see Section 9.2, Range Check and Default Values). Those listed here are the values as shipped. "Acceptable values" give ranges outside of which a value will not be accepted.

\subsection{General House Data}

The following are descriptions of entries for the General House Data screen:

Client Name, Address, City, State, Zip, and Auditor-These are comment fields for general reference information. The entries are not used by NEAT except to be displayed at the top of the output reports. (Optional)

Audit Date-Enter the date of the audit. Most formats which can be recognized as a date will be accepted and converted to a date in the format $\mathrm{mm} / \mathrm{dd} / \mathrm{yyyy}$. Although the entry is mandatory, it is used only at the top of output reports. (Default-current date) 
Job Identifier-Identifies this job (audit) to you and the computer. See Section 5.2, Job Identifiers. A maximum of 50 keyboard characters, including spaces, may be entered.

Number of Conditioned Stories-Include a finished attic if the space is heated or cooled. Include a basement if it is heated or cooled and the majority of its wall area is above-grade. You may enter a decimal like 1.5 for split level or half-story upstairs. (Default-1.0)

Conditioned Living Space Floor Area-Enter the number of square feet of floor area that is heated or cooled. (Default-1200)

Average Number of Occupants-On the average during the year, enter the greatest number of people who occupy the house at any given time (e.g., during dinner). (Defaull-2)

Agency Name-The only acceptable entry is the Weatherization Agency Name you provided in the Agency Information. The name will be available in the dropdown list associated with this field.

Weather File-Select the Weather to be used by the program for the analysis. The associated drop- down list contains all 216 weather cities available to NEAT. They are listed in alphabetical order, first by state, then by city. The selection will be retained for any future executions of the program for that job.

Parameter Set-Select the set of parameters (material and fuel costs, candidate measures, key parameters, etc.) you wish to use during the execution of the job. NEAT allows multiple sets to be defined. Double clicking the mouse within this field will take you to the Key Parameter Setup segment of the program where these parameters can be altered (see Chapter 8, Customizing a NEAT Audit).

Include Billing Adjustments-If checked, and Pre-Retrofit Billing Data has been entered, NEAT will adjust the savings estimates of measures to reflect this billed usage.

Impute Cooling-Designed for extremely southern climates where neither heating or cooling equipment is present in a house. NEAT will "impute" cooling energy use by assuming that an air- conditioner with SEER given in Key Parameters is present in the house. The feature is designed to allow installation of measures which could add to the occupants comfort even though energy cannot be saved.

Last Run On-Gives the date and time the open job was last run. The field cannot be altered during input.

Comment-Enter any general comments regarding the job as a whole. Comment fields for individual component descriptions will also be available. 


\subsection{Exterior Walls}

In order for NEAT to execute and save data, you must enter data for at least one wall. This could represent an apartment with only one outside wall, with no heat transfer assumed through the other walls.

There would normally be at least one wall described for exposed surfaces facing in each cardinal direction, because solar heat gain through windows on a wall varies according to its direction. In order to describe all walls most efficiently, combine multi-storied walls that have the same orientation and construction. Other than cardinal direction, the most important difference is whether the wall is already insulated or can be insulated.

Exterior wall data are presented in the following order:

Wall Code-User entered wall codes identify wall sections that face different directions or are constructed differently. For example, the west-facing wall might be coded W1, WW, or any other designation (up to four characters). The wall code allows NEAT to subtract the correct window and door areas-entered in the Windows and Doors screens-from the corresponding wall area. The wall codes are also helpful when labeling your drawing of the house's floor plan and identifying which walls should receive recommended insulation (see Section 5.3, Component Codes).

Wall Direction-Enter the closest cardinal compass direction the component faces, either North, South, East, or West.

Wall Area-Enter the total area of each wall segment, including the windows and doors in that wall area. This entry must be in units of square feet greater than zero.

Measure Number - This entry field helps to distinguish between wall segments that have different characteristics. For example, there might be insulated and uninsulated walls, walls you can and cannot insulate or whose costs to insulate differ, or walls that are buffered and not buffered. Each of these could have different measure numbers. Note, however, that any wall which has been designated as already insulated or unable to be insulated will be automatically dropped from a group of walls with the same measure number when the wall insulation measure is considered. Give the same measure number to all wall segments to be grouped together in determining their particular SIR (see Sections 5.3 and 5.4, Component Codes and Measure Numbers).

Wall Exposure-NEAT gives you three choices: 1-Exposed to the outside air; 2-Buffered by unconditioned space (for example, a garage or porch); or 3-Adjacent to an unconditioned Attic. 
Exterior Type-Select the type of siding on the exterior wall, not the framing material or load-bearing structure. The six choices are: 1-Wood; 2-Metal, vinyl; 3Stucco; 4-Brick; stone; 5-None; 6-Other. NEAT assumes a layer of wood sheathing under the siding.

Wall Type-NEAT asks for the type of load-bearing structure. The five choices are: 1-Balloon frame; 2-Platform frame; 3-Masonry, stone; 4 -Concrete block; 5Adobe; 6-Other. Only frame walls are considered capable of being insulated by all types of Added Insulation, except User-Defined Wall Insulation Type 2 (see Added Insulation Type, below).

Existing Insulation Type and R-Value-Enter the type of insulation found (inspect an electrical outlet, a drilled hole, or some other penetration). The six choices are: 0-None; 1-Blown cellulose; 2-Blown fiberglass; 3-Rock wool; 4 Fiberglass batts; 5-Polystyrene board; 6-Other. The default R-values displayed in status bar assume a $3 \frac{1}{2}$ in. cavity and a standard R-value/inch for the insulation type indicated by the user. If both cavity insulation and exterior sheathing insulation are present, their R-values should be added to provide input for this field. Walls with existing insulation are not considered for further insulation unless the Existing Insulation Type is Polystyrene Board.

Added Insulation Type-NEAT currently allows entries of: 0-None; 1-Blown cellulose; 2,3-Two types you have defined in Key Parameters. The names you entered in Key Parameters for these additional types will be displayed here. The R-values added to the wall cavity for these two types are also entered in Key Parameters. The Uscr-Defined Type 2 Wall Insulation material is allowed to be installed on any Wall Type, whereas the other wall insulation types will be attempted on only uninsulated frame walls.

Added Insulation Added Cost-Enter added costs not normally associated with installation of wall insulation. For instance, enter additional labor costs for removing and repairing an unusual siding type. (Default -0 )

Comments-Make any comments regarding exterior walls that you want to appear on the NEAT audit report. (Optional)

\subsection{Windows}

The Window form contains information needed to describe different window types. Each screen describes a specific type with given dimensions, shading, construction, etc. Windows of the same type and size on the same wall segment may be entered on a single record. In the Number of Windows field, indicate how many windows have this description. 
A total of twenty-four window descriptions may be entered. If the twenty-four window records are not enough to describe all the windows, you can combine windows of the same height on the same wall by adding their widths in inches and then recording them as one window on one line. You can also combine two or more windows by adding their widths together and then averaging their heights (add the heights together and divide by the number of windows). In both cases, you would enter the combined width with the average height.

Be careful when adding or averaging window dimensions. Window treatments may be priced either by dimension or unit. As a result, if unrealistically large pseudo-windows have been described to NEAT by adding dimensions of individual windows, and window treatment measures have been priced by unit, erroneous SIRs will be reported for these window treatment measures.

Window data are presented in the following order:

Window Code-The Window Code allows you to identify the specific window type in the NEAT reports (see Section 5.3, Component Codes). NEAT will provide default entries of the form "WD\#," where the \# is the next higher consecutive integer above the number of window types already described.

Wall Code-Enter the wall code for the exterior wall in which the window is contained. The acceptable Wall Codes, as determined by your input for the Exterior Walls, will be displayed in a drop- down list associated with the field. This entry allows NEAT to subtract window area from the appropriate gross wall area (see Section 5.3, Component Codes).

Number of Windows-Enter the number of identical windows described by this record of data. If dimensions entered are those derived by combining individual windows into one pseudo-window of equivalent area, enter "1" as the number of windows. (Default-1)

Percent Shaded-Enter approximate percentage of window area frequently shaded by eaves (typically 20 percent), porches (typically 100 percent), or other exterior barriers. Do not enter the \% sign. (Default-20)

Frame Type-Select correct window frame and sash construction materials. The three choices are: 1-Wood or vinyl; 2-Metal; 3-Improved metal (metal frame with a thermal break).

Glazing Type-Select window glazing types, depending on materials and layers of glass. The five choices are: 1-Single; 2-Single with wood storm; 3-Single with metal storm; 4-Double pane; 5-Single with bad storm (offering little or no additional protection from air leakage).

Retrofit Status-Provides you with four options indicating different approaches to retrofitting the window: 1-Optional. Allows NEAT to determine the approach 
recommended, including possibly no action at all; 2-Weatherize. Indicates your decision to weatherize the window using caulk, weatherstripping, incidental repair, etc.; 3-Replace. Due to damage beyond repair, you have decided that the window must be replaced; 4-Add storm. Note that in all but the first selection, NEAT views the action as a repair, providing a recommendation regardless of the SIR. However, an estimated energy savings and SIR will still be determined for the retrofit action chosen.

Leakiness -Provide an estimate of the air leakiness of the window being described. The five choices are: 1-Very tight; 2-Tight; 3-Medium; 4-Loose; 5-Very loose.

Storm Window Width and Height-Enter width and height of a storm window if such were to be installed. NEAT will use these dimensions to estimate the glazing area of the window. NEAT will also subtract this area from the wall area entered on the previous screen. The auditor can refer to these dimensions if storm windows prove to be cost-effective.

Cost-Enter the cost of a retrofit storm window if significantly different from the cost entered in the material cost section of Setup. (Optional)

The default cost can be altered in the Setup Menu (see Chapter 8, Customizing $a$ $N E A T$ Audit). If you have combined windows into a single record, multiply the unit cost by the number of windows combined in the record, and enter it in the "unit cost" column. (Optional)

Comments-Enter comments about windows that you want to appear on the NEAT report. (Optional)

\subsection{Doors}

Storm doors or replacement doors are not evaluated within NEAT because they are normally not cost-effective measures, based solely on heat conduction savings. Storm doors or replacement doors may, however, be considered as repair items related to weatherization or as part of the air-leakage reduction work. If installed, their cost could be entered as part of the Infiltration Reduction Cost (see Section 6.12, Ducts and Infiltration) or a repair cost entered on the Itemized Costs form (see Section 6.16, Itemized Additional Costs and User-Defined Measures).

NEAT subtracts door area from the wall area and figures heat loss from the wall and door separately. If the door area is very small compared with the total wall area, you may consider neglecting it. If wall insulation becomes a recommended measure, however, the area of any doors not described here will be included in cost calculations for wall insulation. 
Door data are presented in the following order:

Door Code-The Door Code allows you to identify the specific door in the NEAT reports. NEAT will provide default entries of the form "DR\#," where the \# is the next higher consecutive integer above the number of doors already described (see Section 5.3, Component Codes).

Wall Code-Enter the wall code for the exterior wall section in which the door is contained. The acceptable Wall Codes, as determined by your input for the Exterior Walls, will be displayed in a drop- down list associated with the field. This entry allows NEAT to subtract door area from the appropriate gross wall area (see Section 5.3, Component Codes).

Door Type-Select one of the four door types: 1-Wood, hollow-core; 2-Wood, solid-core; 3-Steel, insulated; 4-Single (pane) sliding glass; 5-Double (pane) sliding glass. A door with glazing may be described either as a combination of window and door or as the component type with the greatest fraction of area. Normally door areas are small compared with the total window and wall area, making the decision less critical.

Number-Enter the number of identical doors described by the current record. (Default-1)

Area-Enter the area, in square feet, of the door. (Default-20) NEAT will compute the total door area, as the door area entered times the number of doors indicated for the door type described.

Storm Door Condition - Enter one of three choices for the storm door condition: 1-Adequate; 2-Deteriorated, 3-None.

Door Width and Height-Use these two entries to record the width and height, in inches, of door openings, if door replacement or storm door installation is needed as a repair item. Otherwise, the fields may be left blank. The dimensions are for reference and are not used in NEAT calculations. (Optional)

Comments-Enter comments about doors that you wish to appear on the NEAT audit report. (Optional)

\subsection{Unfinished Attics}

Data regarding unfinished attics are presented in the following order:

Attic Code-Enter a code to identify each attic or attic section. NEAT will provide default entries of the form " $\mathrm{A} \#$," where the \# is the next higher consecutive integer above the number of attic segments already described.

Attic Type-Enter one of three choices: 1-Unfloored; 2-Floored; 3-Cathedral/ Flat. If the attic has a floor, an estimate of the additional cost of insulating due to 
this obstruction may be entered in the column marked Additional Installation Cost. Selection 3 above, "Cathedral/Flat," pertains to any segment where the roof and ceiling surfaces are parallel.

Joist Spacing-Enter the joist spacing in inches. This number is for reference and is not used in the calculations. (Default-24)

Floor Area-Enter the area of the ceiling or attic floor that borders a conditioned space. This value must be greater than 0 and is in square feet.

Existing Insulation Type-Enter one of six choices: 0-None; 1-Blown cellulose; 2-Blown fiberglass; 3-Blown rockwool; 4-Fiberglass batt; 5-Other.

Existing Insulation Depth-Enter the depth of existing insulation, in inches. NEAT will skip/hide this field if you have entered "None" for existing insulation type.

Measure Number-Enter a number here, beginning with 1 (see Section 5.4, Measure Numbers). This entry field helps to distinguish between attic segments that have different characteristics such as different existing insulation levels or maximum depth of added insulation. Give the same measure number to all attic segments to be grouped together in determining the SIR for attic insulation.

Added Insulation Type-Select one of five choices: 0-None (attic cannot be insulated); 1-Blown cellulose; 2-Blown fiberglass; 3,4-Two types you have defined in Key Parameters (see Section 8.8, User-Defined Insulation Types). NEAT will consider the same insulation levels for these user-defined types as for blown cellulose or fiberglass.

Added Insulation Maximum Depth-Enter, in inches, the maximum depth of insulation which can exist in the attic (including any existing insulation). It is expected that insulation depth will be restricted at the eaves though virtually unrestricted toward the interior of the attic. For floored attics, this depth will usually be the height of the attic floor joists $\left(3 \frac{1 / 2}{2}\right.$ in. or $5 \frac{1}{2}$ in.). If the space is greater than $15 \mathrm{in}$., NEAT assumes unlimited insulation may be added. If a maximum depth restriction has been indicated for a particular attic segment, NEAT will evaluate not only adding the standard levels (R-11, R-19, R-30, and R-38) but also the level of insulation to fill the attic cavity. Insulation costs use interpolations between costs of installing the standard levels, as given by the User in Setup. NEAT will hide this field if you have entered "0" for added insulation type.

Additional Insulation Cost-Enter costs which are not included in the typical attic floor insulation procedure. These might include the cost for cutting an opening into the attic or for insulating beneath an attic floor. This additional cost is a single dollar amount added to the overall cost of insulating the attic segment, not an 
added cost-per-square-foot. NEAT will hide this field if you have entered "0" for added insulation type. (Optional)

Comments-Enter comments about the attic segment that you want to appear on the NEAT audit report. (Optional)

\subsection{Finished Attics}

The entries on the Finished Attic form are similar to those for the Unfinished Attic. Refer to Section 6.5, Unfinished Attics, for descriptions of each field. You may enter any combination of the four finished attic components you choose.

The components of the finished attic will be automatically assigned the following codes for the purposes of reporting: outer ceiling joist (ocj); collar beam (cbm); kneewall (knw); and roof rafter (rrt).

The following items should be noted:

1. No Attic Type is entered for the kneewall or roof rafter since these components cannot be floored or unfloored.

2. No Measure Number is requested for the kneewall. It is automatically ranked separately.

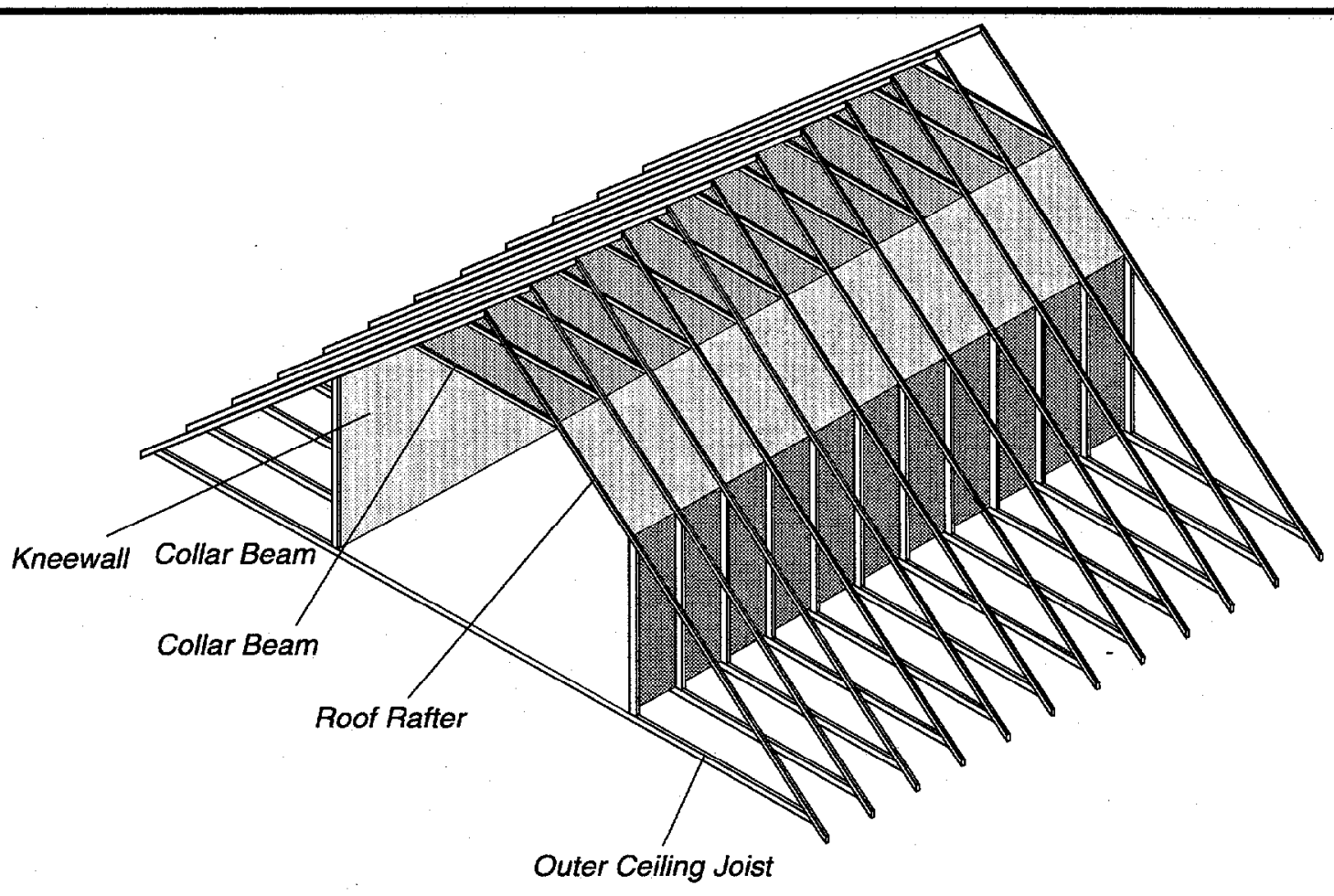

Finished Attic - The four parts of a finished attic define the envelope of the heated area 
3. The Added Insulation Type for the kneewall is assumed to be "4-Fiberglass batts."

4. It is safer not to group finished attic sections because an insulation depth restriction for one will be applied to all segments grouped together.

5. If "0-None" is selected for the type of either the existing or added insulation, the corresponding depth entry will be hid.

\subsection{Foundations}

Data regarding foundation spaces are presented as follows:

Foundation Code-Enter a code to identify each foundation space. The code identifies the entire record of data entered. NEAT will provide default entries of the form "F\#," where the \# is the next higher consecutive integer above the number of foundation spaces already described.

Type-Enter one of seven choices for foundation space: 1-Conditioned (means the space has active thermostat

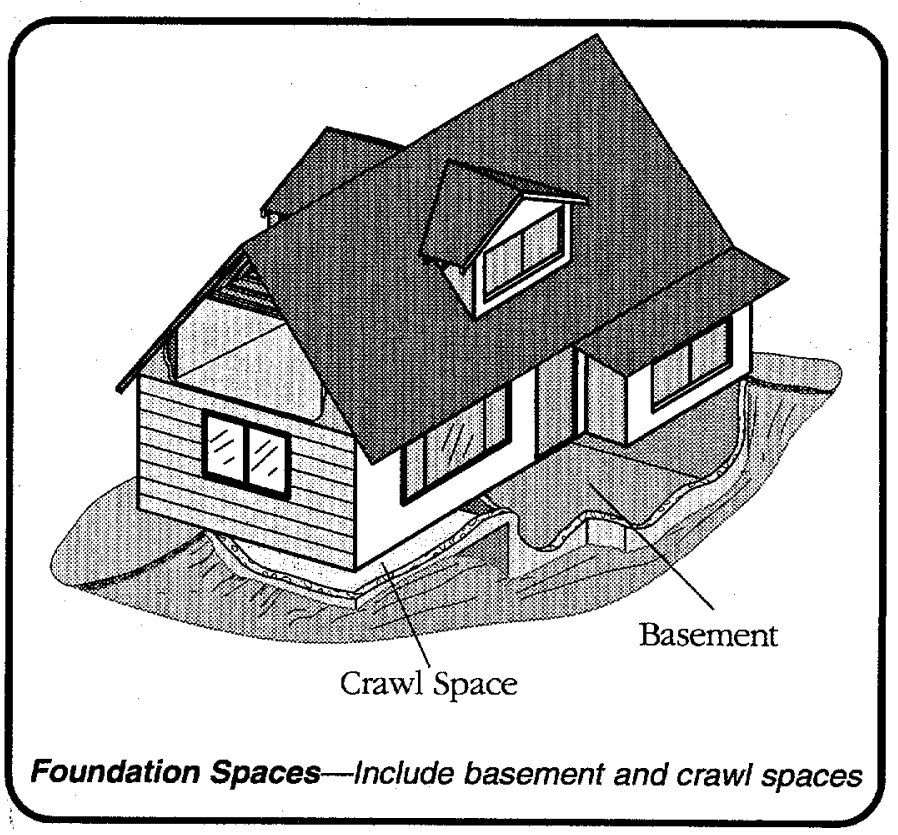
control); 2-Non-conditioned (the space is enclosed but with no sources of heat other than conduction through walls and floors); 3-Vented non-conditioned (the area is vented directly outdoors); 4 Unintentionally conditioned (a furnace, water heater, or other heat source may add heat "unintentionally," but there are no heating registers or radiators in the space); 5-Slab, uninsulated; 6-Slab, insulated; 7-Exposed floor (an overhang or house on stilts).

Certain Foundation Space types do not require data in all fields of this component type while others do. For example, the Slab foundation type requires only a Floor Area and Perimeter Length while the Non-Conditioned type requires all fields. If, through editing an existing component entry, the Type is changed from one not requiring certain fields to one which requires these same fields, a warning will appear when you attempt to leave the Foundation Space screen indicating a need to supply the required data. Exiting will not be permitted until the missing entries are supplied. 
Floor Area-Enter the area, in square feet, of the floor directly above the foundation space you are describing. For slab-on-grade, enter the area of the slab floor in the living space. Your entry must be greater than zero.

Ceiling R-Value-Enter the R-value of the existing insulation in the ceiling over the basement or crawl space. (Defaul-Floor uninsulated)

Perimeter-Enter the length, in feet, of the floor perimeter bordering the outdoors. Do not include the perimeter that borders another foundation space. (Default-uses the perimeter of a square with the area given in the Floor Area field)

Perimeter Exposed \%-Estimate the percentage of floor perimeter for which the band joist is uninsulated and exposed to outdoor air. (Do not enter the \% symbol) (Default - 100)

Measure Number-Supply a number, beginning with 1 (see Section 5.4, Measure Numbers). This entry field helps to distinguish between foundation segments that may be insulated differently. Give the same measure number to all foundation segments to be grouped together in determining the SIR for floor and foundation wall insulation measures.

Wall Height-Enter the height, in feet, of the basement wall or crawl space wall. Estimate an average if height is not uniform. Your entry must be greater than zero. If the wall height is less than two feet, no floor or foundation wall insulation measure will be considered.

Wall Exposed \%-Estimate the percent of the basement wall or crawl space wall exposed to the outside air. You may again need to average. (Do not enter the $\%$ symbol) (Default-100)

Wall R-Value-Enter the R-value of insulation currently on the basement or crawl space wall. (Optional)

Insulation Mode-Indicate how you wish NEAT to consider insulating the foundation space. The choices are: 0-None (do not consider any insulation); 1Floor and wall (choose whichever insulation mode is most cost-effective); 2-Floor only; 3-Wall only. Whichever selection is chosen, NEAT will still not recommend any measure which does not meet the minimum SIR test. Some Foundation Space Types preclude consideration of certain insulation modes (e.g., wall insulation for an exposed floor or a vented crawl space). These are automatically excluded.

Additional Installation Cost-Enter added costs not normally associated with a typical installation of insulation in the foundation space. If either Insulation Modes 2 (Floor only) or 3 (Wall only) has been chosen, the cost will be added to the standard cost of the indicated insulation mode. If Insulation Mode 1 (Floor or 
Wall) has been selected, entry of a positive value will indicate an added cost to floor insulation, while a negative entry will force the positive magnitude of the entry to be added to the cost of installing foundation wall insulation. There is no way to specify added costs to both floor and foundation wall insulation modes at the same time. Note that the added costs are lumped dollar amounts for insulating the entire component, not a dollar amount per square foot of insulation.

As an example, if insulating either walls or floor is possible, yet insulating the floor above the non- conditioned basement could lead to frozen pipes, select Insulation Mode 1 (Floor and Wall) and enter the added cost of protecting the pipes as a positive value in this field. Note that NEAT assumes foundation spaces with wall height of less than two feet cannot be insulated.

Comments -Enter comments regarding the foundation space that you want to appear on the NEAT audit report. (Optional)

\subsection{Air Conditioners}

Data regarding air conditioners are presented in the following order:

AC Code-Enter a code identifying each air conditioner. NEAT will provide default entries of the form "AC\#," where the \# is the next higher consecutive integer above the number of air conditioners already described.

AC Unit Type-Enter one of four choices: 1-Central air conditioning; 2Window unit; 3-Heat pump; 4-Evaporative cooler. The Heat pump type must be indicated for one of the cooling systems if the Heat Pump Replacement measure is to be considered (see Section 10.22, Heat Pump Replacement). If the Evaporative Cooler Unit Type has been chosen, the fields for Size, SEER, and Year Purchased will be automatically hidden.

Manufacturer, Model, Comments-Enter pertinent observations regarding the air conditioning. (Optional)

Area Cooled-Estimate the floor area, in square feet, of those parts of the house cooled by the air conditioner.

Size-Enter the output capacity of the unit $(\mathrm{kBtu} / \mathrm{h})$. (Capacity is printed on the nameplate, or give your best estimate.)

SEER or EER - SEER is the acronym for Seasonal Energy Efficiency Ratio, used to rate central air conditioners. EER is the acronym for Energy Efficiency Ratio, used to rate window air conditioners. Both are measures of how efficiently the unit produces the desired cooling. Enter the SEER, if it is given on the nameplate.

An approximate conversion from EER to SEER may be obtained using the following formulas: 
- $\operatorname{SEER}=(1.2 \times \mathrm{EER})-0.7$ (if the unit's fan runs only when conditioning is required).

- $\operatorname{SEER}=(0.9 \times \mathrm{EER})+0.1$ (if the fan runs continuously while the unit is in use).

If the appropriate efficiency ratio is not known, leave the field blank and press [Enter] while accessing the field. NEAT will display the Year Purchased field for alternate entry.

Year Purchased-Enter the approximate year the unit was purchased new. Use the full year, e.g., "1986," not "96." The purchase year is used to estimate the SEER, if it is not provided. This entry is hid if a value has been provided in the SEER field.

\subsection{Heating Systems-General Data}

NEAT Version 7 allows the definition of two heating systems, a "Primary" and a "Secondary" system. The first record of Heating Systems is always considered the primary system. It is to this system that NEAT will consider installing energy efficiency measures. It is assumed to provide the majority of heat. The form for the primary system is divided into two parts: a general description at the top of the form, and system details at the bottom. Always enter data in the upper portion first, since the system details will not be necessary for all Equipment Types and may differ for others.

Once you have fully described the primary system, if that system does not provide 100 percent of the heat and another heating system exists, such as a space heater, go to the second Heating System record, declare it a Secondary System, and enter the required data.

General data regarding the primary heating system are presented as follows:

System Code-Enter a code identifying the heating system to you and the program. NEAT will provide the default entry, "HS1," for this first and primary system.

Equipment Type-Enter one of ten selections: 1-Gravity furnace; 2-Forced-air furnace; 3-Steam boiler; 4-Hot water boiler; 5-Electric resistance, fixed; 6-Electric resistance, portable; 7-Heat pump; 8-Unvented space heater; 9-Vented space heater; $0-$ Other. If more than one type of system exists, select as the primary heating system the one that supplies the majority of heat and to which the heating retrofits will apply.

Fuel Type-Enter one of seven selections for the primary heating system: 1Natural gas; 2-Oil; 3-Electricity; 4-Propane; 5-Wood; 6-Coal; 7-Kerosene. 
Location-Enter one of three locations of the primary heating system: 1Intentionally heated (space that utilizes a thermostat to control its temperature); 2-Unheated (space not heated by a mechanical system); 3-Unintentionally heated (space which is heated by waste heat from furnace, boiler, or other heat producing appliance).

Heat Supplied \%-Estimate the percent of heat supplied to the house by the primary heating system. A discussion with household occupants will help you to arrive at this figure. (Do not enter the \% symbol)

Manufacturer, Model-Enter make and model information from the nameplate. (Optional)

Uninsulated Supply Duct Length-Enter the length, in feet, of uninsulated supply ducts in unconditioned spaces. This information is for the purposes of evaluating the duct insulation measure. It and the associated information below will be hidden if this measure is not being evaluated. Duct leakage characteristics will be entered on the Ducts \& Infiltration form. (Default-0) (Optional)

Perimeter of Duct-This field will be displayed only if the Duct Length is other than zero. Under these circumstances the entry is mandatory. Enter the average perimeter in inches of uninsulated supply ducts in unconditioned spaces.

Location of Duct-This field will also be displayed only if the Duct Length is other than zero. Select the location where the majority of uninsulated duct exists: Attic or Subspace.

Comments - Enter observations regarding the heating system that you want to appear in the NEAT report. (Optional)

\subsection{Heating Systems-Details Sub-Form}

The data requirements for the Details Sub-Form of the Heating Systems form varies depending on your responses for the general heating system data.

For electrical systems, no further data is needed and the form is not activated. Electrical equipment is assumed $100 \%$ efficient, data normally provided on the details sub-form. Note that distribution losses are described by the data associated with the Uninsulated Supply Duct fields and the Ducts and Infiltration form.

For Heat pumps, the only information required from the details sub-form is the HSPF:

HSPF (Heating Seasonal Performance Factor)-Provide an estimate of the heating seasonal performance factor of the system. Newer systems are required to display the HSPF rating on the unit. Older systems may list a COP value. An exact conversion from COP to HSPF is not possible since the two parameters depend 
on different factors. However, a rough conversion may be accomplished by multiplying the COP by 2.4 to obtain an HSPF. (Default-6.5)

For other systems, most of the controls of the heating systems sub-form become activated. One exception is that oil-fueled systems ask about the presence of a retention head burner while systems using other fuels require data regarding the pilot light, IID, and power burner.

Three parameters on the heating systems sub-form-input rating, output rating, and steady-state efficiency-are interrelated. If you enter input and output ratings, a default efficiency will be calculated from these parameters. If this value is greater than $100 \%$, the standard NEAT default efficiency will be displayed instead. If you enter only an input rating, NEAT's default values for output capacity and steadystate efficiency will correspond to the system type and fuel. $\Lambda$ measured efficiency is desired over a default or name-plate value because it better reflects actual operating conditions and the potential efficiency increase obtained from replacing the system.

The required data is presented as follows:

Input Units and or Input Rating - Enter the appropriate Input Rating Units from the menu provided. The choices are: $0-$ No input; $1-\mathrm{kBtu}$ per hour; $2-$ Gallons per hour; 3-Pounds per hour; 4-CCM (cubic centimeters per minute). Then enter the actual value in the following field. The appropriate value can be measured or taken directly from the nameplate of the furnace, boiler, or space heater. If no input rating is available, choose "0-No input" for the units. The Input Rating field will then be hid.

Output Capacity - Enter the output of the furnace, boiler, or space heater in $\mathrm{kBtu} / \mathrm{h}$.

Steady-State Efficiency-Enter the measured or estimated steady-state efficiency of the primary heating unit. Defaults are based on the system types or previously entered data.

This entry is fairly important. Efforts should be made to obtain the most accurate value possible. NEAT makes recommendations to replace the heating system based on this entry. If you feel that the value provided is not accurate, it is suggested that the Heating System Replacement measure not be implemented in this house, unless for reasons other than energy efficiency.

Condition-Select one of three choices to describe the current condition of the primary heating unit: 1-Poor; 2-Fair; 3-Good. This response is used to estimate an efficiency increase resulting from a tune-up.

Smart Thermostat? - Is there an automatic night-setback thermostat present at the time of the NEAT audit? This check box will appear only for appropriate equipment types. 
Vent Damper Present?-Is a vent damper present? This refers to an automatic vent damper which opens and closes depending on the operation of the heating equipment. It is not referring to a hand operated damper.

Vent Damper Recommended? - Under the specific circumstances found in this house, if found cost- effective, would you recommend installation of an automatic vent damper? Note, if local or state codes do not allow installation of automatic dampers, answer "No" to this question. If you answer "Yes," NEAT will still only recommend a vent damper if it proves to be cost-effective. This check box will be visible only if you have indicated that such a damper does not already exist.

Flue Diameter-Enter the diameter of the flue in inches. This field will be visible only if you have indicated that an automatic vent damper does not already exist and you recommend one bc installed if found to be cost-effective.

IID?-Is there an Intermittent Ignition Device present? This check box is visible for gas- or propane-fueled primary furnace and boilers only.

Pilot Light?-Is a pilot light present on the primary heating equipment? This check box is visible only if you have indicated that an IID is not present.

On in Summer?--Is the pilot light on the heating equipment left on through the summer? This check box is visible only if you have indicated the presence of a pilot light.

Power Burner Present?-Is there a power burner present?-This check box is visible only for gas- or propane-fueled primary furnace-boilers.

Retention Head Present?-Is a retention head burner present? This check box is visible only for oil- fueled equipment.

Retention Head Recommended?-Under the specific circumstances found in this house, if found cost-effective, would you recommend installation of a retention head burner? If you answer "Yes," NEAT will still only recommend installation if it proves to be cost-effective. This check box will be visible only if you have indicated that a retention head burner does not already exist.

System Retrofit Status-Select one of five choices regarding tune-up or replacement of the primary heating unit: 1-Tune-up/replacement optional (treats system tune-up and replacement like any other measure, ranking them in order of the computed SIR); 2-Tune-up already performed (indicates a tune-up has already been performed and the efficiency entered for the system reflects this tune-up-no tune-up measure will be considered); 3-Tune-up mandatory (system tune-up will be placed at the top of the measures list, despite its computed SIR, and will be implemented, thus affecting savings of all measures following it). 4-Replacement mandatory (system replacement will be placed at the top of the measures list, 
despite its computed SIR, and will be implemented, thus affecting savings of all measures following it); 5-High efficiency replacement mandatory (furnaces only).

Selections 4 and 5 would apply to situations where the existing system has been found to be inoperative or unsafe.

System Retrofit Efficiency - Enter manufacturer's estimate of the replacement heating equipment's steady-state efficiency (from the nameplate). For central furnaces and boilers, the default values you have entered in the Key Parameters section of Setup will be default values (see Section 8.7, Altering Key Parameters).

Labor and Material Costs-Enter the Labor and Material costs of replacing the primary system. Default values are taken from your entries in the Material Cost section of Setup (see Section 8.3, Material Costs).

\subsection{Secondary Heating Systems}

Once you have fully described the primary system using the first Heating Systems record, you may describe a secondary system if (1) the primary system does not provide 100 percent of the heat and (2) another heating system exists, such as a space heater. Go to the second Heating System record and declare it a Secondary System by checking the Secondary System check box. This is an important step, since data requirements for a Secondary System differ from those of the Primary System. Then enter the required data, which includes the following items: System Code, Equipment Type, Fuel, and Location. Optional information includes: Manufacturer, Model, and Comments. For more detailed description of these items, see descriptions for corresponding items in Section 6.10, Ileating System-Details Sub-Form.

The only detail required for the Secondary System is the Steady State Efficiency. Recall that most electrical systems are $100 \%$ efficient as are all unvented space heaters. Multiple systems using the same fuel may be combined.

\subsection{Ducts and Infiltration}

NEAT provides means to evaluate the effectiveness of duct sealing and infiltration reduction work. Note, however, it does not direct this work. It assumes that available procedures of locating and repairing air leaks are being used. Air leakage reductions from specific weatherization activities cannot be predicted accurately with calculations.

What information you provide NEAT regarding ducts and infiltration will depend on what measurements you are accustomed to taking during an audit. 


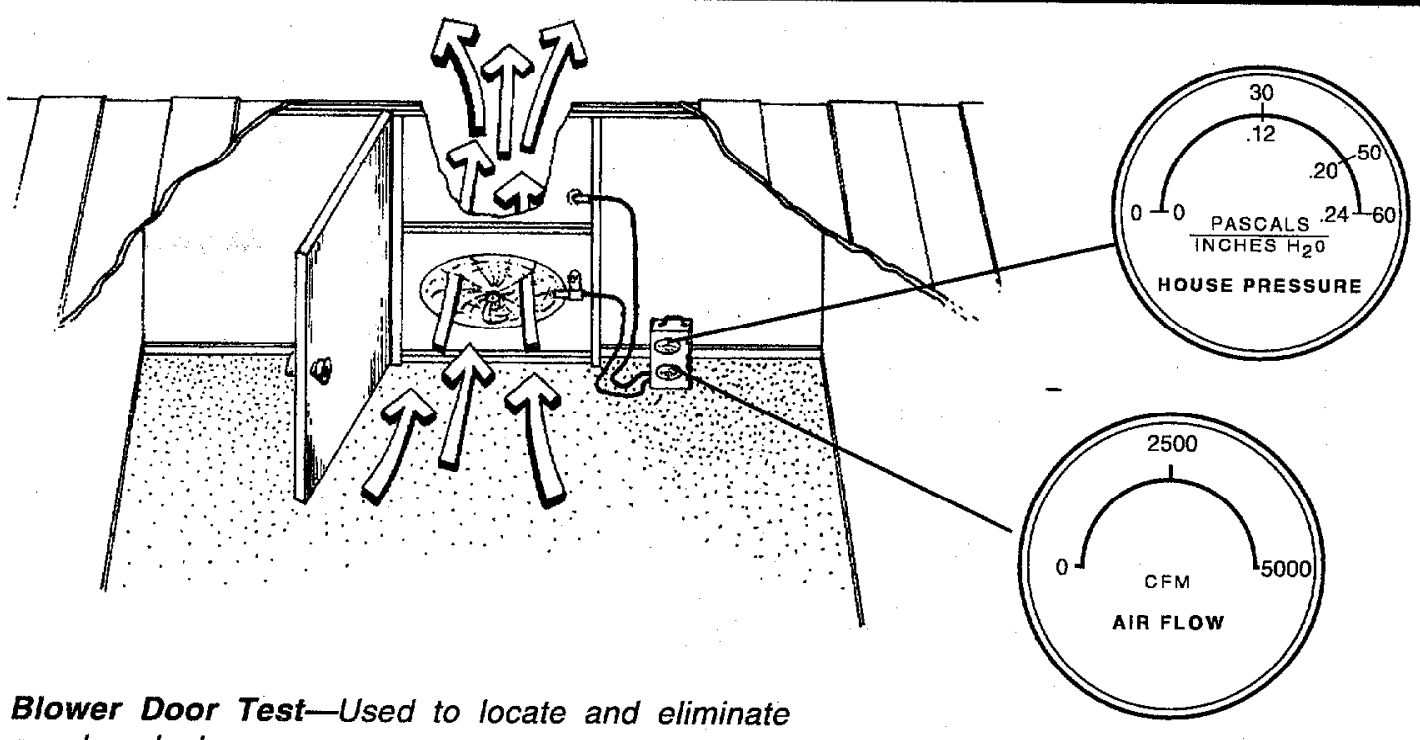

envelope leakage

Blower doors pressurize (or depressurize) a house to some pressure differential (measured in Pascals, PA) with respect to the outside. They can then measure the cubic feet per minute (CFM) of air passing through leaks in the house at that pressure differential. Since the pressure differential is greater than under normal circumstances, the air leaks are exaggerated above what they would be normally, allowing easier detection.

A duct blower works in a similar manner as the blower door, except that it pressurizes only the ducts in the house with respect to the remainder of the house and outdoors. Similarly, it will provide the CFM leaking from the ducts at this pressure differential.

Six different modes of data input relating to ducts and air infiltration are available. The first 3 below assume that no duct leakage measurements are available. For all of these cases, leave the Evaluate Duct Sealing check box, located on the Ducts \& Infiltration form, unchecked. The remaining three modes will evaluate your duct sealing efforts. NOTE: DUCT SEALING WILL BE EVALUATED ONLY FOR $\Lambda$ FORCED-AIR FURNACE OR FORCED-AIR FURNACE AND AIRCONDITIONER COMBINATION. NEAT will not use any duct leakage data unless you have indicated these equipment types.

1. No duct or infiltration measurements available

If you wish to run NEAT without duct and infiltration measurement data (either because your program doesn't address these components or 
because measurements are not available at the time you run NEAT), you can do so by accessing the Ducts \& Infiltration form, leaving the Evaluate Duct Sealing check box unchecked, then supplying entries for the only two required fields on the form:

Post Infiltration Reduction. Whole House Leakage (CFM) - If your audit procedure has established a target post-retrofit CFM leakage rate, enter it here. Otherwise, use the default value of 2500 CFM. (Range of values: 500 to 8000 CFM) (Default-2500 CFM)

Post Infiltration Reduction, Pressure Differential (PA)-Enter either the pressure differential on which your target leakage rate is based or accept the default of $50 \mathrm{PA}$, corresponding to the default leakage. [Range of values: 10 to 100 Pascals $(\mathrm{Pa})$.] (Default-50 Pa)

These settings will allow NEAT to make logical recommendations for the other measures it considers while not addressing the infiltration or duct leakage. The reason a post-retrofit air leakage is required rather than a preretrofit value, is that NEAT assumes some air leakage reduction is likely to occur, particularly if the initial reading is significantly higher than the default or target level. Estimates of savings for other measures will be more accurate if they are based on the air leakage characteristics of the house after this reduction is accomplished, rather than at its pre-retrofit level.

2. Only Pre-infiltration reduction air leakage readings are available

If your audit procedure regularly takes pre-infiltration reduction blowerdoor readings but has no post-reduction values at the time NEAT is run, you may choose to run NEAT without infiltration and duct leakage data, as described in 1 above.

Or, you may enter these readings in the Pre Infiltration Reduction, Whole House Leakage and Pressure Differential fields. However, you must still enter values in the required Post-Infiltration Reduction fields. You could enter a target post-retrofit air leakage rate appropriate for the house. NEAT will then compute an energy savings associated with this reduction. If no infiltration reduction work is deemed necessary for the house, enter the preretrofit rate into the post-retrofit fields since, in this case, both pre- and postretrofit levels will be the same and the post-retrofit levels are required for NEAT to run.

If post-retrofit air leakage rate readings become available at some future time, the house description could be recalled, the readings entered, and an 
appended report printed. However, this may not be worth the time, especially if a target value you chose is anywhere near the final reading obtained.

3. Pre- and post-infiltration reduction air leakage readings are available but no duct readings

Enter data in all fields available on the Whole House Infiltration Reduction with Blower Door form. The Evaluate Duct Sealing check box remains unchecked.

Pre-Infiltration Reduction, Whole House Leakage (CFM) and Pressure Differential $(\mathrm{Pa})$-These entries are from blower door measurements of air leakage before sealing. The CFM reading is normally taken at a pressure differential of $50 \mathrm{~Pa}$, if such can be reached. Pre-retrofit entries are optional but, if provided, used to estimate savings from air sealing. Pre-retrofit entries will not affect savings computed for other measures. (Range of values: 500 to $8000 \mathrm{cfm}$ for air leakage rates, and 0 to $100 \mathrm{~Pa}$ for blower door pressure differentials.) (Air leakage rate default $-2500 \mathrm{cfm}$; pressure differential default$50 \mathrm{~Pa}$ ) (Optional)

Post-Infiltration Reduction. Whole House Leakage (CFM) and Pressure Differential $(\mathrm{Pa})$ - These entries are from blower door measurements after air sealing. The CFM reading is normally taken at a pressure differential of $50 \mathrm{~Pa}$, if such can be reached. If the only air leakage information available is in air changes-per-hour ( $\mathrm{ACH}$ ) at natural conditions, an approximate conversion to CFM at 50 Pascals (CFM50) may be obtained as follows: $\mathrm{CFM} 50=\mathrm{ACH} \times$ House volume $\div 3$. (Range of values: 500 to $8000 \mathrm{cfm}$ for air leakage rates, and 0 to $100 \mathrm{~Pa}$ for blower door pressure differentials.) (Air leakage rate default $-2500 \mathrm{cfm}$; pressure differential default $-0 \mathrm{~Pa}$ )

Infiltration Reduction Cost-Enter the cost in dollars spent to reduce air infiltration from the pre- retrofit to the post-retrofit level. (Range of values: 0.0 to 1000) If a cost is entered together with the above entries of pre- and post-infiltration reduction blower-door data, an SIR, in addition to the energy savings for the air-leakage reduction, will be computed and reported (see Section 7.3, Energy Saving Measure Economics). (Optional)

The remaining modes of data entry for the Ducts \& Infiltration forms provide means of estimating the cost-effectiveness of duct sealing as well as infiltration reduction. NEAT provides input fields to accommodate three different common duct leakage measurement techniques: Whole House Blower Door Measurements; Blower Door Subtraction; and Duct Blower 
Pressure Tests. To access the forms needed, select (check) the Evaluate Duct Sealing check box on the Ducts \& Infiltration form. You will then be presented with the Duct Leakage Method drop-down list. From this list choose one of the three duct leakage measurement techniques. Once you have made your selection, the form's input fields will be altered to accommodate that particular method.

Each of the data input modes associated with the three measurement techniques requires duct operating pressure inputs. Since they are common to all three modes, they will be described once here. The readings are taken during normal conditions with the air handler fan on. Small holes (afterwards repaired) can be drilled in the supply plenum near the air handler and in the return plenum in which to insert pressure probes. It is recommended that a digital gauge be used to then measure the pressure inside of these plenums with respect to the room or part of the house in which they are located. The data entry fields for this data lie under the Duct Operating Pressures title on each of the forms. The four duct operating pressures required are:

Pre Duct Sealing Supply ( $\mathrm{Pa}$ ) - Enter the supply duct-house pressure difference before implementing any duct-sealing measures. [Range of values: 10 to $100(\mathrm{~Pa})]$

Pre Duct Sealing Return (Pa)-Enter the return duct-house pressure difference before implementing any duct-sealing measures. [Range of values: 10 to $100(\mathrm{~Pa})$.]

Post Duct Sealing Supply (Pa) - Enter the supply duct-house pressure difference after implementing any duct-sealing measures. [Range of values: 10 to $100(\mathrm{~Pa})]$

Post Duct Sealing Return (Pa) - Enter the return duct-house pressure difference after implementing duct-sealing measures. [Range of values: 10 to $100(\mathrm{~Pa})]$

The additional entries necessary for each of the three input modes will be discussed separately below. They are arranged in order of complexity, the simplest first. Unfortunately, the simplest tends to also be the least accurate.

4. Pre/Post Whole House Blower Door Measurements

This technique of estimating duct leakage uses whole house blower door leakage measurements before and after duct sealing to estimate the duct leakage reduction accomplished. To provide this method in NEAT, some assumption had to be made with regard to the order in which duct sealing 
and infiltration reduction work was performed. NEAT assumes that the duct sealing is accomplished first, followed, at some point, by the infiltration reduction.

Most of the entries required are from readings you would normally take to estimate the whole house infiltration. These readings are first taken before any duct leakage or infiltration reduction work has been performed, second, after duct sealing is accomplished-but before infiltration reduction work, then a third time after both duct and infiltration reduction work has been performed. For all of these readings, the vents and registers of the distribution system should remain open so that the ducts are as much a part of the conditioned space as possible.

The entries required are described separately below:

Pre-Infiltration Reduction, Whole House Leakage (CFM) and Pressure Differential ( $\mathrm{Pa}$ )-Same as in (3) above, but no longer optional.

Post Duct Sealing. Whole House Leakage (CFM) and Pressure Differential $(\mathrm{Pa})$-These entries are from blower door measurements of whole house air leakage after duct sealing efforts, but before air infiltration reduction work. (Range of values: 500 to $8000 \mathrm{cfm}$ for air leakage rates, and 0 to $100 \mathrm{~Pa}$ for blower door pressure differentials.) (Air leakage rate default-2500 cfm; pressure differential default-50 Pa)

Post-Infiltration Reduction, Whole House Leakage (CFM) and Pressure Differential ( $\mathrm{Pa}$ - - Same as in (3) above, but no longer optional and is assumed to be from readings taken after both duct sealing and infiltration reduction efforts have been accomplished.

Duct Sealing Cost-Enter the cost in dollars spent to reduce the duct leakage from the Pre Infiltration Reduction (and, therefore, the pre duct sealing) to the Post Duct Sealing level. (Range of values: 0.0 to 1000)

Infiltration Reduction Cost-Enter the cost in dollars spent to reduce the air infiltration from the Post Duct Sealing (and, therefore, the pre infiltration reduction) to the Post Infiltration Reduction level. (Range of values: 0.0 to 1000)

5. Blower Door Subtraction

This method uses the same readings as the Whole House Blower Door technique but adds analogous readings, both before and after duct sealing, during which the distribution system has been sealed off from the rest of the house. Use cardboard, plastic, tape, etc., to temporarily cover and seal all 
registers and grills on both the supply and return side. This essentially allows subtraction of the house leakage from the duct plus house leakage to isolate the leakiness of the ducts. One additional reading is required to help compensate for duct leakage to the conditioned space, the duct-house pressure differential with the ducts and registers sealed and the house pressurized (or depressurized) to the same degree as for the other CFM readings (normally $50 \mathrm{~Pa}$ ).

Note, it is normally recommended that this technique not be used if the measured duct-house pressure differential is less than $20 \mathrm{~Pa}$, indicating that the duct system is very well connected to the house interior. This is commonly true in homes which use building cavities for a significant part of the duct work.

The data entry items for this input mode are as follows:

Pre-Infiltration Reduction, Whole House Leakage (CFM) and Pressure Differential ( $\mathrm{Pa}$ ) (with registers/grills open)-Same as in (3) above, but no longer optional.

Pre-Infiltration Reduction, Whole House Leakage (CFM) and Pressure Differential ( $\mathrm{Pa}$ ) (with registers/grills sealed)-Same as immediately above except with registers and grills sealed.

Pre-Infiltration Reduction, Duct House Pressure Differential (Pa) (with registers/grills sealed) - Enter the measured pressure differential between the duct system and the house with the house pressurized (or depressurized) to the same degree as for the CFM readings immediately above (normally $50 \mathrm{~Pa}$ ). This measurement can be taken at the supply or return plenum, or at a supply register or return grill by punching a small hole through the masking tape or other material used to temporarily seal the grills, and inserting a pressure tap or hose connected to a pressure gauge.

Post Duct Sealing, Whole House Leakage (CFM) and Pressure Differential $(\mathrm{Pa})$ (with registers/grills open)-Same as in (4) above. Measured after duct sealing efforts, but before air infiltration reduction work.

Post-Duct Sealing, Whole House Leakage (CFM) and Pressure Differential $(\mathrm{Pa})$ (with registers/grills sealed)-Same as immediately above except with registers and grills sealed.

Post-Duct Sealing, Duct House Pressure Differential (Pa) (with registers/ grills sealed)-Same as Pre-Infiltration Reduction value obtained above, but measured after duct sealing efforts, but before air infiltration reduction work.

Post-Infiltration Reduction. Whole House Leakage (CFM) and Pressure Differential ( $\mathrm{Pa}$ ) (with registers/grills open)-Same as in (4) above. 
Duct Sealing Cost-Enter the cost in dollars spent to reduce the duct leakage from the Pre-Infiltration Reduction (and, therefore, the pre duct sealing) to the Post-Duct Sealing level. (Range of values: 0.0 to 1000)

Infiltration Reduction Cost-Enter the cost in dollars spent to reduce the air infiltration from the Post Duct Sealing (and, therefore, the pre infiltration reduction) to the Post Infiltration Reduction level. (Range of values: 0.0 to 1000)

The Duct Operating Pressures entries are described in the introductory material to mode 4 .

\section{Duct Blower Pressure Tests}

This method uses both a duct blower and a blower door. A duct blower pressurizes the duct system which is sealed off (by taping the registers and grills) from the remainder of the house. The measured CFM through the duct blower is then equal to the total air leakage from the ducts to both the exterior and interior of the house. To obtain leakage to only the outside, the blower door is used to pressurize the entire house to the same pressure, with respect to the outside, as the ducts. With no pressure differential between the house and the ducts, any leakage recorded by the duct blower must then be to the outside. The leakage will be at whatcver duct/outside pressure differential is established by the duct blower.

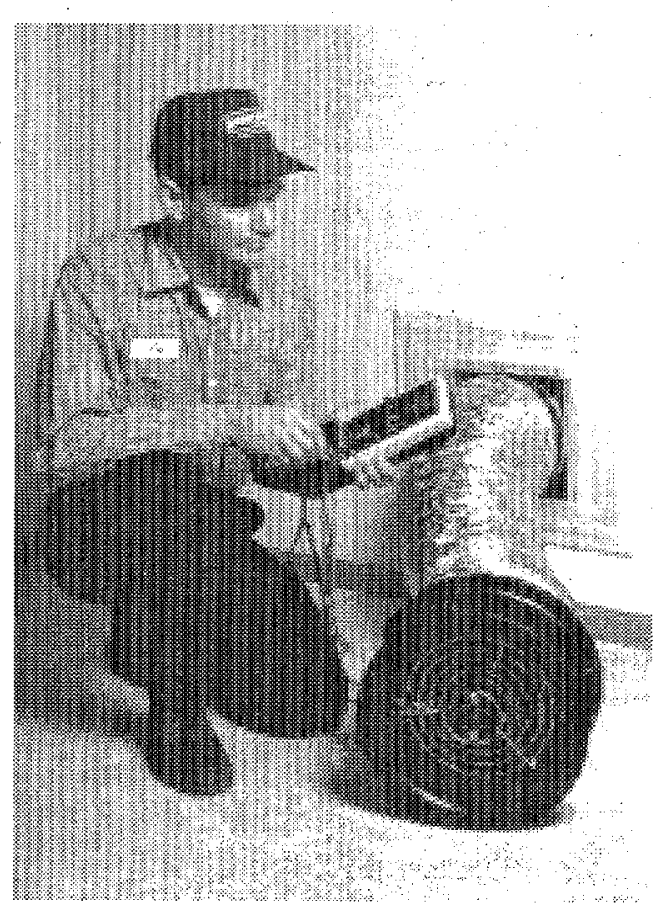

Duct Blower-Used to measure duct leakage. (Courtesy of The Energy Conservatory)

This technique of determining duct leakage is more accurate than the other means, but also the most time-consuming. It requires both a duct blower and a blower door:

The data entry items for this input mode are as follows. Each of the items is determined and entered twice, once before (Pre) permanent duct sealing occurs, and again afterwards (Post).

Pre/Post Duct Sealing Total Fan Flow (CFM) and Duct Pressure (Pa)Enter the CFM measured through the duct blower with the duct pressurized 
with respect to the house and outside. For these measurements, the registers and grills are temporarily sealed off (taped) from the remainder of the house.

Pre/Post Duct Sealing Outside Fan Flow (CFM) and Duct Pressure (Pa)Enter the CFM through the duct-blower measured before/after duct sealing and with the house at the same pressure difference with respect to the outside as the ducts. While the duct-blower is used to pressurize the duct system, a blower- door will be used to pressurize the house. For these measurements, the registers and grills are temporarily sealed off (taped) from the remainder of the house.

House Pressure $(\mathrm{Pa})$ with respect to the outside-Enter the pressure differential between the house and the outside as created by the blower door. Note, for accurate determination of the duct leakage, this pressurc differential should be the same as, or as close as possible to, the pressure differential between the ducts and outside.

The Duct Operating Pressures entries are described in the introductory material to mode 4. The remainder of the entries on this form relate to the infiltration reduction efforts and are the same as given in mode 3 above.

\subsection{Base Loads-Refrigerators}

NEAT includes a refrigerator replacement measure (see Section 10.24, Refrigerator Replacement). In order to evaluate the potential savings obtained from replacing an existing refrigerator with a newer, more efficient unit, NEAT needs to know an estimate of the existing and new refrigerators' annual energy use, in $\mathrm{kWh} /$ year. This data can be obtained in either of three ways:

1. The American Home Appliance Association (AHAM) has accumulated the results of efficiency tests for many manufacturers' models of refrigerators. The data base containing their data has been incorporated into NEAT. Thus, if you are able to locate the manufacturer and model in the look-up table provided, the required annual consumption will be entered for you.

2. Refrigerators are sold with labels that list the estimated annual energy consumption in $\mathrm{kWh} /$ year. If such an energy guide label is available for either the existing or new units (more likely for the latter), it can be used as the source for this required input to NEAT.

3. Small meters exist which are capable of relatively easily monitoring the consumption of a refrigerator. If you use one of these meters, NEAT asks for the $\mathrm{kWh}$ consumed by the refrigerator during the monitoring period and the number of minutes monitored. 
Additional inputs adjust the consumption data for the ambient temperature of the space in which the refrigerator is located, the existing refrigerator's age, and defrost cycles.

The data input is grouped into data items relevant to the three input modes described above. There is some overlap, however. The data entry descriptions for the existing unit are given below:

Manufacturer-Enter the existing refrigerator manufacturer's name. You may use this field to either enter a manufacturer of your own choosing or to search the look-up tables for a matching entry. This entry is optional unless you are using the data look-up tables to identify the unit.

Model-Enter the existing refrigerator's model number. You may use this field to either enter a model number of your own choosing or to search the look-up tables for a matching entry. This entry is optional unless you are using the data look-up tables to identify the unit.

Height, Width, Depth, Size-Enter the dimensions of the existing unit. These entries are always optional. However, if entered for both the existing and replacement units, NEAT will compare the entries and produce a warning if the entries indicate a possible size problem related to the replacement. If you used the look-up tables to identify the existing unit and dimensions are available from the tables, these dimensions will be entered automatically. (Optional)

Location-Select one of three locations for the refrigerator: 1-Heated space (space that utilizes a thermostat to control its temperature); 2-Unheated space (space not heated by a mechanical system); 3-Unintentionally heated (space which is heated by waste heat from furnace, boiler, or other heat producing appliance). (Default-Heated Space)

$\mathrm{kWh} /$ Year - Enter the $\mathrm{kWh} /$ year consumption listed on the energy guide label for the existing unit, if one exists. If you have used the look-up tables to identify the existing unit, this value will be entered automatically. The entry is not required if you are using metered consumption data.

Age-Select one of the categories describing the age of the existing unit: Less than 5 years; 5 to 10 years; 10 to 15 years; More than 15 years. If you used the look-up tables to identify the existing unit and the data is available from the tables, this data will be entered automatically. Note, however, the age from the tables will be based on the first year the model was sold. If you know that the existing model is newer than that indicated from the tables, change the entry. The entry is not required if you are using metered consumption data.

Metering Minutes - If you are using metered consumption data, enter the number of minutes you metered the existing refrigerator. Metering should be performed 
for at least 180 minutes ( 3 hours). You should attempt to prevent refrigerator door openings during the metering period. This entry is not required if the $\mathrm{kWh} / \mathrm{year}$ field has been used to provide the consumption data.

Meter Reading - Enter the metered consumption in $\mathrm{kWh}$ for the period specified by the Metering Minutes. This entry is not required if the $\mathrm{kWh} /$ year field has been used to provide the consumption data.

Temperature-If the location of the existing refrigerator is "Unheated," enter the average ambient temperature surrounding the unit during the metering period.

Manual Defrost-Is the existing unit manual defrost? This entry required for metered consumption only.

Includes Defrost Cycle-Indicate in this check box whether or not the metered consumption entered above included a defrost cycle. This can be determined if either the consumption or refrigerator interior temperature is being monitored by the presence of a peak in either of these parameters extending several times higher than the surrounding peaks. Unpredictable recommendations for the refrigerator replacement measure may occur if the metering time is two hours or less and the period is indicated as having included a defrost cycle. If you are unsure whether the period included a defrost cycle, it may be best to assume that it did not.

Consumption data is also necessary for the replacement refrigerator. This data will be provided either from the energy guide label on the replacement unit, or from values of pre-selected replacement units in your library of replacement refrigerators. This library is defined by you in the Setup portion of NEAT (see Section 8.9, Replacement Refrigerators). Data for the replacement refrigerator are entered on the right side of the form and include the following:

Pre-Defined Replacement-Use this drop-down box to select a replacement unit from your library of refrigerators. If this field is used, the entry must match a unit listed in your library.

Manufacturer - Enter the manufacturer of the replacement refrigerator. If your selection of a replacement has been made from your library of replacement refrigerators, this data will be entered automatically. (Optional)

Model-Enter the model number of the replacement refrigerator. If your selection of a replacement has been made from your library of replacement refrigerators, this data will be entered automatically. (Optional)

$\mathrm{kWh} /$ Year-Enter the annual consumption in $\mathrm{kWh} /$ year for the replacement refrigerator. This value may be obtained from the energy guide label of the replacement unit. Otherwise, if your selection of a replacement has been made from your library of replacement refrigerators, this data will be entered automatically. 
Material and Other Costs-Enter the purchase (material) price of the replacement refrigerator and any other installation or disposal costs associated with the refrigerator replacement. Note that any costs incurred in disposing of the old existing refrigerator must be included in this Other cost.

Height, Width, Depth. Size-Enter the dimensions of the replacement unit. These entries are always optional. However, if entered for both the existing and replacement units, NEAT will compare the entries and produce a warning if the entries indicate a possible size problem related to the replacement. If you choose your replacement from your library of replacement refrigerators and dimensions are available in the library entry, these dimensions will be entered automatically. (Optional)

Comments-Enter comments about the refrigerator replacement you may want to appear in the NEAT audit report. (Optional)

\subsection{Base Loads-Water Heating}

NEAT evaluates several water heating measures: water heater replacement, tank insulation, pipe insulation, and low-flow showerheads. The water heater data required by NEAT depends on which of these measures you have chosen to evaluate in your program. The data are presented in the following order on the Base Loads, Water Heater form:

Manufacturer-Enter the existing water heater's manufacturer's name. You may use this field to either enter a manufacturer of your own choosing or to search the look-up tables for a matching entry. However, if you are evaluating replacing the existing unit, you must locate the manufacturer and model of the unit in the data base in order for NEAT to have the efficiency data necessary to evaluate the replacement. Otherwise, this entry is optional.

Model-Enter the existing water heater's model number. As for the manufacturer, you may use this field to either enter a model of your own choosing or to search the look-up tables for a matching entry. However, if you are evaluating replacing the existing unit, you must locate the manufacturer and model of the unit in the data base in order for NEAT to have the efficiency data necessary to evaluate the replacement. Otherwise, this entry is optional.

Fuel Type-Select the fucl used by the existing water heater from the three choices: 1-Natural gas; 2-Electric; 3-Propane. The entry is required for all water heater measures. If the manufacture and model have been successfully chosen from the data base, this field will be entered automatically. 
Water Heater Location-Select one of three locations for the water heater: 1Heated space (space that utilizes a thermostat to control its temperature); 2Unheated space (space not heated by a mechanical system); 3-Unintentionally heated (space which is heated by waste heat from furnace, boiler, or other heat producing appliance).

Existing Tank R-Value-If the label on the existing water heater lists an R-value, enter it here. Otherwise enter data in the following two fields.

Existing Insulation 'Iype-Select one of two insulation types used in the existing water heater: 1-Fiberglass; 2-Polyurethane. Often an access plate can be removed to view the insulation and determine its type and thickness. This entry is required only for evaluating the tank insulation measure.

Existing Insulation Thickness-Enter the thickness, in inches, of insulation in the existing unit. If an insulating wrap already exists, include its thickness as well. Often an access plate can be removed to view the insulation and determine its type and thickness. This entry is required only for evaluating the tank insulation measure.

Hot Water Pipe Insulation-Indicate whether pipe insulation exists on at least the first five feet of pipe entering and exiting the water heater. Required only for pipe insulation measure.

Number of Shower Heads-Enter the number of showerheads used in the house for which replacement with low-flow models needs to be evaluated. Required only for the low-flow showerhead measure.

Minutes of Shower Usage Per Day-Enter the total minutes per day the showerheads are in use. Combine the times for each showerhead being considered for replacement. Required only for the low-flow showerhead measure.

Average GPM for Shower Heads-Enter the average flow rate in gallons per minute of all shower- heads being considered for replacement. You can determine this easily using a container of known volume and a stop watch. Required only for the low-flow showerhead measure.

Comment-Enter any comments associated with the water heating you want displayed on the output reports. (Optional)

\subsection{Base Loads-Lighting}

Data describing the existing lighting in the house is entered on the Lighting form. If your program does not consider replacing existing incandescent lamps with compact fluorescent ones, you can ignore this form. The form is used only to describe the lighting fixtures you intend to consider for this replacement measure. 
If the Lighting Retrofits measure has been turned off in the Candidate Measures form of Key Parameters, this form will not be accessible.

Entries on this screen are a follows:

Light Code- The Light Code allows you to identify the specific Light description in the NEAT reports. NEAT will provide default entries of the form "LT\#," where the \# is the next higher consecutive integer above the number of lights already described.

Room-Enter the room in which the lights being described are located. The 7 choices are: 1-Family room; 2-Kitchen; 3-Living room; 4-Rec room; 5-Dining; 6-Bedroom; 7-Utility; 8-Other. The entry is for the auditor's use in locating the lights for possible later retrofit. (Optional)

Location (of existing incandescent lamps)-Describe the location of the lighting fixture(s) within the room using one of the following selections: C-Ceiling; FFloor; T-Table; W-Wall. This entry is for the auditor's use only in locating the lights for later retrofit. (Optional)

Lamp Type (of existing incandescent lamps) - Indicate the type of the existing incandescent lamp: S-Standard or F-Flood (reflective or spot). The default for the replacement compact fluorescent's wattage is determined by this entry and the existing lamp wattage. Also, the materials report will indicate that the replacement is to be either standard or flood, depending on your entry here.

Quantity (of existing incandescent lamps) - Enter the number of lamps having the description given by this record and which are candidates for replacement with compact fluorescents. The entry is required with no default.

Watts (of existing incandescent lamps)-Enter the wattage of the existing incandescent lamp which is to be replaced. Standard incandescent lamp wattages are $25,40,50,60,75,90,100$, and 150 . The value is required and used in computing the savings resulting from its replacement with a fluorescent lamp. The default for the replacement compact fluorescent's wattage is determined by this entry and the lamp type. (Default-100)

Hours/Day Used - Enter the average number of hours per day the lamp is normally on. The value must be 24 or less. Your response to this entry has a considerable effect on the savings associated with replacing the lamp. You should target this measure to lamps with substantial on-times. The entry is required with no default.

Replacement CF Watts - Enter the wattage of the compact fluorescent which is to replace the existing lamp. Common replacements given below are used as the default for this field. They depend on your entry for existing lamp wattage and type. 
The lighting measure will use the standard replacement wattage closest to your entry.

Added Cost-Enter any added cost, in dollars per lamp, not normally associated with installation of a compact fluorescent and not included in the standard material costs. Replacing a fixture's harp to allow the CFL to fit, or other size modification, are examples. (Default-0) (Optional)

Comments-Enter any comments relevant to the lamps described or retrofits to be installed, such as the reason for any added cost recorded or physical restrictions. (Optional)

\begin{tabular}{|c|c|c|c|c|c|}
\hline $\begin{array}{c}\text { Existing } \\
\text { Incandescent } \\
\text { (Watts) }\end{array}$ & $\begin{array}{c}\text { Replacement } \\
\text { Fluorescent } \\
\text { (Watts) }\end{array}$ & $\begin{array}{c}\text { Existing } \\
\text { Incandescent } \\
\text { (Watts) }\end{array}$ & $\begin{array}{c}\text { Replacement } \\
\text { Fluorescent } \\
\text { (Watts) }\end{array}$ & $\begin{array}{c}\text { Existing } \\
\text { Incandescent } \\
\text { (Watts) }\end{array}$ & $\begin{array}{c}\text { Replacement } \\
\text { Fluorescent } \\
\text { (Watts) }\end{array}$ \\
\hline \multicolumn{6}{|c|}{ Standard } \\
\hline 25 & 5 & 60 & 13 & 100 & 26 \\
40 & 7 & 75 & 18 & 150 & 38 \\
50 & 80 & 25 & 100 & 18 \\
\hline
\end{tabular}

\subsection{Itemized Additional Costs and User-Defined Measures}

Costs not associated with specific energy conservation measures, yet incurred during weatherization, may be entered on this form. Examples might be travel or administrative costs. If you know the approximate annual MBtu savings for a weatherization activity not addressed by the standard NEAT measures, this screen may also be used to define a new measure associated with the savings. After you define the "user-defined" measure, NEAT will treat it the same as it does all other measures.

For user-defined measures, no fields, except Material, are optional. For added costs, only Description, Cost, Material, and Include in SIR controls are relevant. See Appendix A, Audit Example, for a sample screen. Data entries are presented in the following order:

Description-Enter a brief description of the added cost or user-defined measure. This description will be entered in the Recommended Measure column of the reports.

Cost (\$)-Enter the dollar cost of the item being described. 
Material-Enter a brief description of the major material needed to implement the itemized additional cost or the user-defined measure. The description entered will appear on NEAT's Material Report. (Optional)

Include in SIR? - Do you wish this cost to be included in the cumulative SIR on the reports? If this check box is selected, an itemized cost will appear at the top of the recommended measure list and will be included in the cumulative cost and SIR for the job. If you choose not to include that cost in the SIR, the costs are placed at the end of the measure list after a final cumulative SIR has been displayed. The cost is added to the cumulative cost, but not used to compute the cumulative SIR.

You must select Include in SIR if the record you are entering is to describe a user-defined measure.

Annual Savings (MBtu) - For user-defined measures, enter an estimate of the annual energy savings associated with the measure in millions of Btu. You may need to use standard conversion factors to arrive at savings in MBtu. The entry will be used in the computation of the measure's SIR. This field will be hidden unless you have chosen the Include in SIR check box.

Life-time (Years) - Enter the lifetime of the measure/materials associated with the user-defined measure. Industry standards have been established for many materials. DOE requires the maximum to be 20 years. This field will be hidden unless an Energy Savings has been entered.

Fuel Saved-Select one of seven choices for the type of fuel saved by the userdefined measure: 1-Natural gas; 2-Oil; 3-Electricity; 4-Propane; 5-Wood; 6-Coal; 7-Kerosene. This field will be hidden unless an Energy Savings has been entered.

Comments-Enter any comments you want displayed on the output reports. (Optional)

\subsection{Utility Bills}

Although optional, utility billing data you enter into NEAT for the homes you weatherize can be a valuable source of information. NEAT allows you to compare its consumption predictions with pre- retrofit billing data (see Section 7.7, Heating and Cooling Energy Comparisons). Then, if you desire, it will adjust the measure recommendations and savings to reflect this actual consumption.

Post-weatherization billing data may also be input to NEAT and stored with the other data for a house. Computer software exists which can use both pre- and post-weatherization billing data to derive actual energy savings estimates, possibly useful in program evaluations. 
NEAT permits entry of four sets of utility bills: pre- and post-retrofit heating and cooling energy usage. If you wish to enter billing data, ask the client for up to 12 months of utility bills. If the client has discarded these bills, he or she may request consumption records from the local utility. Or, the client may sign a release which grants you authority to directly obtain the data.

NEAT cannot separate heating and cooling consumptions from a single billing history when the same fuel is used for both conditioning components. Thus, an electrically heated house with air-conditioning or a house with a heat pump cannot use NEAT's billing data features unless you can successfully divide the electric bills into their heating and cooling components before entering the data into NEAT.

NEAT's billing data features work best with metered fuels, such as natural gas and electric. In fact, the billing data entry screens were designed for these two fuels. Use with other fuels will likely require units conversions. Bulk fuels, such as propane or fuel oil, which are delivered in bulk and stored in tanks at the house, are less appropriate. Unless deliveries are relatively frequent and approximately the same amount of fuel remains in the tank at the time of each delivery, use of billing data for these fuels can lead to substantial inaccuracy. The following discussions will assume electric or natural gas heat.

Billing periods entered into NEAT must be consecutive. They may extend from one year into the next, but must span one year or less. Thus, no two periods can include any of the same days of the year in two years. The number of periods entered must be 12 or less. Examples of entries are (1) twelve consecutive monthly readings, (2) one annual consumption, or (3) any number of periods, 12 or less, spanning less than a year in duration.

Each of the four sets of entries has the following data requirements:

Type-Select either 1-Heating or 2-Cooling as the major purpose for which the fuel entered is used. The fuel may also supply non-heating or cooling end uses, such as cooking or water heating. However, you will have to enter an estimate of this "Base Load" in a subsequent field.

Period - Select whether the data being entered pertains to a 1-Pre-Retrofit or 2Post-Retrofit period. Only pre-retrofit data will be used for measure savings adjustments.

Units-Select either 1-Therms or 2-kWh depending on the fuel source and season for which data is to be entered. Normally cooling data will be in kilowatthours of electricity and heating data in either therms or kilowatt-hours. The utility may document natural gas consumption in therms, mcf (thousand cubic feet), or 
ccf (hundred cubic feet). Mcf and ccf can be converted to therms by multiplying by a value obtained from the local gas utility. Because heat content of natural gas varies according to composition, ask the utility for the number of therms contained in a mcf or ccf delivered to homes in the area. This value (in therms-per-ccf) should be entered in the Key Parameters (see Section 8.7, Altering Key Parameters). Most natural gas contains approximately ten therms per mcf and one therm per ccf of natural gas. Other fuels may require additional conversion, such as gallons of propane or oil. However, note the warning above regarding recording bulk fuel consumption.

Days in First Period-Enter the number of days included in the first billing period. Subsequent periods are assumed to be contiguous, thus allowing NEAT to determine their lengths.

Base Temperature-The Utility Bills Data Entry screens provide an option for entering heating degree days (HDDs) and cooling degree days (CDDs) for natural gas and electricity billing data, respectively. The degree-day information will not affect any adjustments to the measure savings. It simply allows you to compare degree-days used by NEAT with those from the actual billing periods. Heating and cooling degree days are available from local utilities, state energy offices or the U.S. Department of Commerce National Weather Service, Asheville, NC.

If degree-day information is to be entered, NEAT requires base temperatures for these $\mathrm{HDD}$ or CDD values. Assume a base temperature of $65^{\circ} \mathrm{F}$ for HDDs and $78^{\circ} \mathrm{F}$ for CDDs, unless a different base temperature is listed on the utility bill.

Base Load-Enter an estimate of the average base load consumption per month in the units chosen in "Units" above. The period consumptions entered likely result from not only heating or cooling, but also from use of appliances, such as stoves, water heaters, or refrigerators. NEAT needs to separate this "base load" consumption from the heating and cooling consumption. This entry is an estimate of this base load consumption for an average 30-day month.

To determine the base load for the heating fuel yourself, select a month when the heating equipment did not operate, most likely during summer. This month should be one of normal household occupancy - no long term visitors or household vacations. Determine the heating fuel consumption for that month, in the units selected in the "Units" field.

To determine cooling base load, select a month with no electric heating or air conditioning consumption, most likely during fall or spring. The number of kilowatt-hours consumed is the base load. 
NEAT will adjust this value to correspond to each of the billing periods, regardless of their duration. You may wish to leave this field blank until after entering the actual billing data for the periods. NEAT will then compute a default value for the base load that reflects the period data entered.

Comments-Enter any comments regarding this particular set of billing data you wish to be displayed in the NEAT output reports.

The above data is entered once per set of billing data. The following data are required for each billing period within a set. They appear on the right side of the input screen in a tabular format. (Optional)

Month-Enter the number of the month in which the meter reading corresponding to the billing period was taken (e.g., January-1; February-2, etc.).

Day-Enter the day of month on which the meter reading corresponding to the billing period was taken.

Usage-Enter the consumption during the billing period. The units are those selected in the "Units" field to the left.

Degree Days - Enter the number of heating or cooling degree-days (depending on the "Type" selected) corresponding to the period. (Optional) 


.




\section{Chapter 7}

Following input of the building description, as described in Chapter 6, and running the program, NEAT provides you with a variety of input and output reports. Section 3.4, Running NEAT and Viewing the Reports, discusses executing the program and accessing these reports. This chapter describes the content of the various reports.

Which reports are available depends on your settings in the Report Sections in Preferences, as described in Section 9.3, Report Sections. Whichever reports are displayed, they will be prefaced by an introductory section identifying at least the Job and Client Name, Audit Date, and Auditor.

All of the reports will be summarized below. If information described here is of interest to you and you do not see it in the reports generated, go to Preferences and make sure the appropriate report sections are selected.

Examples of the reports are provided in Appendix A, Audit Example.

Recall that any of the reports can be printed using the printer button at the extreme left of the Access toolbar at the top of the report or entering the [Ctrl-P] key combination.

\subsection{Input Summary}

The Input Summary reflects your entire building description in a tabular format similar to what you see during input using the Datasheet View (Section 4.8, Data Sheet and Form Views of Records). Following the General Information, each component type is individually described with its own header line printed in large, bold, and italicized letters. If no entries were made for a specific component type or if the specific component type's input summary has been turned off in Preferences, no reference to that type will be made in the input summary.

The remaining reports are part of the Output Summary Report. They also may be turned on or off in the Report Sections in Preferences.

\subsection{Annual Energy and Cost Savings}

This report lists the individual measure recommendations generated by NEAT that reflect the input you provided. Each recommended measure is identified by its name, as given in Candidate Measures of Setup (see Section 8.6, Selecting Candidate Conservation Measures), and, if applicable, by the component codes of those 
components to which the measure is to be applied (see Section 5.3, Component Codes). For example, onc tecommendation might be to install "Wall Insulation" on walls "WL1," "WL2," "WL3," and "WL4."

Appearing first in the list will be (1) those measures assumed to be cost justified outside of NEAT (infiltration or duct sealing), (2) measures declared mandatory (such as the replacement of an unsafe furnace), or (3) measures you may have indicated as having already been performed (such as heating system tune-up).

Following these items, measures will be listed in order of cost-effectiveness (SIR), after all interactions with other measures have been considered. Only measures with SIR greater than the cut-off value selected in Key Parameters of Setup will be displayed.

For each measure recommended, the annual energy and dollar savings associated with the measure is given. These savings parameters will be divided into three categories, Heating, Cooling, and Base Load, for each measure. The heating energy savings is always given in MBtu (million Btu), while the cooling and base load savings will be in $\mathrm{kWh}$. A total energy savings in MBtu is given in the last column of this report section.

\subsection{Energy Saving Measure Economics}

The Energy Saving Measure Economics report section gives individual and cumulative economic parameters for the recommended measures. The measure name and any applicable component codes are given in the first two columns, as for the Annual Energy and Cost Savings section described above. Then, for each measure, the following is listed:

- Total dollar savings per year;

- Dollar cost to install the measure;

- Savings-to-Investment Ratio (SIR) for each recommended energy conservation measure (computed over the measure's lifetime);

- Cumulative cost of recommended measures; and

- Cumulative SIR of recommended measures.

Costs entered as Itemized Additional Costs are displayed in this report section. These costs are not assigned a savings value or SIR, because no energy savings is associated with them. If, on the Itemized Additional Cost screen, you indicated that a cost should not be included in the SIR, it will be listed at the end of the recommended measure list and its cost added to the cumulative cost, but not the 
SIR. If, on the other hand, you have requested that a cost be included in the SIR, it will be listed at the top of the measurc list and its value added to both the cumulative cost and SIR.

User-defined measures are reported in exactly the same manner as standard NEAT measures.

The results of air leakage calculations will be listed in one of four ways: 1-If you enter pre- and post-retrofit air leakage rates and the cost of infiltration reduction, NEA'I will list the cost of reduction, projected savings, and the SIR; 2-If you leave the cost of infiltration reduction blank, NEAT will list the dollar and Btu savings of infiltration reduction in the Annual Energy and Cost Savings report, but not here. However, NEAT will not list infiltration reduction on the cumulative part of the report; 3-If you list only the cost of infiltration reduction, NEAT will add it to the cumulative cost without calculating savings of infiltration reduction-the cumulative SIR will reflect the added cost; 4-If you enter no infiltration data, NEAT ignores the infiltration-oriented conservation measure.

Duct sealing will be considered and results reported only if the Evaluate Duct Sealing check box has been checked and sufficient data has been supplied (see Section 6.12, Ducts and Infiltration).

\subsection{Material List}

This report section lists the major materials and their quantities necessary to install the recommended measures reported in the Energy Saving Measure Economics report section. Some material descriptions include a material type as well as a name. For example, the material "Wall Insulation" may have type, "Blown Cellulose." Please note that minor materials, such as fasteners and other hardware, are not listed.

\subsection{Pre- and Post-Retrofit Energy and Loads (Annual Loads)}

NEAT provides estimates of annual loads and energy consumption for both heating and cooling, before and after installing the recommended measures. The loads represent the energy addition or extraction the heating and cooling equipment must deliver to keep the conditioned spaces at the specified set point temperature. The energy is the consumption of the equipment in meeting these loads. The loads and energy differ essentially by a factor of the seasonal efficiency of the equipment. Both the loads and consumption have units of MBtu (million Btu) per year. 
Also provided is an estimate of the peak heating energy consumption, as determined by an estimate of the Manual J technique (see Section 7.8, Equipment Sizing below). The "Heat loss" is the peak consumption prior to application of a duct loss factor and the "Output required" the peak with the duct loss factor applied. Both have units of $\mathrm{kBtu}$ (thousand Btu) per hour. No analogous estimates are available for cooling.

\subsection{Billing Data Adjusted Results}

Pre-retrofit utility billing data you enter into NEAT (see Section 6.17, Utility Bills) allows NEAT to show you a comparison of its energy consumption predictions and this billing data (see Section 7.7, Heating and Cooling Fnergy Comparisons). Then, if you desire, it will adjust the measure recommendations and savings to reflect the data.

Results in three of the above reports (Annual Energy and Cost Savings, Energy Saving Measure Economics, and the Material List) are altered whenever you enter this billing data and request that the results be adjusted accordingly (using the Include Billing Adjustment check box on the General Information form). Thus, if so requested, NEAT will print these same three reports except with adjusted values. You may choose to print both the unadjusted and the adjusted reports, or, to avoid confusion, only the adjusted if you have made the decision to weatherize according to billing adjusted recommendations.

Note, however, NEAT was designed to make its recommendations based on average weather and occupancy characteristics rather than the specific life styles of the occupants. If adjustment is requested, the recommendations will then be specific to the life styles of the occupants during the period in which the billing data were gathered.

\subsection{Heating and Cooling Energy Comparisons}

The Heating and Cooling Energy Comparison reports allow you to see a comparison of the NEAT predicted consumptions and the billed consumptions. These reports are available only if the corresponding heating and/or cooling billing data have been previously entered.

The predicted values are based on assumptions used in estimating measure savings and the building description you have entered. They correspond to the same time intervals for which the billing data were taken, allowing a one-to-one comparison. They will be displayed side-by-side with actual values taken from the 
billing data. If you have entered the values, NEAT will use the pre-retrofit air leakage data in computing the predicted consumptions. Otherwise, NEAT will use the post-retrofit air leakage data.

Also displayed side-by side will be the heating or cooling degree-days assumed by NEAT in its computations as well as those you entered with the billing data (if available). Both will be based on the base temperature you indicated during entry of the billing data. Comparison of predicted and actual consumptions and degreeday totals should assist you in determining whether to use NEA'T adjusted measure savings based on the billing data entered. Percent differences of the totals of these two quantities are displayed to further aid in the decision.

Note that NEAT was designed to make its recommendations based on average weather and occupancy characteristics rather than the specific life styles of the occupants. Thus, it should not be expected to reproduce the billing data with great accuracy.

\subsection{Equipment Sizing}

The size of a home's heating equipment should correspond to the peak heat loss of the house, normally expressed in thousand of Btus per hour $(\mathrm{kBtu} / \mathrm{h})$. NEAT estimates this size both before and after weatherization using the building description information you provide and formulas taken with permission from tables published by the Air Conditioning Contractors of America (ACCA) in their Seventh Edition (1986) of Manual J, Load Calculation for Residential Winter and Summer Air Conditioning.

However, you should verify NEAT"s estimates with the results of the actual Manual J procedure for types of building components common in your area before regularly using them to guide the purchase of new replacement equipment. The sizing estimate calculated by NEAT is different from a complete Manual J calculation procedure in several ways: (1) the range of building components available in NEAT is not as extensive as the range available in Manual $\mathrm{J}$, which could result in differences; (2) NEAT performs the estimate on the building as a whole, whereas Manual J may be applied by zones or even room by room; and (3) generic duct-loss factors are used in NEAT, whereas Manual J estimates a specific unique duct loss factor for each zone.

The Manual J Component Contributions report in NEAT's Output Summary will list each building component's contribution to the total design heat loss. You can compare these individual componcnt contributions with standard Manual J calculations for an indication of variations between the two sizing procedures. 


\section{Nathrastis}

NEAT converts the total building heat loss to a required heating system output by multiplying the former by a duct-loss factor. NEA'I does not have sufficient information to accurately predict this factor. The standard Manual $J$ technique recommends computing the building heat loss zone-by-zone, assigning a specific heat-loss factor for the duct supplying heat to each zone (refer to Manual J). NEAT assumes no duct loss if the heating system is cither a space heater or a portable electric resistance heater. Otherwise, it uses a factor of 1.15, assuming that either exposed duct has been insulated by the weatherization of the house or the duct is not in an unconditioned space. Pre-retrofit duct-loss factors of 1.20 are assigned to systems having more than ten feet of uninsulated duct in an unconditioned space.

These duct-loss factors may be inappropriate for hot water or steam boilers which may have lower or higher heat loss through their pipes than forced-air systems have through ducts. You may be able to assign a more accurate duct-loss (or "pipe loss") factor based upon your examination of a home after weatherization. For example, a hydronic heating system with insulated pipes or a forced-air system with insulated ducts may merit a lower "duct-loss" factor. A steam system with uninsulated pipes may merit a higher "duct-loss" factor. You can estimate the heating system output required by multiplying this factor by the building heat loss reported on the Sizing report.

If a heating system replacement is recommended, NEAT's material list (see Section 7.4, Material List) will give both a pre- and a post-retrofit equipment size. The pre-retrofit size reported is taken from your input on the Heating Systems form, not the Manual J estimate. You may wish to compare your entered value with the Manual J estimate reported in the Manual J Component Contributions report in NEAT's Output Summary. The post-retrofit equipment size reported in the Materials List is the Manual J estimate from the Output Summary Report.

\subsection{Special Notes and Comments}

The Special Notes section of NEAT's Output Summary is devoted to notes generated internally by NEAT as it executes. They should be reviewed to see if any may alter your retrofit decisions.

The Comments section contains all comments you may have entered during the building description input. Each is associated with both a component type and the specific component code you chose for the component, if applicable. 


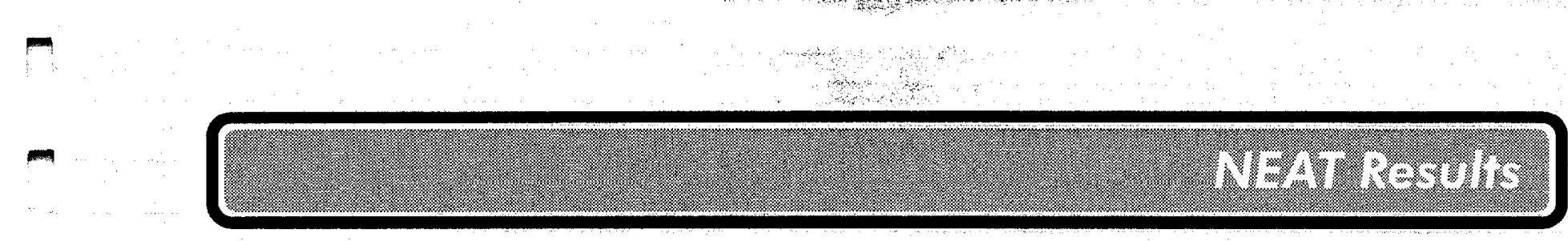

NOTES:

1 
、 


\section{Chapter 8}

NEAT computes energy savings and selects conservation measures using assumptions in addition to the building description, such as fuel and material costs. These and other parameters should be customized to produce audit results tailored to your location. By changing the parameters, you can reflect specific local conditions. You can create up to 10 sets of parameters to choose from at any time.

\subsection{Creating Your Own Parameter Sets}

NEAT is distributed with a set of standard parameters. Although some of the standard values for these parameters may be appropriate for your location, others must be altered before your NEAT audits can accurately reflect conditions in your area.

This chapter will describe the various parameters you can adjust with NEAT's Setup. However, before you do this, it is suggested that you copy the standard parameter set and make modifications to the values in this copy, thus preserving the original standard set for future reference.

This is easily done by selecting Setup on NEAT's introductory screen. You will automatically be presented with the Parameter Set form. If you have never created any additional parameter sets beyond the standard parameter set, you will see reference to this "Standard" set in the Parameter Set Name field. To make a copy of this set for future modification, click on the tool bar button showing two cascading pages with writing on them, located under the word "New" at the top of the form. This will create a copy of the standard set. You will see the Parameter Set Name change to "Standard (copy)." Change this name to whatever you desire, possibly reflecting the geographic location to which this parameter set will apply, the subcontractor providing the weatherization services, or the fuel supplier for the homes audited (if more than one exists in your agency's jurisdiction). Note, however, that all parameter set names must be unique. The only Agency Name allowed will be the one you entered on the Agency Information form. Change the Description to your satisfaction. The creation date will automatically change to the current date. You may also enter any comments applicable to this parameter set you may wish preserved. 
Now that you have your own parameter set, you can make any of the changes in parameters described in this chapter while still being able to refer back to the original parameter set if you so desire.

You may also create additional parameter sets of your own by applying the same procedure. Note, you do not always need to use the standard parameter set as the starting point for a new set. If the new set you wish to create more closely resembles a set other than the standard one, simply choose the existing set from those available under the Find control on the Parameter Set toolbar. Then use the copy button to create a copy of this set from which to make your changes.

Multiple parameter sets may be useful if you have different contractors in your agency area who have different costs or possibly different fuel suppliers with significantly different fuel prices.

\subsection{Changing Parameters}

The remainder of this chapter will be devoted to describing the changes you can make in parameters included in the parameter set. They are grouped by categories corresponding to forms available through tabs on the Parameter Set screen. The categories are:

\author{
Material Costs \\ Fuel Costs \\ Fuel Escalation \\ Candidate Measures
}

Key Parameters

User Defined Insulation Types

Refrigerators

Water Heaters

\subsection{Material Costs}

You can tell NEAT what values to use for the material and labor costs of installation and the lifetime of each energy-saving conservation measure. They are entered on five individual screens, one for each of the material categories: Insulation, Heating Equipment, Cooling Equipment, Windows, and Baseloads. These material categories are accessed through second level tabs under the Material Costs tab in Setup.

NEAT assesses costs to energy-saving conservation measures by the square foot, linear foot, or per item. Costs listed in the "Material" Cost and "Labor" Cost columns are costs for the unit of measure listed on that line. For example, if the "Material" for "Celluls, Blwn-R-11" is "0.0732" and the Unit is "Sqft," that means 
blowing in cellulose will cost $\$ 0.0732$ per square foot for materials. Labor costs are listed scparatcly under the "Labor" column. NEAT simply adds the costs in the Material and Labor columns and does not preserve the distinction in the reports. So, if you wish to enter the total (material plus labor) cost in one or the other of these columns, leaving the other as zero, NEAT will accommodate you.

The column marked "ItemCost" is designed specifically for window treatments, where the "Units" is either "Lnft/E" or "Sqft/E." Because these materials may be priced either by dimension (per linear foot or square foot) or by application (per window), NEAT permits you to enter cost information either way. If the window treatment is priced by dimension, use the "Material" and "Labor" columns to record the material and/or labor cost associated with installation. The unit will be either "Lnft" or "Sqft," whichever is listed to the left of the "/" in the "Units" column.

If, however, the treatments are priced per application, i.e., a fixed price per window treated, enter this cost in the "ItemCost" column. If costs are entered for both of these approaches for the same material, the total cost will be the sumprobably not the result intended unless there is a flat price per window plus a cost per dimension.

The "ItemCost" column is not appropriate for other measures.

NEAT permits you to also change the "Life" of each measure, if you so desire. The lifetimes in the standard set reflect industry standards, and will likely be sufficient for your use. However, if you have documented cause to alter them, you may do so from this form. Note, lifetimes are in years except for the Compact Fluorescent materials, for which they are in thousands of hours burn time.

\subsection{Fuel Costs}

The Fuel Costs form contains dollar costs of the listed fuels in common units (mcf of natural gas, $\mathrm{kWh}$ of electricity, gallons of \#2 oil, gallons of propane, cords of wood, tons of coal, gallons of kerosene). Assemble a list of fuel costs in your area and enter these values into this form. Since fuel costs vary widely throughout the United States, the values in the standard parameter set do not likely sufficiently reflect costs in your location and should be changed.

Check the costs of fuels in your area at least once a year and update the costs, if necessary. Fuel costs should be typical-avoid high or low short-term values. 


\subsection{Fuel Escalation Rates}

Each year, the Department of Commerce prepares and publishes for the Department of Energy fuel escalation rates to be used by the Weatherization Assistance Program. The Program rules require agencies to update the fuel escalation rates at least every five years. Each release "of NEAT will contain the most recent values published. Thus, unless your version of NEAT was released more than five years ago, you should not have to make any changes in these values.

Fuel escalation rates represent the annual fractional change of fuel costs anticipated for the next 25 years (excluding inflation).

\subsection{Selecting Candidate Conservation Measures}

This form allows you to prevent NEAT from considering conservation measures which may not be appropriate for your location. For instance, if the weather in your location suggests that evaporative coolers are cost-effective, but they are not accessible or practical to install, this measure may be turned off. Or, you may lack confidence that occupants will not override the automatic setback thermostat, giving cause for eliminating this measure.

The infiltration reduction and duct sealing measures perform as described in Section 7.3, Energy Saving Measure Economics and cannot be turned on and off from Setup.

Click on the check boxes adjacent to the measure name to change its status. The presence of a " $\checkmark$ " in the check box indicates the measure is to be considered.

Note, decisions regarding regularly preventing measures from being considered by NEAT are usually made with the guidance of State personnel.

\subsection{Altering Key Parameters}

Key parameters are accessible to give you more flexibility in applying NEAT. If you have more accurate numbers than NEAT's default values, enter them to replace existing values. For example, if your energy conservation program installs furnaces that are 82 percent efficient, you should change the furnace replacement AFUE from 85 percent to 82 percent. Caution should be exercised in altering parameters. NEAT attempts to find energy conservation retrofits for houses with "average" occupants. Again, no effort should be made to adjust parameters to coincide with life-styles of individual occupants. 
The following parameters are accessible from four major categories:

Real discount ratc-The rate at which dollars saved in the future are discounted to a worth in current dollars. DOE supplies this rate each year and has specified that it must be changed no less than every five years.

Minimum acceptable SIR-The savings to investment ratio (SIR) for an individual measure below which the measure will not be recommended. A minimum SIR of 1.0 has been specified by DOE.

Heating and cooling set-points for day and nighttime-The assumed thermostat set-points in the house being audited. NEAT has been designed to make recommendations based on average occupancy. The set-point values should not be altered to reflect any unusual life-styles of the occupants.

Night setback accomplished by smart thermostats-The number of degrees Fahrenheit an automatic set-back thermostat decreases the heating set-point during the night.

Average annual outside film coefficient (Btu/h-sqft-F) - The winter/summer average film coefficient assumed for exterior surfaces.

Base value of free heat from internals $(\mathrm{Btu} / \mathrm{h})$ - This base amount accounts for appliances and lights. NEAT adds to this base amount the heat generated by as many as two adults $(276 \mathrm{Btu} / \mathrm{h}$ per adult) and one child $(224 \mathrm{Btu} / \mathrm{h})$ for every occupant above two in number.

$\mathrm{R}$-Values associated with "Other" menu items-Three R-values are included as choices denoted as "other" in the building description menus. You can change these $\mathrm{R}$-values to reflect unique building characteristics that may not be included in existing options provided in the menus. For example, if you commonly encounter vermiculite as the "other" insulation choice, enter an R-valuc of $2.3 \mathrm{R}$ per inch.

$\mathrm{R}$-value added by foundation wall insulation measure-The R-value assumed added to an existing foundation space wall when implementing the Foundation Wall Insulation measure.

Water heater wrap added $\mathrm{R}$ value-The $\mathrm{R}$-value (h-sqft-F/Btu) of the water heater wrap installed by the Water Heater Tank Insulation measure.

Added duct insulation $\mathrm{R}$-value-The $\mathrm{R}$-value ( $\mathrm{h}$-sqft-F/Btu) assumed added to the supply ducts by the Duct Insulation measure.

Furnace/boiler replacement seasonal efficiencies (\%)-The AFUE (annual fuel utilization efficiency) for the standard replacement furnace and boiler.

High efficiency furnace replacement seasonal efficiency (\%)-The AFUE for the high efficiency replacement furnace. 
Heat content for natural gas (therms/ccf) - The number of therms of heat generated during combustion of onc hundred cubic feet of natural gas. This value can be supplied by the gas company. Values are normally about 1.0.

Window A/C replacement SEER - The SEER (seasonal energy efficiency ratio) of the replacement window air-conditioner.

Central A/C replacement SEER-The SEER of the replacement central airconditioner.

Heat pump replacement SEER (cooling)-The SEER of the replacement heat pump when operating in cooling mode.

Heat pump replacement HSPF-The HSPF (heating seasonal performance factor) of the replacement heat pump operating in heating mode.

SEER used to optionally impute cooling savings-The SEER of an air conditioning unit that would most likely be installed in the home sometime in the future.

This data item controls NEAT's optional feature of computing cooling savings for measures in a home without air conditioning. A home without air conditioning cannot actually save cooling energy, since no energy is expended for cooling in the first place. However, most measures which would save cooling energy in a home with air conditioning can make living conditions more comfortable during the summer in homes without air conditioning. Thus, you may "impute" a savings in these homes in order to install measures to increase the comfort. The homes may install air conditioning in the future, thus eventually allowing this imputed savings to occur. This feature would be more commonly used in the far south where cooling is the dominant factor. The feature is activated from the General Information input form.

Low flow shower head flow rate-The flow rate in gallons per minute of replacement shower heads.

Refrigerator defrost cycle energy-The electrical energy (kWh) assumed consumed by the existing refrigerator's defrost cycle. The value is used to adjust metered consumption if the user indicates that the metering period included a defrost cycle.

\subsection{User Defined Insulation Types}

The NEAT building description forms contain two wall and two attic insulation material types which you may define to meet your needs. Under the User Defined Insulation Types form of Sctup, you may define these materials and have your descriptions be applied throughout the program. 
As shipped to you, these user defined insulation types are given the names "Uscr Type 1" and "Uscr Type 2." In the ficlds labclcd "Uscr Defincd Cciling/ Wall Insulation Type 1/2 Name" enter the name of an insulating material you wish to use, not already provided by NEAT (e.g., Rockwool or Blwn Fbrgls). Once entered, these names will appear in place of the "User Defined" name in the Material Cost section of Setup, in the building description forms for walls and attics, and in any reports which recommend a measure using these materials.

Below each of these material names are numeric fields giving the $\mathrm{R}$-values per inch of the ceiling insulation types you are defining and the total R-value added to a wall for the wall insulation types. The $\mathrm{R}$-values have dimensions $\mathrm{h}-\mathrm{ft}^{2}-{ }^{\circ} \mathrm{F} / \mathrm{Btu}$. Typical values corresponding to various insulation types may be found in building manufacturers' data sheets or in ASHRAE's (American Society of Heating, Refrigerating, and Air-Conditioning Engineers) Handbook of Fundamentals. Entries in these fields permit your defined insulation types to have the physical characteristics you desire.

\subsection{Replacement Refrigerators}

The Refrigerators form under Setup allows you to create a library of refrigerators from which you select replacements when entering building description base load data for a house. It is anticipated that you would have a relatively small stock of replacement refrigerators that are available to you and that you have chosen to use in your program. By creating a library of these models, you can quickly select the most appropriate one when entering data for each individual house. You may have models of varying capacities in your library, to allow replacement of the existing unit with one of equal capacity.

You may choose models from the AHAM data base of refrigerators by selecting the Manufacturer and Model for the replacement from the drop down lists, as you possibly do in selecting the existing model (see Section 6.13, Base LoadsRefrigerators). If the specific model does exist in the data base, its annual consumption (in $\mathrm{kWh} / \mathrm{year}$ ) will automatically be entered in the table for you.

Alternatively, you may enter all of the data manually, most likely taking the annual consumption from the energy guide label posted on the refrigerator itself.

However you choose to enter the models for your replacement refrigerators, you will have to manually enter the cost of the refrigerator into your library. The cost column in the form is the material cost of purchasing the refrigerator. Other costs (labor, disposal, etc.) may differ from one house to another and are, therefore, 
not included in the library input, but are requested during the building description input.

A default lifetime of 15 years is automatically entered for you. If you have a well established reason to change this value, you may do so on the form, keeping in mind that twenty years is the maximum lifetime allowed by the Department of Energy.

The Capacity, Height, Width, and Depth fields are optional, as is the case on the building description input form. If entered, however, they will allow you to compare the size of the existing and replacement units to insure a proper fit.

\subsection{Replacement Water Heaters}

The Water Heaters form under Setup allows you to create a library of replacement water heaters from which you select replacements when entering building description base load data for a house. The process is similar to that used for Refrigerators above. Your library might contain replacement models of varying fuel type (electric or gas) and capacity.

Because of the added data needed to evaluate the water heater replacement measure, only entries from the data base are acceptable. This added data is not visible to you during input.

\section{NOTES:}




\section{Chapter 9}

NEAT allows you to further tailor the program to your needs through preference settings. These settings alter the operation of NEAT and produce debugging reports, allow you to set individual field range checks and default values, and determine which input and output reports will be displayed and printed. You may alter these settings through the Preferences button on the NEAT Introductory screen. Note that only one set of preferences is retained and it applies to all parameter sets you may have defined.

The preference setting categories are General, Range Check and Default Values, and Report Sections. Appendix B, Setup Screens, shows images of the Preferences forms.

\subsection{General}

Three check boxes under General of the Preferences screen are available to you.

The first check box allows automatic display of the chosen output reports after execution. If checked, these reports will be displayed after you have chosen to run the program, using the exclamation mark (!) button, and the execution is complete. If unchecked, no obvious change in the display will be seen following execution. To view the output reports, you will have to request them using the magnifying glass button under the word "Run/Report" on the Building Characterization and Analysis Window (see Section 3.4, Running NEAT and Viewing the Reports).

The second check box displayed on the General screen under Preferences allows you to view messages produced by the program during execution. If checked, NEAT will write diagnostic messages to the file "lastrun.txt" in the Weatherization Assistant execution subdirectory (c:/Program Files/Weatherization Assistant by default). The file can later be viewed and/or printed using a text editor such as Notepad. The file will indicate the program and version number and date followed by the contents of three arguments submitted to NEAT on execution. Below this is the word "NEAT" followed by a number, the return code, in parentheses. Neither the arguments or the return code will mean anything to the user. However, should the program not operate correctly, this information would assist technical support in diagnosing the problem. Under some situations, other messages may be added to the above, which would further aid in solving execution problems. 
The last check box allows detailed debug reports to be written to the lastrun.txt file. You personally will not find these reports useful, but they can help technical support personnel discover the reasons for problems you might encounter when running the program. If checked, following your request to execute the program, you may be presented with several informational boxes in which you will have to click on the OK button to continue. This debug data can also be viewed using a text editor such as Wordpad.

\subsection{Range Check and Default Values}

As discussed in Sections 4.6, Field Defaults, and 4.7, Field Range Checking, NEAT provides you with default values and range checks for the various numerical input parameters in order to assist you in properly describing a building. Though the values for these defaults and ranges are set for a variety of parameters during installation of the program, you may wish to alter or set additional defaults and checks. This can be done from Preference's Range Check and Default Values form. Here, each parameter is listed by its field name and the form on which it lies. Designated columns allow you to adjust the "Min," "Max," and "Default" values to meet your needs.

If any entry in the table is left blank, no default will be available or no range checking will occur for that particular field. Also, any computed default over-rides the default in the table. For instance, if you supply and input and an output for a furnace, the default steady state efficiency for the furnace will be computed from these two parameters, with the result over-riding the listed default value in Preferences' table.

The Range Check and Default Values form must be exited before any changes made during a visit to the form will take effect.

\subsection{Report Sections}

As described in Chapter 7, NEAT Results, NEAT's input and output reports are divided into sections.

In the Report Sections of Preferences, you may turn on or off the display of any sections you do not regularly use. Here, the sections are listed by their name and report name (Input or Output). Check boxes to the right of each listing allow you to select whether a particular section will be displayed whenever you choose to view reports. If the box is checked, the associated report section will be displayed. 


.




\section{Chapter 10}

The list of energy conservation measures considered by NEAT may be accessed through the Setup Menu, Select Candidate Measures option (see Section 8.6, Selecting Candidate Conservation Measures).

NEAT currently examines 34 energy conservation measures:

1. Attic insulation (R-11, 19, 30, 38)

2. Fill ceiling cavity

3. Sillbox (bandjoist) insulation

4. Foundation wall insulation

5. Floor insulation (R-11, 19, 30)

6. Wall insulation (Blown)

7. Wall insulation (R-11 batt for kneewalls)

8. Duct insulation

9. Window sealing

10. Storm windows

11. Window replacement

12. Low-E windows

13. Window shading (awnings)

14. Sun screens (fabric and louvered)

15. Window films

16. Thermal vent dampers

17. Electric vent dampers

18. Intermittent ignition devices (IID)

19. Electric vent dampers and IIDs combined

20. Flame retention head oil burners (FRHOB)

21. Furnace tune-ups

22. Mid-efficiency furnace replacement

23. High efficiency furnace replacement

24. Space heater replacement

25. Smart thermostats (setback thermostat)

26. Air conditioner tuneup

27. Air conditioner replacement (window and central)

28. Evaporative coolers

29. Heat pump replacement 
30. Lighting

31. Refrigerator replacement

32. Water heater tank insulation

33. Water heater pipe insulation

34. Low-flow showerheads

The first eight conservation measures are designed to reduce heat loss or gain through walls, floors, ceilings, and ducts. Measures 9 through 15 affect the way windows behave in the house. They can alter the conduction heat loss, solar gain, and infiltration through the windows. Window shading reduces solar gain-a major element of total heat gain. Shading the windows may affect the heating load, because shade blocks some solar heat from the house during the heating season.

Conservation measures 16 through 25 improve heating system efficiency by decreasing heating energy consumed by the house. They do not affect heat loss through the envelope, however.

Conservation measures 26 through 29 improve cooling efficiency during the cooling season. Evaporative coolers and new air conditioners can reduce cooling costs markedly, if properly installed. Conservation measures 30 through 34 reduce the energy consumption not directly related to the climate. Such measures are referred to as "base load" measures. They can have minor effects on the heating and cooling costs.

\subsection{Attic Insulation}

NEAT analyzes the addition of R-11, $\mathrm{R}-19$, R-30, or R-38 blown insulation to the attic as separate measures. For example, if NEAT recommends addition of $\mathrm{R}-11$ insulation to an attic already having $\mathrm{R}-19$ insulation, a total of $\mathrm{R}-30$ is being seen as cost-effective for the house. The maximum possible depth of insulation is the maximum number of inches of existing and added insulation which could exist in the attic, not including possible compression at the eaves.

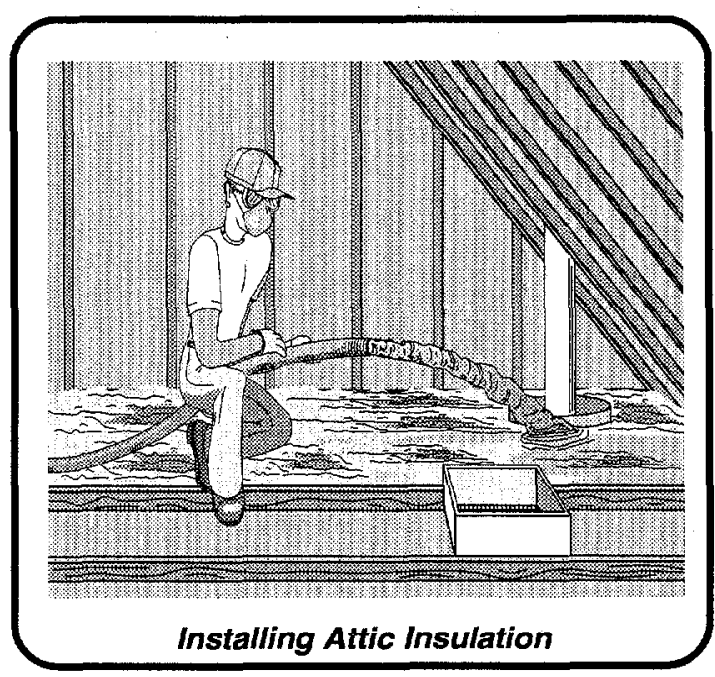

If you specify no maximum depth restriction (see Section 6.5, Unfinished Attics) for an attic segment, NEAT will determine the correct standard R-value of insulation 
to be added for your region. If a depth restriction has been specified, NEAT will evaluate not only adding the standard levels (R-11, R-19, R-30, and R-38) up to the maximum depth, but also the level of insulation necessary to exactly fill the attic cavity. Installation costs use interpolations between costs of installing the standard levels, as given by the User in Setup.

NEAT assumes that heat flow has a choice of two paths: one through the ceiling joist and any insulation resting on top of it, and the other through the ceiling panel and insulation in the joist spaces. NEAT assumes that joists occupy 15 percent of the attic area and spaces between them occupy the other 85 percent.

\subsection{Sill Insulation}

The sill box area on many houses is uninsulated. Insulating this sill box is often cost-effective. Seal the big air leaks in the sill box area before insulating.

NEAT will compute the change in the overall conductance of the foundation space that results from installing sill box insulation. NEAT may recommend installation of R-19 fiberglass insulation to areas of the band joist that are uninsulated and exposed to the outdoors.

Sill and floor insulation measures are considered mutually exclusive, i.e., NEAT will not recommend both measures - only the most cost-effective one.

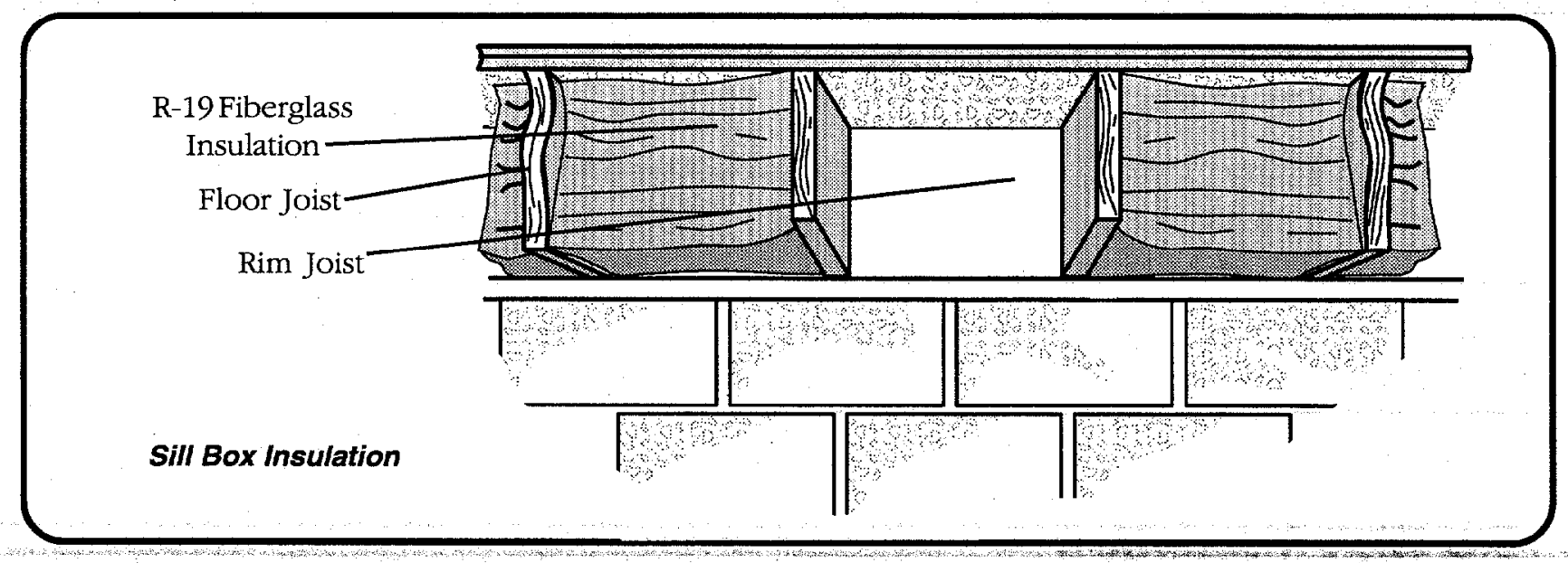

\subsection{Foundation Wall Insulation}

The foundation wall insulation measure assumes a uniform addition of insulation to both above- and below-grade foundation space walls. The R-value of insulation added is supplied in Key Parameters and the cost per square foot is set in the Material Costs section of Setup. No insulation will be added to foundation walls of a subspace having average height less than two feet. 
See Section 10.4, Floor Insulation, for information regarding selecting between the foundation wall insulation and floor insulation measures.

\subsection{Floor Insulation}

NEAT considers adding $\mathrm{R}-11, \mathrm{R}-19$, or $\mathrm{R}-30$ fiberglass batt insulation to the floor between the living space and the foundation space. If the foundation space is unintentionally heated, you might consider reducing lost heat by insulating the water heater

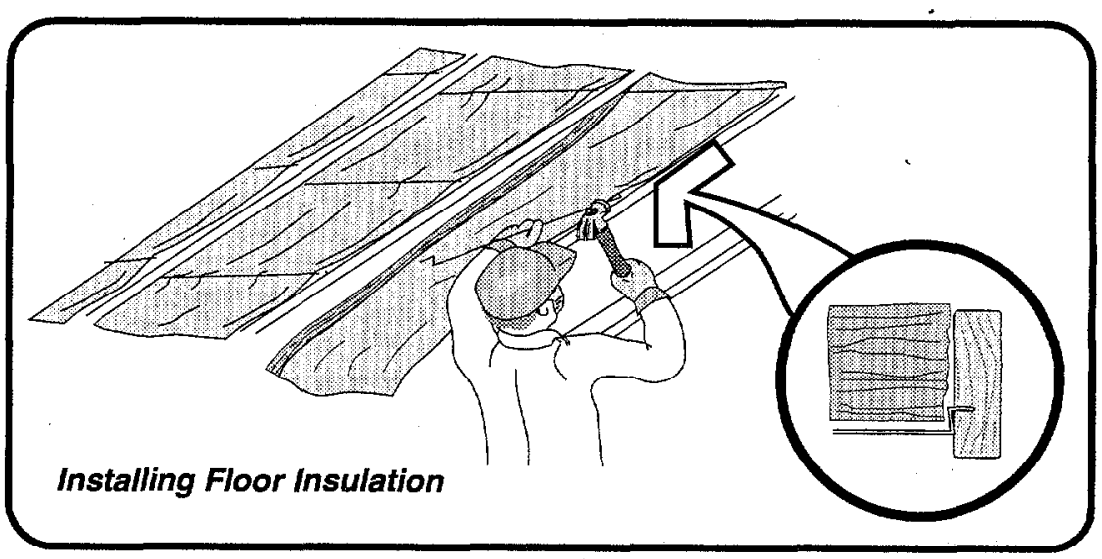
and air ducts, or by sealing duct leaks, if conditions call for these low-cost measures.

You may enter the cost of duct repair, pipe insulation, and/or electric heat tape to protect pipes in the field provided on the Foundation Space data input screen if you want these costs to affect the SIR of installing floor insulation (see Section 6.7, Foundations).

The foundation wall insulation and the floor insulation measures are mutually exclusive, i.e., only one of the measures can be recommended for a given subspace. Which, if either, is determined by your choice of the Insulation Mode on the Foundation Spaces input form (see Section 6.7, Foundations). You may have NEAT consider only one of the two modes of insulating the space, both of them (recommending the most cost-effective), or neither. Note, however, just asking for consideration of only one of the two modes does not guarantee it will be recommended. It still must have an SIR above the minimum allowable.

\subsection{Wall Insulation}

The wall insulation measure of NEAT assumes the same 15 percent framing and 85 percent cavity area as the attic.

NEAT reduces the free solar heat transmission through insulated walls. If a wall is located next to a sheltered but unheated area, NEAT reduces the predicted savings from wall insulation by one-third, since this buffered area serves to reduce the heat loss. 


\section{NeAT Energr Consevromion Measures}

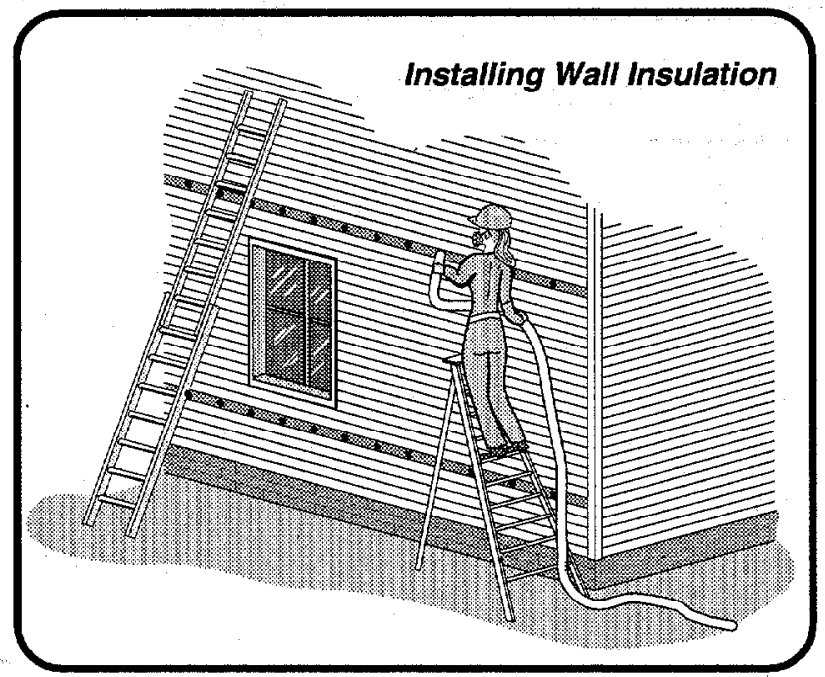

NEAT estimates savings from insulating a kneewall (a wall next to an unconditioned attic space) separately, assuming R-11 batt insulation would be used for this purpose.

\subsection{Duct Insulation}

Insulating uninsulated duct which exists in unconditioned (or unintentionally heated) spaces will most often be cost-effective. The duct insulation measure in NEAT examines heat lost from the furnace supply duct during winter as well as heat gained by the duct during summer (if central air conditioning is present). These heat exchanges are assumed to occur between the duct and either a foundation space or the attic, depending on your input for the location of uninsulated duct on the heating system form (see Section 6.7, Foundations).

\subsection{Window Sealing}

Leaky windows can often be a source of wasted energy as the HVAC attempts to condition the outside air that passes through them. NEAT estimates the savings that can be obtained from weatherizing an existing window to reduce its leakiness. Both heating and cooling (latent and sensible) energy is considered in this estimate. The amount of energy saved depends on your declaration of each window's preretrofit leakiness, as indicated on the Windows input form (see Section 6.3. Windows, as well as the overall house leakiness described on the Ducts and Infiltration Form, Section 6.12, Ducts and Infiltration).

NEAT translates your leakiness designation into an estimate of air leakage through the window that results primarily from a pressure differential created by wind. It then uses empirically-based relations to reduce this air leakage through the window to reflect caulking, weatherstripping, and general repairs to the window. The energy saved from this reduction is computed in much the same way savings from whole house infiltration reduction is determined.

Note that if pre-retrofit whole house infiltration data has been entered, NEAT subtracts from it that leakage determined for the windows. Thus, if window treatments are assumed to be performed, the savings from general air sealing will likely be reduced, so as to avoid accounting for the window sealing twice. 
The Window Sealing measure is one of three mutually exclusive window measures, along with Storm Window and Window Replacement. Only the measure found most cost effective from a set of mutually exclusive measures will be recommended. Thus, NEAT would never recommend both sealing and replacing the same window. The only exception to the cost-effectiveness criteria is when a specific measure has been declared mandatory, as might be the case for the Window Replacement measure for a window whose frame is so rotted that weatherization or use of a storm window is not practical. How the measure is viewed depends on the selection you make for Retrofit Status on the Windows form during data input (see Section 6.3, Windows).

\subsection{Storm Windows}

NEAT predicts that a storm window will add $0.59 \mathrm{R}$ to a single-pane window. However, when the prime windows leak, storm windows-especially interior storms which tend to be tighter-will produce an additional benefit of reducing air leakage. The change in air leakage through the window system with and without a storm window is estimated in NEAT from published and empirical data as well as your indication of the existing window's initial leakiness (see Section 10.7, Window Sealing, for more information on infiltration reduction in windows).

The cost of storm windows varies widely due to quality, quantity purchased, shipping, and labor costs. In the building description input (see Section 6.3, Windows), the user is given the opportunity to enter the cost for an individual storm window-if a more accurate cost than that entered during "Setup" on the material cost screen can be given.

This measure, as other window retrofit measures, may be considered mandatory or as an alternative with other such

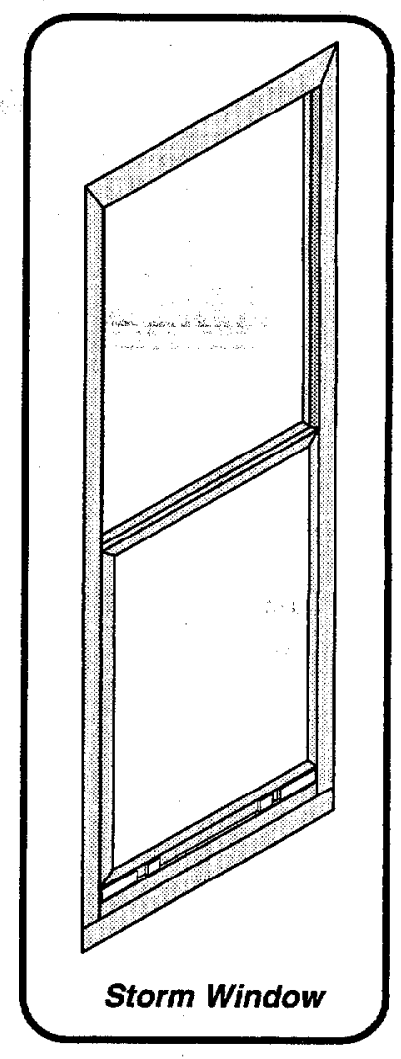
measures, whose recommendation is determined by its costeffectiveness (see Section 10.7, Window Sealing, for additional discussion).

\subsection{Window Replacement}

There may be instances when replacing an existing window is preferred to other alternative approaches to its weatherization, either due to its being inoperative 
or because simple caulking and weatherstripping can't decrease the leakiness significantly. NEAT assumes the installation of a MEC (Model Energy Code) quality double pane window with a thermally broken metal frame. The leakiness is that assumed in MEC. The energy savings estimated for the measure considers both conduction and infiltration reductions.

This measure, as other window retrofit measures, may be considered mandatory or as an alternative with other such measures, whose recommendation is determined by its cost-effectiveness (see Section 10.7, Window Sealing, for additional discussion).

\subsection{Low-E Window}

NEAT considers double-pane windows with a metalized coating on one of the interior glass surfaces. These low-E windows save energy during the winter by reflecting heat rays originating in the house back indoors. During the summer, low-E windows reflect solar heat outdoors. Low-E windows also have a higher R-value than single- or standard double-pane windows. The leakiness assumed for the window is that prescribed by the Model Energy Code (MEC).

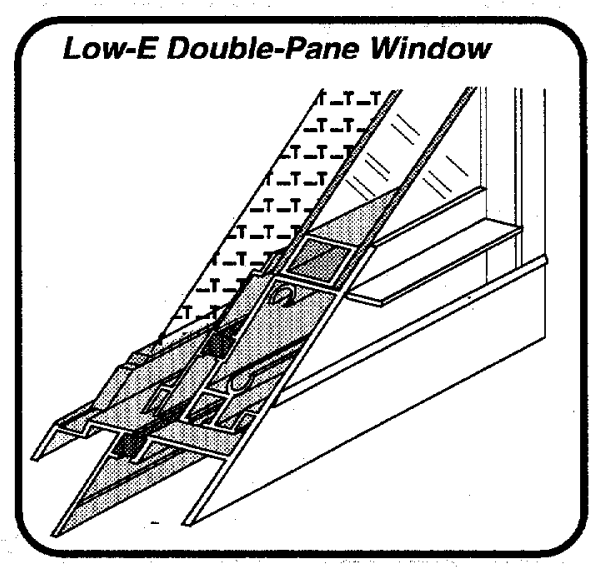

\subsection{Window Shading}

NEAT may suggest one of three types of window shading: 1-Awnings; 2-Sun screens; and 3-Window films.

Awnings are an effective conservation measure because they stop solar heat before it contacts the house. However, awnings are expensive, they require more planning, and they restrict views through windows more than other conservation measures.

There are two kinds of sun screens. NEAT assumes that fabric sun screens block about 66 percent of solar heat and that aluminum louvered sun screens block about 89 percent of solar heat. Fabric sun screens are cheaper and easier to assemble than louvered sun screens.

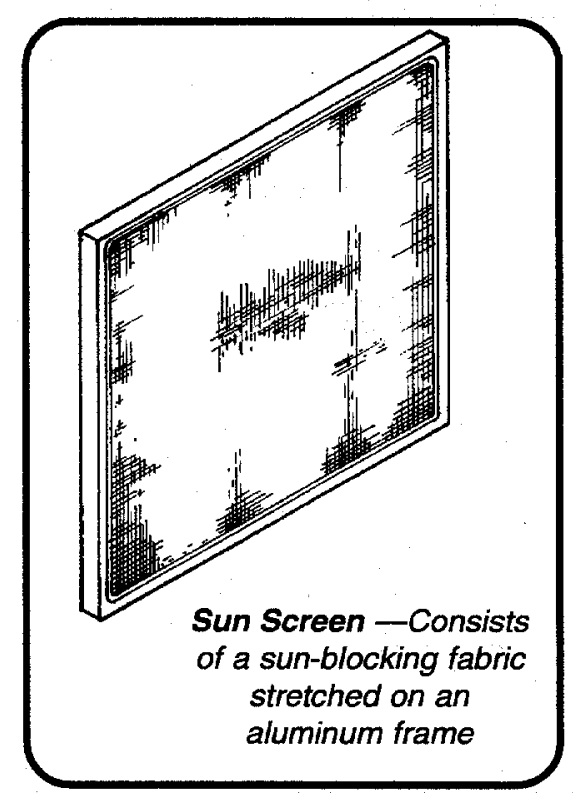


NEAT assumes that window films block 74 percent of solar heat. The more reflective, hence more cffective, films are highly metalized and appear mirror-like from outdoors. Special all-season metalized films, sometimes called low-E films, also reflect heat energy from inside the house during the heating season. In all but the hottest, sunniest climates, these low-E films are more cost-effective than films that merely reflect solar heat.

NEAT assumes that these window treatments, if installed, will cover the entire glazed portion of the window.

\subsection{Vent Damper}

A vent damper reduces heat loss from a heating system by closing the chimney when the burner is not operating. The vent damper prevents most of the residual heat from escaping the heat exchanger, allowing the pump or fan to deliver the leftover heat to the house instead of losing it up the chimney.

Electric vent dampers are recommended by NEAT for installation with central gas heating systems that currently have intermittent ignition devices (IID) or will have an IID installed during retrofit.

Electric vent dampers use a solenoid or a small electric motor. A solenoid is a magneticallyoperated lever that opens the damper when the burner fires and closes it when the burner goes off.

Vent dampers for use with oil systems or with gas systems with UDs may have dampers that close almost completely.

Electric vent dampers for gas systems with pilot lights do not close completely. To vent the pilot light, these dampers leave about 10 percent of the chimney's cross-sectional area open.

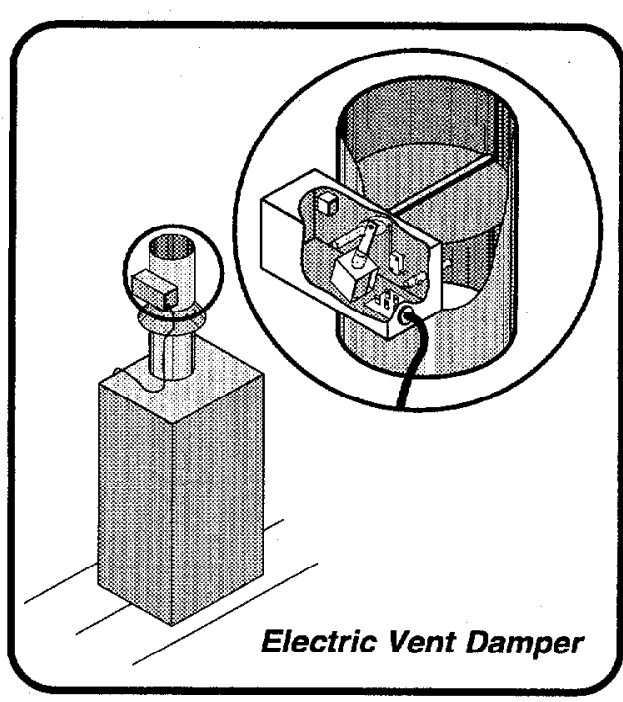

NEAT recommends thermal vent dampers for

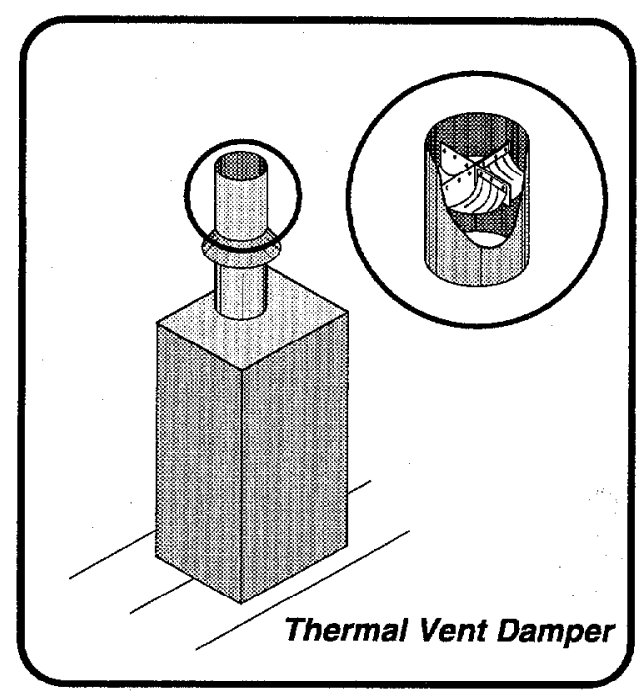
heaters with and without pilot lights. These dampers open a bimetallic damper when they sense heat. Thermal vent dampers close when the burner is off and the 
chimney cools. Thermal vent dampers may be dangerous in heaters with marginal draft and may not be permitted by some local codes.

Some locations may have regulations barring installation of vent dampers. Should a damper fail in the closed position, serious health problems may be incurred by the occupants.

\subsection{Intermittent Ignition Device}

An intermittent ignition device (IID) saves energy by eliminating the need for a standing pilot light. The IID consists of a special gas valve, an electric igniter, and a pilot light that remains on only while the main burner is lit. NEAT assumes that an electric vent damper will be installed only with an IID, or that an IID will be present before an electric vent damper is recommended.

NEAT uses formulas to estimate savings for two possible conditions: 1-Pilot light on during the summer; 2-Pilot off during the summer.

Indicate on the heating screen (see Section 6.10, Heating System-Details Sub-form) which of these conditions exists. Rather than computing savings based on a percentage of annual consumption, NEAT links savings to the location's heating degree days. For most climates, this results in annual savings from 4 to 6 percent of gas consumed by the heater.

\subsection{Flame Retention Head Oil Burner}

A flame retention head oil burner (FRHOB) is a burner that provides higher combustion efficiency by mixing the mist of oil and air more vigorously than conventional burners. Furnaces and boilers with FRHOBs have steady-state efficiencies of 80 percent or more. Replacing an existing oil burner with a FRHOB is usually cost-effective if existing steady-state efficiency is less than 75 percent.

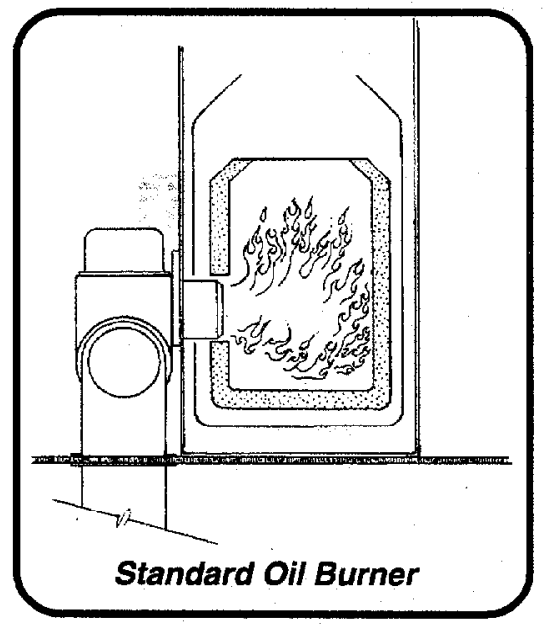

Intermittent Ignition Device

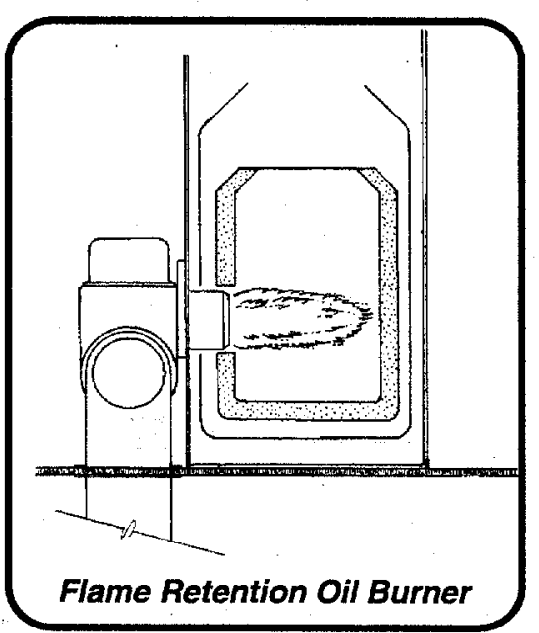


When a conventional oil burner is replaced with an FRHOB, the burner nozzle is usually reduced a size to account for the oversizing of the original burner, the higher efficiency of the FRHOB, and improvements to the envelope of the house. NEAT does not account for any additional savings that may result from this down-rating of capacity.

The combustion chamber of the existing heating unit may be re-lined with a ceramic liner-installed like a plaster cast-when the burner is replaced. If installation of a flame retention burner in your state's program includes this procedure, the price of the FRHOB should include its cost.

\subsection{Furnace Tune-Up}

Heating systems may function far below their potential efficiency or may be unsafe due to the following common problems:

- Dirt, soot, or other materials interfering with the burner flame;

- Dirt, soot, or corrosion on heat exchanger surfaces;

- Electric controls malfunctioning or out of adjustment;

- Air hotter than necessary to heat the house;

- Incomplete combustion;

- Faulty draft;

- Incorrect fuel input;

- Blockages or leaks in heating distribution system; or

- Faulty thermostatic setting, anticipator adjustment, or location.

Heating technicians performing tune-ups should have specific training on increasing the efficiency of heating systems. Technicians should have test equipment to measure efficiency, air temperature, carbon monoxide, draft, and all other parameters relevant to the seasonal efficiency of each heating system.

NEAT assumes a tune-up performed by a qualified technician will save from 0 to 14.5 percent of the fuel used for heating, depending on condition of the furnace and its fuel type.

\subsection{Furnace/Boiler Replacement}

Replacing the heating system makes economic sense when the steady-state efficiency of the existing system is low and can't be significantly improved. 
Low-efficiency heating units allow up to twice the amount of air needed for combustion to pass through the heat exchanger. This excess air takes heat with it up the chimney while the burner is both on and off. Mid-efficiency gas heaters allow the minimum air required for complete combustion. They also close the chimney when the burner is off. The naturally-drafting chimney and draft diverter are eliminated in favor of a fan that draws combustion air in and propels combustion products out of the heater. Mid-efficiency gas heaters use an intermittent ignition device that eliminates the standing pilot, which uses 4 to 6 percent of the energy consumed by a conventional unit. With these improvements, mid- efficiency gas heaters achieve seasonal efficiencies of 80 percent or more.

Mid-efficiency oil heaters use a flame retention head oil burner. They also eliminate the natural draft chimney and the barometric draft control by using an induced draft fan and a smaller flue pipe. These improved oil heaters achieve seasonal efficiencies of around 85 percent.

The most efficient gas heaters cause water vapor formed in the combustion process to condense into liquid water. These condensing heaters reclaim the heat in the water vapor and achieve seasonal efficiencies of more than 90 percent. These heaters liberate latent heat using a corrosion-resistant heat exchanger that is not damaged by corrosive water condensing out of combustion gases.

NEAT provides for two separate furnace replacement measures: 1-An improvedefficiency heating unit ( $80+$ percent); or 2-A high-efficiency unit for gas heating units only $(90+$ percent). To enter heating unit efficiencies, see Chapter 8 , Customizing a NEAT Audit.

\subsection{Space Heater Replacement}

If the original system is a very inefficient gas, propane, or oil space heater, NEAT may suggest replacing the existing space heater with a new higherefficiency space heater of the same fuel type. Space heaters fueled by electricity, wood, or coal are not considered by NEAT. Because the efficiencies of replacement space heaters vary greatly, the user is given the opportunity to input replacement efficiency on the space heater input screen or to accept NEAT's default values.

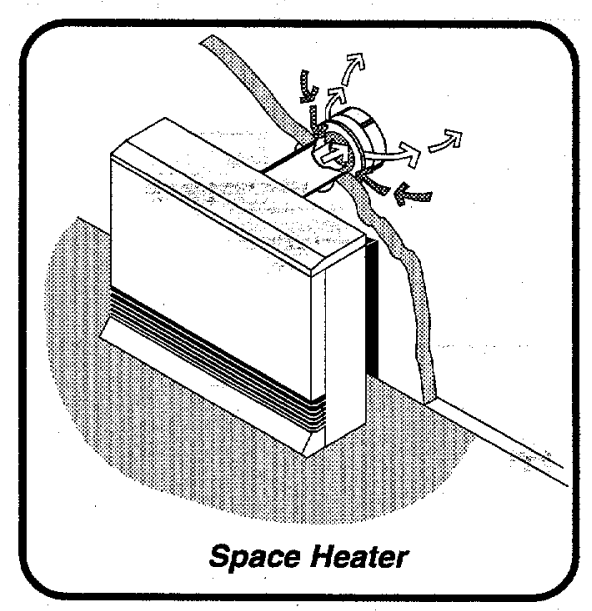




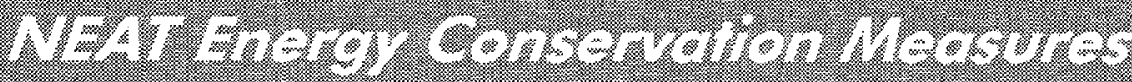

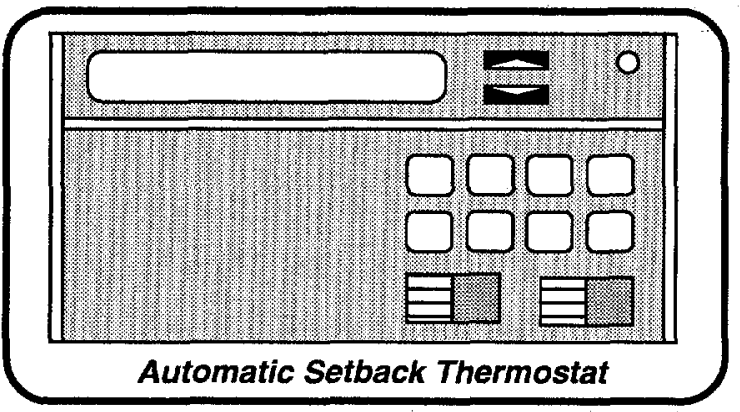

thermostat. Define the number of degrees Fahrenheit of nightly setback when you set the key parameters (see Section 8.7, Altering Key Parameters).

\subsection{Air Conditioning Tune-up}

Significant efficiency increases for an air-conditioner may be possible through proper maintenance and periodic tune-ups. The following steps are suggested in performing the tune-up of an existing air conditioner:

- Replace or clean existing air filters,

- Check and clean condensate trough and drain,

- Clean evaporator (indoor) and condenser (outside) coils,

- Straighten bent or flattened coil fins if necessary,

- Insure unobstructed air flow to the condenser coil,

- Check for proper refrigerant charge,

- Remove dust and dirt from fan blades,

- Examine and oil motor and fan bearings,

- Inspect and/or tighten electrical connections and contacts,

- Check for blockages or leaks in the supply and return ducts.

Properly trained HVAC technicians should perform the tune-up insuring the use of proper equipment, especially in checking the refrigerant charge and the electrical wiring, and straightening the coil fins.

NEAT assumes that a thorough air conditioner tune-up will increase the system's SEER from 0 to 36 percent, depending on its existing condition.

\subsection{Air Conditioner Replacement}

Air conditioners move heat from indoors to outdoors with a cooling coil (the evaporator), a heating coil (the condenser), and a compressor, which moves a heattransfer fluid (the refrigerant) between the two coils. 


\section{NeAT Enerey Conservaition Measures}

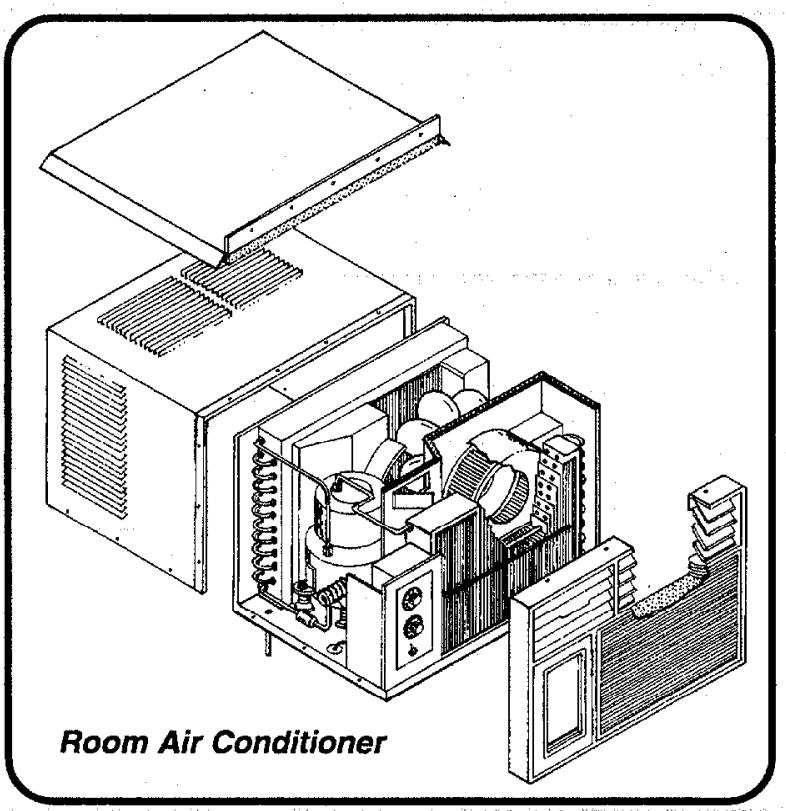

The federal government requires all air conditioners to carry a yellow energy label listing its annual cost of operation and a measure if its efficiency, EER for room air conditioners and SEER for central systems. A room air conditioner with an EER of 12 will use half as much electricity for cooling as one with an EER of 6 .

All room air conditioners manufactured after January 1, 1990 must have an EER of at least 8 or 9 depending on size, but the most efficient units have an EER of around 12. However, you can still buy room air conditioners with EERs as low

as 5.3. Central air conditioners manufactured after this date must have a SEER of about 10 or greater, varying slightly by the type of unit.

NEAT will consider replacement with either a room or central air conditioning system, depending on the type of the existing system.

Enter the cost of replacing individual air conditioners having each of the three capacities listed for both room and central systems in the Material Cost section of the Setup. For room air conditioners, NEAT will interpolate to arrive at a cost of replacing the size of unit specified in the building description. For central systems, the program will use the capacity of the nearest $1 / 2$-ton increment from 1 to 4 tons, using interpolation or extrapolation of costs for those three standard sizes not specifically listed.

Since NEAT accepts only Seasonal Energy Efficiency Ratio (SEER) values, you may need to convert EER to SEER values (see Section 6.8, Air Conditioners, for converting EER to SEER). Replacement SEERs may be altered in the Key Parameters of the Setup Menu (see Section 8.7, Altering Key Parameters).

\subsection{Evaporative Cooler}

In the warm, dry climates of the western United States, evaporative coolers (also called swamp coolers) are a popular and energy-efficient cooling device. The lower the summertime relative humidity, the

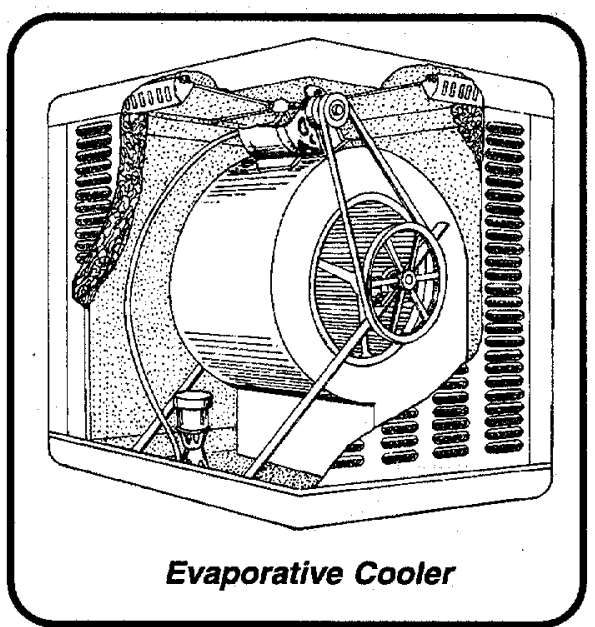


more the evaporative cooler will drop the indoor temperature: Evaporative coolers use one-quarter to onc-sixth of the energy of air conditioners and they cost about one-half as much to install. Unlike central air conditioners, evaporative coolers provide a steady stream of fresh, humid air to the house.

Because NEAT will recommend evaporative coolers in many climates due to their low cost and high efficiency, it is important to determine whether this measure is suitable for your own location. Be sure to turn it off permanently in the Setup section (see Chapter 8, Customizing a NEAT Audit) if it is not to be considered, since its high cost-effectiveness will usually place this measure at the top of the recommended measures list, making other cooling measures less costeffective.

\subsection{Heat Pump Replacement}

Heat pumps operate like air conditioners except that the heating and cooling coils can switch functions to supply heat as well as cooling.

Federal government regulations require all heat pumps manufactured after January 1, 1990 to have minimum SEERs of between 9.7 and 10 and heating seasonal performance factors (HSPF) of between 6.6 and 6.8, depending on type.

The heat pump replacement measure will only be evaluated if you have designated an A/C component as Type "Heat Pump" and the Primary Heating System is also of type "Heat Pump." No more than one cooling system should be designated as a "Heat Pump" whenever the measure is to be evaluated.

The efficiencies of the replacement system are set by the user in Key Parameters of Setup. The material costs are determined from the user-supplied costs for three sizes of heat pumps supplied in the Material Cost screens of Setup, in a manner similar to the central air-conditioning measure described above. The Material List will display the Size (KBtu) from the Air Conditioners screen for the size of the system to be installed as the replacement system, not the tonnage.

Due to the relatively high cost of replacing a heat pump, this measure is not commonly recommended.

\subsection{Lighting}

Replacing existing incandescent interior lighting with compact fluorescent lights is a relatively straight forward way to reduce the electric consumption of a home.

The development of the compact fluorescent bulb has made this retrofit an extremely simple one to accomplish because most compact fluorescent lights are 
fitted with screw-in bases identical to the incandescent bulbs which allow a quick and easy one-for-one replacement. Compact fluorescent lights should be chosen carefully because physical size and weight can prevent some bulbs from being used in certain fixtures. A variety of bulbs is available making it possible to find a compact fluorescent replacement for just about any fixture type that currently exists.

One of the main advantages of the compact fluorescent is its extended life, approximately 10,000 hours versus a normal incandescent's life of approximately 750 to 1000 hours. This equates to approximately thirteen incandescents to equal the same life as one compact fluorescent. The considerably longer life of compact fluorescent bulbs coupled with their energy savings helps to offset the substantially higher initial cost of the compact fluorescent versus the normal incandescent bulb.

NEAT computes the savings of using the lower wattage compact fluorescent bulb to replace an existing incandescent bulb. The watt reduction is determined from the user's input of existing and replacement bulb consumption, though default values for replacement wattage give the standard replacement for the existing bulb.

Neat also accounts for the longer life of the fluorescent bulb over that of the incandescent.

You must enter the cost for various wattage compact fluorescent bulbs in the Material Cost section of Setup.

\subsection{Refrigerator Replacement}

On an average, refrigerators use nine percent of a home's total energy consumption. They can consume as much as $2000 \mathrm{kWh} /$ year to as little as $400 \mathrm{kWh} /$ year-a factor of five! Significant energy efficiency improvements have been made in refrigerator construction. Units manufactured prior to 1990 will most often use substantially more energy than today's units. NEAT evaluates the cost-effectiveness of replacing an older unit with a more energy efficient model.

The savings associated with refrigerator replacement is computed from the difference in the annual consumptions of the existing and replacement units. Several methods of data collection can be used to determine this information (see Section 6.13, Base Loads-Refrigerator). Depending on the method used, NEAT makes adjustments for the location of the unit, its age, existence of defrost cycles, and door openings. 


\subsection{Water Heater Tank Insulation}

Older water heaters will likely have less insulation surrounding the hot water tank than is economically justified. NEAT evaluates the installation of an R-6 water heater wrap to increase this insulation level. Greater dollar savings will occur from this measure when applied to electric units in unconditioned spaces. Common practice is to also insulate the tops of electric units, but not gas or propane due to potential fire hazards associated with the flue or interference with the draft diverter.

Due to the measure's relatively low cost, it will often be found cost-effective.

\subsection{Water Heater Pipe Insulation}

NEAT evaluates the savings from insulating the first five feet of both the cold and hot water pipes entering and exiting a water heater. This not only reduces direct conductive heat loss from the hot water pipe, but also loss from convected water in both the hot and cold pipes. The insulation was assumed to be R-1.85, $1 / 2$ in. elastomer foam rubber. The savings estimates are based on first principle heat transfer calculations and compare favorably with published data.

Due to the measures relatively low cost, it will often be cost-effective.

\subsection{Low-Flow Showerheads}

Low-flow showerheads are inexpensive, easily installed, energy efficiency. measures. NEAT uses your input of the approximate minutes of shower use per day and the gallons per minute discharged from existing showerheads to estimate an energy savings associated with installing low-flow heads. Replacement showerheads are assumed to discharge 1.8 gallons per minute. (The flow rate of replacement showerheads can be adjusted in Setup's Key Parameters. See Section 8.7, Altering Key Parameters.) The temperature difference of water discharged from the replacement showerheads is assumed to be four degrees Fahrenheit greater than water from the existing showerheads. This is to compensate for the lower output from the replacement heads.

Due to their relative low cost, low-flow showerheads will often be recommended as long as they are not already installed and there is at least avcrage shower use. 


\subsection{Water Heater Replacement}

NEAT will evaluate the cost-effectiveness of replacing an existing water heater with a higher efficiency model. However, over the recent years, efficiency of water heaters has not changed dramatically. Thus, this measure may not prove costeffective. NEAT allows you to evaluate the effectiveness of fuel switching. However, you must be sure that all costs associated with the switch are included in the Water Heater Replacement measure cost.

The Water Heater savings are computed using equations from the Lawrence Berkeley Laboratory's Water Heater Analysis Model (WHAM) (Lutz, et. al.). The derivation requires the water heater characteristics of energy factor, recovery efficiency, and input rating, all available from the GAMA data base referenced by NEAT. Estimates of daily hot water consumption are based on the number of occupants you indicate in the building description data.

\section{NOTES:}





\section{Appendix A}

\section{Example House}

Shown below is a drawing of the Morris residence, located ia St. Louis, Missouri. The finished attic and foundation spaces are shown as cutaway sections.

Succeeding pages feature working sketches and completed input screens for a NEAT audit of this house. For conciseness, the datasheet view screens have been used whenever practical. Notice how the sketches show the codes for the doors, walls, and windows as they need to be entered into NEAT.

The sketches and screens appear in the order of a typical audit. Please note the Morris house does not require all NEAT screens (it has no space heaters, for example). For a complete set of screens, refer to Appendix C, NEAT Input Forms.

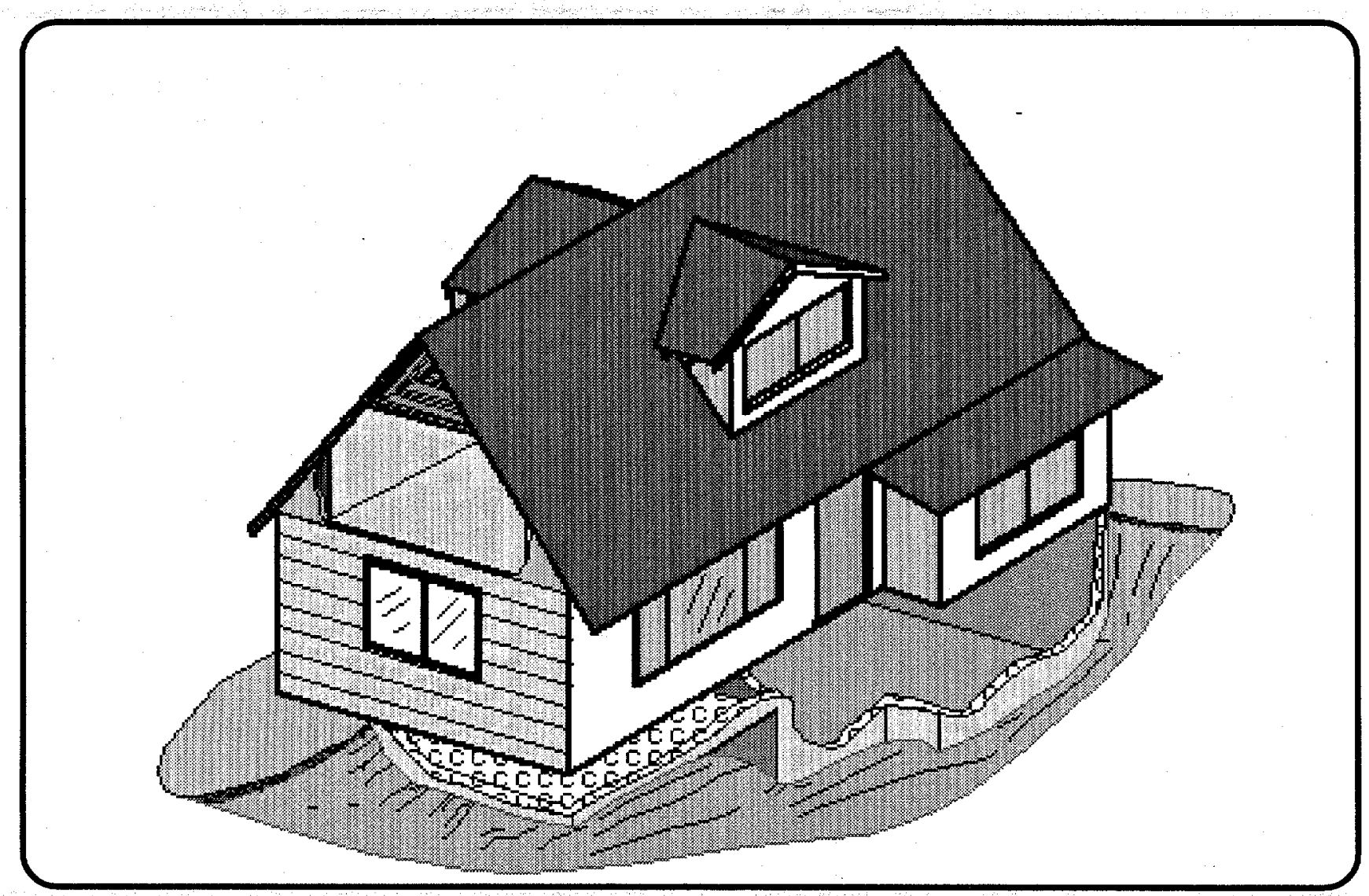




\section{1st Floor and Basement Plan Morris Residence}

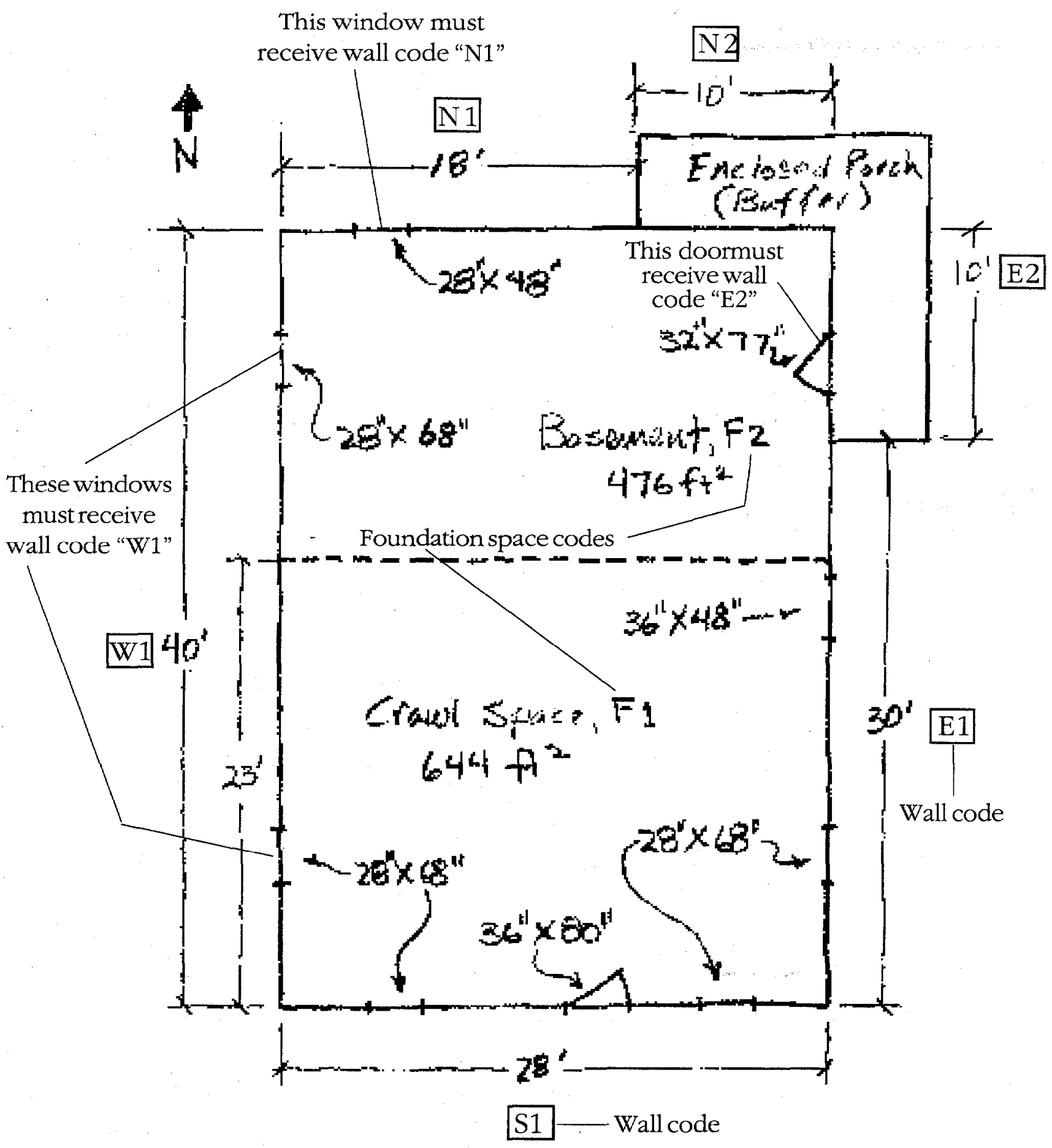


Finished Attic Plan

Morris Residence

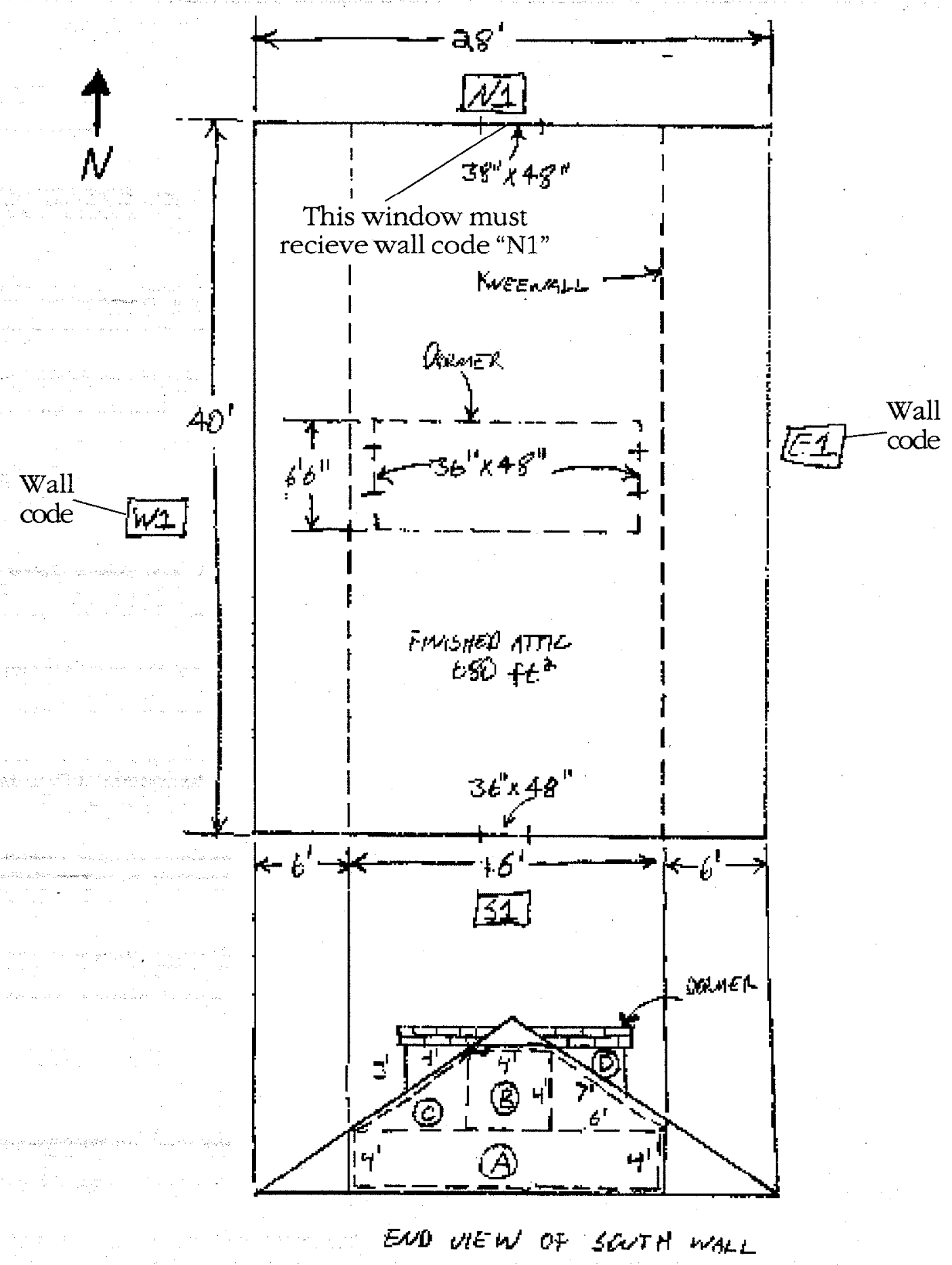




\section{Area Calculations for Exposed and Buffered Walls (refertosketches)}

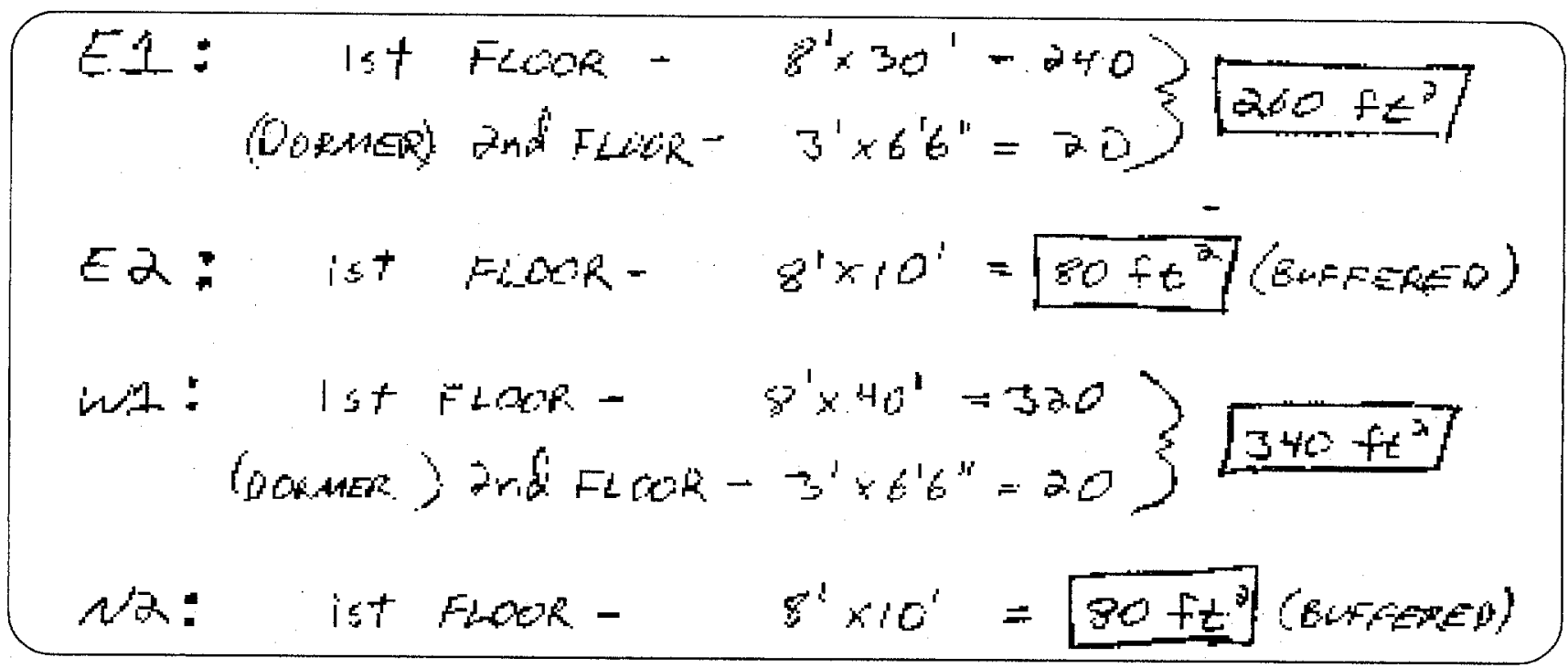

Like dormer exterior walls, the end walls of finished attics must also be added to exposed wall areas. To simplify area calculations, the exposed end wall of any finished attic can be divided into rectangles and right triangles like the $\mathrm{A}, \mathrm{B}$, and $\mathrm{C}$ areas shown by dashed lines in the end view of the south wall, 2nd floor. The individual areas can then be summed (as for S1 below) to get the total exposed wall area (remember, the area of a right triangle is width $\times$ height $\div$ two).

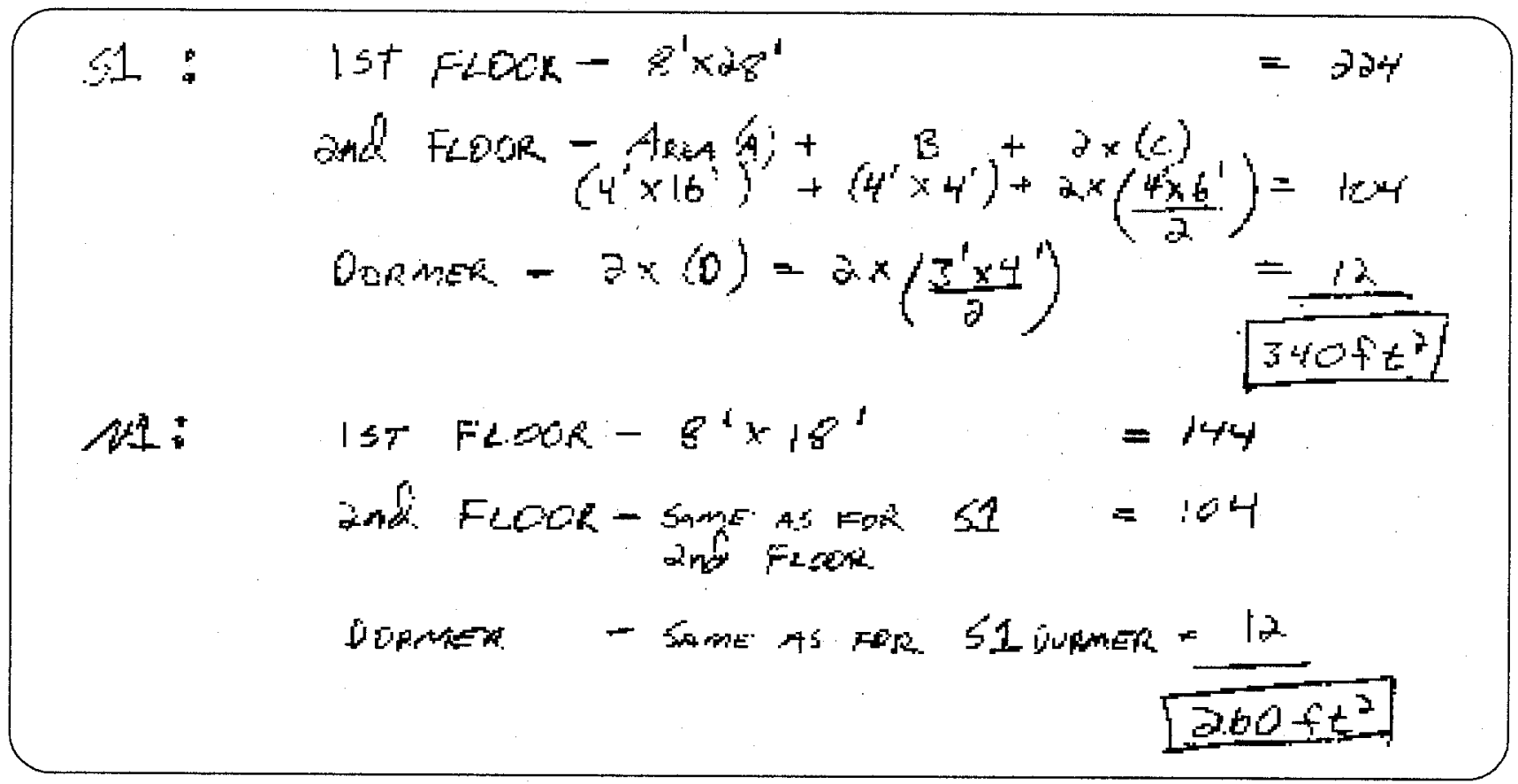




\section{Area Calculations for FinishedAttic Components (refer to 2nd floorsketches)}

$$
\begin{aligned}
& \text { dTeR cernt Tart } 2 \times\left(6^{\prime} \times 40^{\prime}\right)=480+t^{2} \\
& \text { Gowne extm }
\end{aligned}
$$

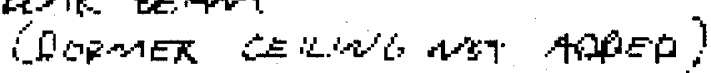

$$
\begin{aligned}
& { }^{\prime} \times \mathrm{n}^{\prime}=160+\mathrm{O}^{2}
\end{aligned}
$$

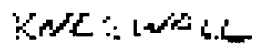

$$
\begin{aligned}
& 2 \times\left(4^{1} \times 40^{\prime}\right)=320 \mathrm{ft}^{2} \\
& \text { ROCF RAFTER } \\
& \text { KAITER AREA MEFACED ET } \\
& \text { DORAER NOT SUTRACTED ONT) }
\end{aligned}
$$

\section{Dormer Shortcut}

When the building was constructed, the builder had to remove some roof rafter area to install a dormer (refer to picture of house). 'This means that, to make exact calculations, some roof rafter area at a dormer needs to be subtracted from the gross $(7 \mathrm{ft} \times 40 \mathrm{ft}$ ) roof rafter area. Also, because addition of the dormer adds more collar beam area (the dormer ceiling), dormer ceiling areas need to be added to the gross $(4 \mathrm{ft} \times 40 \mathrm{ft}$ ) collar beam area. Doing this can be complex and laborious. This can be avoided because the removed roof rafter area at the dormer and the dormer ceiling are similar in size and energy loss characteristics (close enough when the whole house is considered). The auditor may assume the areas are equal and need not perform the subtraction or addition. Making this assumption, as done in this example (see collar beam and roof rafter area calculations above), provides close approximation and saves the auditor considerable effort. 


\section{ApeandixA - Avoh Branple}
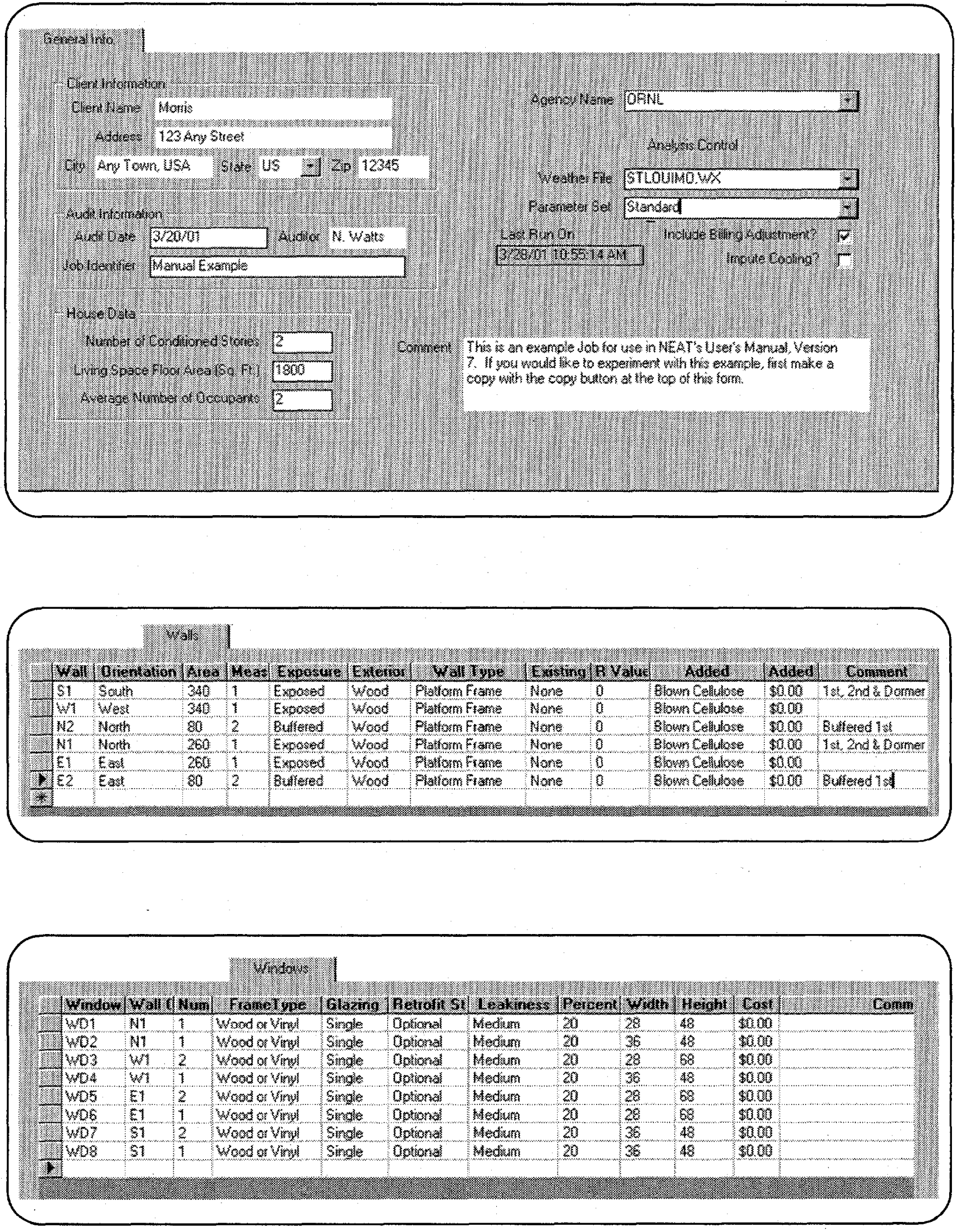


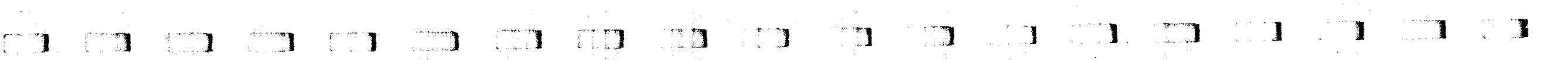
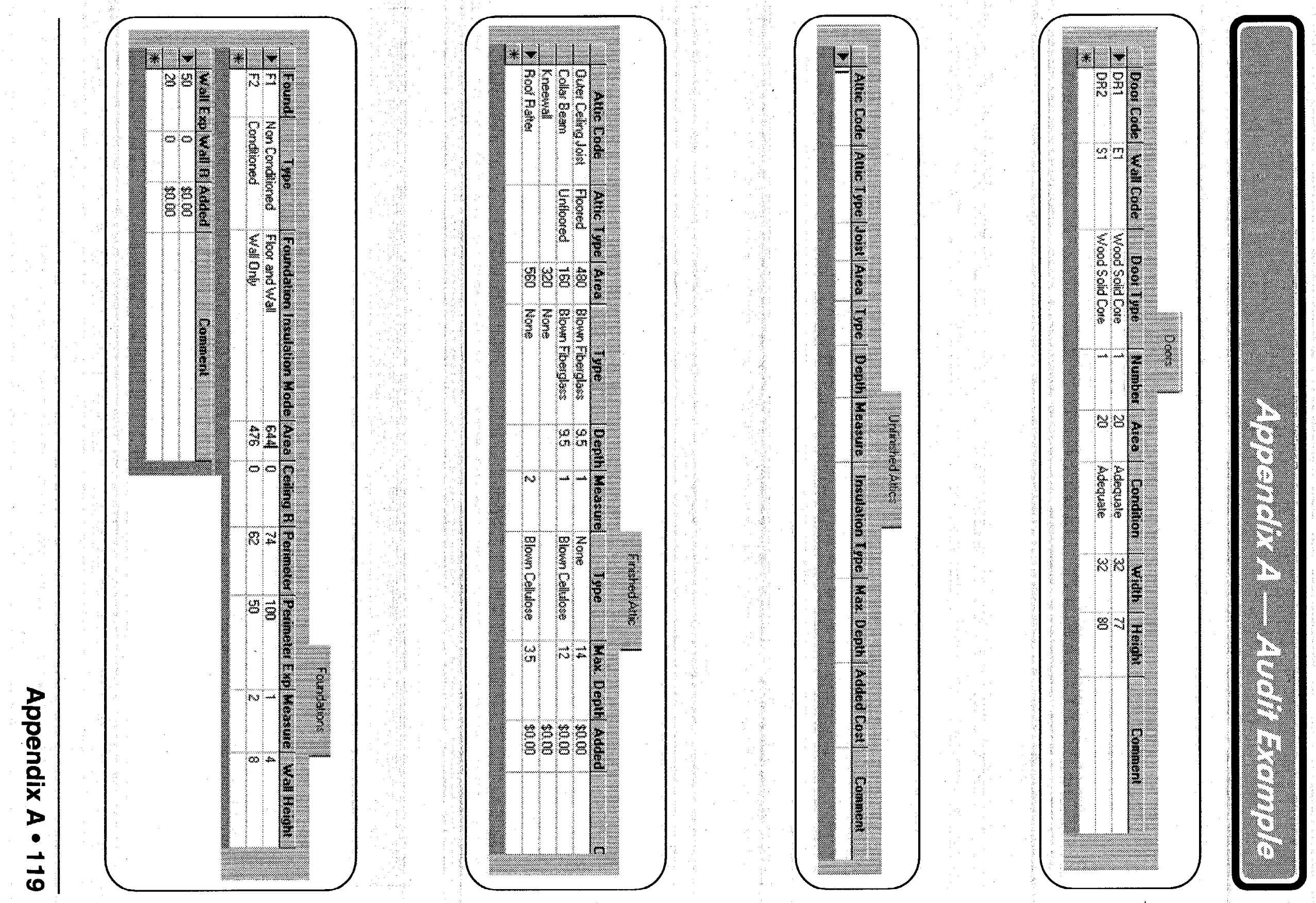


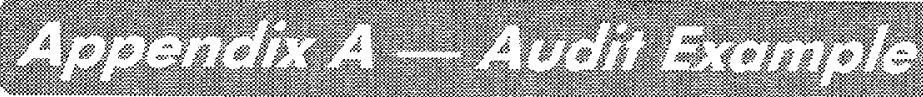
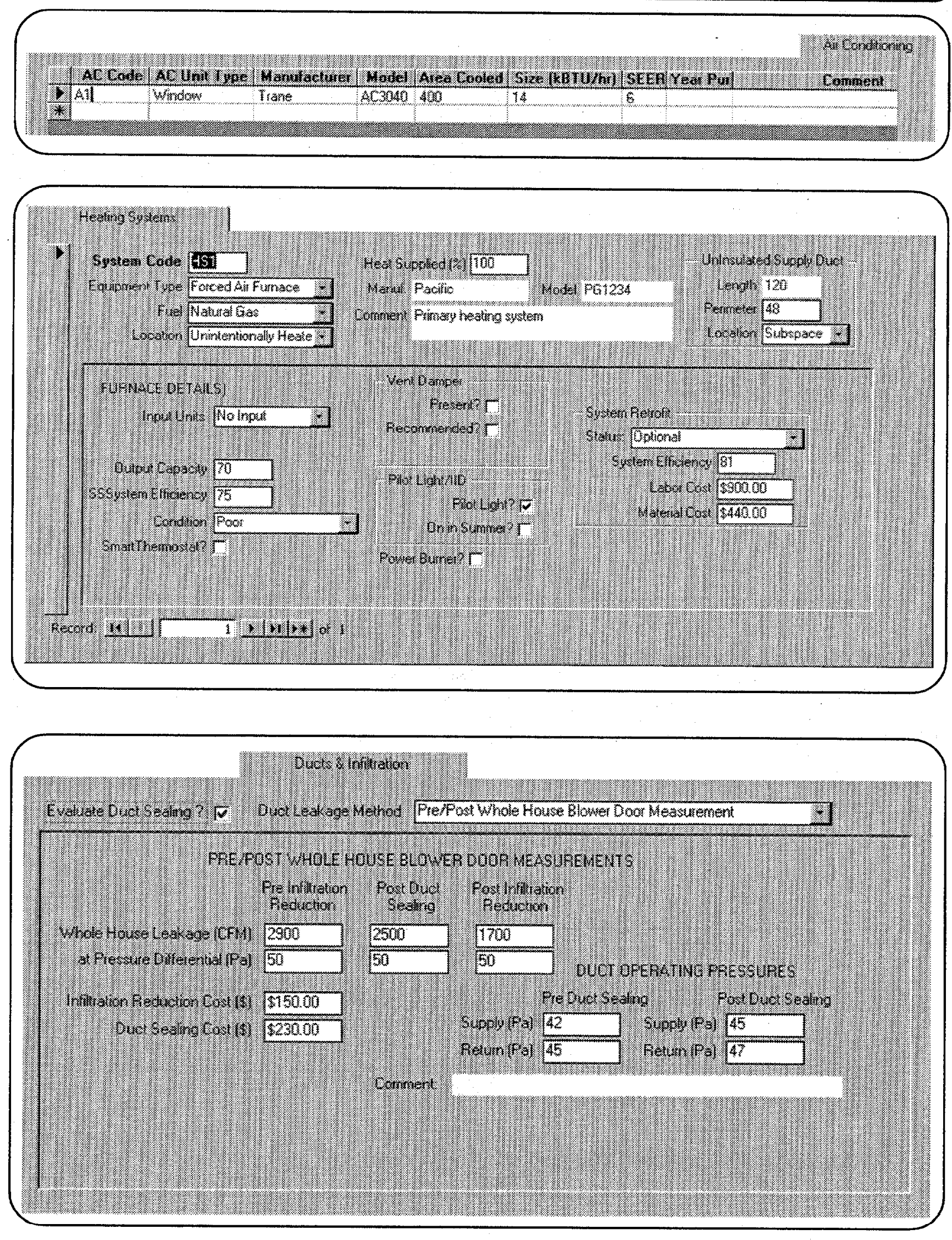


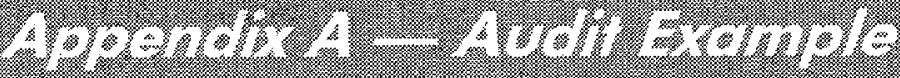
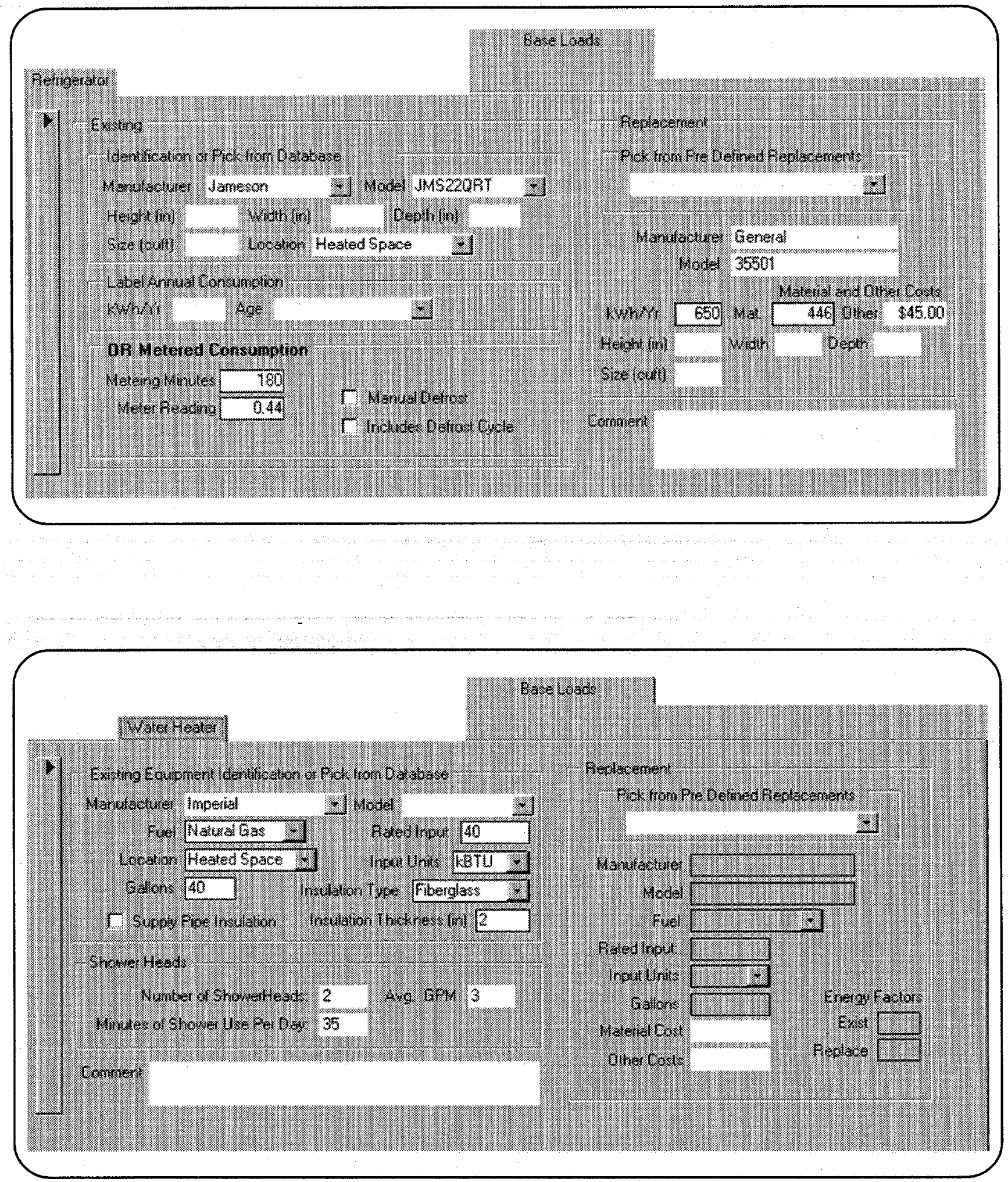


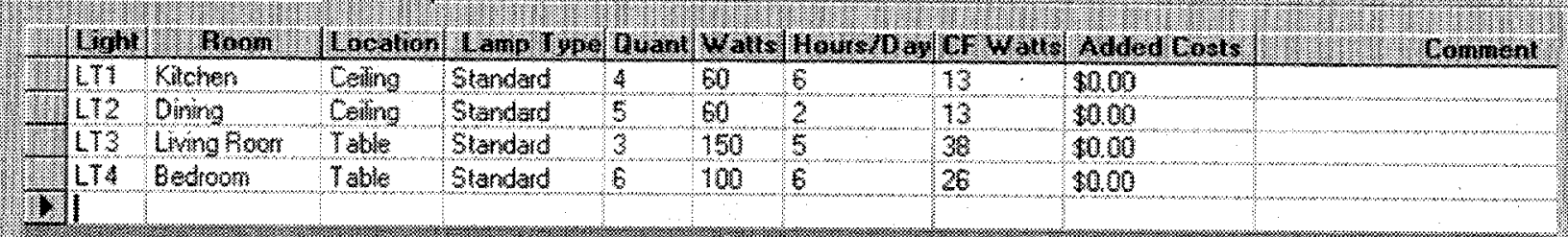

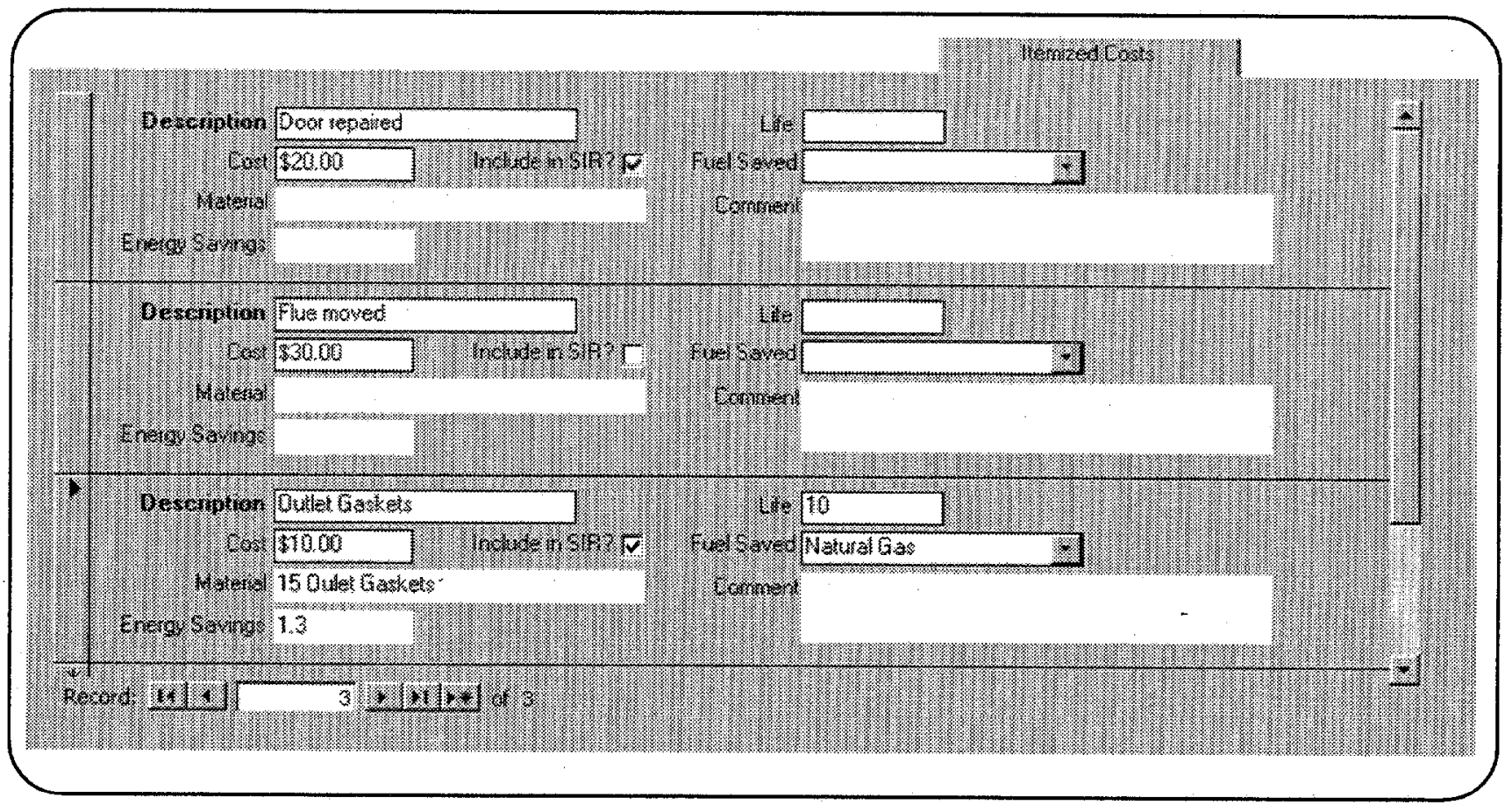




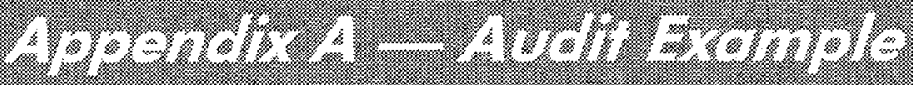
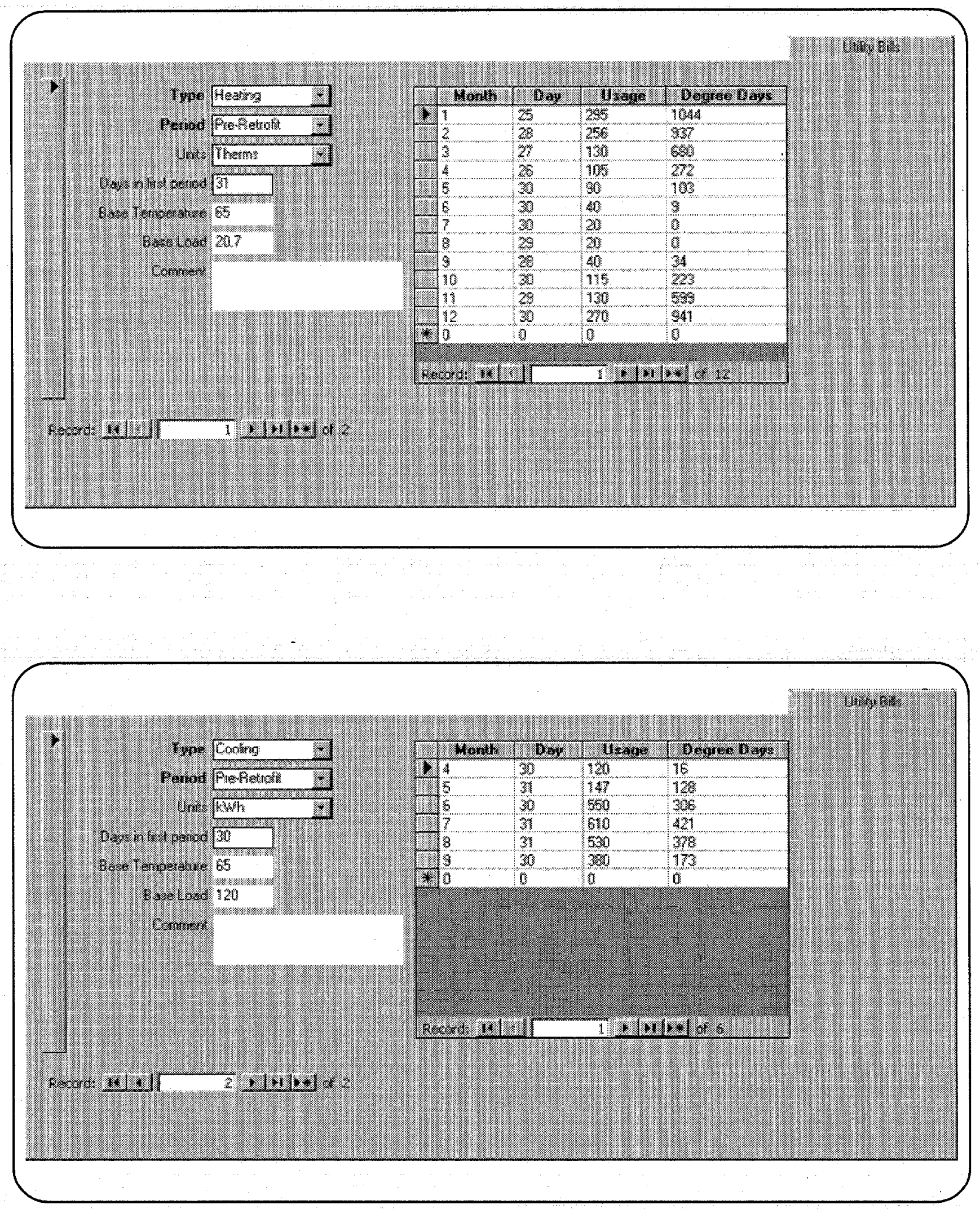


\section{National Energy Audit Tool (NEAT) Agency Enter Agency Name Here Output Report \\ Run On 4/24/01 9:07:08 AM ID 988128428 \\ Version $\quad 7.0 .64 / 23 / 01$ \\ $J o b$ \\ Manual Example \\ AuditDate \\ $3 / 20 / 01$ \\ Client Name \\ Morris \\ WeatherFile \\ STLOUIMO.WX \\ Auditor \\ N. Walts \\ Param Name \\ Standard}

Comment

This is an example Job for use in NEAT's User's Manual, Version 7. If you would like to

experiment with this example, first make a copy with the copy button at the top of this form.

\section{Annual Energy and Cost Savings}

Index Recommended

\section{Measure}

1 Infiltration Redctn

2 Seal Ducts

3 Low Flow Showerheads

4 Wall Ins. R-11 Batt

5 Fill Ceiling Cavity

6 Smart Thermostat

7 Sillbox Ins.

8 Outlet Gaskets

9 Duct Insulation

10 DWH Pipe Insulation

11 Lighting Retrofits

12 Wall Insulation

13 Floor Ins. R-19

14 DWH Tank Insulation

15 Wall Insulation

16 Refrigerator Rplcmn

17 Replace Htg. System

\section{Components}

KNW
RRT
F2
LT1,LT2,LT3,LT4
E1,N1,S1,W1
F1
E2,N2

\section{Heating}

(MBtu)

17.2

50.7

0.0

17.7

27.3

8.1

1.0

0.0

46.1

0.0

0.0

23.3

11.9

0.0

2.5

0.0

22.0
Cooling

BaseLoad

Total

(\$)

(kWh)

(kWh)

(\$) (MBtu)

91

57

$$
267
$$

0

$$
0
$$

0

$$
79
$$

$$
122
$$

$$
0
$$

(\$)

. 0

17.4

2943

0
0

0

50.7

$\begin{array}{lll}2943 & 53 & 10.0\end{array}$

$\begin{array}{lll}0 & 0 & 18.0\end{array}$

$\begin{array}{lll}0 & 0 & 27.8\end{array}$

$\begin{array}{lll}0 & 0 & 8.1\end{array}$

$\begin{array}{lll}0 & 0 & 1.0\end{array}$

$\begin{array}{lll}0 & 0 & 1.3\end{array}$

$\begin{array}{lll}0 & 0 & 46.1\end{array}$

246

0.8

$2169 \quad 185 \quad 7.4$

$\begin{array}{lll}0 & 0 & 23.7\end{array}$

$\begin{array}{lll}0 & 0 & 11.9\end{array}$

$\begin{array}{lll}239 & 4 & 0.8\end{array}$

$\begin{array}{lll}0 & 0 & 2.5\end{array}$

$\begin{array}{lll}923 & 79 & 3.2\end{array}$

$\begin{array}{lll}0 & 0 & 22.0\end{array}$ 


\section{Energy Saving Measure Economics}

\begin{tabular}{|rll} 
Index Recommended & Components \\
\multicolumn{3}{|c}{ Measure } \\
1 & Door repaired & \\
2 & Infiltration Redctn & \\
3 & Seal Ducts \\
4 & Low Flow & \\
5 & Wall Ins. R-11 Batt & KNW \\
6 & Fill Ceiling Cavity & RRT \\
7 & Smart Thermostat & \\
8 & Sillbox Ins. & F2 \\
9 & Outlet Gaskets & \\
10 & Duct Insulation & \\
11 & DWH Pipe Insulation & 4 \\
12 & Lighting Retrofits & LT1,LT2,LT3,LT4 \\
13 & Wall Insulation & E1,N1,S1,W1 \\
14 & Floor Ins. R-19 & F1 \\
15 & DWH Tank Insulation & \\
16 & Wall Insulation & E2,N2 \\
17 & Refrigerator Rplcmnt & \\
18 & Replace Htg. System & \\
19 & Flue moved & \\
& &
\end{tabular}

\section{Materials}

$$
\begin{aligned}
\text { Index } & \text { Material } \\
1 & \text { Wall Insulation } \\
2 & \text { Kneewall Ins. } \\
3 & \text { Sill Insulation } \\
4 & \text { Floor Insulation } \\
5 & \text { Duct Insulation } \\
6 & \text { Smart Thermostat } \\
7 & \text { Compact Fluorescen } \\
8 & \text { Compact Fluorescen } \\
9 & \text { Compact Fluorescen } \\
10 & \text { DHW Tank Insulatio } \\
11 & \text { DHW Pipe Insulatio } \\
12 & \text { Low-Flow Shower He } \\
13 & \text { Ceiling Insulation } \\
14 & \text { Rcplacement Furnac } \\
15 & \text { New Refrigerator } \\
16 & \text { 15 Oulet Gaskets }
\end{aligned}
$$

Measure Measure Meas

\section{Cummulative Cummulative} Savings (\$/yr) Cost (\$)

SIR

Cost (\$)

SIR

$\begin{array}{rrr}0 & 20 & 0.0 \\ 95 & 150 & 5.3 \\ 267 & 230 & 9.7 \\ 53 & 8 & 76.6 \\ 100 & 93 & 15.3 \\ 154 & 151 & 14.5 \\ 43 & 65 & 7.6 \\ 6 & 10 & 6.4 \\ 7 & 10 & 5.7 \\ 243 & 706 & 4.9 \\ 15 & 3.4 & 1457 \\ 185 & 279 & 3.1 \\ 132 & 623 & 3.0 \\ 62 & 335 & 2.6 \\ 4 & 15 & 2.4 \\ 13 & 94 & 2.0 \\ 79 & 491 & 1.8 \\ 116 & 1340 & 1.0 \\ 0 & 30 & 0.0\end{array}$

Type

Blwn Cellulose

Faced Batt - R-11

Faced Batt - R-19

Faced Batt - R-19

13 Watt

26 Watt

38 Watt

Celluls,Blwn - 4 in.

70 kBtu Existing, 39 kBtu Post-ret. sizcd 35501
Quantity Units

$\begin{aligned} 1217 & \text { Sqft } \\ 320 & \text { Sqft } \\ 21 & \text { Sqft } \\ 644 & \text { Sqft } \\ 480 & \text { Sqft } \\ 1 & \text { Each } \\ 9 & \text { Each } \\ 6 & \text { Each } \\ 3 & \text { Each } \\ 1 & \text { Each } \\ 1 & \text { Each } \\ 2 & \text { Each } \\ 560 & \text { Sqft } \\ 1 & \text { Each } \\ 1 & \text { Each } \\ 1 & \text { Each }\end{aligned}$




\section{Pre/Post Retrofit Energy and}

Pre Ketrofit

Heating

Annual load (MBtu/yr)

Annual Energy (MBtu/yr)

Heat loss $(\mathrm{kBtu} / \mathrm{hr})$

Output required (kBtu/hr)
100.7

219.3

76.5

91.8
Cooling

7.3

4.2

0.0

0.0
Post Retrofit

Heating Cooling

$36.4 \quad 5.3$

$37.3 \quad 3.0$

$34.3-0.0$

$39.4 \quad 0.0$

\section{Annual Energy and Cost Savings (Adjusted)}

\begin{tabular}{|c|c|c|c|c|c|c|c|c|c|}
\hline Index & $x \quad$ Recommended & Components & Heating & & Cooling & & BaseLoad & & Total \\
\hline & Measure & & (MBtu) & $(\$)$ & $(\boldsymbol{k W h})$ & $(\$)$ & $(k W h)$ & $(\$)$ & (MBtu) \\
\hline 1. & Infiltration Redetn & & 9.3 & 49 & 74 & 6 & 0 & 0 & 9.6 \\
\hline 2 & Seal Ducts & & 27.4 & 144 & 0 & 0 & 0 & 0 & 27.4 \\
\hline 3 & Low Flow Showerheads & & 0.0 & 0 & 0 & 0 & 2943 & 53 & 10.0 \\
\hline 4 & Wall Ins. R-11 Batt & KNW 9.6 & 50 & 102 & 9 & 0 & 0 & 9.9 & \\
\hline 5 & Fill Ceiling Cavity & $\begin{array}{ll}\text { RRT } & 14.8\end{array}$ & 78 & 158 & 13 & 0 & 0 & 15.3 & \\
\hline 6 & Outlet Gaskets & & 0.0 & 0 & 0 & 0 & 0 & 0 & 1.3 \\
\hline 7 & Smart Thermostat & & 4.4 & 23 & 0 & 0 & 0 & 0 & 4.4 \\
\hline 8 & Sillbox Ins. & F2 & 0.6 & 3 & 0 & 0 & 0 & 0 & 0.6 \\
\hline 9 & DWH Pipe Insulation & & 0.0 & 0 & 0 & 0 & 246 & 4 & 0.8 \\
\hline 10 & Lighting Retrofits & LT1,LT2,LT3,LT4 & 0.0 & 0 & 0 & 0 & 2169 & 185 & 7.4 \\
\hline 11 & Duct Insulation & & 24.9 & 131 & 0 & 0 & 0 & 0 & 24.9 \\
\hline 12 & DWH Tank Insulation & & 0.0 & 0 & 0 & 0 & 239 & 4 & 0.8 \\
\hline 13 & Floor Ins. R-11 & F1 & 5.5 & 29 & -2 & 0 & 0 & 0 & 5.5 \\
\hline 14 & Refrigerator Rplcmnt & & 0.0 & 0 & 0 & 0 & 923 & 79 & 3.2 \\
\hline 15 & Wall Insulation & $\mathrm{E} 1, \mathrm{~N} 1, \mathrm{~S} 1, \mathrm{~W} 1$ & 12.5 & 66 & 121 & 10 & 0 & 0 & 12.9 \\
\hline 16 & Furnace Tuneup & & 5.7 & 30 & 0 & 0 & 0 & 0 & 5.7 \\
\hline
\end{tabular}




\section{Energy Saving Measure Economics (Adjusted)}

\begin{tabular}{rrl} 
Index Recommended & Components \\
1 & \multicolumn{1}{c}{ Measure } \\
1 & Door repaired & \\
2 & Infiltration Redctn & \\
3 & Seal Ducts & \\
4 & Low Flow & KNW \\
5 & Wall Ins. R-11 Batt & RRT \\
6 & Fill Ceiling Cavity & \\
7 & Outlet Gaskets & \\
8 & Smart Thermostat & \\
9 & Sillbox Ins. & F2 \\
10 & DWH Pipe Insulation & \\
11 & Lighting Retrofits & LI'LI2,LI3,LI4 \\
12 & Duct Insulation & \\
13 & DWH Tank Insuiation & \\
14 & Floor Ins. R-11 & F1 \\
15 & Refrigerator Rplcmnt & \\
16 & Wall Insulation & E1,N1,S1,W1 \\
17 & Furnace Tuneup & \\
18 & Flue moved & \\
&
\end{tabular}

Measure

Savings $(\$ / y r)$

0

55

144

53

59

91

7

23

3

4

185

131

4

29

79

76

30

0

\section{Measure}

Cost (\$)

20

150

230

8

93

151

10

65

10

15

279

706

15

219

491

623

45

30
Measure Cummulative Cummulative

SIR

0.0

3.1

5.3

76.6

9.0

8.6

5.7

4.1

3.5

3.4

3.1

2.7

2.4

1.9

1.8

1.7

1.3

0.0
Cost (\$)

20

170

400

408

501

651

661

726

736

751

1030

1736

1751

1970

2461

3084

3129

3159
SIR

\section{Materials (Adjusted)}

$\begin{array}{cl}\text { Index } & \text { Material } \\ 1 & \text { Wall Insulation } \\ 2 & \text { Kneewall Ins. } \\ 3 & \text { Sill Insulation } \\ 4 & \text { Floor Insulation } \\ 5 & \text { Duct Insulation } \\ 6 & \text { Smart Thermostat } \\ 7 & \text { Compact Fluorescen } \\ 8 & \text { Compact Fluorescen } \\ 9 & \text { Compact Fluorescen } \\ 10 & \text { DHW Tank Insulatio } \\ 11 & \text { DHW Pipe Insulatio } \\ 12 & \text { Low-Flow Shower He } \\ 13 & \text { Ceiling Insulation } \\ 14 & \text { New Refrigerator } \\ 15 & \text { 15 Oulet Gaskets }\end{array}$

Type

Blwn Cellulose

Faced Batt - R-11

Faced Batt - R-19

Faced Batt - R-11

13 Watt

26 Watt

38 Watt

Celluls,Blwn - 4 in.

35501
Quantity Units

1057 Sqft

320 Sqft

21 Sqft

644 Sqft

$480 \quad$ Sqft

1 Each

9 Each

6 Each

3 Each

1 Each

1 Each

2 Each

560 Sqft

1 Each

1 Each 


\section{Heating Energy Consumption Comparison}

Month Day

$\begin{array}{rr}1 & 25 \\ 2 & 28 \\ 3 & 27 \\ 4 & 26 \\ 5 & 30 \\ 6 & 30 \\ 7 & 30 \\ 8 & 29 \\ 9 & 28 \\ 10 & 30 \\ 11 & 29 \\ 12 & 30\end{array}$

Total

\%Difference
Days in

\section{Period}

31

34

27

30

34

31

30

30

30

32

30

31

370
Consumption Actual Predicted

274

233

111

84

67

19

0

0

19

93

109

249

1258
Degree

Actual Predicted

$1044 \quad 1084$

$937 \quad 1137$

$680 \quad 641$

$272-383$

$103 \quad 158$

927

04

$0 \quad 15$

$34 \quad 76$

$223 \quad 278$

$599 \quad 618$

$941 \quad 960$

$4842 \quad 5381$

\section{Cooling Energy Consumption Comparison}

\begin{tabular}{|c|c|c|c|c|c|c|}
\hline \multirow[t]{2}{*}{ Month } & \multirow[t]{2}{*}{ Day } & \multirow{2}{*}{$\begin{array}{c}\text { Days in } \\
\text { Period }\end{array}$} & \multicolumn{2}{|c|}{ Consumption } & \multicolumn{2}{|r|}{ Degree } \\
\hline & & & Actual & Predicted & Actual & Predicted \\
\hline 4 & 30 & 30 & 0 & 11 & 16 & 24 \\
\hline 5 & 31 & 31 & 23 & 78 & 128 & 130 \\
\hline 6 & 30 & 30 & 430 & 277 & 306 & 324 \\
\hline 7 & 31 & 31 & 486 & 391 & 421 & 435 \\
\hline 8 & 31 & 31 & 406 & 330 & 378 & 396 \\
\hline 9 & 30 & 30 & 260 & 151 & 173 & 21.9 \\
\hline Total & & 183 & 1605 & 1238 & 1422 & 1528 \\
\hline \%Diffe & rence & & & .9 & & 7.5 \\
\hline
\end{tabular}




\begin{tabular}{|c|c|c|c|c|}
\hline \multirow[t]{2}{*}{ Component Type } & Component & $\begin{array}{r}\text { Area or } \\
\text { Volume }(\text { Inf })\end{array}$ & Pre Retrofit & $\begin{array}{r}\text { Post Retrofit } \\
\text { Load }(B T U / h)\end{array}$ \\
\hline & & & $\operatorname{Load}(B t u / h)$ & \\
\hline Wall & E1 & 210 & 3866.4 & 1195.6 \\
\hline Wall & E2 & 80 & 1476.4 & 1476.4 \\
\hline Wall & $\mathrm{N} 1$ & 244 & 4504.1 & 1392.8 \\
\hline Wall & N2 & 80 & 1476.4 & 1476.4 \\
\hline Wall & S1 & 293 & 5401.2 & 1670.2 \\
\hline Wall & w1 & 311 & 5731.4 & 1772.3 \\
\hline Window & WD1 & 7 & 460.0 & 460.0 \\
\hline Window & WD2 & 9 & 613.4 & 613.4 \\
\hline Window & WD3 & 20 & 1368.8 & 1368.8 \\
\hline Window & WD4 & 9 & 613.4 & 613.4 \\
\hline Window & WD5 & 20 & 1368.8 & 1368.8 \\
\hline Window & WD6 & 10 & 684.4 & 684.4 \\
\hline Window & WD7 & 18 & 1226.7 & 1226.7 \\
\hline Window & WD8 & 9 & 613.4 & 613.4 \\
\hline Door & DR1 & 20 & 414.8 & 414.8 \\
\hline Door & $\mathrm{DR} 2$ & 20 & 414.8 & 414.8 \\
\hline Attic & OCJ & 480 & 1095.6 & 1095.6 \\
\hline Attic & CBM & 160 & 365.2 & 365.2 \\
\hline Attic & $\mathrm{KNW}$ & 320 & 13034.2 & 1820.8 \\
\hline Attic & RRT & 560 & 9652.7 & 2566.3 \\
\hline Foundation & F1 & 644 & 5365.4 & 1698.4 \\
\hline Foundation & F2 & 476 & 6573.6 & 6573.6 \\
\hline Infiltration & Inf & 14400 & 10192.1 & 5974.7 \\
\hline Total heat loss & Tot & 0 & 76513.2 & 36856.8 \\
\hline Duct loss & Duct & 0 & 15302.6 & 5528.5 \\
\hline Output required & Output & 0 & 91815.9 & 42385.3 \\
\hline
\end{tabular}




\section{Special Notes}

NOTE: Read cautions in NEAT User's Manual related to sizing results.

NOTE: Heat loss and Output required are only guides to sizing equipment.

NOTE: See NEAT User's Manual for further sizing details.

NOTE: Read cautions in NEAT User's Manual related to sizing results.

\section{Comments}

$\begin{array}{lll}\text { Type } & \text { Code } & \text { Comment } \\ \text { Wall } & \text { E2 } & \text { Buffered 1st } \\ \text { Wall } & \text { N1 } & \text { 1st, 2nd \& Dormer } \\ \text { Wall } & \text { N2 } & \text { Buffered 1st } \\ \text { Wall } & \text { S1 } & \text { 1st, 2nd \& Dormer } \\ \text { Heating System } & \text { HS1 } & \text { Primary heating system }\end{array}$




\section{Appendix B}

This appendix contains screens from the Preferences and Setup portions of NEAT. They show settings as they are when the program is newly installed. You will have to modify the values and settings to reflect your local conditions and costs.

\section{General Preferences}

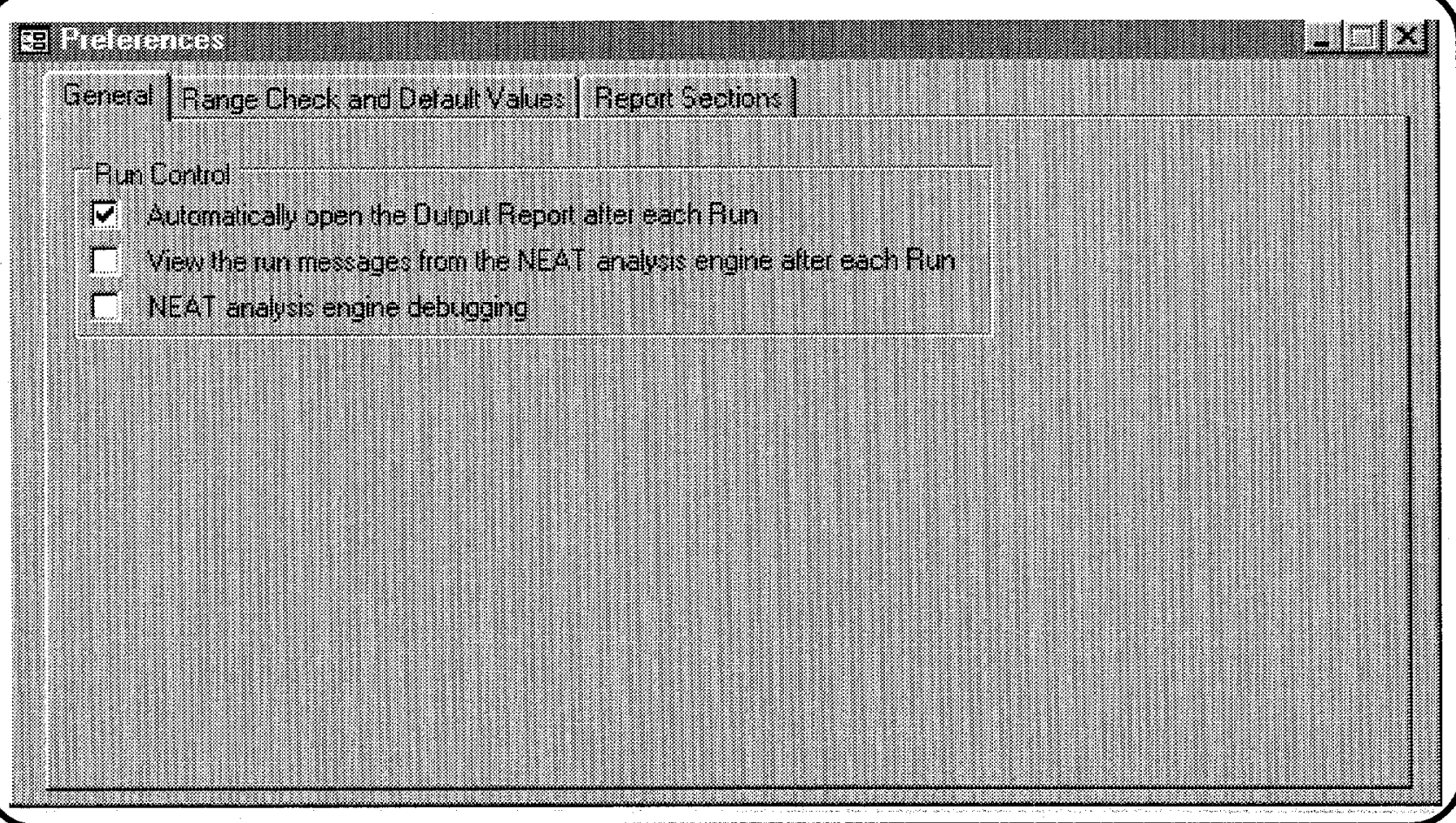


Range Check and Default Values

\begin{tabular}{|c|c|c|c|c|c|c|}
\hline \multicolumn{7}{|c|}{ 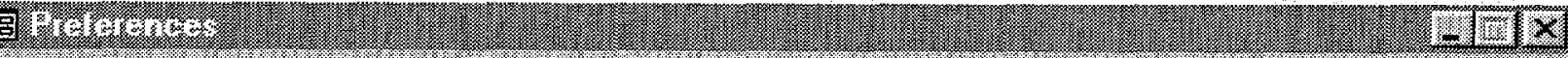 } \\
\hline Gernen & Eal Fange Ches: and Deto & 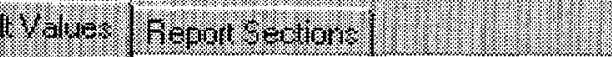 & & & & \\
\hline $2: 2$ & 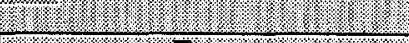 & 2.20 & 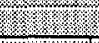 & 20 & $4=2.20$ & \\
\hline 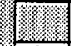 & 21: & 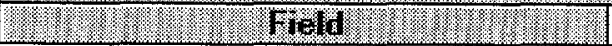 & Win & Migax & Default & (7) \\
\hline TI: & Gemelmo & Number of Condthned Swips & 1 & 4 & & \\
\hline 2 & Gentello & 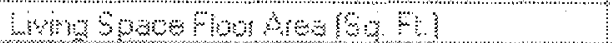 & 700 & 3600 & 1200 & \\
\hline U: & generulm. & 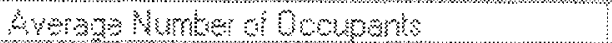 & 1 & 10 & & \\
\hline 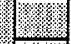 & Dues 8 mithetim & 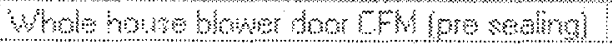 & 500 & 8000 & & \\
\hline 2 & Dupres mbitum & 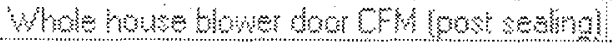 & 500 & 8000 & 25010 & \\
\hline ? & Dus B blethon & 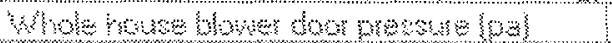 & 10 & 100 & & \\
\hline 10 & Dot inflown & Dud bluber CFIne and por sedimo & 100 & 5000 & & \\
\hline 10 & Oune chmokn & Dum tham meture & 10 & 100 & & \\
\hline II: & Duet onlbern & 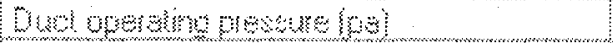 & 10] & 100 & & \\
\hline 40 & 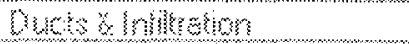 & Whatmedemmisets & a & 1000 & & \\
\hline 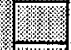 & Wes 8 millem & Oue sesing moll & 0 & 1000 & & \\
\hline ? & Yrikg & Wubsum & 20 & 4000 & & \\
\hline 10 & His & evalus & 0 & 30 & & \\
\hline 2 & bill & Aded Son & 0 & 500 & & \\
\hline : & Whens & Mumber of broms & 1. & 15 & & \\
\hline 20 & Whomens & Prementhed & 0 & 100 & & \\
\hline 02 & Wmons & Stom Windos shinh $\{\mathrm{ml}$ & 12 & 100 & & \\
\hline ? & W1:cose & Stm Grome Hemt mi & 12 & 100 & & \\
\hline 12 & Bundows & 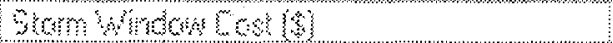 & [] & 1000 & & \\
\hline 28 & Deos & Whmber Doge & 1 & 8 & & \\
\hline$\sqrt{20}$ & nous & 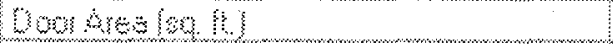 & 10. & 40 & & \\
\hline 2 & Doges & Stom Uro woll In & 24 & 100 & & \\
\hline I: & vons & Smm Corteing $[\mathrm{m}$ & 72 & 100 & & \\
\hline 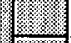 & Unfringed anes & Uersponeln & 12 & 30 & & \\
\hline - & Unmens thes & Alo bes sall & 25 & 3000 & & \\
\hline (2) & Whimber atres & Eyelno Inctation Deph in] & 0 & 16 & & \\
\hline 8 & Whithens stis: & 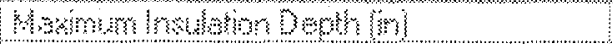 & d] & 16 & & \\
\hline 12 & Uninged Bns & $\mathrm{AdB} \times \mathrm{ONO}$ & (1) & 500 & & \\
\hline 20 & Finhedshe & Frined Bne brea 10. 1 & 25 & 3000 & & \\
\hline 1828 & Fithed ane & 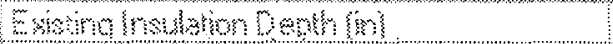 & 0 & 16 & & \\
\hline 2010 & Frened ante & Mesimum linsulyon seph [in] & 0 & 16 & & \\
\hline 2 & Finthed and & Bdted Couls & 0 & 500 & & \\
\hline 10 & Foundetion & Fontrighor Ares lsy. it & 25 & 3000 & & \\
\hline In: & Fomdations & Cenng vins & []: & 40 & & \\
\hline D. & Founderims & Eemele Lmonitu & 1 & 3000 & & \\
\hline 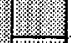 & Fundetich & Pymerer Exposedo & 0 & 100 & 100 & \\
\hline 10 & Fomderins & Weblempln & 1 & 12 & & \\
\hline 20 & Fardetions & Bolsspoed & 0 & 100 & 100 & \\
\hline 20 & Fom & Walp value & 0 & 25 & & \\
\hline ?. & Fondaton & $\mathrm{Abded} 0 \mathrm{OBS}$ & (1) & 500 & & \\
\hline (1) & Limbre & Dwank & 1 & 25 & & \\
\hline 2 & Lighming & 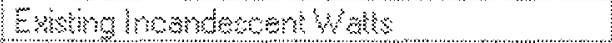 & 15 & 250 & & \\
\hline 20 & Liphen: & Hose $\operatorname{mes}$ & 1 & 24 & & \\
\hline 8 & Lighting & PeplasonentCF wat & 5 & 50 & & \\
\hline 2 & Unghes & Addinenal Mos & 0 & 100 & & \\
\hline
\end{tabular}




\section{Range Check and Default Values (continued)}

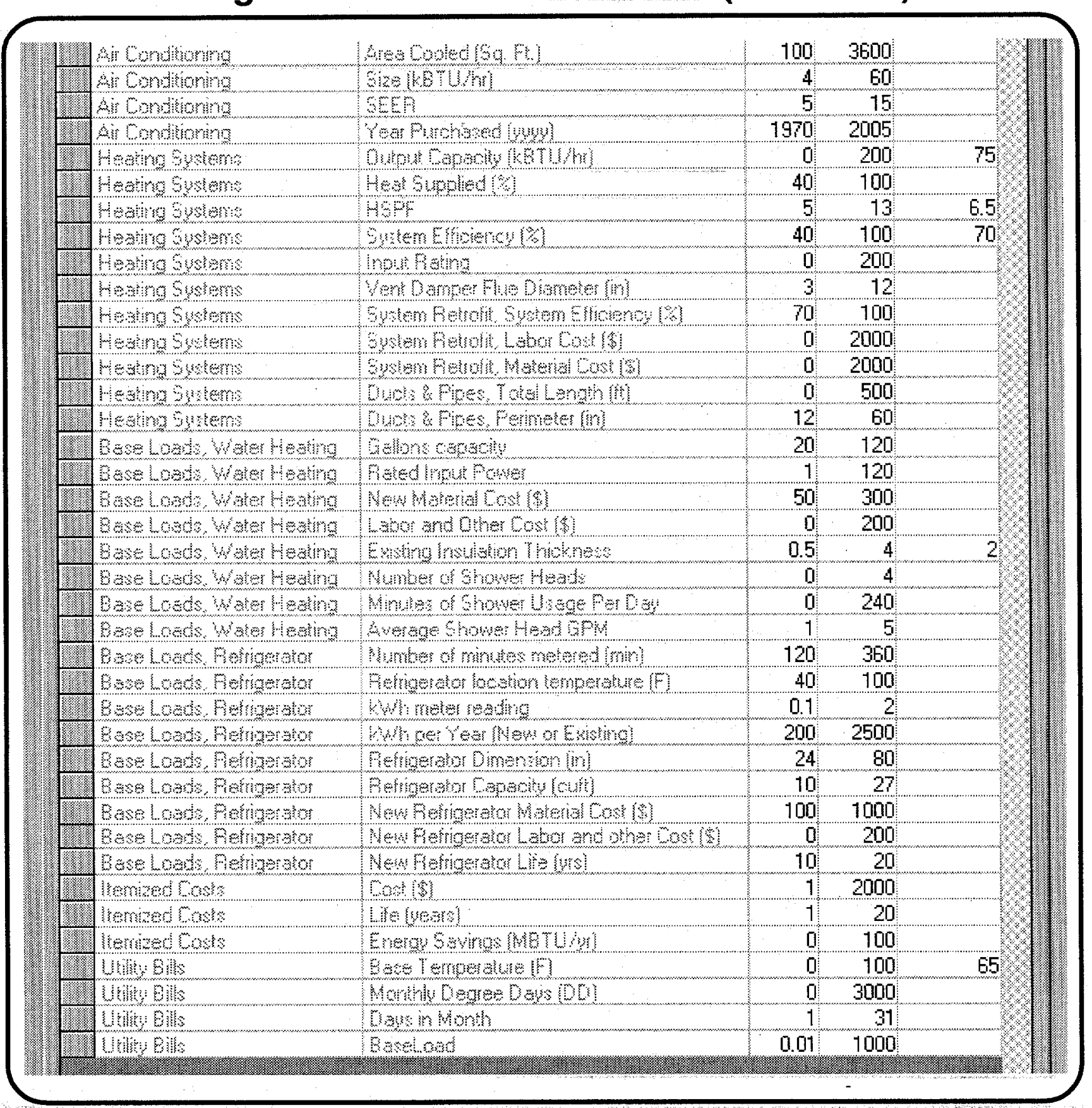


Report Sections

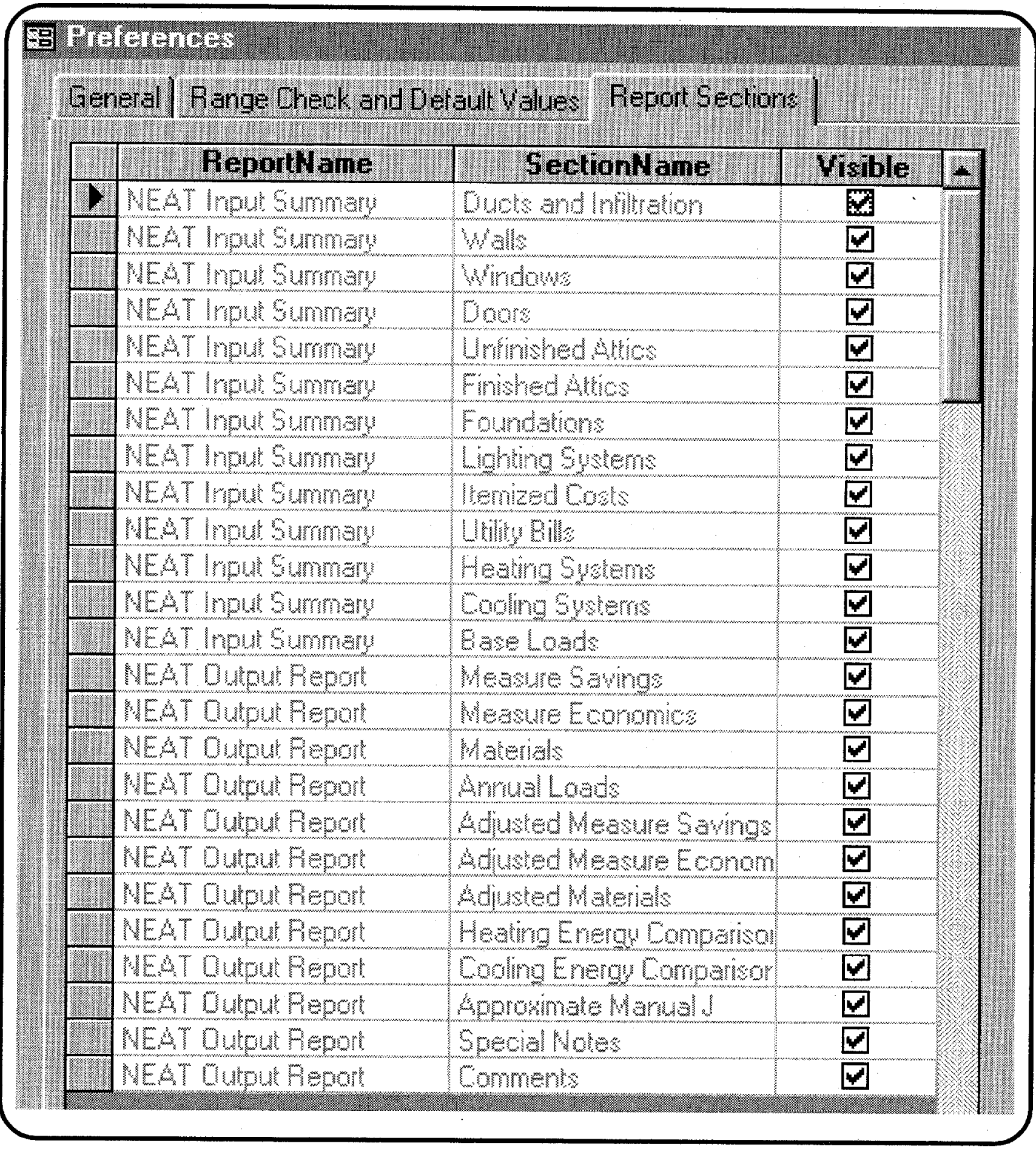




\section{Appendix B-Setup Soreens}

\section{Parameter Set Selection Screen}

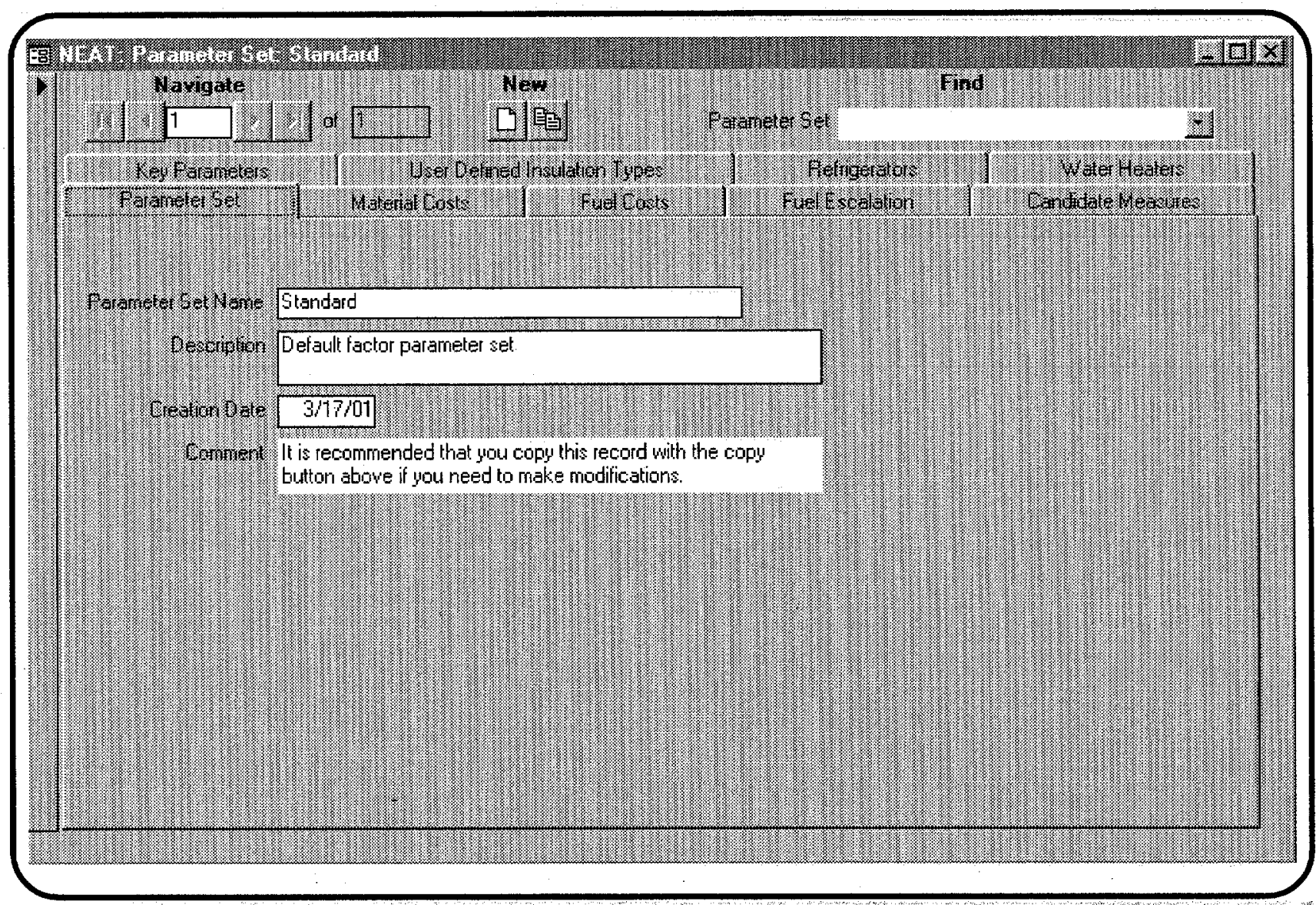


Material Costs-Insulation

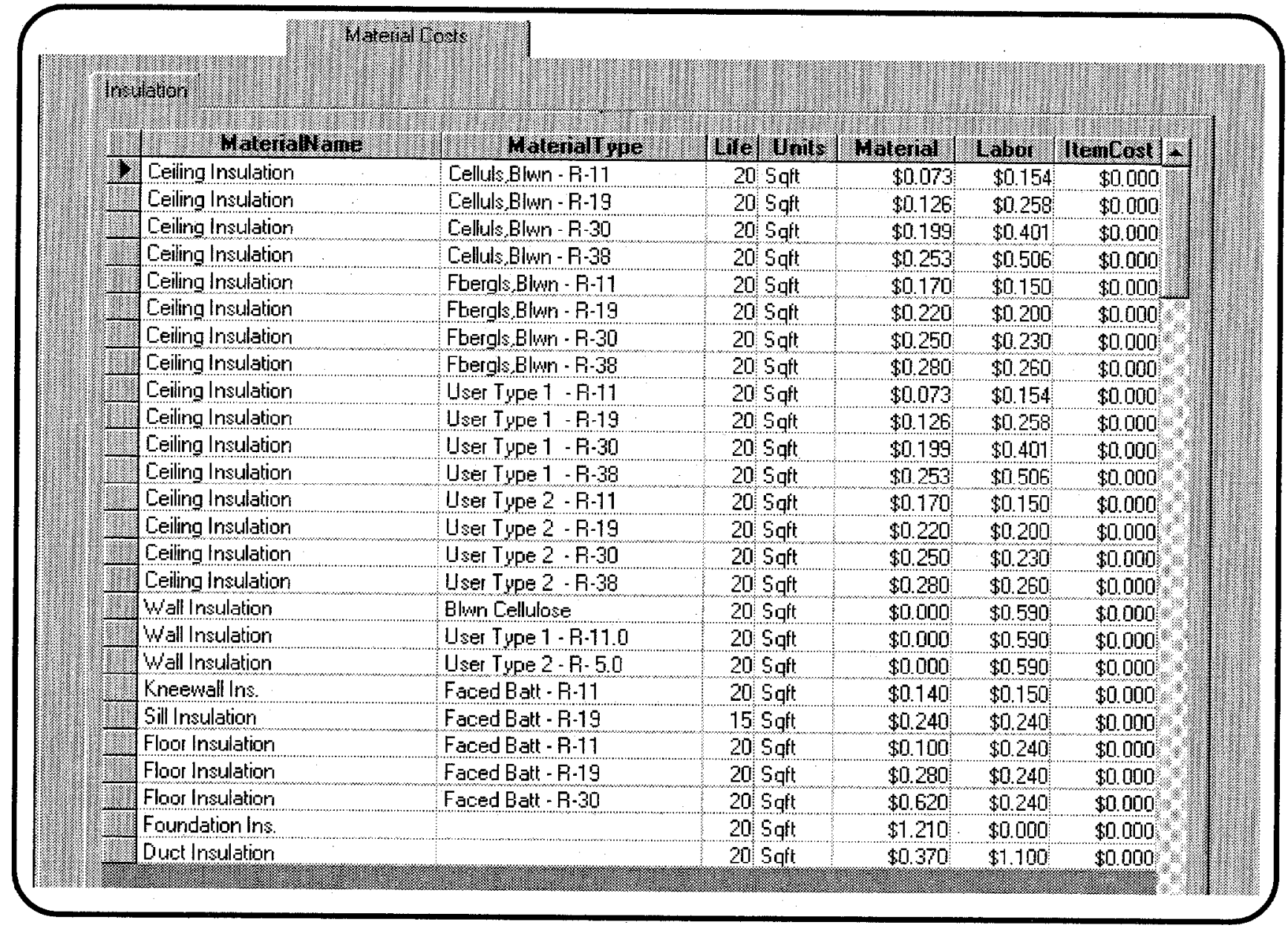




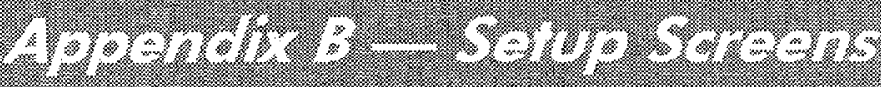

\section{Material Costs-Heating Equipment}

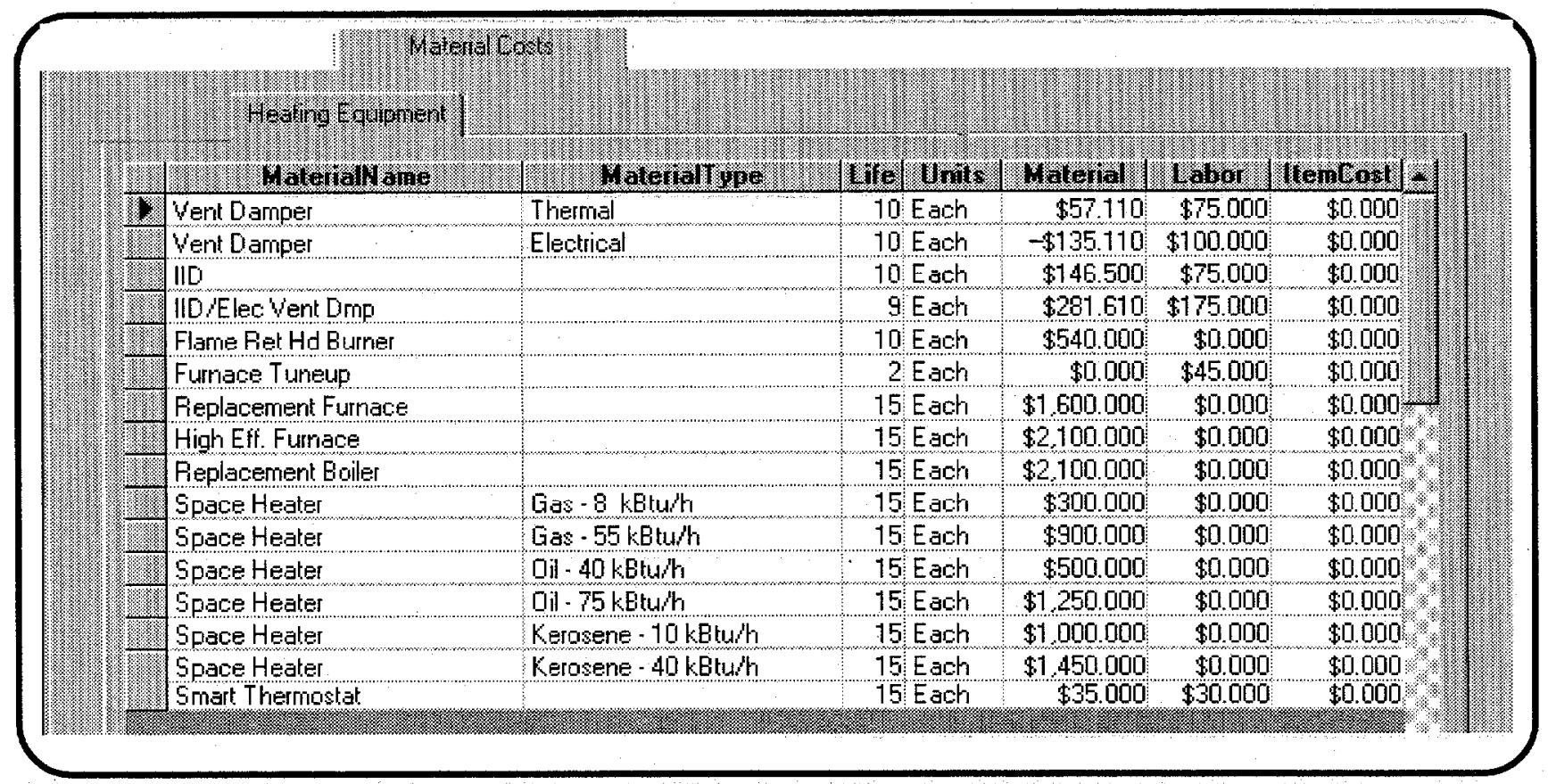

\section{Material Costs-Cooling Equipment}

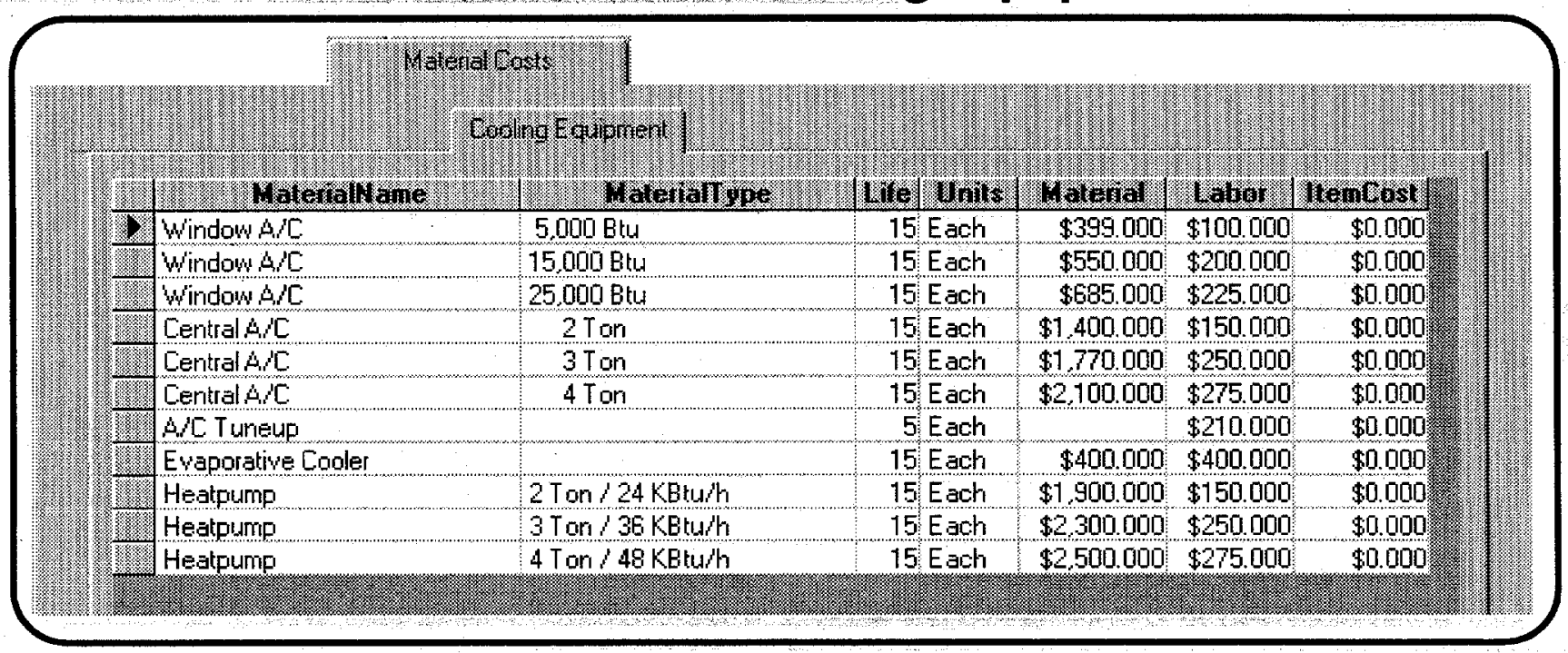




\section{Material Costs-Windows}

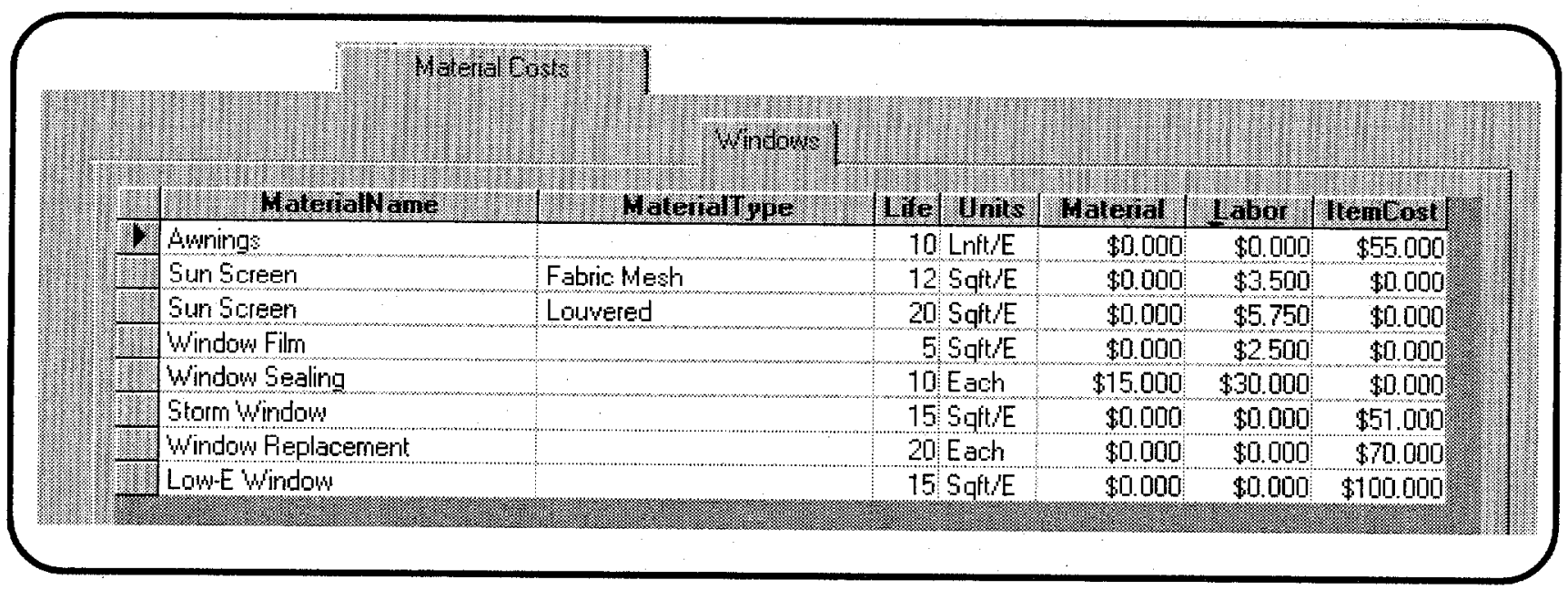

\section{Material Costs-Baseloads}

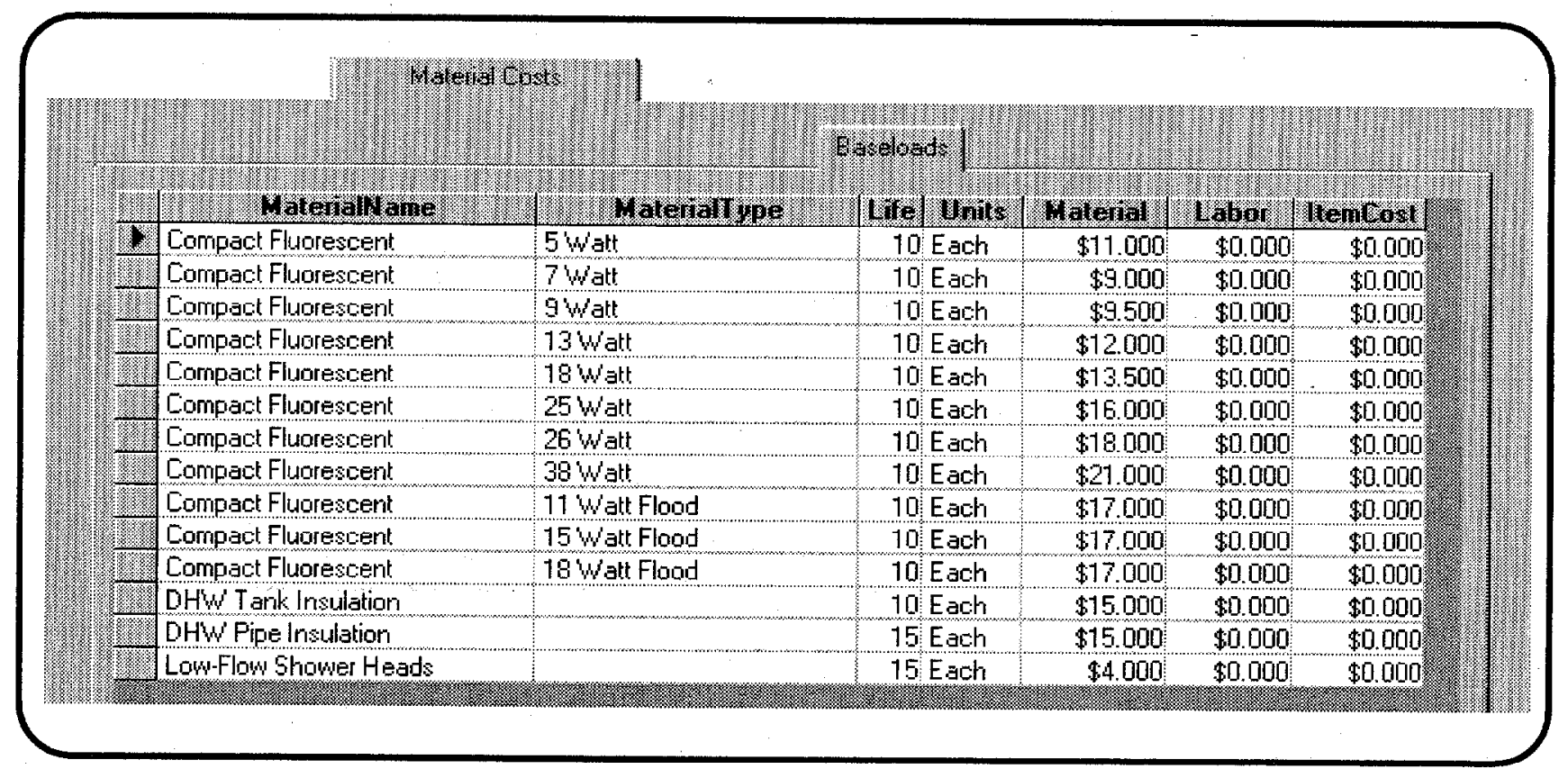




\section{Fuel Costs}

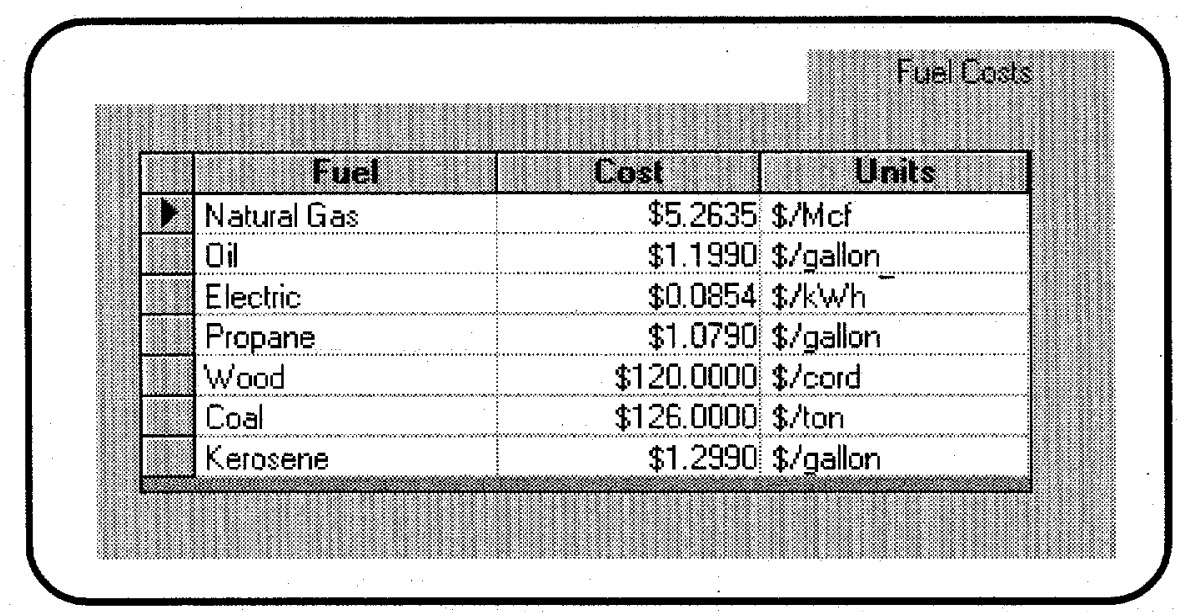

\section{Escalation (Repeated for all other fuel types) Rates}

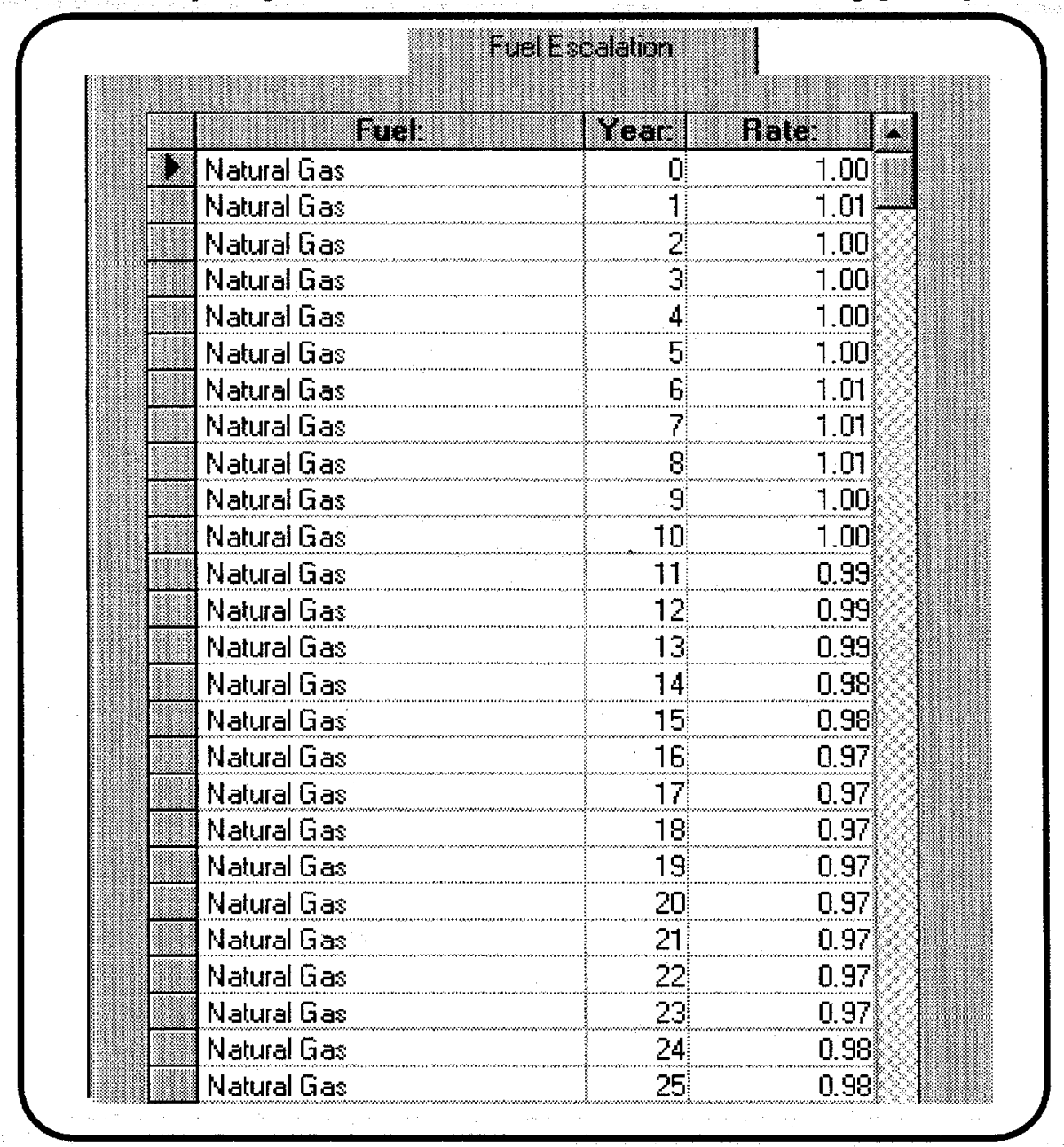




\section{Candidate Measures}

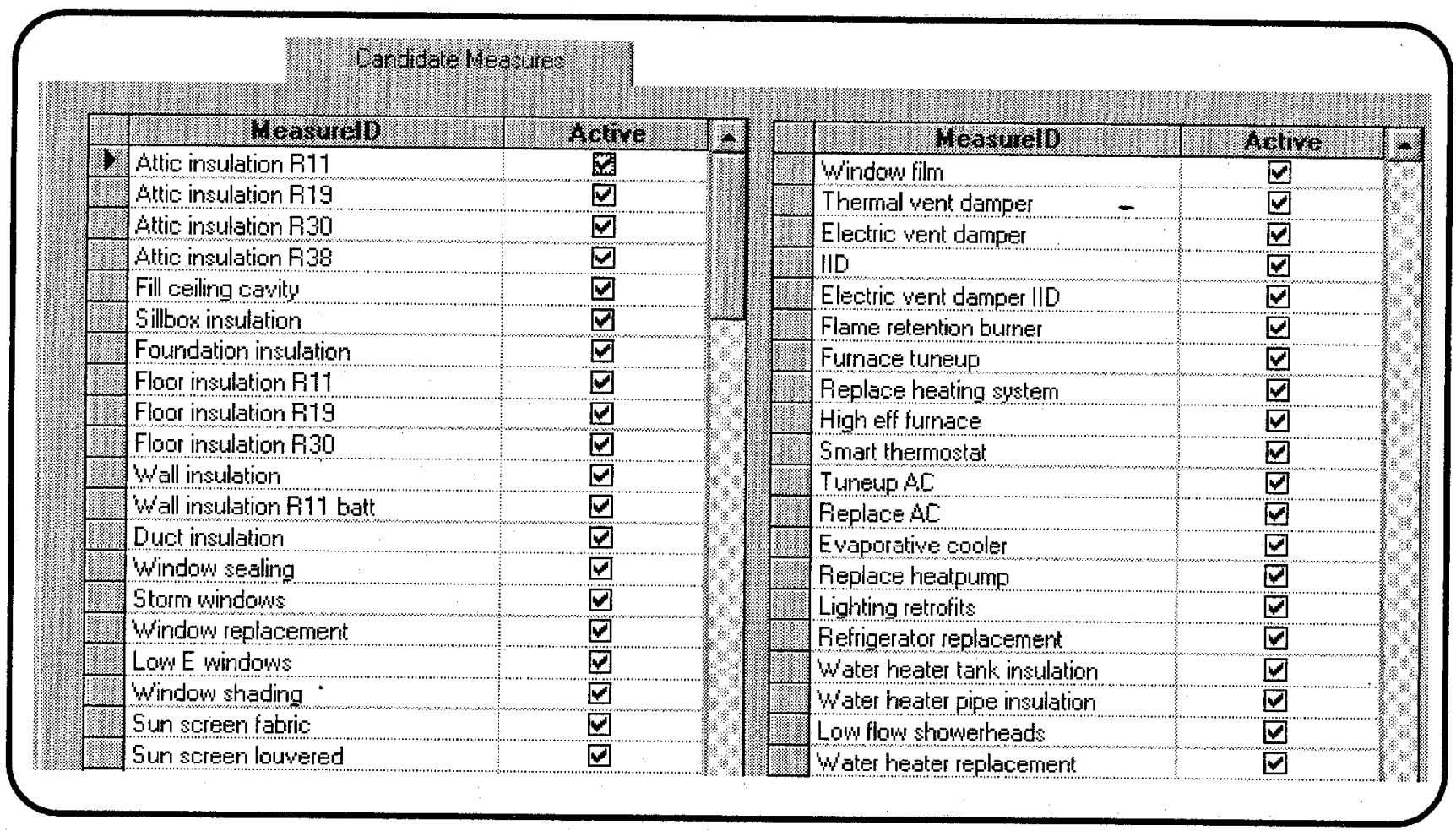

\section{Key Parameters-Economics}

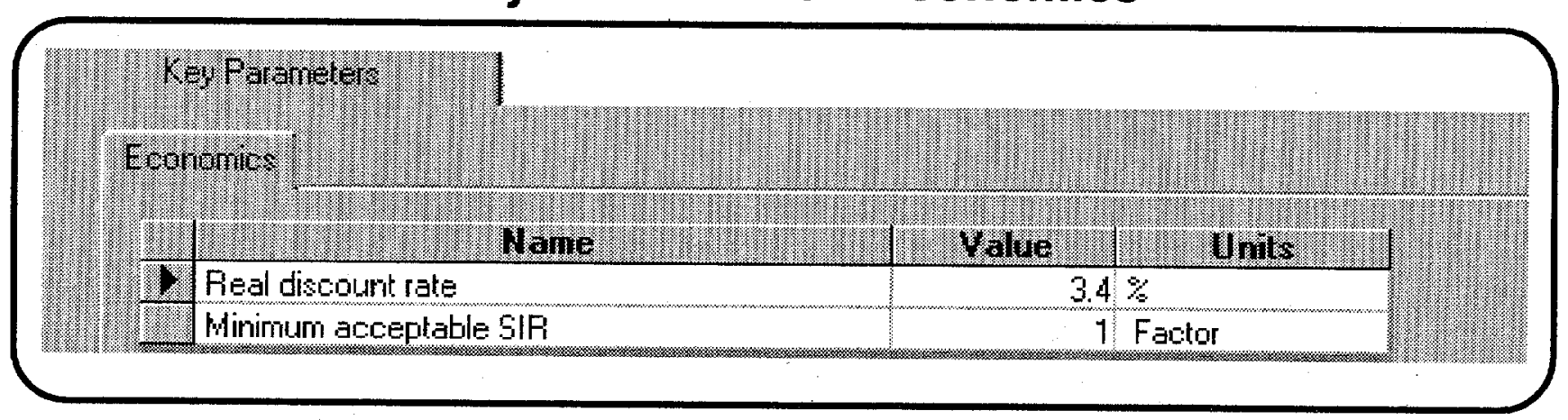




\section{Appendis B-Sacpstreens}

\section{Key Parameters-Set Points}

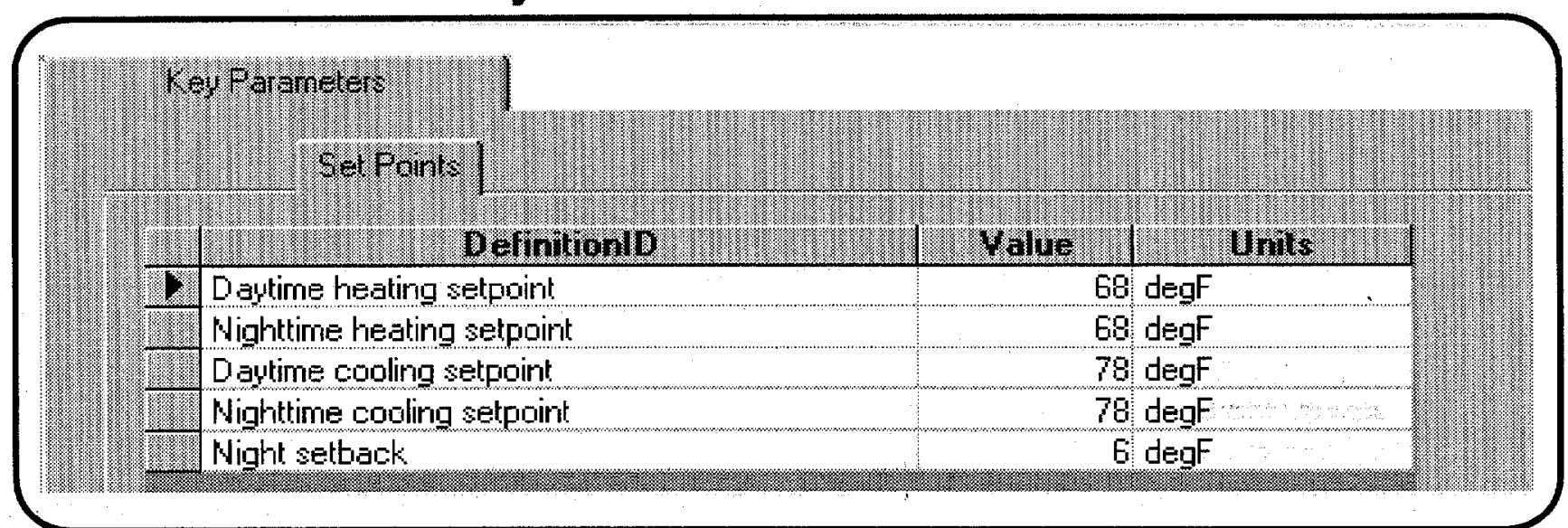

\section{Key Parameters-Insulation and Heat Transfer}

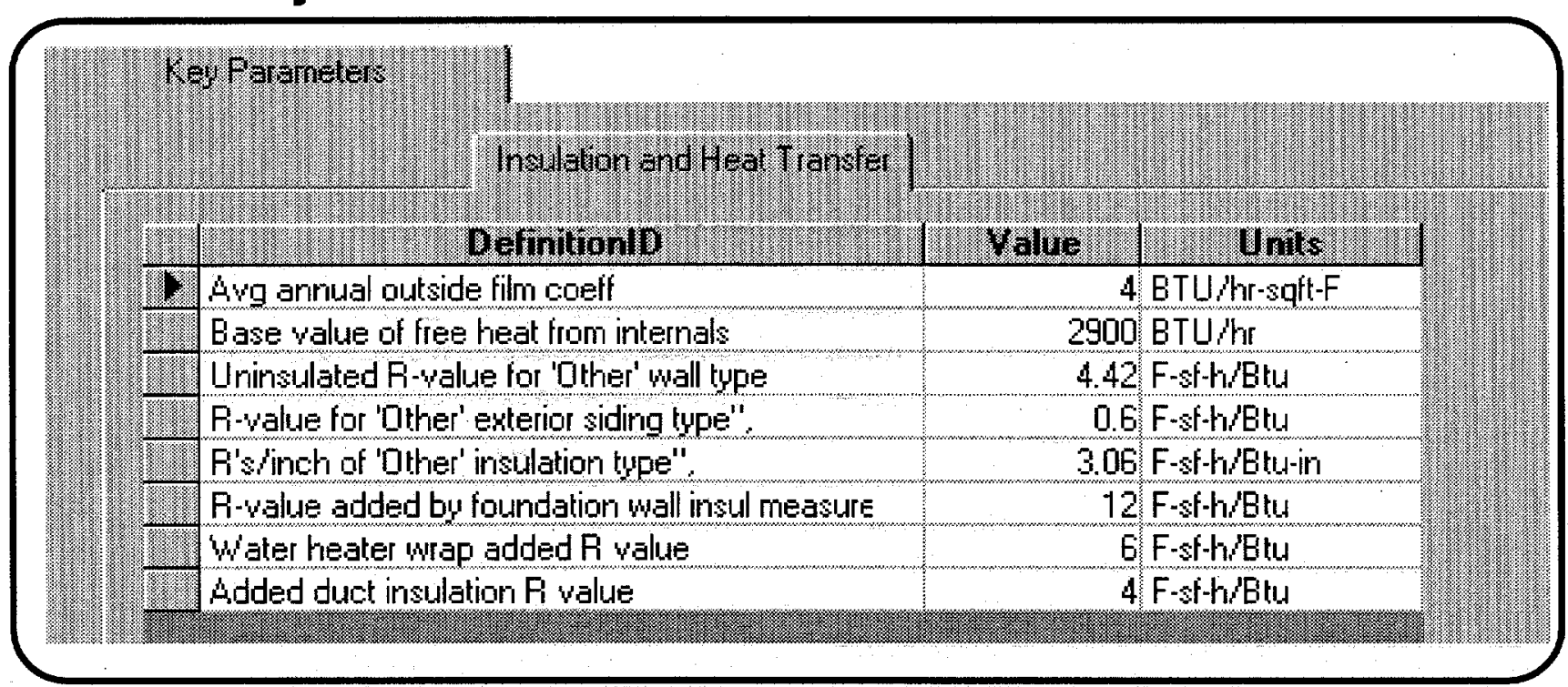


Key Parameters-Equipment

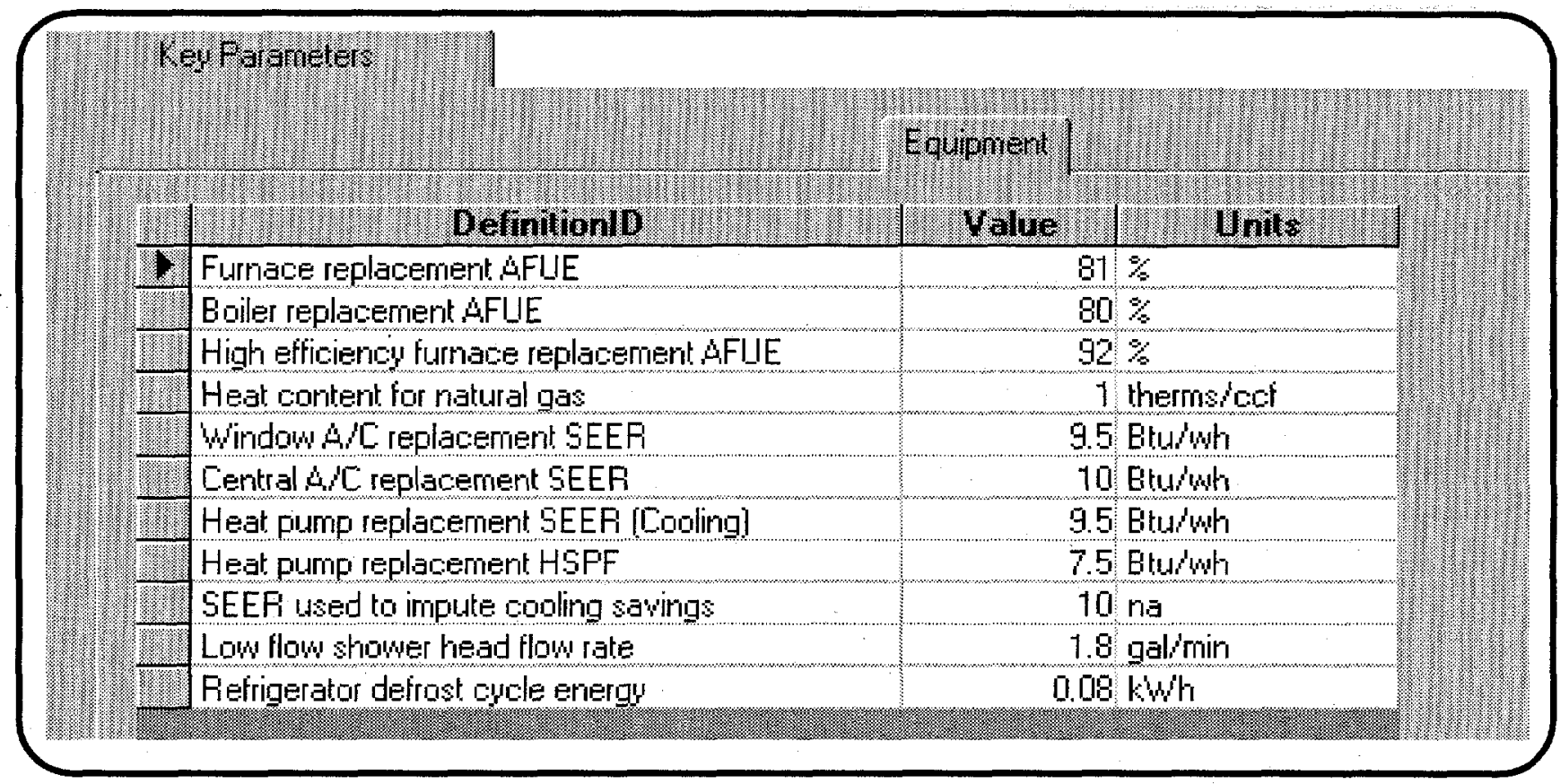

User-Defined Insulation Types

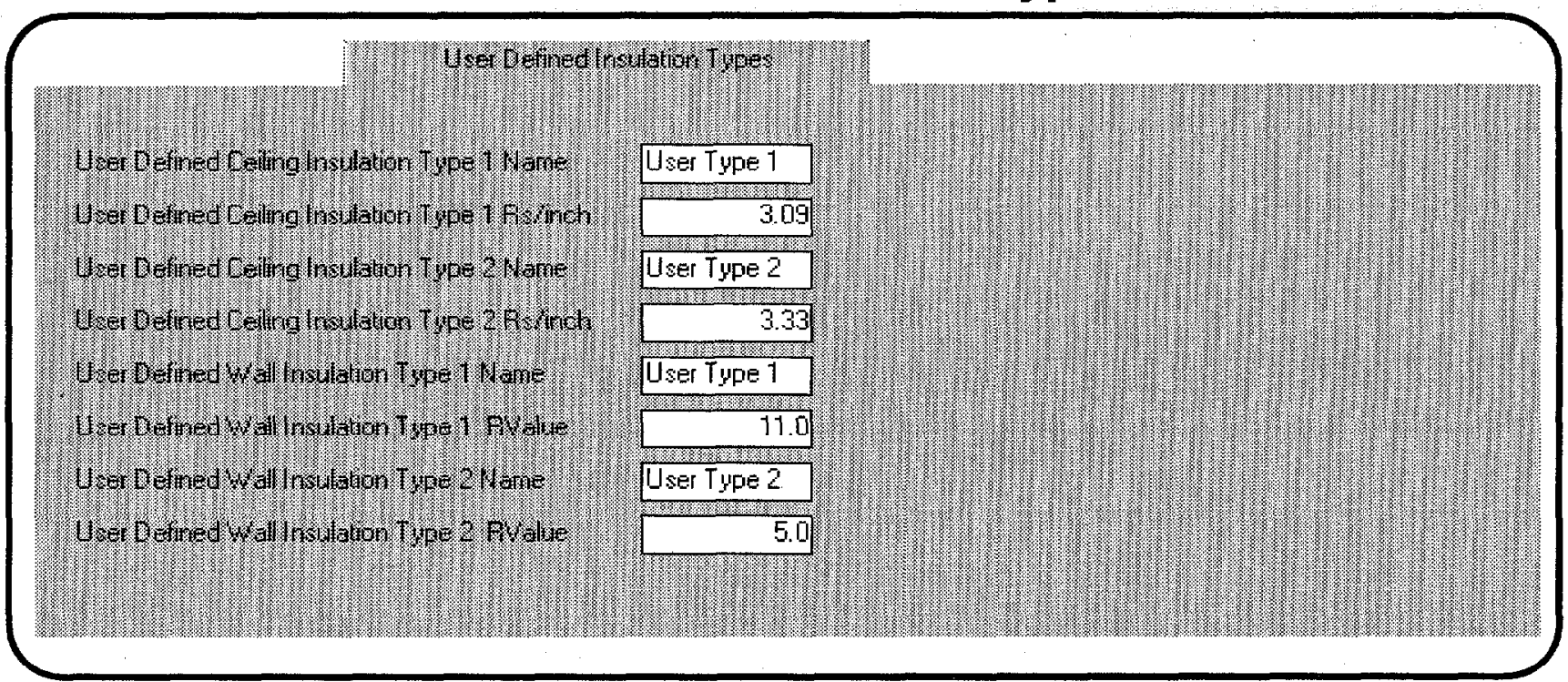




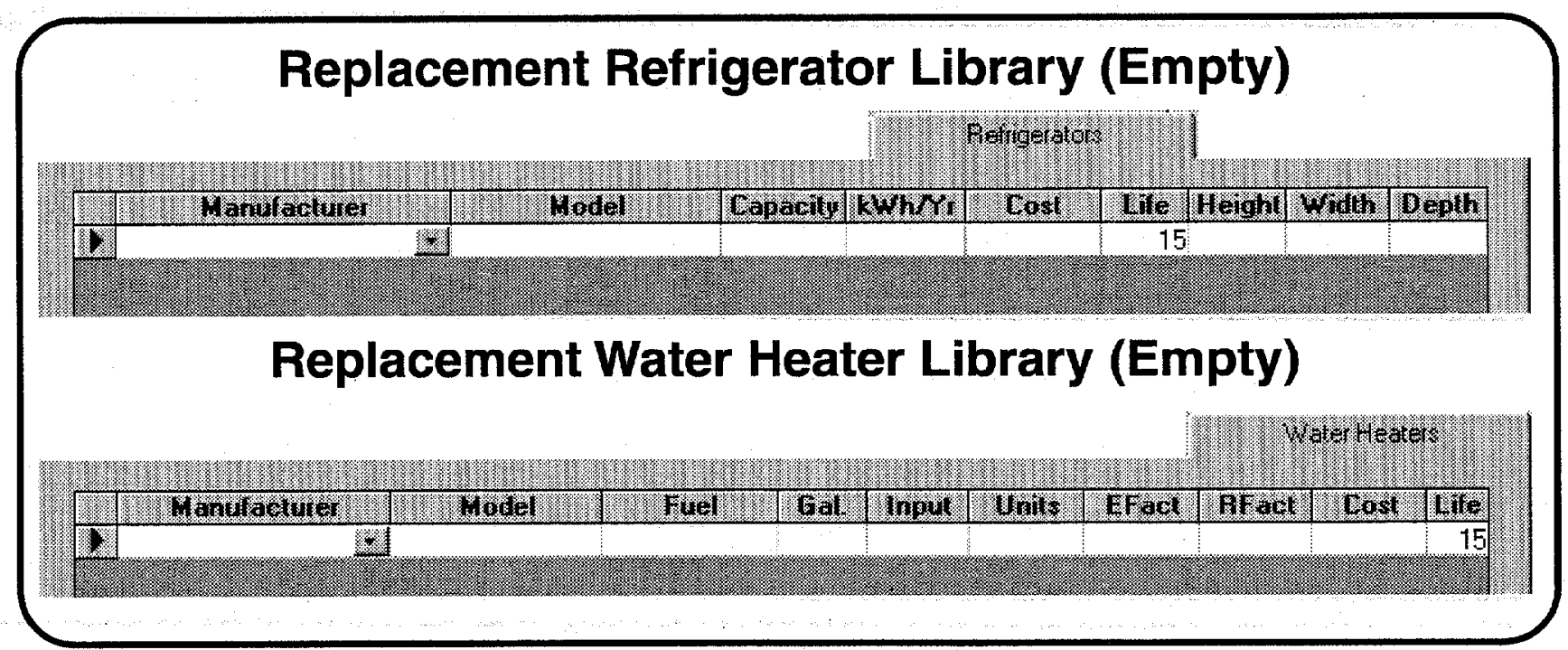





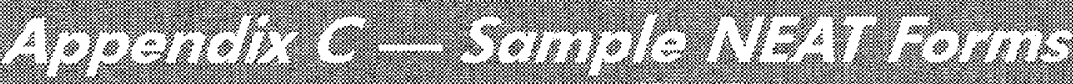

\section{Appendix C}

Here are all NEAT data input forms, presented in the Form View.

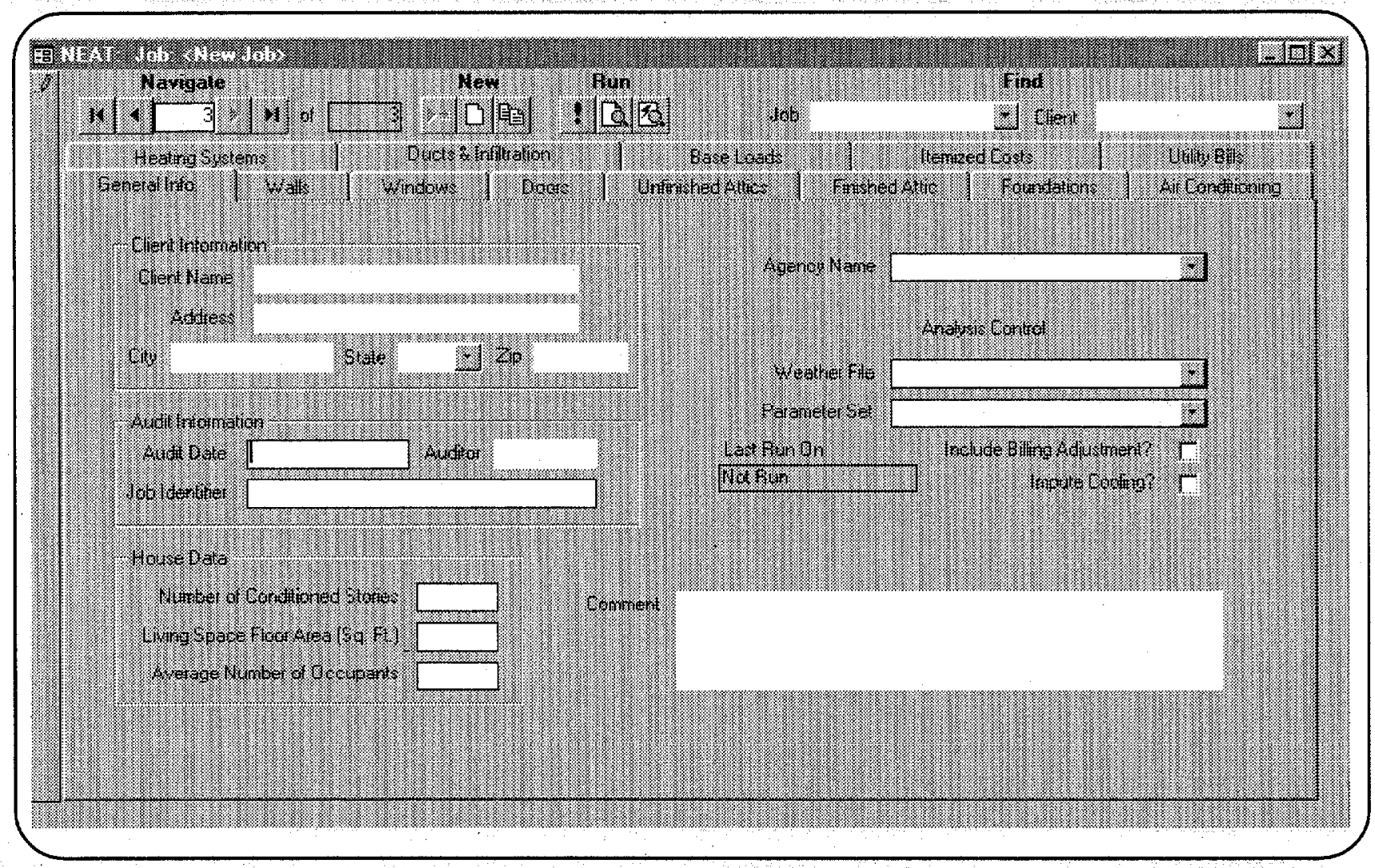




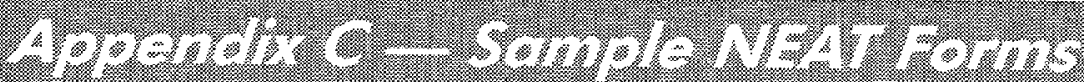
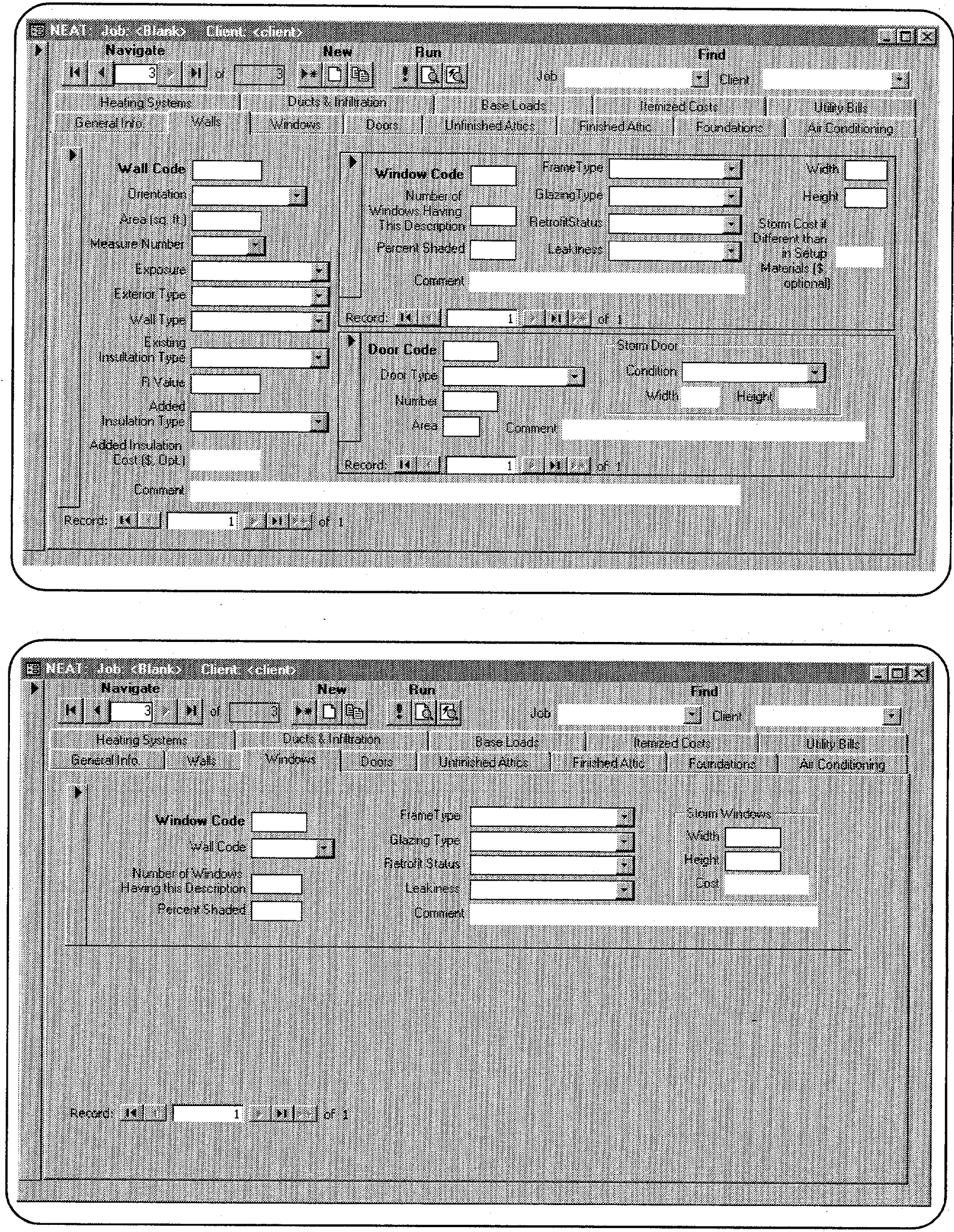


\section{Appentix C-Sompole N BA Forms}
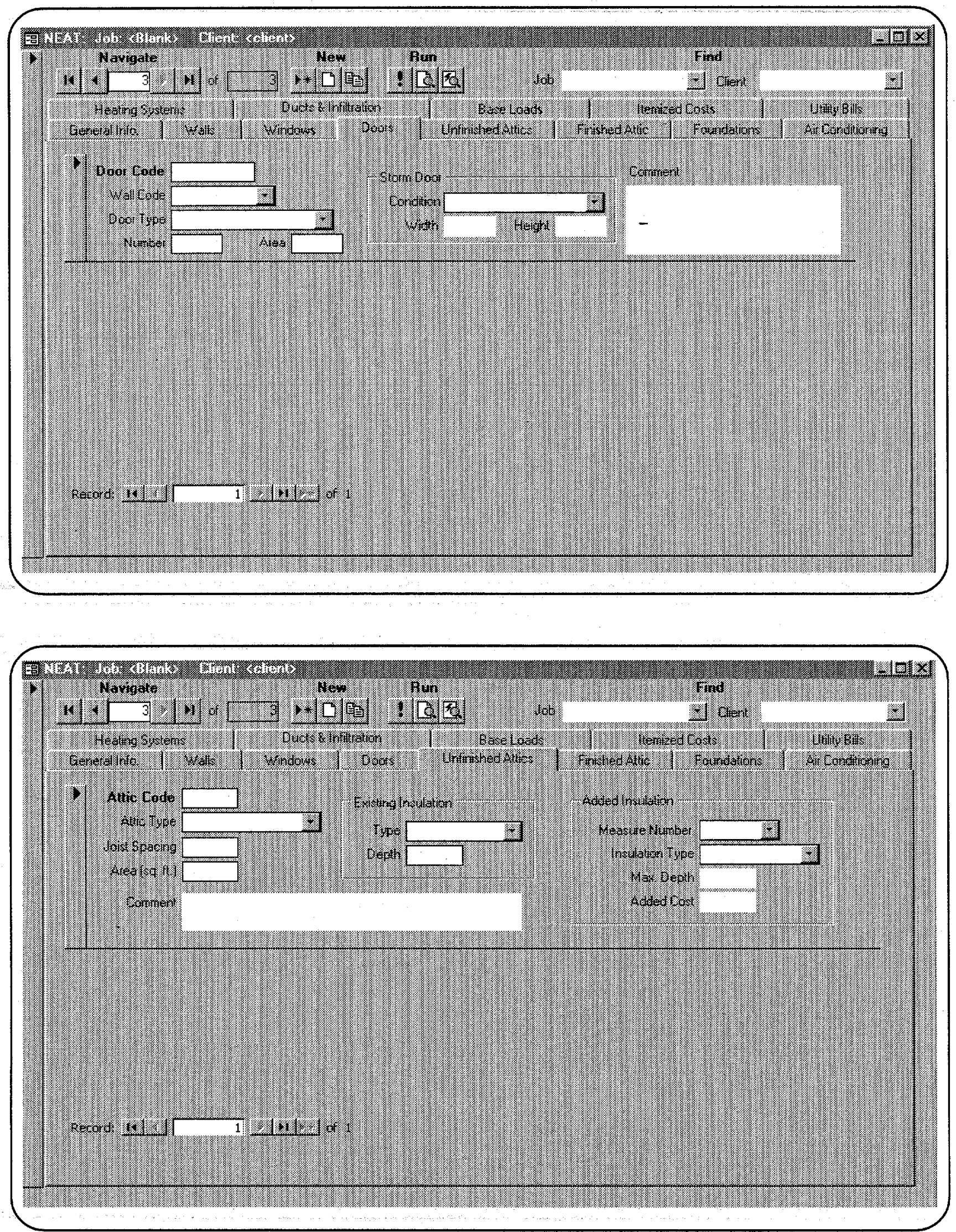


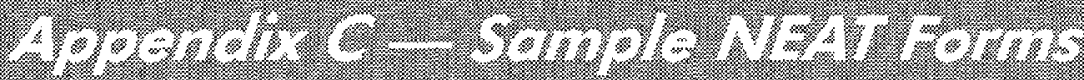
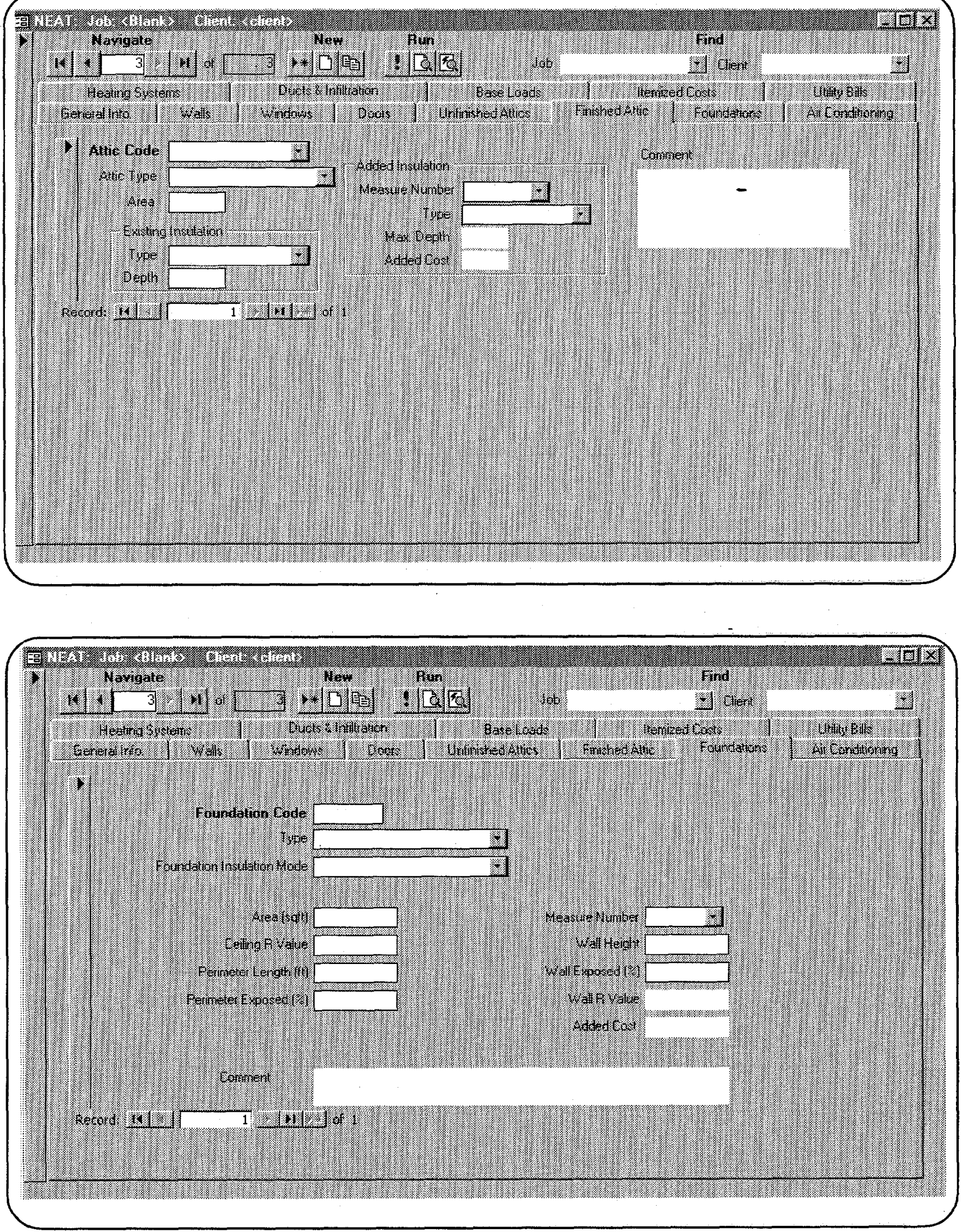


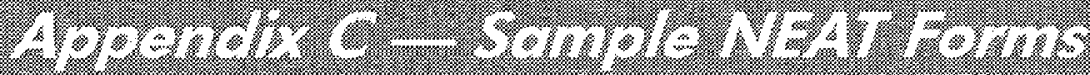
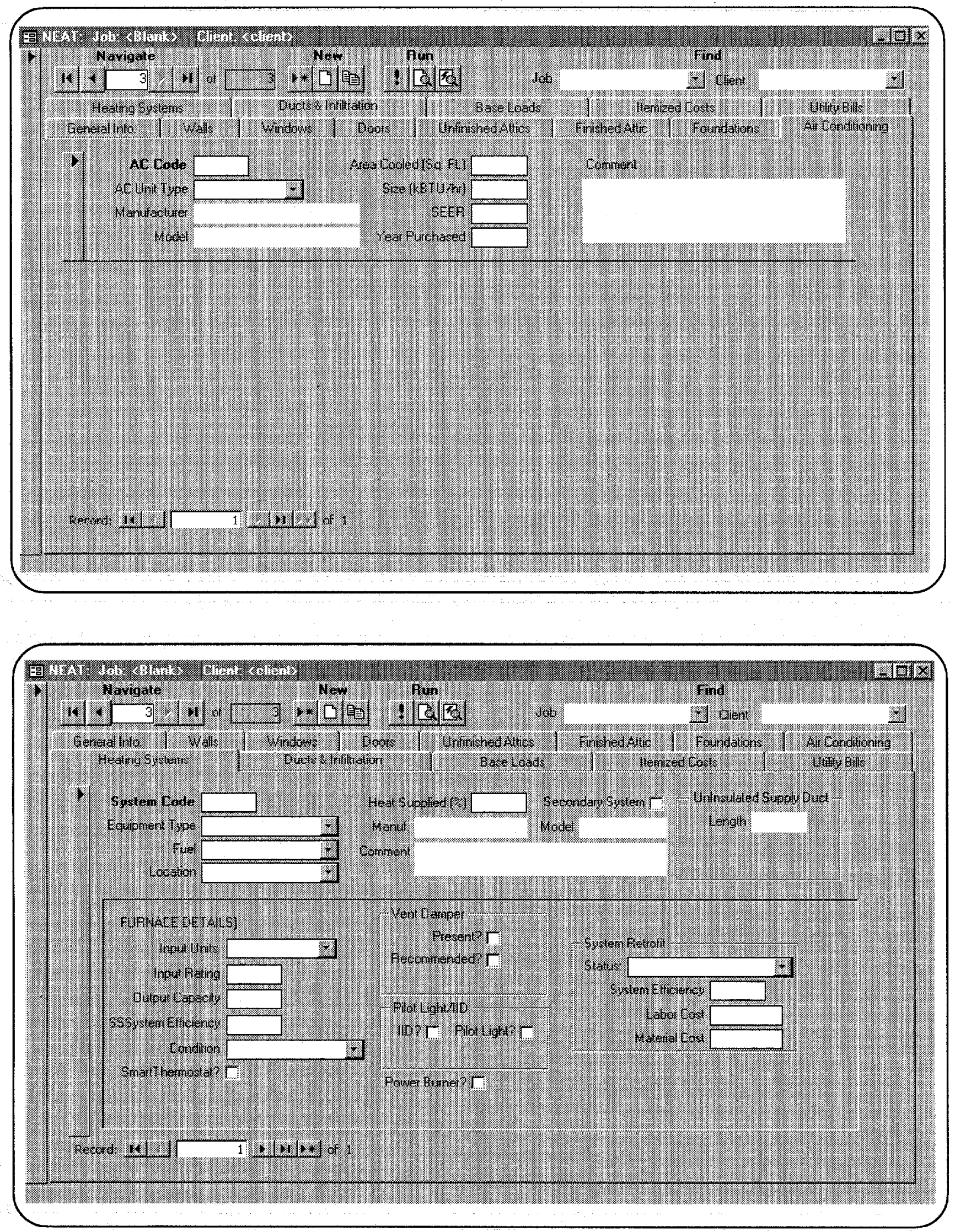

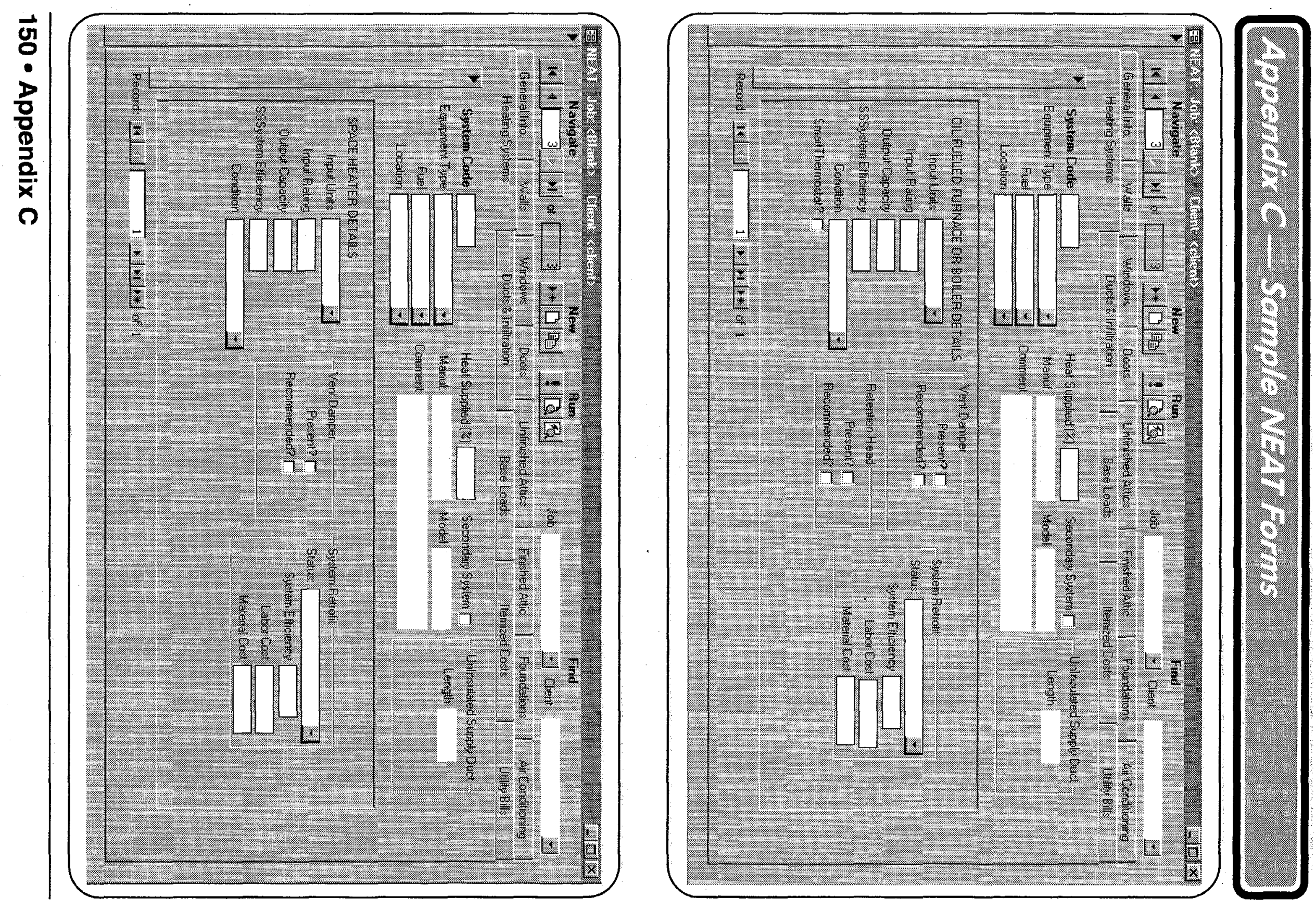

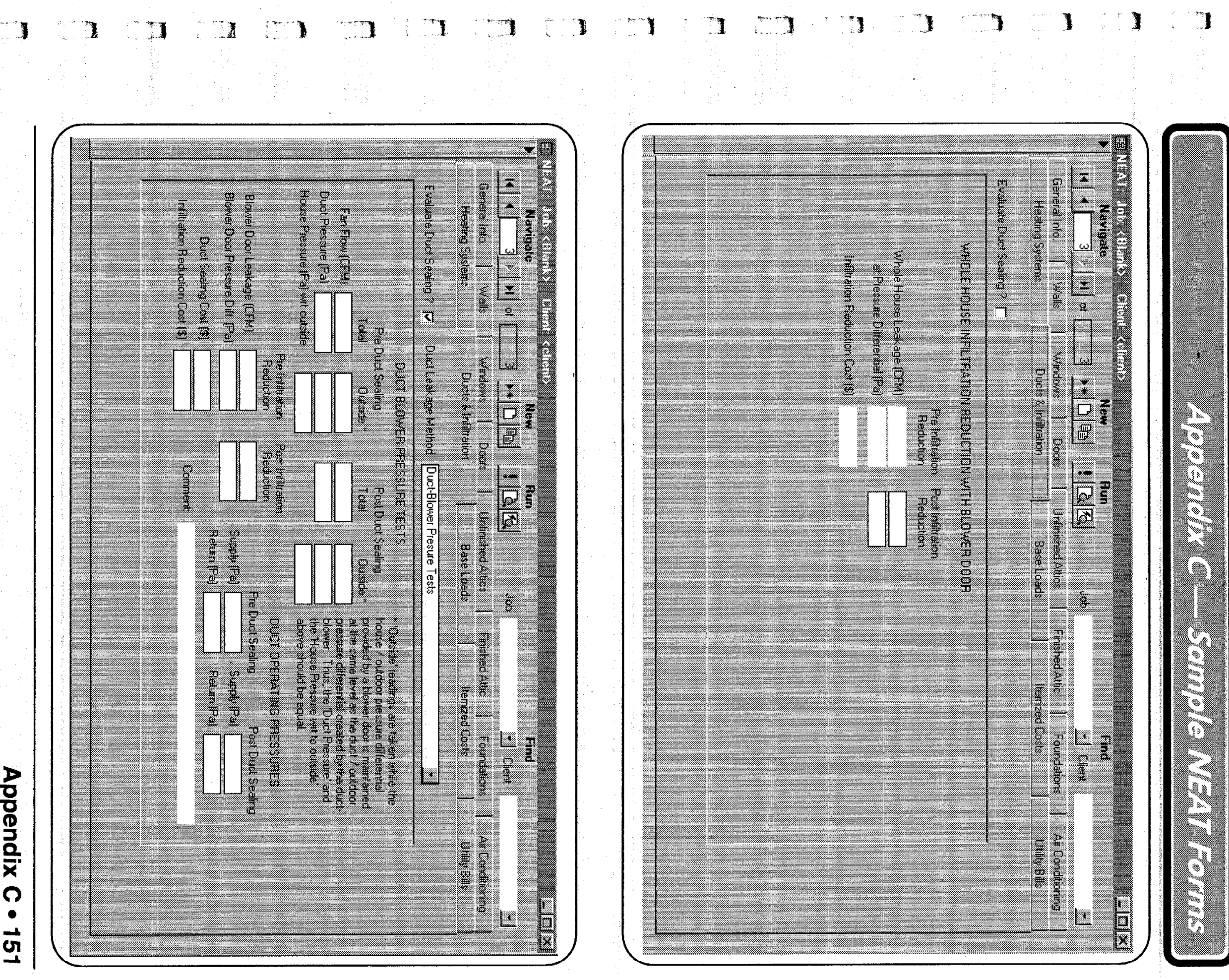


\section{Appendix C-Sample NEAT Forius}
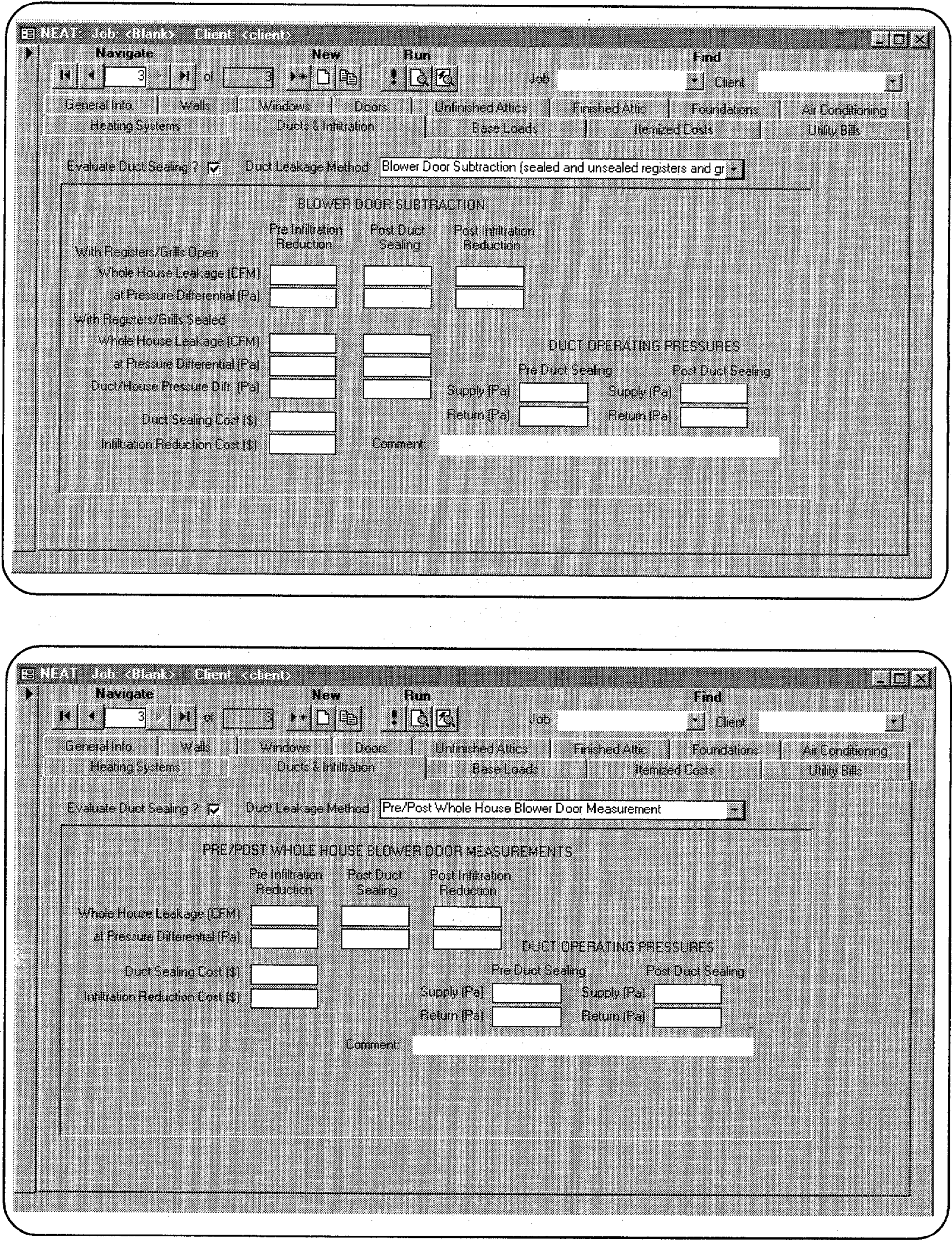


\section{Appendix C-Sample Nat Forms}
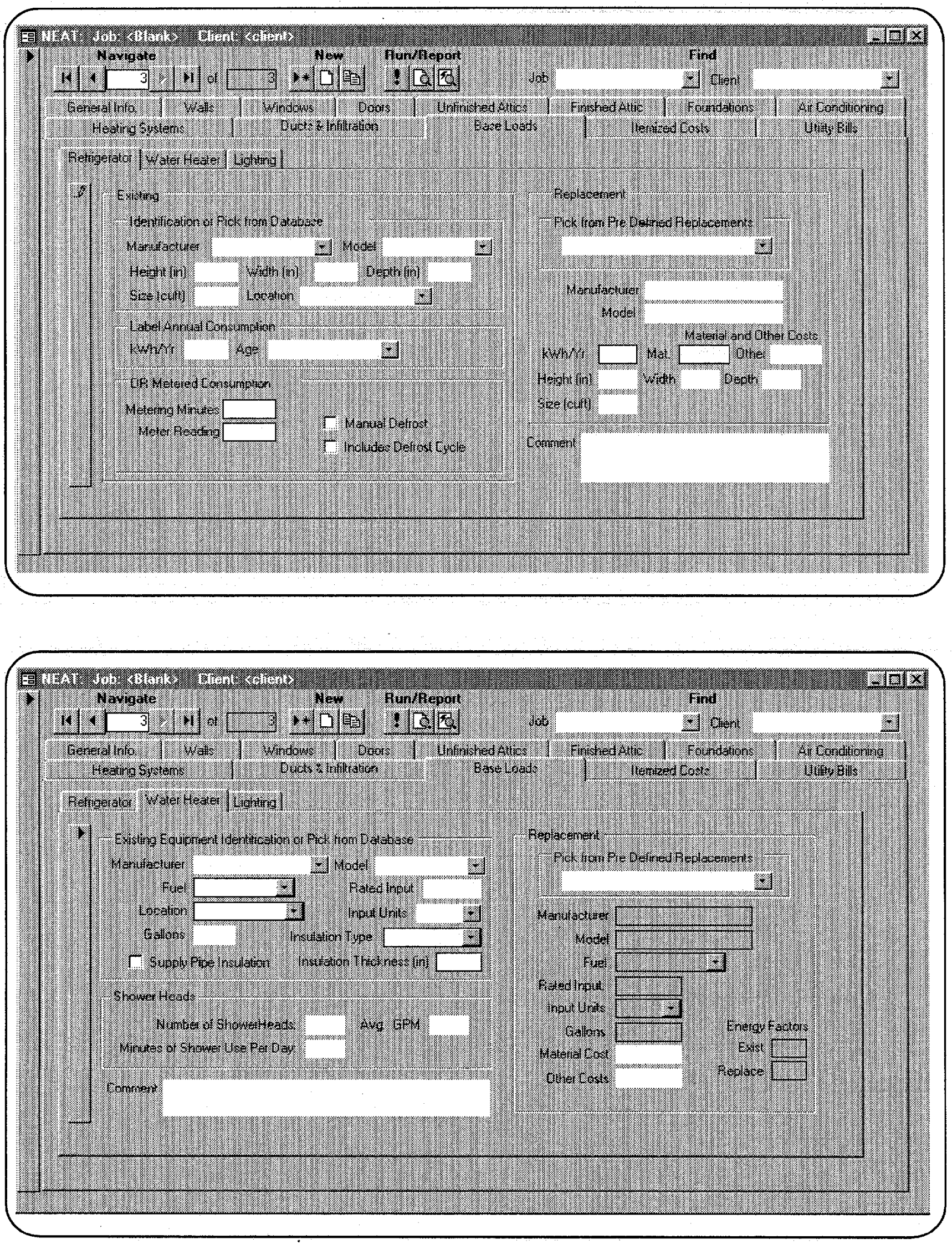


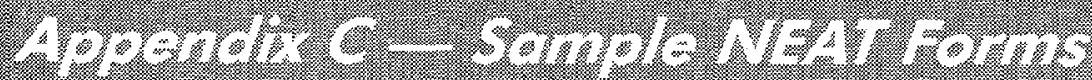
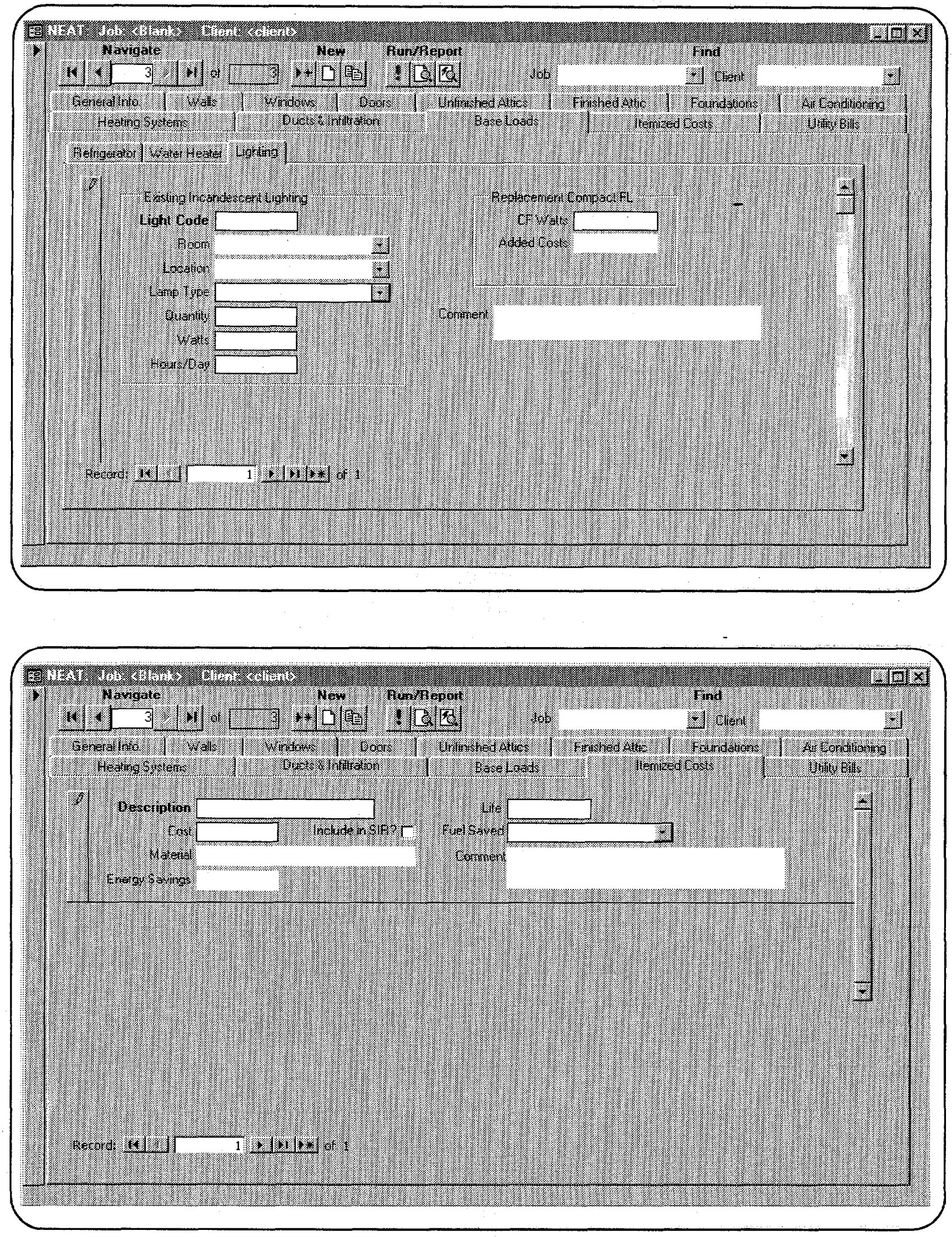


\section{Apoepde C - Sombla NaA Forms.}

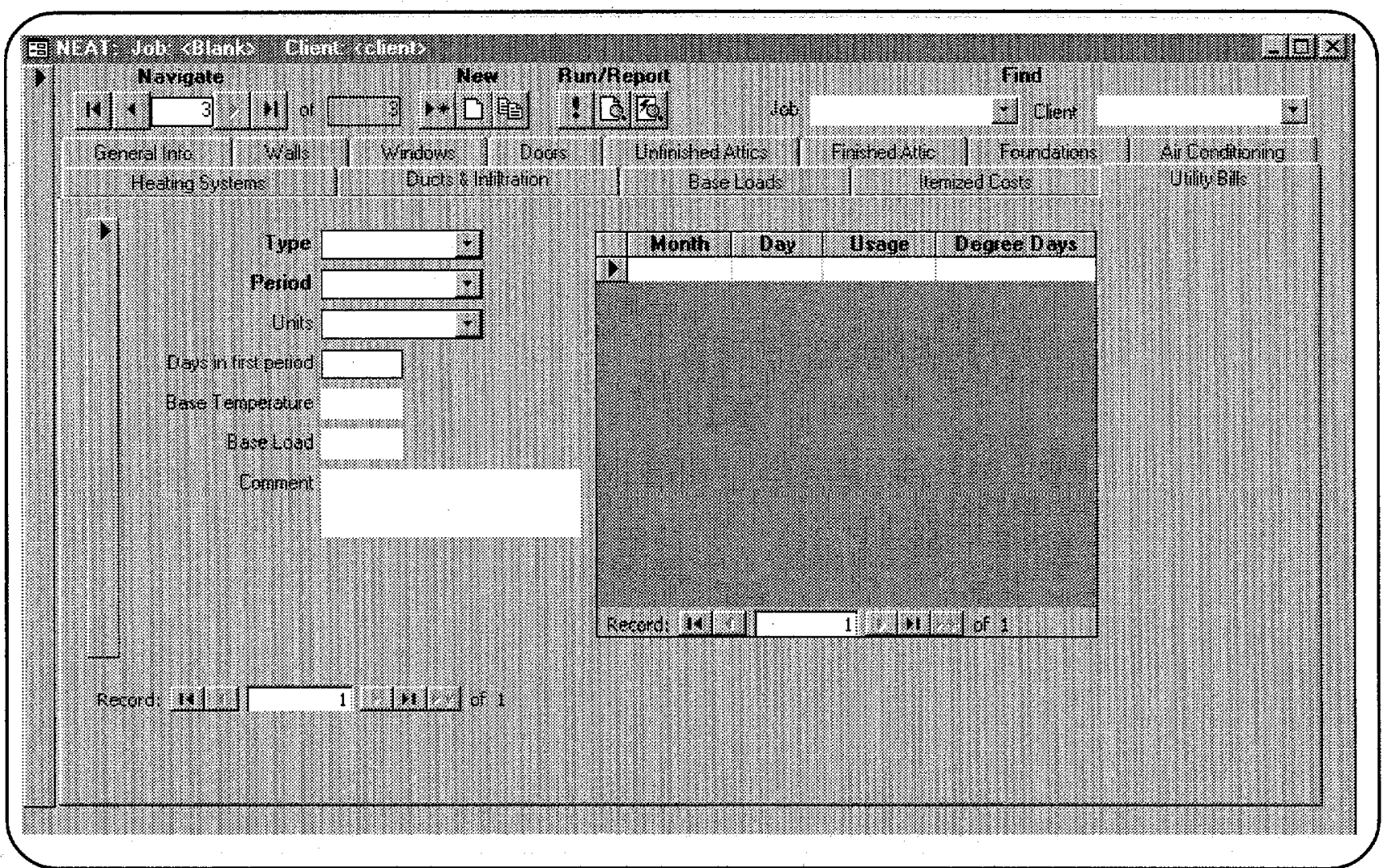




\section{Appendix D}

Here are all the NEAT data sheet view input forms, presented in the order of a typical audit. To see how these forms are completed, refer to Appendix A, Audit Example. Columns with shaded description are optional.

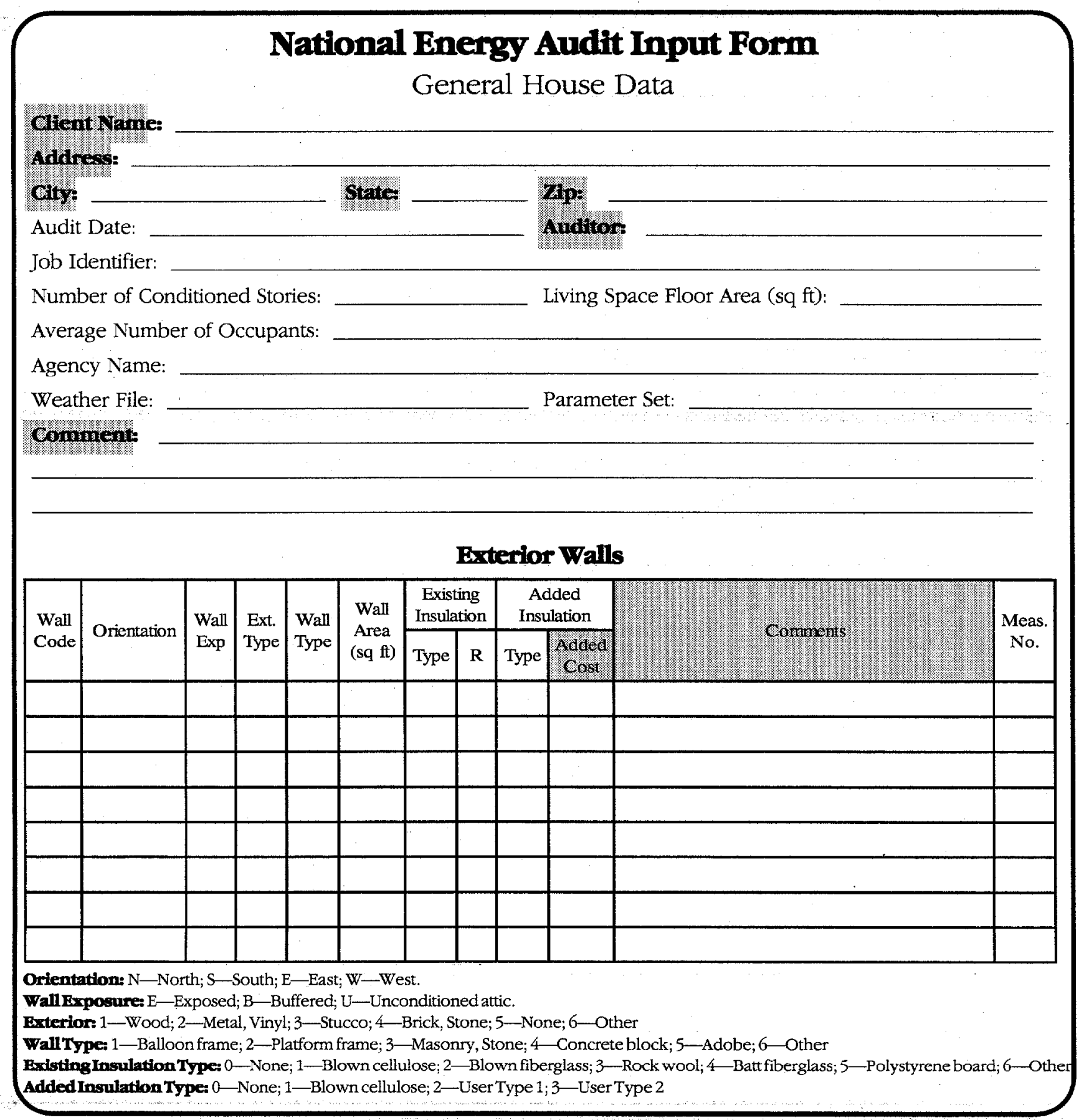




\section{National Energy Audit Input Form (Continued)}

Windows

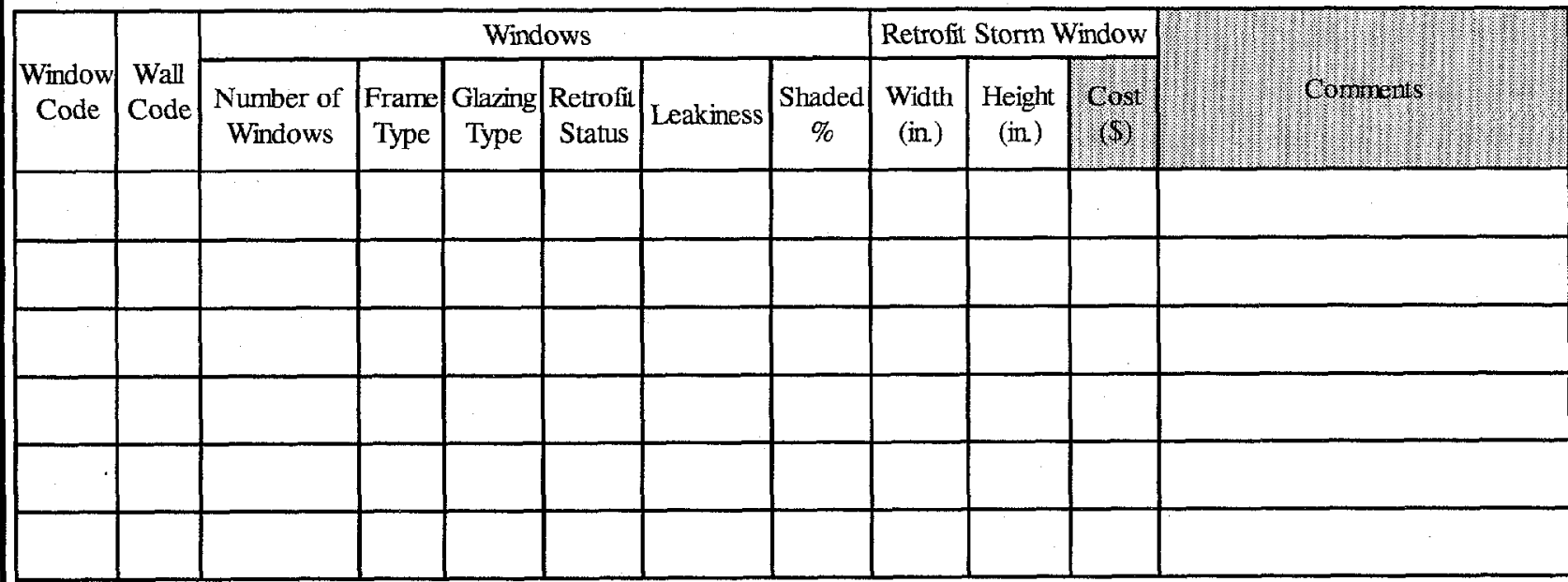

Frame Type: 1-Wood, Vinyl; 2-Metal; 3-Improved metal

Glaxing Type: 1 -Single; 2 - Single with wood storm; 3-Single with metal storm; 4-Double pane; 5--Single with bad storm

RetrofitStatus: 1-Optional; 2-Weatherize; 3-Replace; 4-Add storm

Leakiness: 1-Very tight; 2-Tight; 3-Medium; 4-Loose; 5-Very loose

Shaded Percentage Example: $20 \%$-Eaves; $100 \%$-Porch

Retrofit Storm Window Cost: If other than default cost

Note: "Wall Code" is keyed to sketch of floor plan

\section{Doors}

\begin{tabular}{|c|c|c|c|c|c|c|c|c|}
\hline \multirow[b]{2}{*}{$\begin{array}{l}\text { Door } \\
\text { Code }\end{array}$} & \multirow[b]{2}{*}{$\begin{array}{l}\text { Wall } \\
\text { Code }\end{array}$} & \multicolumn{3}{|c|}{ Door } & \multicolumn{3}{|c|}{ Storm Door } & \multirow[b]{2}{*}{ Commerus } \\
\hline & & $\begin{array}{l}\text { Door } \\
\text { Type }\end{array}$ & $\begin{array}{c}\text { Number of } \\
\text { Doors }\end{array}$ & $\begin{array}{l}\text { Area } \\
\text { (sq ft) }\end{array}$ & Condition & Wiuls & $\begin{array}{l}\text { Meghin } \\
\text { (nin) }\end{array}$ & \\
\hline & & & & & & & & \\
\hline & & & & & & & & \\
\hline & & & & & & & & \\
\hline & & & & & & & & \\
\hline & & & & & & & & \\
\hline & & & & & & & & \\
\hline
\end{tabular}

Type: 1-Wood, hollow-core; 2-Wood, solid-core; 3 -Steel, insulated; 4 -Single sliding glass; 5-Double sliding glass Door Area: Standard door area is 20 square feet

Condition: 1-Adequate; 2-Deteriorated; 3-None

Note: "Wall Code" is keyed to sketrh of flont plan 


\section{National Energy Audit Input Form (Continued)}

\section{Unfinished Attic Areas}

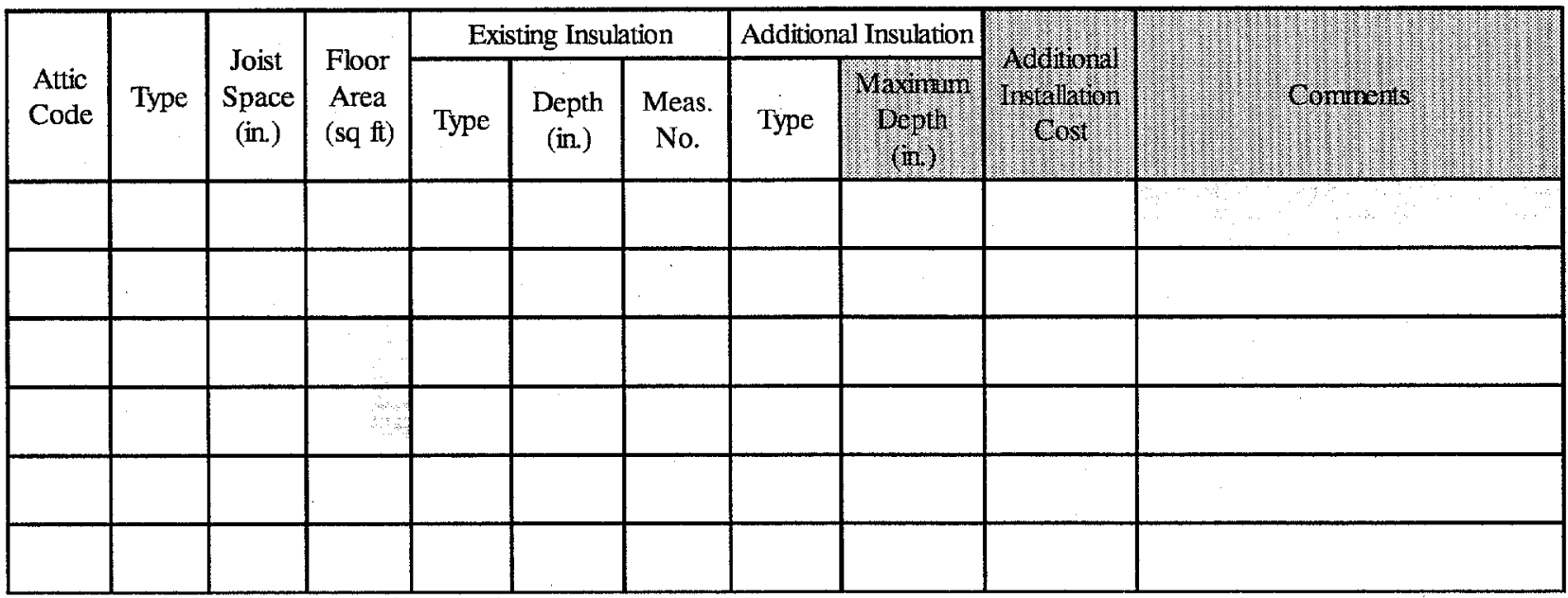

Type: 1-Unfloored; 2-Floored; 3 -Cathedral flat

ExistingInsulation Type (with depth default vahues for existing insulation); 0-None; 1 -Blown cellulose ( 5 in.); 2-Blown fiberglass

(6 in.); 3-Blown rockwool ( 6 in.); 4-Fiberglass batt ( 6 in.); 5 -Other (6 in.)

Additional Insulation Type: 0-None; 1-Blown cellulose; 2-Blown fiberglass; 3-User Type 1; 4 -User Type 2

Maximum Depth: Press "Enter" if unlimited

Note: "Attic Code" is keyed to sketch of floor plan

Finished Attic Areas

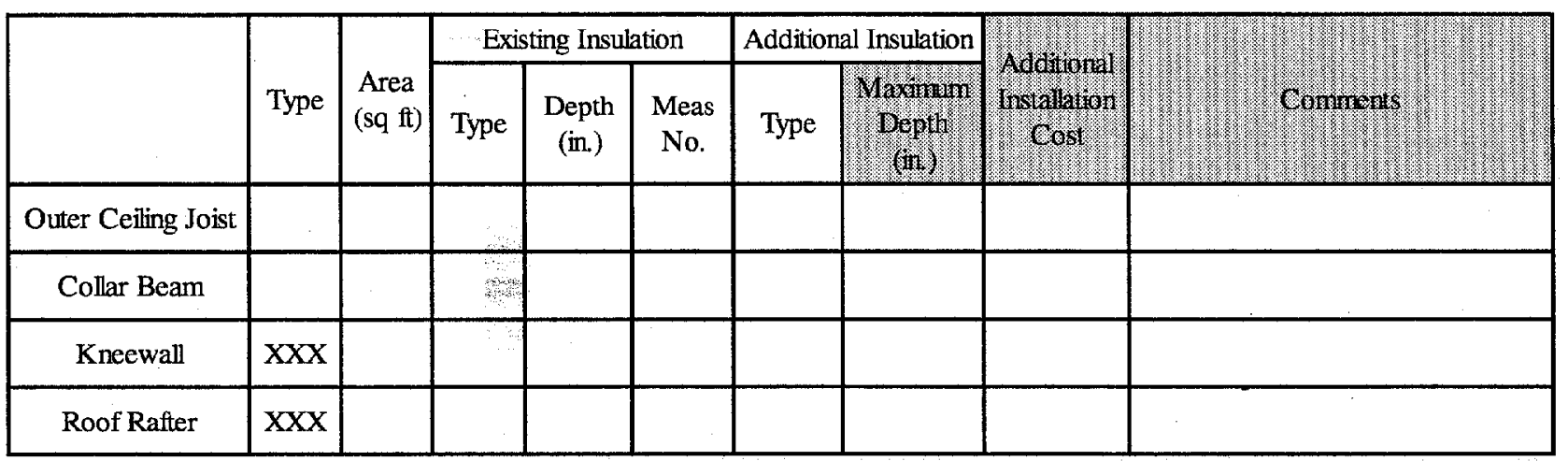

Outer Ceiling Joist, Collar Beam Type: 1-Unfloored; 2 -Floored

Existing Insulation Type 0 -None; 1-Blown cellulose; 2-Blown fiberglass; 3-Blown rockwool; 4-Fiberglass batt; 5-Other

Additional Insulation Type: 0-None; 1-Blown cellulose; 2-Blown fiberglass; 3-User Type 1; 4-User Type 2

Maximum Depth: Press "Enter" if unlimited 


\section{National Energy Audit Input Form (Continued)}

Foundation Spaces

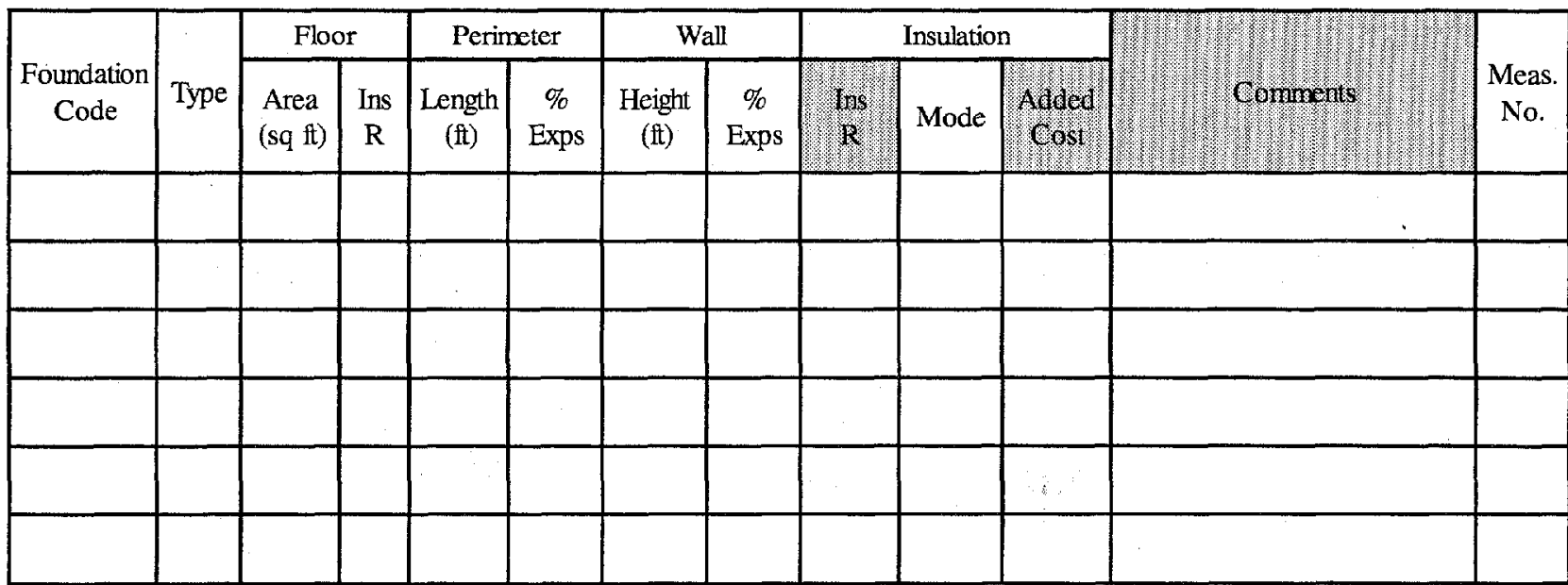

Type: C—Conditioned; $\mathrm{N}-$ Nonconditioned; $\mathrm{V}$-Vented nonconditioned; $\mathrm{U}$ - - Unintentionally conditioned; S-Slab, uninsulated; I-Slab, insulated; E-Exposed floor.

Mode: 0-None; 1-Floor or wall; 2-Floor only; 3-Wall only

Air Conditioners - Central Window

\begin{tabular}{|c|c|c|c|c|c|c|c|c|}
\hline $\begin{array}{c}\text { Unit } \\
\text { Code }\end{array}$ & $\begin{array}{l}\text { Unit } \\
\text { Type }\end{array}$ & Mampracumer & Model & $\begin{array}{c}\text { Area } \\
\text { Cooled }\end{array}$ & $\begin{array}{r}\text { Size } \\
\mathrm{kBtu}\end{array}$ & SEER & $\begin{array}{c}\text { Year } \\
\text { Bought }\end{array}$ & cuminets \\
\hline & & & & & & & & \\
\hline & & & & & & & & \\
\hline & & & & & & & & \\
\hline 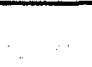 & & & & & & & & \\
\hline & & & & & & & & \\
\hline & & & & & & & & \\
\hline
\end{tabular}

Unit Type: 1 -Central; 2-Window; 3-Heat pump; 4-Evaporative

SERR/EER: Enter if known. Otherwise press enter and give approximate year purchased in the next field 


\section{National Energy Audit Input Form (Continued)}

\section{Heating Systems}

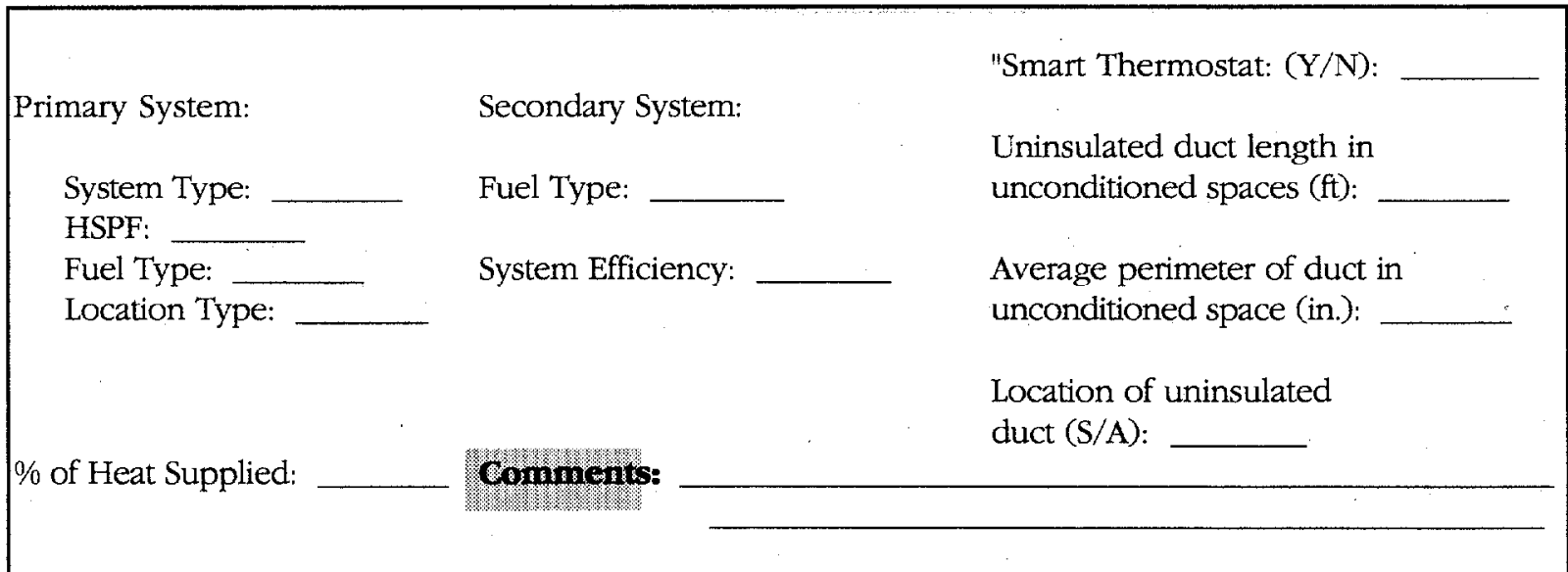

EquipmentType: 1-Gravity furnace; 2-Forced-air furnace; 3-Steam boiler; 4-Hot water boiler; 5 -Electric resistance, fixed; 6-Electric resistance, portable; 7-Heat pump; 8-Vented space heater; 9-Unvented space heater; 0-Other Fuel: 1-Natural gas; 2-Oil; 3-Electricity; 4-Propane; 5-Wood; 6-Coal; 7-Kerosene

Location: 1 -Intentionally heated; 2 - Unheated; 3 - Unintentionally heated

Location of duct: A-Attic; S-Subspace

Note: Use the appropriate form depending on the fuel type and heating system type

\section{(3)}

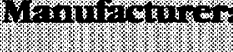

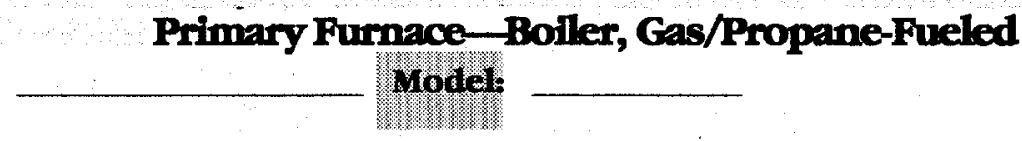

Input Rating $(\mathrm{kBtu} / \mathrm{h})$ :

Output Capacity $(\mathrm{kBtu} / \mathrm{h})$

Steady-State Efficiency $(\%)$ :

Pilot Light: Present?

$(\mathrm{Y} / \mathrm{N})$

On in summer?

$(\mathrm{Y} / \mathrm{N})$

IID Present? $(\mathrm{Y} / \mathrm{N})$

Power burner present? $(\mathrm{Y} / \mathrm{N})$

Vent Damper: Present? $(\mathrm{Y} / \mathrm{N})$

Recommended? $(\mathrm{Y} / \mathrm{N})$

Diameter (in.)

General Condition:

Tuneup/Replacement Status:

Estimated Replacement Costs:

Labor

Equipment

\section{Comintos to:}

Input Units: See same entry on next screen

GeneralCondition: 1-Poor; 2-Fair; 3-Good

System Tuneup/ReplacementStatus: 1-Tuneup/replacement optional; 2-Tuneup already performed; 3-Tuneup mandatory;

4-Replacement mandatory; 5-High efficiency replacement mandatory

Note: Enter estimated replacement costs. Default values are from setup. 


\section{National Energy Audit Input Form (Continued)}

Manufactirer:

\section{Space Heaters/Other Systems}

\section{Mrodel:}

Input Rating Units:

Value:

Output Capacity $(\mathrm{kBtu} / \mathrm{h})$ :

Steady-State Efficiency (\%):

Vent:Damper: Present?

(Y/N) Recommended?

$(\mathrm{Y} / \mathrm{N}) \quad$ Diameter (in.)

General Condition:

Tuneup/Replacement Status:

System Replacement: Labor Cost

Equipment Cost

SS Efficiency (\%)

\section{Comments:}

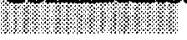

Input Units: $0-$ No input; $1-\mathrm{kBtu} / \mathrm{h} ; 2-\mathrm{gal} / \mathrm{h} ; 3-\mathrm{lb} / \mathrm{h} ; 4-\mathrm{ccm}$

GeneralCondition: 1-Poor; 2-Fair; 3-Good

SystemTuneup/ReplacementStatus: 1-Tuneup/replacement optional; 2-Tuneup already perfurmed; 3-Tuneup mandatory;

4-Replacement mandatory

Note: Enter estimated replacement costs if different from default value

12.0

Manufacturer:

Input Rating Units:

Steady-State Efficiency (\%):

Vent Damper: Present?

$(\mathrm{Y} / \mathrm{N}) \quad$ Recommended?

$(\mathrm{Y} / \mathrm{N}) \quad$ Diameter (in.)

Burner: Flame Retention Head Present?

$(\mathrm{Y} / \mathrm{N})$ Recommended?

$(\mathrm{Y} / \mathrm{N})$

General Condition:

Tuneup/Replacement Status:

Estimated Replacement Costs: Labor

Equipment Cost

\section{Comments:}

(2)

Input Units: $0-N o$ input; $1-\mathrm{kBtu} / \mathrm{h} ; 2-\mathrm{gal} / \mathrm{h} ; 3-\mathrm{lb} / \mathrm{h} ; 4-\mathrm{cm}$

GeneralCondition: 1-Poor; 2-Fair; 3 - Good

System Tuncup/ReplacementStatus: 1-Tuneup/replacement optional; 2-Tuneup already performed; 3-Tuneup mandatory;

4-Replacement mandatory

Note: Enter estimated replacement costs if different from default value 


\section{National Energy Audit Input Form (Continued)}

\section{Ducts and Infiltration}

Use sample NEAT Forms in Appendix C

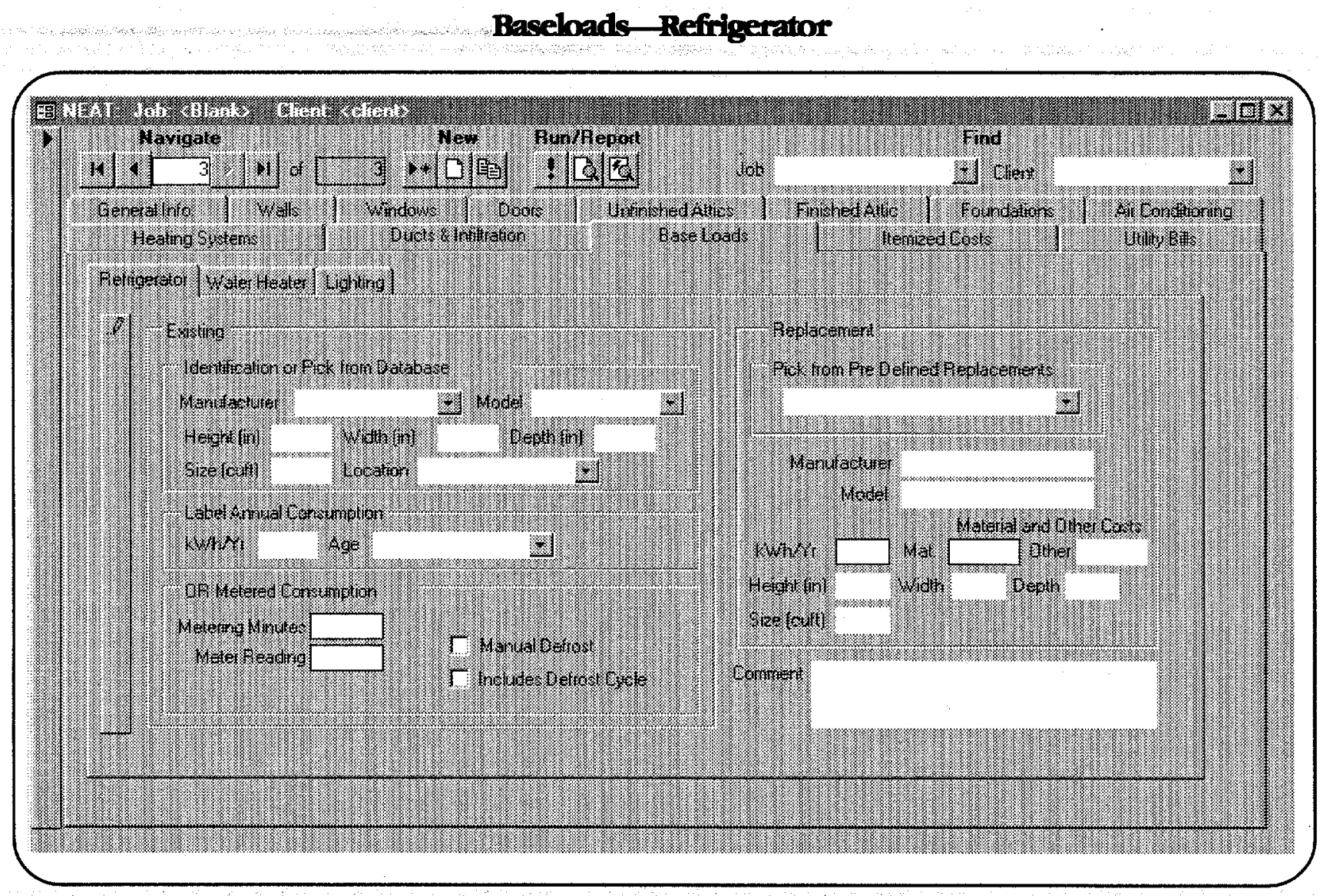

Location: 1-Heated space; 2 - Unheated space; 3 -Unintentionally heated space

Age: Less than 5 years; 5 to 10 years; 10 to 15 years; More than 15 years 


\section{National Energy Audit Input Form (Continued)}

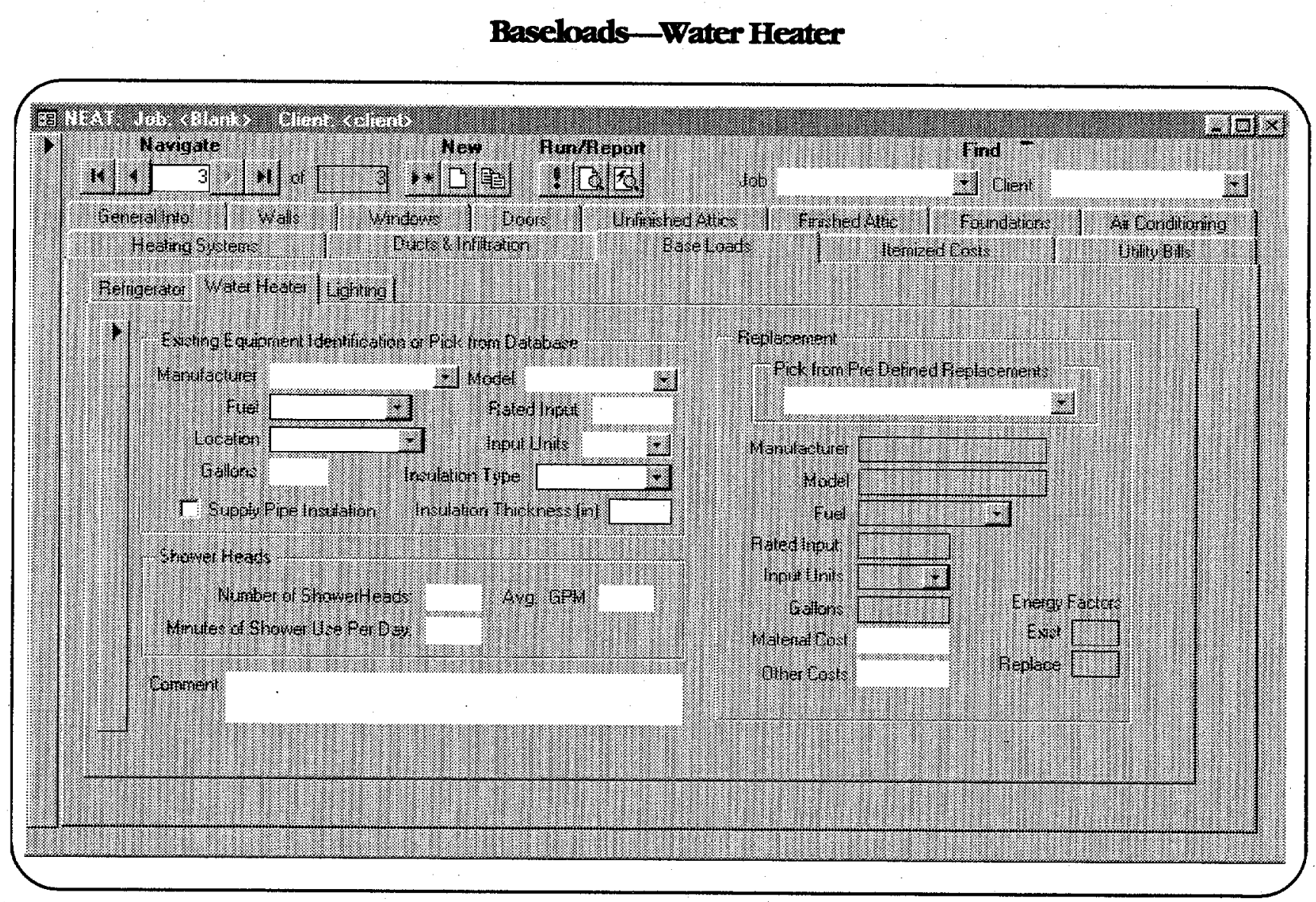

Fuel: 1-Natural gas; 2-Electric; 3-Propane

Location: 1- Heated space; 2-Unheated space; 3-Unintentionally heated space

Input Units: 1-kBtu; $2-\mathrm{kW}$

Insulation Type: 1-Fiberglass; 2-Polyurethane 


\section{National Energy Audit Input Form (Continued)}

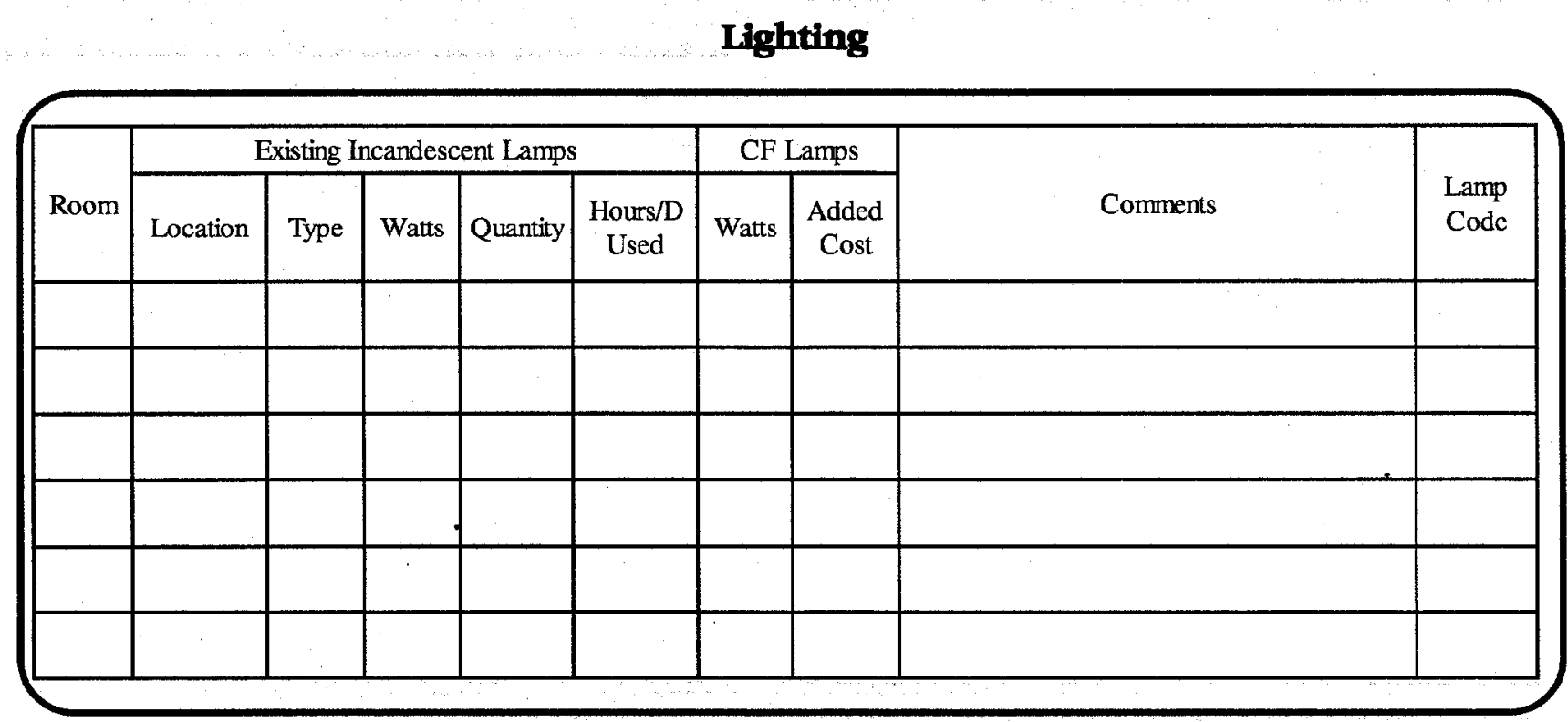

Room: F-Family room; K-Kitchen; L-Living room; R-Rec room; D-Dining; B-Bedroom; U-Utility; O-Other Location: C-Ceiling; F-Flor; T-Table; W-Wall

Type S-Standard; F-Flood

\section{Itemized Additional Costs and User Defined Measures}

\begin{tabular}{|l|l|l|l|l|l|l|}
\hline $\begin{array}{c}\text { Item Description or } \\
\text { User-Defined } \\
\text { Measure Name }\end{array}$ & $\begin{array}{c}\text { Cost } \\
(\$)\end{array}$ & $\begin{array}{c}\text { Incl in } \\
\text { SIR }\end{array}$ & Materials Required & $\begin{array}{c}\text { Annual Savings } \\
\text { (MBtu) }\end{array}$ & Fuel Saved & $\begin{array}{c}\text { Life-Time } \\
\text { (years) }\end{array}$ \\
\hline & & & & & & \\
\hline & & & & & & \\
\hline & & & & & & \\
\hline & & & & & & \\
\hline & & & & & & \\
\hline
\end{tabular}

Fuelsaved: 1-Natural gas; 2-Oil; 3-Electricity; 4 -Propane; 5-Wood; 6-Coal; 7-Kerosene 


\section{National Energy Audit Input Form (Continued)}

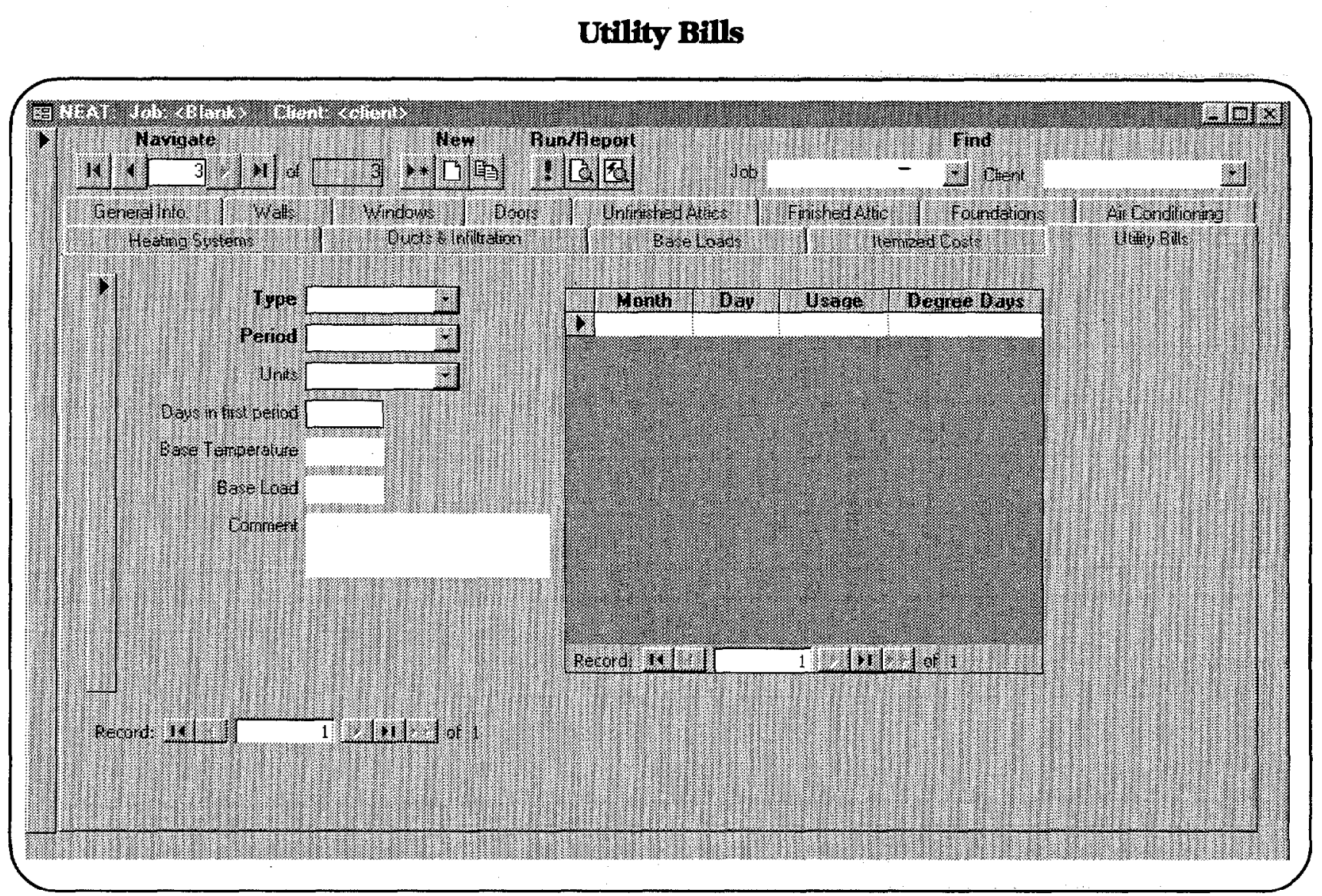

Type: 1-Heating; 2 -Cooling

Period: 1-Pre-Retrofit; 2-Post-Retrofit

Units: 1-Therms; 2-kWh 
Audit - The process of identifying energy conservation opportunities in houses. As used here, NEAT audit means a computer selection technique which optimizes the Savings-to-Investment Ratio of various energy conservation measures.

Auditor-A person who performs an audit.

Balance point-For heating, the balance point is the outside temperature above which no heating is needed. For cooling, the balance point is the outside temperature below which no cooling is needed.

Band joist-A horizontal framing member resting on top of the foundation.

Base temperature - Base temperature is the outdoor temperature below which heating or above which cooling systems are used. Assume a base temperature of $65^{\circ} \mathrm{F}$ for HDD's and $78^{\circ} \mathrm{F}$ for CDD's, unless a different base temperature is listed on the utility bill.

Boot-The process of turning on or re-initializing a computer.

British thermal unit - The quantity of heat required to raise one pound of water one degree Fahrenheit.

Buffered - A wall which is protected by an unconditioned, attached enclosurelike a garage or an enclosed porch.

Building description-Information used to describe the house to NEAT.

Btu-Acronym for British thermal unit.

Cof-One hundred cubic feet (usually natural gas).

CDD_Acronym for Cooling Degree Day.

Ccm-Cubic centimeter per minute. Refers to fluid flow.

Cfim-Cubic feet per minute.

Ceilling joist-The horizontal wood framing member that holds up the ceiling (see outer ceiling joist).

Character - A single digit, letter or symbol. 
Check Box-A small white box on a screen form which allows you to select yes or no in response to a specific condition. A check in the box indicates a "Yes" response. Checks are added or removed by clicking the mouse on the box.

Code-Abbreviated names composed of a four or less group of letters and/or numbers that identify a particular component of a house on the NEAT data entry screens. NEAT uses the codes to cross reference input screens and indicate what components are to receive specific energy conservation measures.

Collar beam-A horizontal piece of lumber that ties the rafters together near the peak of the roof, and forms the ceiling for a section of a finished attic.

Combustion tester-A device used to analyze the steady-state efficiency of combustion heating units.

Combo-Box-A control used to enter information into NEAT which allows you to select one of several prescribed responses.

Component-A segment of a building normally described by a single line within the NEAT building description data input, having sufficiently uniform construction and orientation to be considered as a single unit (for example, a portion of a house's exterior walls facing the same direction with similar construction and retrofit potential).

Conditioned - Intentionally heated or cooled areas of the home are conditioned.

Cooling degree day (CDD)-During a 24 hour period, each degree that the average daily temperature is above the base temperature (usually $78^{\circ} \mathrm{F}$ ) constitutes one cooling degree day unit.

Cost-effective-Having an acceptable Savings-to-Investment Ratio to the person using the term. The standards for cost-effectiveness vary.

Cursor-A flashing line or rectangle on the computer screen that tells you where a letter, number or space will appear when you next strike a key.

Cumulative-Including all previously identified items or items higher on the list.

Datasheet View-A format of data entry similar to a spread sheet. All fields for a given item of requested information from all records of a given component type are in the same column in the spreadsheet. Horizontal scrolling may be necessary to view all data items associated with a given record.

Default-A choice made by the computer representing a typical value of the number in question. 
Directory-(See "sub-directory.") A named collection of files grouped together for convenience of the computer user in finding and accessing the files. A root directory is named by the drive (for example, c: or a:).

Discount rate-The percent by which a dollar today is worth more than a dollar one year from today. For example, when you put money into a 5 percent savings account, you are agreeing that today's dollar is worth a dollar and five cents of next year's currency.

Disk-The physical devices on which information (files) are stored on the computer. Two broad types exist: 1. Hard disks, integral parts of the computer itself; 2. Floppy disks (or diskettes), which are portable and may be transferred from one computer to another. Floppy disks are either $51 / 4$ in. or $31 / 2$ in. in size.

Disk Operating System (DOS)-The Disk Operating System is the software that controls the operation of the computer, and is normally included with the computer purchase.

Draft diverter-A device located in exhaust pipes, used to prevent outside air from flowing into the pipe.

DOS-Acronym for Disk Operating System.

ERR-Acronym for Energy Efficiency Ratio.

Electric damper-See "vent damper."

Energy cost escalation rate-The energy cost escalation rate is the federal government's best guess of how much energy costs will increase above the rate of inflation from one year to another.

Energy efficiency ratio (EER) - A measurement of energy efficiency for room air conditioners. The EER is computed by dividing cooling capacity-measured in British Thermal Units per hour $(\mathrm{Btu} / \mathrm{h})$-by the watts of power used. This is a steady-state efficiency.

Envelope - The physical boundary of a building (i.e., wall, roof) which encloses the interior space.

Exposed - In the context of NEAT "exposed" means that a building component is in direct contact with the outside air.

Field-An entry blank on the screen used for data entry or comments. 
File-A collection of information stored in the computer, referenced by a "file name" normally selected by the user. Examples of information stored in files include a letter, a report, data, or instructions for the computer to perform a specific function.

Flame retention head oil burner (FRHOB)-A modern, improved efficiency oil burner that burns the oil more completcly through enhanced mixing of the oil particles with air.

Floor joist-The framing members (often $2 \times 8$ lumber) which support the floor.

Floppy disk-See "disk."

Form-A computer screen containing information you enter describing a particular component of a house, such as a wall or furnace.

Form View-A format of data entry which allows you to see and edit all of the information for a particular record. Data entry controls may be arranged or grouped in ways which contribute to your understanding of the information requested.

FRHOB - Acronym for Flame Retention Head Oil Burner.

Hard disk-See "disk."

Heat anticipator-A device located in a thermostat which can be adjusted to prevent overshooting the desired thermostatic set point.

Heating degree day (HDD) - During a 24 hour period, each degree that the average daily temperature is below the base temperature (usually $65^{\circ} \mathrm{F}$ ) constitutes one heating degree day unit.

HDD - Acronym for Heating Degree Day.

IID-Acronym for Intermittent Ignition Device.

Infiltration-Air leakage in or out of a building under natural conditions rather than under artificial pressurization by a blower door.

Input rating - The rate of the fuel's theoretically available energy the furnace, boiler, or space heater is capable of receiving (kBtu/hour; gal/hour; lb/hour; $\mathrm{ccm}$ ).

Intermittent ignition device (IID) - A device that automatically ignites the gas burner on a gas heater only when the thermostat calls for heat, thus saving the energy that a continuous pilot light consumes. 
Job Identifier-A string of 50 or less typed characters you enter on the General Information screen that uniquely identifies a building description (house) to you and the computer. It may include symbols and spaces.

Joist-A horizontal, wooden framing member supporting a floor or ceiling.

Kilowatt-hour - A unit of energy (usually in reference to electricity).

Kneewall - A short wall that separates the unconditioned part of a finished attic from the conditioned part. The kneewall borders the floor and sloping ceiling.

Low-E window-A multi-pane window with a metalized coating on one of the interior surfaces. Low-E windows save energy during the winter by reflecting heat rays originating in the house back indoors. During the summer, low-E windows reflect solar heat outdoors. Low-E windows have a higher R-value than standard windows.

Measure number-Measure numbers group together building parts which will have the same energy treatment. Assign the same measure number to a group of components of the same type which should be considered together when determining the SIR for retrofitting the components.

Mcf-Thousand cubic fect (usually natural gas).

Measures -Energy conservation projects under consideration for a house which are analyzed by NEAT.

NEAT-Acronym for the WAP-supported energy audit - the National Energy AudiT.

Outer ceiling joist-The portion of the ceiling joist extending from kneewall to roof rafter.

Output capacity - The rate of actual heat delivered by the heating device after flue losses and combustion inefficiencies are considered (in $\mathrm{kBtu} / \mathrm{h}$ ).

Pascal-A unit of pressure (kilogram-per-square meter).

Random access memory (RAM) - This is memory that can be changed. It is the primary type of memory storage.

RAM-Acronym for Random Access Memory.

Re-boot-See "boot."

Real discount rate-See "discount rate." 
Record-All information entered into NEAT describing a particular component of a house, such as the west wall or a south facing window. In a broader sense, a Job Record can be considered all of the information of all the components for an entire house associated with a specific Job Identifier.

Report-The product of the NEAT audit is a report that lists the measures with their costs, savings, and SIRs. The report also contains a materials list for the recommended measures.

Retention head-See "flame retention head oil burner."

Retrofit-The process of improving the efficiency of a system, such as adding insulation to the walls of a house.

Rim joist - See "band joist."

Roof rafter-A sloping wooden framing member supporting the roof.

Savings-to-investment ratio (SIR)-A ratio of the lifetime savings-to-initial investment. 'The SIR calculates the "present value" of dollars saved by an energy conservation measure, by adjusting the future savings to reflect energy cost escalation rates and discount rates. A SIR of one indicates that the investment will pay for itself over the lifetime of the measure. A SIR greater than one indicates an earlier recovery of initial investment.

Seasonal energy efficiency ratio-A measurement of energy efficiency for central air conditioners. The SEER is computed by dividing cooling capacity-measured in British thermal units per hour (Btu/h) - by the watts of power used. This seasonal efficiency accounts for start-up, jacket, and flue losses.

SEER-Acronym for Seasonal Energy Efficiency Ratio.

Setup-Accessed by selecting "Setup" on NEAT's Introduction screen. "Setup" contains material cost data, fuel prices, key parameters, weather data, fuel escalation rates, and measures to be considered, all of which can be altered to meet the auditor's specifications and local conditions.

Screen-The contents of a single screen of the computer.

Sheathing - The rigid exterior covering over wall studs in the exterior walls of wood-frame houses. Plywood and asphalt-impregnated fiberboard are common sheathing materials. 
Sill box - The area bounded on three sides by the rim joist, sill plate, and sole plate.

SIR-The acronym for Savings-to-Investment Ratio.

Slab-on-grade-A concrete foundation resting on a surface even with level ground.

Space bar-The bar-shaped key at the bottom of the keyboard that inserts a space between letters or numbers when struck.

Steady-state efficiency-The efficiency of a combustion heater reflecting how much of the fuel's theoretically available heat exits the heat exchanger.

Stud-A vertical framing member that is the structure of the wall of a wood frame home.

Therm - A unit of energy. One therm equals 29.3 kilowatt-hours.

Unconditioned space-An area within the house's envelope which is not intentionally heated or cooled.

Vent damper-A device that conserves energy by closing part or all of the flue when a heater is not burning fuel. Vent dampers prevent heated air from escaping up the flue while the heater is not operating.

Wall code-The letter/number system used to identify each exterior wall on the floor plan. Analogous codes exist for windows, doors, attics, subspaces, and air conditioners.

Window frame-The sides, top, and sill of the window which forms a box around all the window components.

Window sash-The part of the window that surrounds and supports the glass. 

Air Conditioning Contractors of America (ACCA), Manual J, Load Calculation for Residential Winter and Summer Air Conditioning, 1986. (Material used by permission).

American Society of Heating, Refrigerating and Air-Conditioning Engineers (ASHRAE), Handbook of Fundamentals, 1989.

American Society of Heating, Refrigerating and Air-Conditioning Engineers (ASHRAE), Handbook of Fundamentals, 1985.

Alliance to Save Energy, Gas Retrofit Manual: Auditing Techniques and Efficiency Improvements for Residential Heating Systems, Sept., 1986.

Alliance to Save Energy, Technicians Manual: Low-Income Oilheat Retrofit Program, Dec., 1985.

Alliance to Save Energy, Making Residential Weatherization Programs More CostEffective-A Guide for Program Managers, 1990.

Andrews, J. W., et al., Triage of Oil and Gas Retrofits for Residential/Light Commercial Heating Systems, BNL 38090, Brookhaven National Laboratory, May, 1986.

Arasteh, D. K., Reilly, M. S., and Rubin, M. D., "A Versatile Procedure for Calculating Heat Transfer through Windows," ASHRAE Transactions, 95(2); 1989, pp. 55-765.

Berry, L., et al., Evaluation of Gas Heating System Retrofit Pilot Programs in Kentucky and Minnesota, ORNL/CON-229, Oak Ridge National Laboratory, March, 1987.

Berry, L. and Witte, P., " Gas Heating System Retrofits for Low-Income Households: Evaluation Results and Future Directions," Energy Systems and Policy, vol. 12, pp. 119-134.

Commonwealth of Pennsylvania, Department of Community Affairs, "Weatherization Directive 87-17A (Revision 2): Oil Retrofit Guideline," April 1, 1989.

DeSoto, R. L., State of Colorado, personal communications to H. A. McLain, Oak Ridge National Laboratory, July 19, 1991. 
Fulger, D. W., "Canadian Residential Combustion Spillage Monitoring," ASHRAE Transactions, 95:(1), 1989, pp. 100-106.

Gathers, W., "Vent Dampers," Energy Auditor and Retrofitter, May/June 1985, pp. 28-31.

Geddes, G. D., Geddes Enterprises, personal communication to H.A. McLain, Oak Ridge National Laboratory, July 19, 1991.

Gettings, M. B. and Kolb, J. O., Survey Results and Recommendations for WAP Single- and Multi-Family Measure Selection Techniques, draft report, Oak Ridge National Laboratory, May, 1989.

Greenberg, S., "Duty Cyclers for Furnaces and Air Conditioners: Energy Savers or Energy Waster?" Energy Auditor and Retrofitter, May/June, 1987, pp. 25-29.

Honnold, F. V., "Residential Heat Pump Market and Technology Overview," Conference on Meeting Customer Needs With Heat Pumps-Proceedings, Atlanta, Georgia, 1989.

Hopkins, M., "Applying the Best Technology to Assist Low-Income Households: Programs Results, Research Findings, and Recommendations," American Council for an Energy Efficient Economy (ACEEE) Summer Study on Energy Efficiency in Buildings Proceedings, vol. 5, 1988, pp. 5.62-5.72.

Illinois Department of Commerce and Community Affairs, Home Weatherization Assistance Program Whole House Energy Audit, 1989.

Knight, P. A., Mechanical Systems Retrofit Manual: A Guide for Residential Design, Van Nostrand Reinhold Company, 1987.

Krishna, C. R. and Butcher, T. A., Evaluation of Energy Saving Devices for GasFired Furnaces, ORNL Report, Oak Ridge National Laboratory, Aug., 1987.

Kweller, E., "Criteria for Mechanical Energy Saving Retrofit Options for SingleFamily Residences," 1984 American Council for an Energy Efficient Economy (ACEEE) Summer Study-Proceedings, vol. B, 1988, pp. B.144-B.158.

Lawrence Berkeley Laboratory, CIRA 1.0 Reference Manual, University of California, 1982.

Lawrence Berkeley Laboratory, Applied Science Division, Window 3.1-A PC Program for Analyzing Window Thermal Performance, LBL-25686, Oct., 1988. "Low-E Meets Low-Income in Massachusetts," Home Energy, July/Aug., 1989. 
Lutz, J. D., et. al., "Modeling Residential Hot Water Use Patterns," LBL-37805, Lawrence Berkeley Laboratory, November 1996.

Lutz, J. D., et. al., "A Simplified Energy Consumption Equation for Water Heaters," American Council for an Energy Efficient Economy (ACEEE) Summer Study of Energy Efficiency in Buildings-Proceedings, vol. 1, 1998, pp. 1.177-1.183.

Lyberg, M. D., ed., Source Book for Energy Auditors, International Energy Agency, April, 1987.

Macriss, R. A., et al., Analysis and Correlation of Seasonal Performance Data from Gas Industry's Space Heating Efficiency Improvement Program (SHEIP), Institute of Gas Technology, May, 1980.

Macriss, R. A., Zawacki, T. S., and Cole, J. T., "Residential Gas Furnace Retrofit in 150 Homes in Illinois," ASHRAE Transactions, vol. 93, pt. 1, 1987.

McCold, L. N., Field Test Evaluation of Conservation Retrofits of Low-Income, Single-Family Buildings: Combined Building Shell and Heating System Retrofit Audit, ORNL/CON-228/P3, Oak Ridge National Laboratory, May, 1987.

Oak Ridge National Laboratory, Residential Conservation Service-Model Audit Manual, ORNL/CON-103, 1983.

Ontario Ministry of Municipal Affairs and Housing, Home Energy Fact SheetThe Total Tune-up for Gas, Oil or Electric Forced Air Systems, March, 1984.

Pilati, D.A., Room Air-conditioner Lifetime Cost Considerations: Annual Operating Hours and Efficiencies, ORNL-NSF-EP-85, Oct., 1975.

Pletzer, R. K., Jones, J. W., and Hunn, B. D., "Energy Savings from Shading Devices in Single-Family Residences in Austin, Texas," Fourth Annual Symposium on Improving Building Energy Efficiency in Hot and Humid Climates, Sept., 1987, pp. 112-121.

Proctor, J., "Low Cost Furnace Efficiency Improvements," 1984 American Council for an Energy Efficient Economy (ACEEE) Summer Study-Proceedings, vol. H, 1984, pp. H.200-H.214.

Proctor, J. and Foster, B., "Low Cost Furnace Efficiency Program-10,000 Furnaces Later," 1986 Summer Study_Proceedings, vol. 1, 1986, pp. 1.203-219.

Proctor, J. and Mills, E., "Making Furnace Retrofit Programs More Efficient: 14,000 Homes Later," Energy Auditor and Retrofitter, March/April, 1987. 
Scanadia-Sheltair Consortium Inc., Chimney Safety Tests Users' Manual: Procedures for Determining the Safety of Residential Chimneys, 2nd Ed., Canada Mortgage and Housing Corporation Report, Jan. 12, 1988.

Sharp, T. R. and Ternes, M. P., The North Carolina Field Test: Experimental Plan, Oak Ridge National Laboratory, ORNL/TM-11339, Aug., 1990.

Sherman, M. H., "Estimation of Infiltration from Leakage and Ctimate Indicators," Energy and Buildings, vol. 10, no. 1, 81, 1987.

Screen Manufactures Association, Test Results on Fiber Glass Solar Screen, Pamphlet.

Ternes, M. P., Hu, P. S., Williams, L. S., and Goeway, P., The National Fuel EndUse Efficiency Fuel Test: Energy Savings and Performance of an Improved Energy Conservation Measure Technique, ORNL/CON-303, March, 1991.

Tomany, R. J., "The Measurement of Window Treatment Effectiveness in Reducing Residential Heating and Cooling Costs," ASHRAE Transactions, 88(2), 1982, pp. 235-249. 


\begin{tabular}{|c|c|c|c|c|c|c|c|c|}
\hline \multirow[t]{2}{*}{ Name of City } & \multicolumn{2}{|c|}{ Degree-Hours / 24} & \multirow[t]{2}{*}{ Name of City } & \multicolumn{2}{|c|}{ Degree-Hours / 24} & \multirow[t]{2}{*}{ Name of City } & \multicolumn{2}{|c|}{ Degree-Hours / 24.} \\
\hline & Heating & Cooling & & Heating & Cooling & & Heating & Cooling \\
\hline ABILENE, TX & 3032 & 2579 & FLINT, MI & 7103 & 674 & PATUXENT RIVEA, MD & 4141 & 1370 \\
\hline AKRON, OH & 6359 & 809 & FOAT SMITH, AR & 3734 & 2190 & PHILADELPHIA, PA & 5113 & 1185 \\
\hline ALBANY, NY & 6888 & 830 & FORT WAYNE, IN & $63 \overline{41}$ & 900 & PHOENIX, AZ & 1672 & 4044 \\
\hline ALBUQUERQUE, NM & 4618 & 1546 & FORT WORTH, TX & 2643 & 2595 & PIERAE, SD & 7668 & 1142 \\
\hline ALLENTOWN, PA & 5979 & 865 & FAESNO, CA & 3173 & 2078 & PITTSBEURGH, PA & 6174 & 782 \\
\hline ALPENA, MI & 8208 & 490 & GLASGOW, MT & 8989 & 744 & POCATELLO, ID & 7353 & 861 \\
\hline AMARIILO, TX & 4648 & 1611 & GOODLAND, KS & 6500 & 1098 & POINT MUGU, CA & 2430 & 340 \\
\hline APALACHICOLA, FL & 1534 & 2735 & GRAND ISLAND, NE & 6830 & $11 \mathrm{BB}$ & POAT ARTHUR, TX & 1628 & 2656 \\
\hline ARCATA, CA & 5091 & 10 & GRAND JUNCTION, CO & 6042 & 1398 & POATLAND, ME & 7424 & 447 \\
\hline ASHEVILLE, NC & 4537 & 864 & GRAND RAPIDS, MI & 6949 & 792 & POATLAND, OR & 4879 & 452 \\
\hline ASTORIA, OR & 5331 & 90 & GREAT FALLS, MT & 7989 & 578 & PAESCOTT, AZ & 4937 & 1245 \\
\hline ATLANTA, GA & 3215 & 1602 & GREEN BAY, WI & 8147 & 602 & PAOVIDENCE, RI & 6148 & 774 \\
\hline AUGUSTA, GA & 2938 & 1971 & GREENSBORO, NC & 4023 & 1419 & PUEBLO, CO & 5775 & 1340 \\
\hline AUSTIN, TX & 2026 & $2930^{\circ}$ & GAEENVILLE, SC & 3496 & 1480 & RALEIGH-DURHAM, NC & 3778 & 1507 \\
\hline BAKERSFIELD, CA & 2529 & 2461 & HARRISBURG, PA & 5411 & 1127 & AAPID CITY, SD & 7529 & 868 \\
\hline BALTIMORE, MD & 5137 & 1267 & HARTFORD, CT & 6507 & 902 & FED BLUFF, CA & 3278 & 2098 \\
\hline BANGOR, ME & 8168 & 406 & HELENA, MT & 8149 & 578 & REDMOND, OA & 6923 & 621 \\
\hline BARSTOW, CA & 2405 & 2964 & HOUSTON, TX & 1580 & 2883 & RENO, NV & 6417 & 950 \\
\hline BATON ROUGE, LA & 1814 & 2556 & HURON, SD & 8590 & 979 & AICHMOND, VA & 4166 & 1466 \\
\hline BILINGS,MT & 7466 & 817 & INDIANAPOLIS, IN & 5831 & 1133 & ROANOKE, VA & 4451 & 1268 \\
\hline BINGHAMTON, NY & 7551 & 550 & INTERNATIONALFALLS, MN & 10582 & 304 & ROCHESTER, MN & 8250 & 612 \\
\hline BIRMINGHAM, AL & 3020 & 1907 & JACKSON, MS & 2602 & 2345 & ROCHESTER, NY & 7112 & 741 \\
\hline BISMARCK, ND & 9283 & 751 & JACKSONVILLE, FL & 1561 & 2655 & ROCK SPRINGS, Wr & 8731 & 492 \\
\hline BOISE, ID & 6185 & 1009 & KANSAS CITY, MO & 5007 & 1775 & ROSWELL, NM & 3961 & 2034 \\
\hline BOSTON, MA & 5874 & 772 & KINGSVILLE, TX & 1066 & 3617 & SACRAMENTO, CA & 3304 & 1340 \\
\hline BROWNSVILLE, TX & 728 & 3687 & KNOXVILLE, TN & 4005 & 1531 & SALEM, OA & 5278 & 472 \\
\hline BRYCE CANYON, UT & 9432 & 293 & LACROSSE, WI & 7417 & 845 & SALT LAKE CITY, UT & 6137 & 1293 \\
\hline BUFFALO, NY & 6830 & 659 & LAKE CHARLES, LA & 1718 & 2686 & SAN ANGELO, TX & 2512 & 2801 \\
\hline BURLINGTON, IA & 6234 & 1109 & LAKEHURST, NJ & 5498 & 1065 & SAN ANTONIO, TX & 1805 & 2913 \\
\hline BURLINGTON, VT & 7948 & 528 & LAREDO, TX & 1082 & 4105 & SAN DIEGO, CA & 1461 & 670 \\
\hline CAPE HATTERAS, NC & 2740 & 1696 & LAS VEGAS, NV & 2795 & 3192 & SAN FRANCISCO, CA & 3703 & 213 \\
\hline CARIBOU, ME & 9564 & 284 & LEWISTON, ID & 5702 & 895 & SANTA MARIA, CA & 3700 & 294 \\
\hline CASPER, WY & 7895 & 794. & LEWISTOWN, MT & 8345 & 478 & SAULT STE MARIE, MI & 9409 & 272 \\
\hline CEDER CITY, UT & 6259 & 994 & LEXINGTON, KY & 4862 & 1278 & SAVANNAH, GA & 2227 & 2222 \\
\hline CHARLESTON, SC & 2414 & 2075 & LITTLE ROCK, AR & 3420 & 2165 & SCOTTSBLUFF, NE & 7330 & 928 \\
\hline CHARLESTON, WV & 4876 & 1192 & LONG BEACH, CA & 1928 & 929 & SCAANTON, PA & 6410 & 789 \\
\hline CHARIOTTE, NC & 3574 & 1584 & LOS ANGELES. CA & 1969 & 510 & SEATTLE, WA & 5529 & 242 \\
\hline CHATTANOOGA, TN & 3896 & 1622 & LOUISVILLE, KY & 4756 & 1497 & SHERIDAN, WY & 7712 & 679 \\
\hline CHERRY POINT, NC & 2709 & 1802 & LOVELOCK, NV & 6233 & 1262 & SHERMAN, TX & 2920 & 2463 \\
\hline CHEYENNE CITY, WY & 7613 & 574 & LUBBOCK, TX & 4000 & 1962 & SHREVEPORT, LA & 2466 & 2441 \\
\hline CHICAGO, IL & 6331 & 1104 & LUFKIN, TX & 2095 & 2669 & SIOUX CITY, IA & 6993 & 1149 \\
\hline CHINA LAKE, CA & 2752 & 3213 & MACON, GA & 2643 & 2153 & SIOUX FALLS, SD & 7925 & 955 \\
\hline CINCINNATI, OH & 5251 & 1155 & MADISON, WI & 7826 & 677 & SOUTH BEND, IN & 6466 & 876 \\
\hline CLAYTON, NM & 5193 & 1052 & MASON CITY, IA & 7931 & 832 & SPOKANE, WA & 6984 & 620 \\
\hline CLEVELAND, OH & 6313 & 822 & MASSENA, NY & 8440 & 552 & SPRINGFIELD, IL & 5607 & 1344 \\
\hline COLORADO SPRINGS, CO & 6440 & 757 & MEDFORD, OH & 5523 & 919 & SPAINGFIELD, MO & 4790 & 1414 \\
\hline COLUMBIA, MO & 5265 & 1367 & MEMPHIS, TN & 3359 & 2147 & ST. LOUIS, MO & 5090 & 1544 \\
\hline COLUMBIA, SC & 2942 & 2177 & MERIDIAN, MS & 2763 & 2232 & SUNNYVALE, CA & 3034 & 390 \\
\hline COLUMBUS, $\mathrm{OH}$ & 5723 & 967 & MIAMI, FL & 283 & 4011 & SYAACUSE, NY & 6987 & 704 \\
\hline CONCORD, NH & 7583 & 696 & MIDLAND, TX & 2954 & 2347 & TALLAHASSEE, FL & 1760 & 2506 \\
\hline CORPUS CHRISTI, TX & 1065 & 3505 & MILES CITY, MT & 8260 & 975 & TAMPA, FL & 884 & 3145 \\
\hline CUT BANK, MT. & 9135 & 382 & MILWAUKEE, WI & 7214 & 648 & TOLEDO, OH & 6638 & 839 \\
\hline DALLAS FORT WORTH, TX & 2604 & 2649 & MINNEAPOLIS, MN & 8134 & 885 & TONOPAH, NV & 6061 & 1062 \\
\hline DAYTON, OH & $5 B 03$ & 1073 & MINOT, ND & 9374 & 605 & TOPEKA, KS & 5459 & 1552 \\
\hline DAYTOONA BEACH, FL & 1009 & 2699 & MISSOULA, MT & $792 B$ & 487 & TORONTO, ONT & $755 B$ & 584 \\
\hline DEL RIO, TX & 1656 & 3159 & MOBILE, AL & 1795 & 2397 & TRAVERSE CITY, MI & 7744 & 597 \\
\hline DENVER, CO & 6111 & 972 & MOLINE, IL & 6383 & 1077 & THUTH OR CONSEQUENCES, N & 3880 & 1724 \\
\hline DES MOINES, IA & 6724 & 1078 & MONTGOMEAY, AL & 2572 & 2198 & TUCSON, AZ & 2025 & 3167 \\
\hline DETAOIT, MI & 6730 & 743 & MONTREAL, QUE & 8270 & 490 & TUCUMCARI, NM & 4367 & 1690 \\
\hline DILLON, MT & 8582 & 444 & MOUNT SHASTA, CA & 5810 & 743 & TULSA, OK & 3964 & 2185 \\
\hline DODGE CITY, KS & 5484 & 1616 & NASHVILLE, TN & 3858 & 1729 & WACO, TX & 2443 & 2969 \\
\hline DULUTH; MN & 10017 & 303 & NEW ORLEANS, LA & 1526 & 2610 & WASHINGTON, DC & 4410 & 1494 \\
\hline EAGLE, CO & 8843 & 533 & NEW YOHK, NY & 5029 & 1076 & WEST PALM BEACH, FL & 281 & 3893 \\
\hline EAU CLAIRE, WI & 8393 & 778 & NEWARK, NJ & 5105 & 1108 & WHIDBEY ISLAND, WA & 5424 & 61 \\
\hline EDMONTON, ALB & 11206 & 160 & NORFOLK, VA & 3737 & 1603 & WICHITA FALLS, TX & 3378 & 2463 \\
\hline ELPASO, TX & 2867 & 2429 & NORTH BEND, OR & 4808 & 20 & WILMINGTON, DE & 5211 & 1169 \\
\hline EL TORO, CA & 2195 & 970 & NORTH PLATIE, NE & 7339 & 969 & WINNEMUCCA, NV & 6812 & 1136 \\
\hline ELKO,NV & 7570 & 894 & OAKLAND, CA & 3215 & 171 & WINNIPEG, MAN & 10906 & 433 \\
\hline$E L Y, N \bar{V}$ & $\mathrm{~B} 081$ & 602 & OKLAHOMA CITY, OK & 4036 & 2019 & WINSLOW, AZ & 5148 & 1516 \\
\hline ERIE, PA & 6533 & 588 & OLYMPIA, WA & 5852 & 318 & YAKIMA, WA & 6220 & 861 \\
\hline EVANSVILLE, IN & 4847 & 1446 & OMAHA, NE & 6274 & 1310 & YOUNGSTOWN, OH & 6728 & 700 \\
\hline FARGO, ND & 9410 & 765 & ORLANDO, FL & 796 & 3171 & YUCCA FLATS, NV & 5202 & 1775 \\
\hline & & & - & & & YUMA, AZ & 1171 & 4424 \\
\hline
\end{tabular}




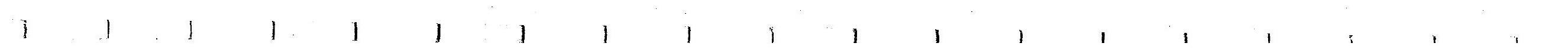




\section{INTERNAL DISTRIBUTION}

1. J. E. Christian

2. W. G. Craddick

3. T. R. Curlee

4-24. Mike Gettings

25. R. B. Shelton

26. Lab Records

27. Laboratory Records-for transmittal to OSTI

\section{EXTERNAL DISTRIBUTION}

28. Dr. Lilia A. Abron, President, PEER Consultants, P.C.,1460 Gull Blvd. Apt. 1103, Clearwater, FL 33767

29. Dr. Douglas Bauer, Executive Director, Commission on Engineering and Technical Systems, National Research Council, Harris 280, 2001 Wisconsin Ave NW, Washington, DC 20007

30. Dr. Susan L. Cutter, Professor and Chair, Director, Hazards Research Lab, Department of Geography, University of South Carolina, Columbia, SC 29208

31. Jean M. Diggs, U.S. Department of Energy, Forrestal Building Route Symbol: EE-42, Room 5E-080, 1000 Independence Avenue, S.W., Washington, DC 20585

32. Joel Eisenberg, Oak Ridge National Laboratory, 901 D Street, S.W., Suite 910; Washington, DC 20024

33. Dennis J. Feck, U.S. Department of Energy, 1000 Independence Avenue, S.W., Forrestal Building, Route Symbol: EE-42, Room: 5E-098, Washington, DC 20585

34. Mark B. Ginsberg, U.S. Department of Energy, 1000 Independence Avenue, S.W., Forrestal Building, Route Symbol: EE-40, Mail Stop: 6A-116, Room: 5E-052, Washington, DC 20585

35. Dr. Stephen G. Hildebrand, Director, Environmental Sciences Division, Oak Ridge National Laboratory, P.O. Box 2008, Oak Ridge, TN 37831-6037

36. Gail N. McKinley, U.S. Department of Energy, 1000 Independence Avenue, S.W., Forrestal Building, Route Symbol: EE-42, Room: 5E-080, Washington, DC 20585

37. Gregory. M. Reamy, U.S. Department of Energy, 1000 Independence Avenue, S.W., Forrestal Building, Route Symbol: EE-42, Room: 5E-066, Washington, DC 20585 
38. Mr. P. Richard Rittelmann, FAIA, Executive Vice President, Chairperson Burt Hill Kosar Rittelmann Associates, 400 Morgan Center, Butler, PA 16001-5977

39. Dr. C. Michael Walton, Ernest H. Cockrell Centennial Chair In Engineering, Department of Civil Engineering, University of Texas at Austin, Austin, TX 78712-1076 